\title{
Evaluation of Travel Time Data Quality and Impacts on the I-95 corridor and in the Hampton Roads Area of Virginia
}

A Thesis
Present to
The Faculty of the School of Engineering and Applied Science
University of Virginia

\author{
In Partial Fulfillment \\ of the requirements for the Degree \\ Master of Science, Civil Engineering
}

by

Kittisak Siripollawat

December 2012 


\begin{abstract}
APPROVAL SHEET
The thesis is submitted in partial fulfillment of the

Requirements for the degree of

Master of Science (Civil Engineering)
\end{abstract}

Kittisak Siripollawat

This thesis has been read and approved by the Examining Committee:

Dr. Michael J. Demetsky

Dr. Michael D. Fontaine

Dr. Brian L. Smith

Accepted for the School of Engineering and Applied Science

James Aylor, Dean, School of Engineering and Applied Science

December 2012 


\begin{abstract}
Traveler information systems are key tools for allowing commuters to make better travel decisions, especially during congested conditions. Travel times are often the most valuable piece of information to commuters. Although travel time information is important to commuters, in the past several conditions limited the availability of travel time information. First, the high costs of putting technology in place to collect travel time data acted as a barrier. These costs include the costs of equipment, installation, maintenance, and operation. Second, technology such as point sensors requires that point data be extrapolated over segments and often have significant maintenance requirements. Recent improvements in probe vehicle based systems have reduced these financial and technical hurdles, allowing for more widespread deployment of travel time systems.
\end{abstract}

The Virginia Department of Transportation (VDOT) began posting travel time information on existing Dynamic Message Signs (DMSs) on I-66 and I-95 in Northern Virginia in 2011. They have also sought to expand the program to additional potential segments on I-64 and I-264 in the Hampton Roads area. The goal of the program is to provide accurate real-time travel time information to commuters so that they can make informed decisions in terms of their route choices. Travel times posted on the DMSs were derived using data from the private sector provider INRIX. INRIX is a private company providing real-time information derived from both fixed-pointed sensors and probe data. Instead of investing in detectors, radars, or video cameras to collect real-time data, VDOT uses data available through its agreement with INRIX via the I-95 Corridor Coalition. With INRIX data, the cost of providing travel time information can be significantly reduced. However, it is important to reconfirm the INRIX data quality 
before posting the travel times. This study collected and analyzed the INRIX data quality from several segments on the I-95, I-64, and I-264 corridors. To analyze the INRIX data quality, Bluetooth data was selected as a benchmark data source for this study based on findings from previous studies.

Besides evaluating travel time information data quality, this study also analyzed how drivers responded to the travel times on I-95 corridor. Diversion data comparing data during one month before and three months after the start of the DMS travel time program were used to analyze the impact of travel time information at selected interchanges. Both mainline and off ramp volumes are needed for the analysis. Since ramp volume data were limited, there were only two out of eight segments on I-95 corridor that could be analyzed for the impacts of travel time information.

The data analysis results suggest that the data quality of short segments (i.e., less than 15 miles) generally satisfied the VDOT business requirements. During this study, there were 7 out of 18 segments where the INRIX and Bluetooth data disagreed. The possible factors causing the errors were the Bluetooth characteristics, distance discrepancies, and the segment geometries. The Bluetooth characteristics tend to lower the Bluetooth speeds, while the other two factors can affect both INRIX and Bluetooth data depending on the situation. Discrepancies between the INRIX and Bluetooth endpoints can have a significant impact if a bottleneck occurs near the boundaries of the links. If a bottleneck occurs at one of the endpoints, Bluetooth data may not be able to capture all the impacts since the Bluetooth distances are typically shorter than INRIX distances in this study. Lastly, a major intersection within a segment could create congestion at merging area, which may not be fully captured by Bluetooth data. 
The diversion analysis results on I-95 from MM 165.65 to the DC Line segment NB14 demonstrate a high correlation (i.e., over 0.6) between number of vehicles diverting and the travel time and mainline volume during operational and congested periods on weekdays. The model equations suggest that travel time messages encourage diversion during operational periods. However, the impact of mainline volumes seems to be much greater than travel time messages due to the higher normalized coefficients (e.g., 0.612 versus 0.328 ). The ANOVA analysis results where P-values is significant (i.e. at 95\% confidence level) on I-95 from MM 165.65 to DC Line segment suggests an increasing number of diverting vehicles during operational periods and congested periods after travel times were posted. On the other hand, the diversion analysis on MM 151.1 to MM 170 does not show a high correlation between the number of diverting vehicles, travel time, and mainline volume for any period. Since the results from both segments do not agree, it may be too soon to conclude whether travel time messages impact diversion. 


\section{ACKNOWLEDGEMENTS}

I would like to express my sincere appreciation to Dr. Michael Fontaine, whom I work closely for the thesis, for his patience, time, and useful guidance in the past year. Without his mentor, dedication, and enormous emails responses, I would not have completed my thesis within one and a half year.

I would also like to thank Dr. Brian Smith for his support and guidance throughout my study at UVA.

Special thanks go to Dr. Michael Demetsky for serving as a committee chair. I am also thankful that the Virginia Department of Transportation allows me to have an access to all data I needed for the project.

I would like to thank Sampson Asare for helping me started on the project and continue to offer assistance when needed. Also, I would like to thank Tim Ngov, Parinya Anantachaisilp, and Daniel Haileselassie, for their helps and supports during the past 17 months.

Lastly, I would like to thank mom for her continuous support and encouragement sending to me from Thailand. Also, I appreciate my brothers and sisters for taking a great care of our mom while I am away, which allowed me to focus on school and accomplish what I came here for. 


\section{TABLE OF CONTENTS}

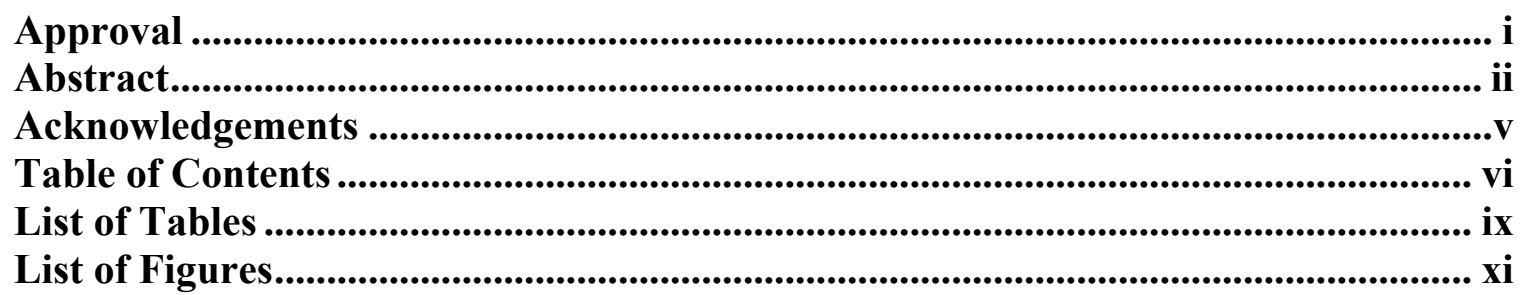

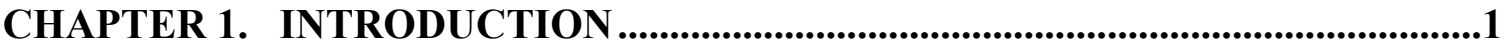

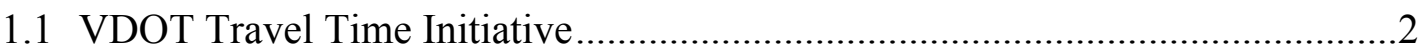

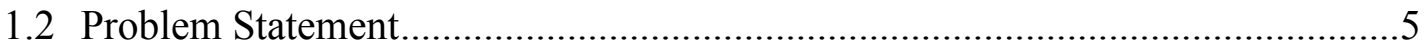

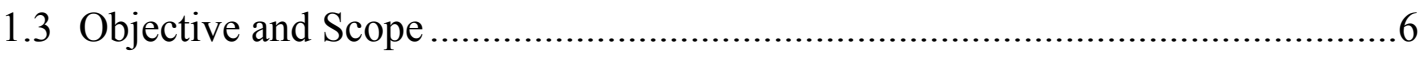

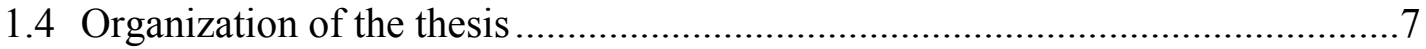

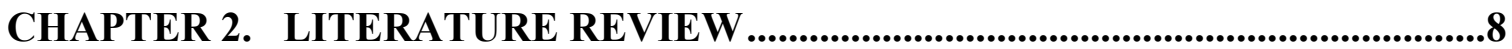

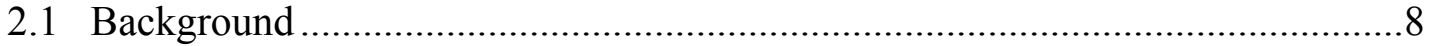

2.2 VDOT Business Rules for DMS Travel Time Program ……………………....10

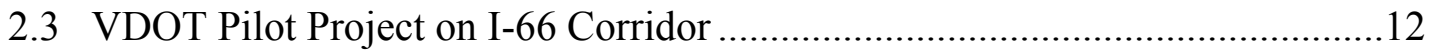

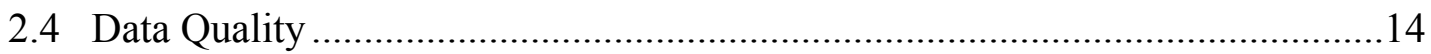

2.4.1 Data quality measures ......................................................................14

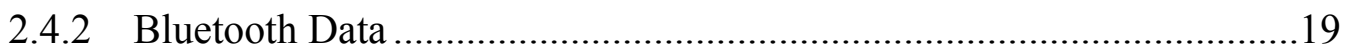

2.4.3 Bluetooth Case Study from I-95 Corridor Coalition ...............................20

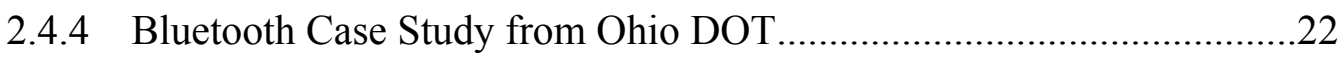

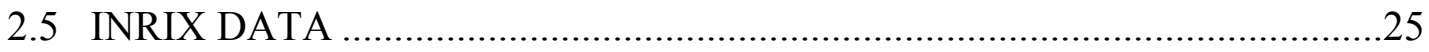

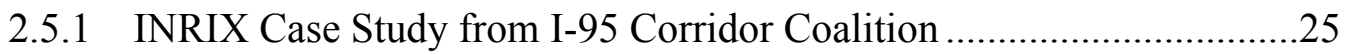

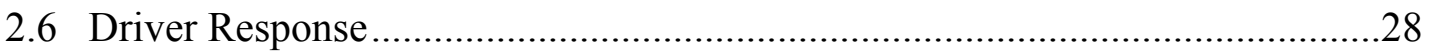

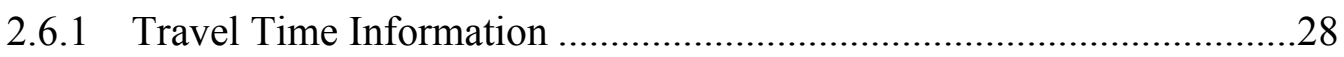

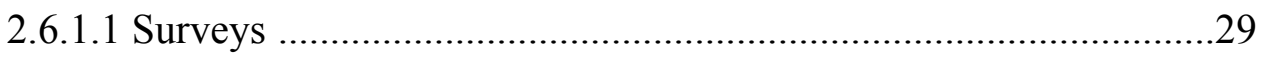

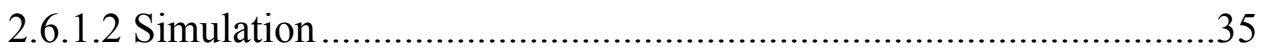

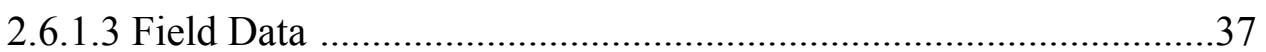

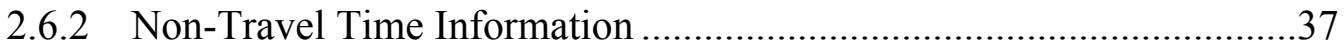

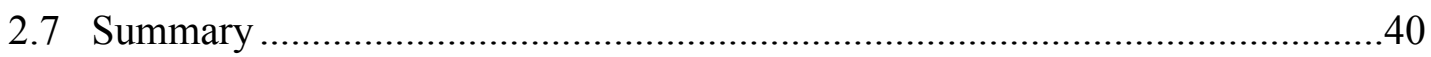

CHAPTER 3. METHODOLOGY ......................................................................41

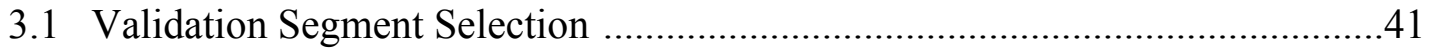

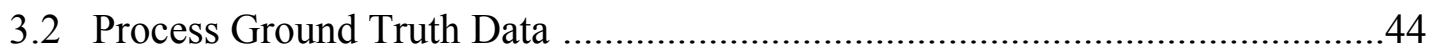

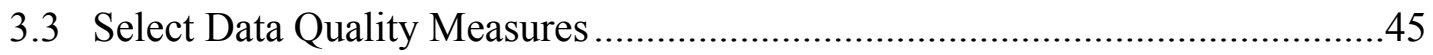

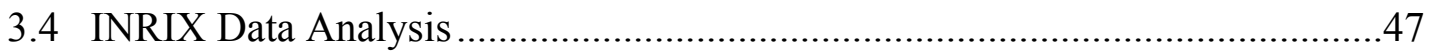

3.4.1 Quality assessment of INRIX data on Interstate 95 ...............................47

3.4.2 Quality assessment of INRIX data in Hampton Roads Area ..................52

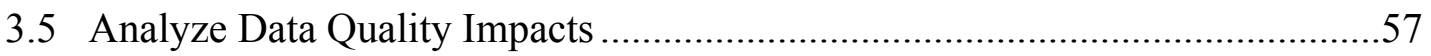


3.6 Diversion Analysis .58

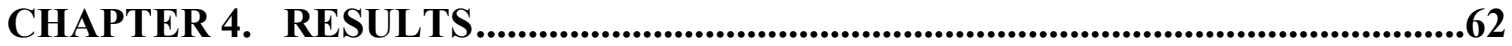

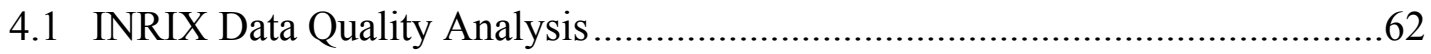

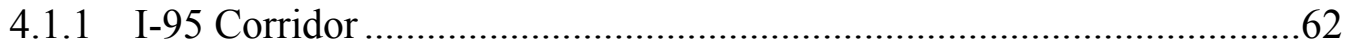

4.1.1.1 I-95 NB from MM 151.10 to MM170 (NB18) ………………......63

4.1.1.2 I-95 NB from MM 159.9 to MM 170 (NB10) ………………......64

4.1.1.3 I-95/I-395 NB from MM 165.65 to the DC Line (NB14)...............66

4.1.1.4 I-395 SB from MM 9.3 to 0.0 (SB8) …………….......................67

4.1.1.5 I-395/I-95 SB from MM 2.2 to I-95 SB MM 160 (SB12).............68

4.1.1.6 I-95 SB from MM 168.1 to SR 234 (SB15) ……………….........70

4.1.1.7 I-95 SB from MM 162.7 to MM 130 (SB33) ……………….......72

4.1.1.8 I-95 SB from MM 162.7 to MM 143 (SB19) ………………........74

4.1.1.9 Overall Performances on I-95 Corridor .........................................76

4.1.2 Bluetooth Preliminary Test on Hampton Roads Area ……………….....81

4.1.3 I-64 Corridor, Hampton Roads Area …………….................................

4.1.3.1 Link 5840 WB I 64 at Denbigh (u424) to EB I 64 At Magruder,

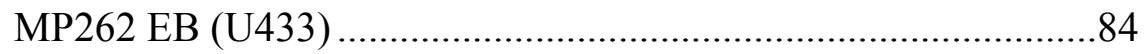

4.1.3.2 Link 5841 EB I 64 At Magruder, MP262 EB (u433) to WB I 64 at

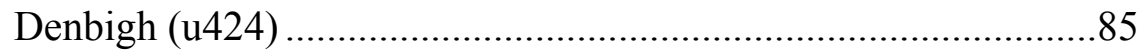

4.1.3.3 Link 5842 EB I 64 At Magruder, MP262 EB (u433) to EB I 64 At

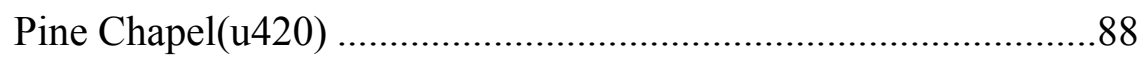

4.1.3.4 Link 5843 EB I 64 At Pine Chapel (u420) to EB I 64 At Magruder, MP262 EB (u433) .89

4.1.3.5 Link 5846 EB I 64 At Pine Chapel (u420) to I-64W @ I-664 Pole \#270403 (u434) .90

4.1.3.6 Link 5847 I-64W @ I-664 Pole \#270403 (u434) to EB I 64 At Pine Chapel (u420).

4.1.3.7 Link 5850 I-64 prior to I-264 Square I-Beam Sign Structure (u427) to Outer Loop I 64 before I 264 interchange (u438)

4.1.3.8 Link 5853 Outer Loop I 64 Between Greenbrier Pkwy and Indian River Rd (u426) to Outer Loop I 64 before I 264 interchange (u438).

4.1.3.9 Overall Performances on I-64 Corridor

4.1.4 I-264 Corridor, Hampton Roads Area .97

4.1.4.1 Link 5856 WB I 264 before Witchduck Rd (u439) to WB I 264 before Independence Blvd (u444). 
4.1.4.2 Link 5857 WB I 264 before Independence Blvd (u444) to WB I 264 before Witchduck Rd (u439) ............................................ 100

4.1.4.3 Overall Performances on I-264 Corridor ...................................102

4.1.5 Overall Data Quality Performance across Sites................................103

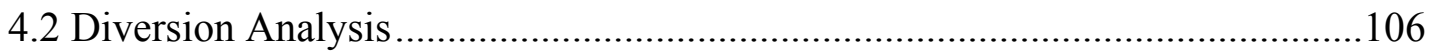

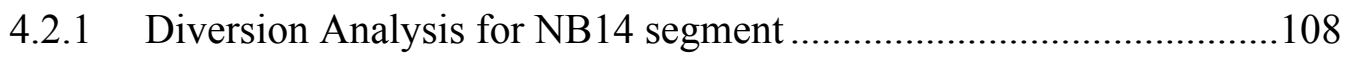

4.2.1.1 Operational period ............................................................... 108

4.2.1.2 Congested period .................................................................113

4.2.2 Diversion Analysis on NB18 segment...........................................118

4.2.2.1 Operational period .............................................................. 118

4.2.2.2 Congested period ................................................................121

4.2.3 Overall diversion analysis on I-95 corridor (i.e., NB14 and NB18)....123

CHAPTER 5. CONCLUSION \& RECOMMENDATIONS.................................125

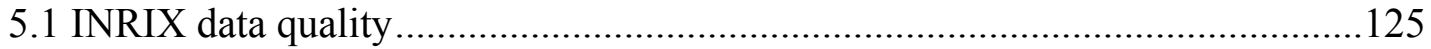

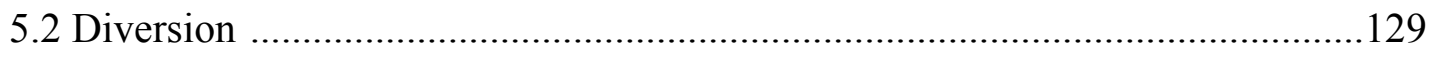

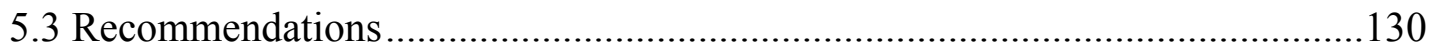

5.3.1 Recommendations on using INRIX data for posting travel times data131

5.3.2 Recommendations on evaluating data quality ...............................131

5.3.3 Recommendation for future research.......................................... 132

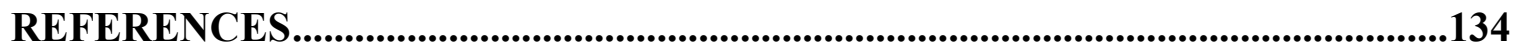

APPENDIX A DATA QUALITY ASSESSMENT ON I-95 CORRIDOR ..............139 APPENDIX B DATA QUALITY ASSESSMENT IN HAMPTON ROADS

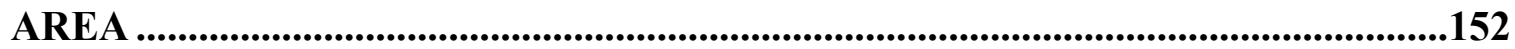




\section{LIST OF TABLES}

Table 2-1 Accuracy Measures 18

Table 2-2 Driver responses to travel time information

Table 3-1 Bluetooth locations and distances of each segment on I-95 corridor .........................................42

Table 3-2 Locations of all 27 selected segments for validation on Hampton Roads Area .........................43

Table 3-3 Example of Bluetooth data provided by TrafficCast .......................................................45

Table 3-4 Difference between INRIX and Bluetooth distances on I-95 corridor ....................................49

Table 3-5 Example of raw travel time data provided by Open Roads .....................................................50

Table 3-6 Bluetooth locations and distances of each segment on I-64 and I-264 corridors ........................54

Table 3-7 Difference between INRIX and Bluetooth distances on I-64 and I-264 corridors .....................56

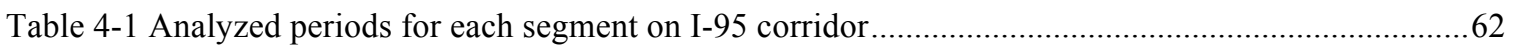

Table 4-2 Performance measures during operational periods, NB18 .....................................................64

Table 4-3 Speed error distributions during operational periods, NB18 ...................................................64

Table 4-4 Performance measures during operational periods, NB10 ...................................................65

Table 4-5 Speed error distributions during operational periods, NB10 ….............................................66

Table 4-6 Performance measures during operational periods, NB14 ....................................................66

Table 4-7 Speed error distributions during operational periods, NB14 .............................................67

Table 4-8 Performance measures during operational periods, SB8 ....................................................67

Table 4-9 Speed error distributions during operational periods, SB8 .....................................................68

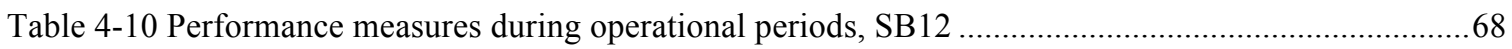

Table 4-11 Speed error distributions during operational periods, SB12 ...............................................69

Table 4-12 Performance measures during operational periods, SB15 ................................................. 71

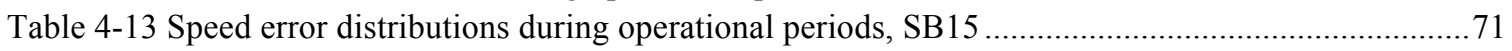

Table 4-14 Performance measures during operational periods, SB33 …..............................................72

Table 4-15 Speed error distributions during operational periods, SB33 ..............................................72

Table 4-16 Performance measures during operational periods, SB19 …...........................................75

Table 4-17 Speed error distributions during operational periods, SB19 ..............................................75

Table 4-18 Overall performance measures on I-95 Corridor ................................................................... 77

Table 4-19 Bluetooth preliminary test on Hampton Roads area ............................................................82

Table 4-20 Details information on each link on Hampton Road area .......................................................83

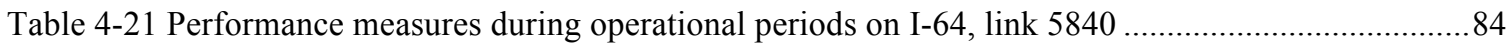

Table 4-22 Speed error distributions during operational periods on I-64, link 5840 ...............................84

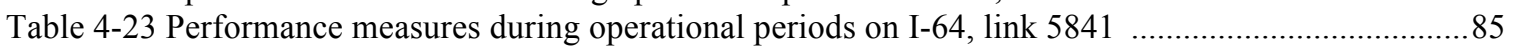

Table 4-24 Speed error distributions during operational periods on I-64, link 5841(8 TMCs) .................88

Table 4-25 Speed error distributions during operational periods on I-64, link 5841(9 TMCs) ..................88

Table 4-26 Performance measures during operational periods on I-64, link 5842 .................................89

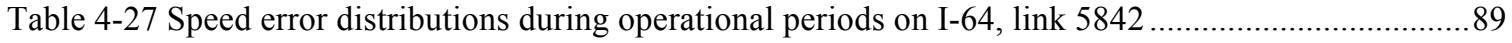

Table 4-28 Performance measures during operational periods on I-64, link 5843 ...................................90

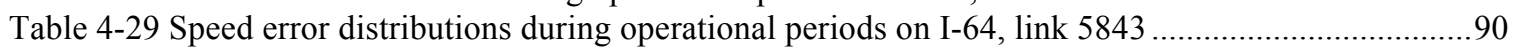

Table 4-30 Performance measures during operational periods on I-64, link 5846 ...................................91

Table 4-31 Speed error distributions during operational periods on I-64, link 5846 ..............................91

Table 4-32 Performance measures during operational periods on I-64, link 5847 ................................92

Table 4-33 Speed error distributions during operational periods on I-64, link 5847 ..............................93

Table 4-34 Performance measures during operational periods on I-64, link 5850 ................................94

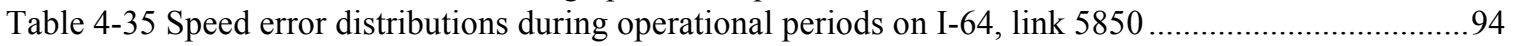

Table 4-36 Performance measures during operational periods on I-64, link 5853 ...................................95

Table 4-37 Speed error distributions during operational periods on I-64, link 5853 ..............................95

Table 4-38 Overall performance measures on I-64 Corridor. .............................................................96 
Table 4-39 Performance measures during operational periods on I-264, link 5856 .............................98

Table 4-40 Speed error distributions during operational periods on I-264, link 5856 (2 TMCs) .................99

Table 4-41 Speed error distributions during operational periods on I-264, link 5856 (3 TMCs) ....................99

Table 4-42 Performance measures during operational periods on I-264, link 5857 ...............................100

Table 4-43 Speed error distributions during operational periods on I-264, link 5857 (2 TMCs) ...............101

Table 4-44 Speed error distributions during operational periods on I-264, link 5857 (3 TMCs) ...............101

Table 4-45 Overall performance measures on I-264 Corridor ......................................................... 102

Table 4-46 Data points during before and after periods on NB14 and NB18 segments ...........................107

Table 4-47 ANOVA results (adjusted R-squares) during operational periods on NB14 segment..............109

Table 4-48 ANOVA results (P-values) during operational periods due to number diversion on

NB14 segment.

Table 4-49 ANOVA results (adjusted R-squares) during congested periods on NB14 segment

Table 4-50 ANOVA results (P-values) during congested periods due to number diversion on NB14 segment.

Table 4-51 Summary of unstandardized coefficients during operational and congested periods of NB14 segment

Table 4-52 ANOVA results (adjusted R-squares) during operational periods on NB18 segment

Table 4-53 ANOVA results (P-values) during operational periods due to number diversion on NB18 segment

Table 4-54 ANOVA results (adjusted R-squares) during congested periods on NB18 segment 122

Table 4-55 ANOVA results (P-values) during congested periods due to number diversion on NB18 segment.

Table A-1 Summary of Speed Error Bias (mph) on each segment on I-95 corridor for each report period 139 Table A-2 Summary of Absolute Error Bias (mph) on each segment on I-95 corridor for each report period

Table A-3 Summary of Speed Error Bias (mph) on each segment on I-64 and I-264 corridors................ 140

Table A-4 Final tables and percent blank out of INRIX data analysis on I-95 corridor, NB10 segment ....140

Table A-5 Final tables and percent blank out of INRIX data analysis on I-95 corridor, NB14 segment .... 141

Table A-6 Final tables and percent blank out of INRIX data analysis on I-95 corridor, NB18 segment ....143

Table A-7 Final tables and percent blank out of INRIX data analysis on I-95 corridor, SB8 segment .......144

Table A-8 Final tables and percent blank out of INRIX data analysis on I-95 corridor, SB12 segment .....146

Table A-9 Final tables and percent blank out of INRIX data analysis on I-95 corridor, SB 15 segment .... 147

Table A-10 Final tables and percent blank out of INRIX data analysis on I-95 corridor, SB19 segment ... 149

Table A-11 Final tables and percent blank out of INRIX data analysis on I-95 corridor, SB33 segment...150

Table B-1 Final tables and percent blank out of INRIX data analysis on I-64 corridor, link 5840 152

Table B-2 Final tables and percent blank out of INRIX data analysis on I-64 corridor, link 5841 153

Table B-3 Final tables and percent blank out of INRIX data analysis on I-64 corridor, link 5842 ............154

Table B-4 Final tables and percent blank out of INRIX data analysis on I-64 corridor, link 5843 ........... 155

Table B-5 Final tables and percent blank out of INRIX data analysis on I-64 corridor, link 5846 ............156

Table B-6 Final tables and percent blank out of INRIX data analysis on I-64 corridor, link $5847 \ldots \ldots \ldots . . .157$

Table B-7 Final tables and percent blank out of INRIX data analysis on I-64 corridor, link 5850 ........... 158

Table B-8 Final tables and percent blank out of INRIX data analysis on I-64 corridor, link $5853 \ldots \ldots \ldots \ldots . .159$

Table B-9 Final tables and percent blank out of INRIX data analysis on I-264 corridor, link $5856 \ldots \ldots \ldots . .160$

Table B-10 Final tables and percent blank out of INRIX data analysis on I-264 corridor, link 5857 ........ 161

Table B-11 Speed categories analysis of 10 BlueTOAD links on I-64 and I-264 corridors .......................162 


\section{LIST OF FIGURES}

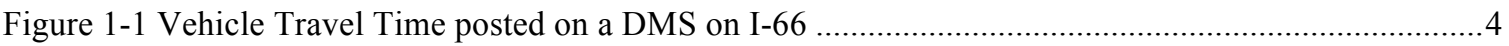

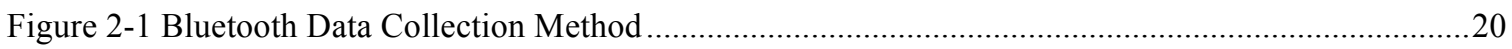

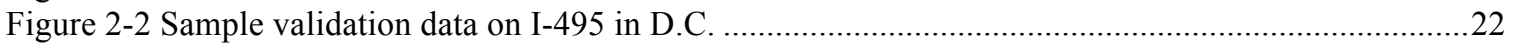

Figure 2-3 Data Collection from a highway 2.6 miles segment on I-75, 7/29/2009 …................................23

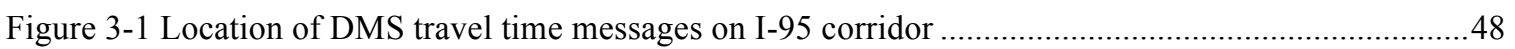

Figure 3-2 Location of DMS travel time messages on I-64 and I-264 corridors ...........................................54

Figure 4-1 SB12, predicted speeds compared with Bluetooth "Ground Truth" Data,

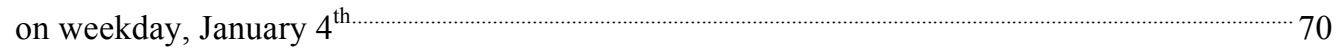

Figure 4-2 SB33, predicted speeds compared with Bluetooth "Ground Truth" Data,

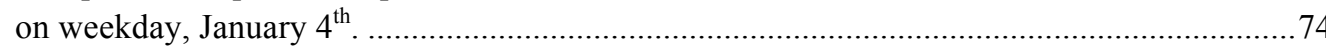

Figure 4-3 SB19, predicted speeds compared with Bluetooth "Ground Truth" Data,

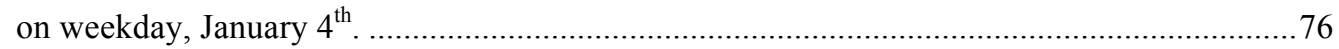

Figure 4-4 INRIX distances compared to speed error biases of each segment on I-95 corridor. ...................79

Figure 4-5 INRIX distances compared to absolute error biases of each segment on I-95 corridor. ...............80

Figure 4-6 Link 5841, the average predicted speed from the entire weekend data compared with

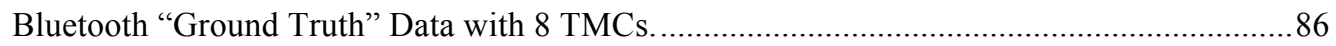

Figure 4-7 Link 5841, the average predicted speed from the entire weekend data compared with

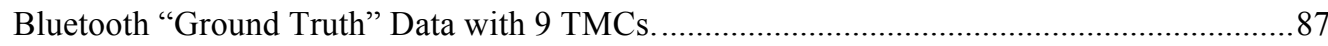

Figure 4-8 Link 5847, the average predicted speed from all the Wednesday data compared with Bluetooth "Ground Truth" Data.

Figure 4-9 Link 5856, the average predicted speed from all the Wednesday data compared with

Bluetooth "Ground Truth" Data with 2 TMCs.

Figure 4-10 Link 5857, the average predicted speed from all the Wednesday data compared with Bluetooth "Ground Truth" Data with 2 TMCs............................................................................101

Figure 4-11 INRIX distances compared to average speed error biases of all evaluated segments..............104

Figure 4-12 INRIX distances compared to percent of speed bias within $10 \mathrm{mph}$ threshold.........................105

Figure 4-13 INRIX distances compared to INRIX travel times availability of all evaluated segments......106

Figure 4-14 Number diversion versus mainline volume and travel time on weekdays, during operational periods - Before posted DMS travel times..............................................111

Figure 4-15 Number diversion versus mainline volume and travel time on weekdays, during operational periods - After posted DMS travel times ..............................................111

Figure 4-16 Number of vehicle diverting on Tuesday, NB14 segment, in the before and after periods .....112

Figure 4-17 Number diversion versus mainline volume and travel time on weekdays, during congested periods - Before posted DMS travel times.

Figure 4-18 Number diversion versus mainline volume and travel time on weekdays, during congested periods - After posted DMS travel times

Figure 4-19 Number of vehicle diverting on Tuesday, NB18 segment, during operational periods 


\section{CHAPTER 1. INTRODUCTION}

Traffic congestion is a major problem in the Washington D.C. metropolitan area, and has major impacts on the economy in the region. In 2010, the total congestion cost added up to close to $\$ 4$ billion dollars [1]. Congestion occurs when the demand exceeds the capacity. Increasing capacity (i.e., adding another lane) can be extremely expensive and often is not an option. Although capacity may be difficult to change, the demand can be controlled. One of the strategies to control demand is to inform commuters of current traffic conditions with real-time information and let commuters make informed decisions about whether to continue on the congested route or divert to other routes.

Traveler information systems are an effective way to mitigate congestion. The road network can be better utilized when drivers have access to traffic information, especially during non-recurrent congestion [2]. Dynamic Message Signs (DMSs) have been used to inform drivers about traffic conditions. Providing information allows drivers to be prepared and better react to the traffic. DMSs can not only improve travel times, but also decrease drivers' uncertainty about the traffic situation [2].

A large transportation investment has been put into traffic monitoring infrastructure with dedicated equipment, such as loop detectors, cameras, and radar. A major concern is the cost related to these technologies. With such a high cost of installation, operation, and maintenance, these technologies have only been deployed on a relatively small network. In particular, some sensors like inductive loops require significant maintenance in order to prevent system failure and maintain functionality. Maintaining inductive loops has been a challenge because these loops are embedded 
underneath the pavement. If there is a problem with a loop that prevents it from performing properly, lane closures are often required to perform maintenance. Closing a lane on a major corridor can severely affect the traffic flow and cause hundreds of thousands of dollars of user delays.

VDOT has been trying to improve traffic flow using Intelligent Transportation System (ITS) technology. Traveler information systems (TIS) are one of the ITS techniques which are used to inform travelers about the traffic. Many states DOT realize the importance of Dynamic Message Sign (DMS) as part of a TIS program, especially when travel time estimates are provided. A memorandum issued by the FHWA in 2004 stated [4]:

"No new DMS should be installed in a major metropolitan area or along a heavily traveled route unless the operating agency and the jurisdiction have the capacity to display travel time.”

\subsection{VDOT TRAVEL TIME INITATIVE}

VDOT recently began posting travel time information to existing overhead DMSs using INRIX data. In August 2011, VDOT started a pilot project displaying travel time information on the I-66 corridor. Sampson K. Asare evaluated the travel time data quality of the pilot project on the I-66 corridor since the beginning of the project until September 2011. Because of positive results from his work, two months later the pilot project was deemed a success and VDOT expanded travel time information to existing DMSs on the 
I-95 corridor [8]. More details on the pilot project on I-66 results and how the VDOT travel time program operates are provided in the literature review

The travel times are displayed from 5 a.m. to 9 p.m. during weekdays and from 8 a.m. to 8 p.m. during weekends [8]. There are three and eight DMSs with travel time messages on I-66 and I-95, respectively. Also, another ten segments in the Hampton Roads area were selected for data quality assessment to explore how well the system will work if the travel time messages were posted. Estimated travel times are changed every 5 minutes based on current traffic conditions, making it easier for commuters to cope with both recurring and non-recurring congestions. During non-recurring congestion, travel time estimates will let drivers know the estimated travel time for their journey, which is easy to understand and much more meaningful to drivers than a warning message sign. During recurring congestion, travel time information will allow commuters who know the network fairly well to make an informed decision about whether to divert onto another route. An example of the travel time information displayed on the DMSs is shown in Figure 1-1. 


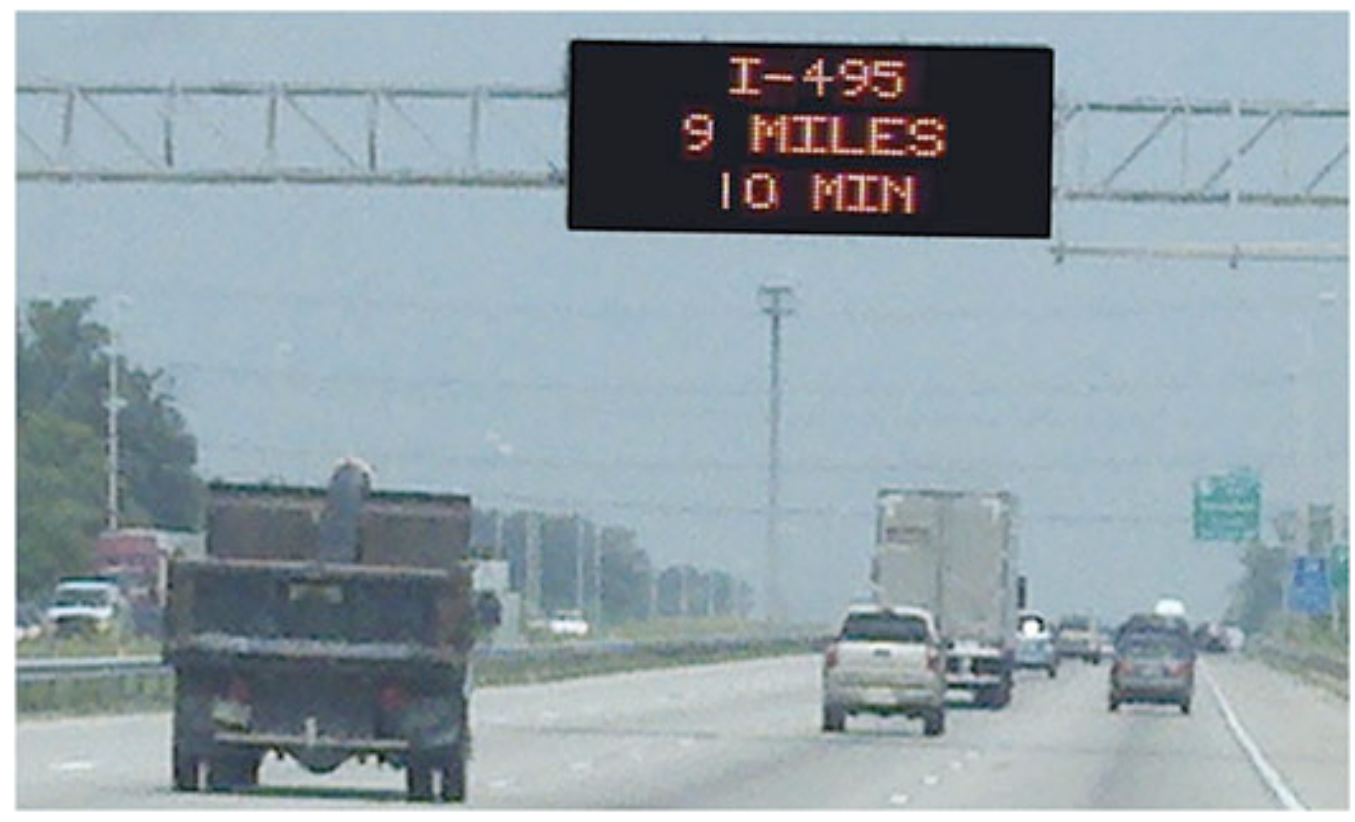

Figure 1-1 Vehicle Travel Time posted on a DMS on I-66

Travel time information is not only useful, but also relatively cheap in terms of investment, especially since VDOT can take advantage of existing DMS infrastructure and obtain travel time data using VDOT's agreement with INRIX through I-95 Corridor Coalition. Travel time information has historically not been one of the messages posted on DMSs in Virginia due to difficulty in obtaining this data. However, technology now allows the provision of travel time information to be more feasible. Instead of investing in sensors to collect real-time data, VDOT uses data from INRIX which has already collected travel time information on the network and made it available via the I-95 Corridor Coalition. Even though there are no installation, operating, or maintenance costs related to using INRIX data, other costs (i.e. initial purchase price and ongoing licensing agreements) are still significant and need to be considered.

The primary concerns when posting estimates of travel times or any traveler information, in general, are accuracy and reliability. The benefits of DMS travel times 
depend on the accuracy of travel time estimate [9]. Providing inaccurate travel time information is not only is useless to commuters, but it also hurts the credibility of the service [10]. One of the lessons learned about traveler information is that displaying inaccurate messages on DMSs can cause confusion and adversely affect both traffic flow and the transportation agency's credibility [7]. Once commuters lose faith in the service, it is often difficult to regain it. Therefore, the best practice is to ensure the quality of the data prior to making it public. Even though INRIX data had been tested several times by University of Maryland for the I-95 Corridor Coalition [11], it is still important to analyze the data before posting them on a new site to ensure accuracy and increase the credibility of the service.

Once travel time information is posted, the impact of estimated travel times on drivers' responses also need to be studied. The results will be useful for the improvement of travel time estimates at current sites and the future deployment at other sites. One of the goals of providing estimated travel times is to increase diversion, which will mitigate the congestion on the corridor. Even though the decision making process for each individual is complicated and involves many factors, travel time information is likely to be one of the key factors influencing diversion decisions. To evaluate the impact of travel time estimates, the change in vehicle volumes exiting the freeway will be investigated.

\subsection{PROBLEM STATEMENT}

Travel time information is a powerful tool for influencing drivers' decisions (i.e. diversion), especially during congested periods and improving the travel experience of 
individual. To provide travel time information in real-time, VDOT now heavily relies on the quality of travel time estimates from the INRIX. Inaccurate travel time estimates not only will discredit the service, but more importantly, they are useless to commuters. Thus, the quality of the DMS travel times developed using INRIX data must be confirmed.

Besides the accuracy of the travel time, it is also important to know whether commuters react to the travel time information. Even though this decision-making process is sophisticated, involves many factors, and is often unpredictable [12], the impacts of the estimated travel times on drivers still needed to be investigated.

\section{3 OBJECTIVE AND SCOPE}

The scope of this study is limited to the sections of interstates where VDOT has deployed DMS travel time messages and areas under investigation for potential deployment. In order to evaluate the quality of the INRIX data that are used by VDOT and investigate the impacts of estimated travel times on DMSs, the objectives are defined as follows.

Assess the data quality and availability of the travel time messages posted by VDOT that were developed using INRIX data

Determine conditions that appear to impact the quality of the travel time messages

Assess whether travel time messages increase diversion from the freeway

Provide recommendations to VDOT on how to improve system operation and future data quality evaluations 


\section{4 ORGANIZATION OF THE THESIS}

The remainder of this thesis is organized as follows:

CHAPTER 2 reviews information related to the VDOT Travel Time Program, INRIX

data, and data quality measures which are used in the research. Also, the previous studies

related to driver responses to both travel time and non-travel time information are included in this chapter.

CHAPTER 3 presents the overall research process including segment validation, benchmark selection, travel time data quality analysis, and diversion analysis.

CHAPTER 4 summarizes the results from the data quality analysis of the I-95, I-64, and I-264 corridors. The diversion analysis comparing data before and after posting travel time messages on two segments on I-95 corridors is also reviewed in this chapter.

CHAPTER 5 includes the conclusions on overall data quality and the impact of travel time information. Also, this chapter provides recommendations for future implementation of travel time information and future research. 


\section{CHAPTER 2. LITERATURE REVIEW}

This chapter illustrates VDOT's business rules for posting travel time on DMSs, reviews past studies of data quality measures, provides an overview of travel time data sources, and examines drivers' responses to travel time information from previous studies.

\subsection{BACKGROUND}

Travel condition information is not only important for the public sector as a means to improve traffic flow on the entire network, but also valuable to commuters. A study done by Khattak suggests that individuals are willing to pay for travel information as long as information is customized [5]. TIS could include the 511 phone system, radio broadcasts, internet information, and dynamic message signs (DMSs). Commuters can plan their trip ahead of time by calling 511, using media broadcast information, or accessing internet travel information websites. While they are on the road, they can use DMSs as another source of information to check on the upcoming traffic conditions and adjust their travel plans accordingly. From a survey of travel behavior throughout the 12county Greater Research Triangle region of North Carolina, researchers found that accessing an increasing number of information sources is positively and significantly associated with a higher likelihood of diversion [6]. Since congestion often cannot be predicted, providing onsite real-time information with travel time estimates can be another important factor in mitigating congestion and improving traffic flow. 
Even though some people may still rely on commercial radio broadcasts for traffic condition information, DMSs provide more specific information related to the DMS locations while radio broadcasts provide more generalized traffic information over an area. Moreover, estimated travel times on DMSs require no action from drivers in order to receive travel time information, unlike the internet or 511 services which require drivers to actively call or search for information. Drivers can instantaneously receive information and make a decision by quickly glancing at the DMS.

Travel time information may also be beneficial to commuters in terms of reducing anxiety [9], especially for those who need to be in a certain place at a certain time. The estimated travel times allow drivers to change or manage their plans accordingly. Instead of sitting in the traffic without knowing how long the congestion is going to last, they now can decide how to respond to the estimated congestion. A survey conducted by Houston TranStar staff, using an Internet-based survey, found that $82 \%$ of drivers would like to see travel time information posted on the DMSs [7].

Historical barriers to providing travel time information on DMSs included travel time accuracy and high costs related to data collection. As a result, DMSs were often used only to provide general traveler information (i.e. LANE CLOSED AHEAD, DELAYS AHEAD). This information is useful to drivers but it would have been more meaningful if commuters were able to know how long their journeys are going to be.

Advances in probe data systems have made provision of travel time data more accurate and cost effective. Many private companies are providing real-time travel time information on roadways network. Examples of private providers are INRIX, NAVTEQ, TomTom, Total Traffic Network, and TrafficCast [4]. This new source of data offers the 
opportunity to significantly increase the quantity of roadways where travel time information is disseminated.

\subsection{VDOT BUSINESS RULES FOR DMS TRAVEL TIME PROGRAM}

VDOT developed a business rules document to provide a framework for day-to-day operations and to provide guidelines on how to post travel times on DMSs. The hours for DMS travel time operations are as follows, with exceptions for construction work zones [4].

$$
\begin{array}{ll}
\text { Monday - Friday } & 5 \text { AM to } 9 \text { PM } \\
\text { Saturday and Sunday } & 8 \text { AM to } 8 \text { PM }
\end{array}
$$

During these hours, travel time messages are displayed on a continuous basis unless the message is over-ridden by a message with a higher priority on the DMS usage hierarchy [4]. The prioritization of all messaging is shown below [4].
1) Emergency
2) Incidents
3) AMBER Alerts
4) Construction/Work Zone
5) Weather
6) Special Events
7) HOV/HOT Special Messages
8) Travel Time
9) Ozone 
10) Safety Campaigns

11) Test Messages

12) VDOT Hearing

The Open Roads Statewide Travel Time Data Clearinghouse (STTDC) produces estimated travel time information based on INRIX data [4]. All travel time information disseminated within Virginia comes from the STTDC [4]. The STTDC stores the real time data at a Traffic Message Channel (TMC) segment level for each segment and sends travel time data in real-time to VDOT [4]. TMC segments are defined by mapping companies as units for providing traveler information. The travel time can be calculated by adding up the travel time values for a series of TMC code travel times provided by the STTDC [4]. If the real-time users (i.e. VDOT's Traffic Operation Centers (TOCs)) find that the data provided by the STTDC is be incorrect based on the local ground truth, they can "turn-off" travel time values for a TMC code or series of TMC codes and notify the STTDC [4]. During that period, there will be no travel times provided on DMSs and the signs will be blanked out.

Each speed range should have absolute speed error less than $10 \mathrm{mph}$ and speed error bias within $+/-5 \mathrm{mph}$ to satisfy VDOT data quality requirements [4]. If TMC data quality fails to meet the minimum availability requirement, the DMS sign will be blanked out. VDOT also requires at least $85 \%$ accuracy and $90 \%$ availability of TMC data quality to be posted on DMSs $[4,13]$. The $85 \%$ accuracy is calculated based on the ratio of the number of TMCs with a high confidence level based on real-time data to the number of the TMCs within a travel time segment, while availability is calculated based on the 
percentage intervals where the sign is blanked out. The sum of availability and blank out percentages should add up to 100 percent. To avoid speed violations, the threshold for minimum travel time posted should not result in an average speed over the segment greater than the posted speed for that segment [4]. The threshold for maximum travel time posted is when a travel time value is ten times the time required to travel related links at the posted speed [4].

\subsection{VDOT PILOT PROJECT ON I-66 CORRIDOR}

Prior to starting the travel time project, VDOT launched a pilot project to assess the feasibility of the system on the I-66 corridor. Sampson K. Asare evaluated the travel time data quality on three segments of this corridor. The three segments are listed below.

1. MM 54.58 to MM 64.6 (Eastbound)

2. MM 54.58 to MM 43.6 (Westbound)

3. MM 59.46 to MM 43.6 (Westbound).

At the beginning of the pilot project, Asare evaluated travel time data on the eastbound segment using July and August travel time data. He found the quality of INRIX data for this segment to be acceptable: $-1.8 \mathrm{mph}$ of speed error bias, $5.1 \mathrm{mph}$ of absolute speed error, and 95 percent of raw speeds within an error threshold of $+/-10$ mph based on data

from June $30^{\text {th }}$ to August $12^{\text {th }}$ [38]. From the same evaluation period, he also found a high discrepancy between raw travel time error and reported travel time error. Raw travel time is the actual INRIX travel time, and reported travel time is the actual travel time posted on DMSs. The raw travel time error was 6.2 seconds of overprediction, while the 
reported travel time error was 223.9 seconds overprediction [38]. This high discrepancy trend was continuously shown throughout his analysis, and led to the change in the operation of the DMSs. Prior to this evaluation, VDOT rounded travel times up to the next 5-minute interval when posting messages to DMSs. Following the evaluation, travel times were rounded up to the next 1-minute interval.

Using the entire month of data in September 2011, Asare conducted another analysis on all three segments on I-66 corridor. During the weekday operational periods on the I-66 MM 54.58 to 64.6 eastbound segment, he reported $-2.4 \mathrm{mph}$ of speed error, $6.4 \mathrm{mph}$ of absolute speed error, 96 percent of raw speeds within error threshold of $+/-10$ $\mathrm{mph}$, and 0.7 percent of intervals blanked out during operational period [38]. In September, the MM 54.58 to 43.6 westbound segment had only two weekday data to be evaluated. The results from two weekdays were $2.7 \mathrm{mph}$ of speed error, $7.8 \mathrm{mph}$ of absolute speed error, 89 percent of raw speeds within error threshold of $+/-10 \mathrm{mph}$, and 0.25 percent of intervals blanked out during operational period [38]. Lastly, the results on the MM 59.46 to MM 43.6 westbound segment during weekday operational periods were $0.7 \mathrm{mph}$ of speed error, $8.2 \mathrm{mph}$ of absolute speed error, 94 percent of raw speeds within error threshold of $+/-10 \mathrm{mph}$, and 1.2 percent of intervals blanked out during operational period [38]. These results demonstrated that the pilot project on I-66 corridor showed good data quality. 


\subsection{DATA QUALITY}

Since providing inaccurate travel times will not benefit drivers, data quality plays an important role in defining TIS applications' success. This section discusses general ways to define travel time data quality, and reviews the characteristics of two major sources of probe data relevant to this project: Bluetooth reidentification and INRIX data.

\subsubsection{Data quality measures}

The Federal Highway Administration (FHWA) has recommended six fundamental measures of traffic data quality: accuracy, completeness, validity, timeliness, coverage, and accessibility [14]. These measures are defined by FHWA as follows [14].

- Accuracy - The measure or degree of agreement between a data value or set of values and a source assumed to be correct. It is also defined as a qualitative assessment of freedom from error, with a high accuracy assessment corresponding to a small error.

- Completeness (also referred to as availability) - The degree to which data values are present in the attributes (e.g., volume and speed) that require them.

Completeness is typically described in terms of percentages or number of data values. Completeness can refer to both the temporal and spatial aspect of data quality, in the sense that completeness measures how much data is available compared to how much data should be available.

- Validity - The degree to which data values satisfy acceptance requirements of the validation criteria or fall within the respective domain of acceptable values. Data 
validity can be expressed in numerous ways. One common way is to indicate the percentage of data values that either pass or fail data validity checks.

- Timeliness - The degree to which data values or a set of values are provided at the time required or specified. Timeliness can be expressed in absolute or relative terms.

- Coverage - The degree to which data values in a sample accurately represent the whole of that which is to be measured. As with other measures, coverage can be expressed in absolute or relative units.

- Accessibility (also referred to as usability) - The relative ease with which data can be retrieved and manipulated by data consumers to meet their needs. Accessibility can be expressed in qualitative or quantitative terms.

For travel time information, accuracy is often viewed as the most important factor out of these measures. Therefore, the following discussion will focus on accuracy measures. Commonly used accuracy measures are listed below [15]. Also a recent Travel Time Data Quality Pooled Fund Study categorized these accuracy measures into a table, as shown in Table 2-1 [15].

- Percent of correct category classifications

- The percent of correct category classifications (with a specified boundary tolerance) is an accuracy measure for congestion categories. The specified boundary tolerance is used to improve the accuracy of the TIS value by letting a measured value, which closes to one of the category ranges, be considered as correct classification [15]. 
- Root mean square error, or RMSE (units of mph)

- The RMSE is used to measure the difference of raw data from the benchmark, as shown in Equation (1). By squaring the error term, the RMSE is a good accuracy measure because it can identify where data diverge from the ground truth by large amounts [15].

Root_Mean_Square_Error $($ RMSE $)=\sqrt{\frac{\sum_{i=1}^{n}(\text { RawData }- \text { Benchmark })_{i}^{2}}{N}}$

- Average absolute error (ASE, units of mph)

- The average absolute error is simple accuracy measure, which is often used because is easy to calculate and easy to understand [15]. This measure conveys the average magnitude of the error, but it does not indicate whether there is a consistent negative or positive bias [15]. The ASE equation is shown below in Equation (2).

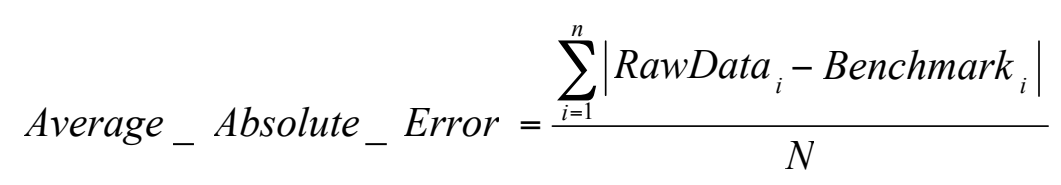

- Average error (also called bias, units of $\mathrm{mph}$ )

- The average error is similar to the ASE, except the average error is not the absolute value, as shown in Equation (3). Because of that, users need to be cautioned that the average error may cause a misleading estimate of the magnitude of the error because positive and negative errors can cancel each other [15]. 


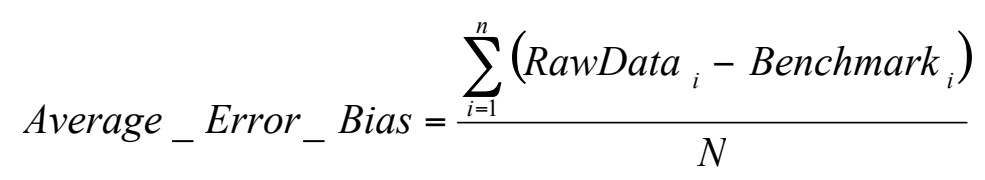

- $\quad$ Average absolute percent error (units of \%)

- The average absolute percent error is similar to the average absolute error, except the error terms (units of time) in this measure will be divided by the ground truth values (units of time) in order to get results in percentages.

Because of the absolute value, this measure conveys only the magnitude of the error.

- Average absolute error per unit length (units of seconds per mile)

- The average absolute error per unit length is similar to the average absolute error, except the error terms (units of time) in this measure will be divided by the route length (in miles). Because of the absolute value, this measure conveys only the magnitude of the error.

- Average absolute error (units of minutes)

- The average absolute error (units of time) is identical to the average absolute error (units of $\mathrm{mph}$ ). Since route length is not considered, this measure should not be used to aggregate accuracy results from different routes [15]. 
Table 2-1 Accuracy Measures [15]

\begin{tabular}{|c|c|c|}
\hline Accuracy Measure & Strengths & Limitations \\
\hline $\begin{array}{l}\text { Average Difference } \\
\text { (mph or minutes) } \\
\text { [also called bias] }\end{array}$ & $\begin{array}{l}\text { - Simple measure, easy to } \\
\text { calculate } \\
\text { - Indicates whether there is } \\
\text { consistent bias } \\
\text { - Units of mph or minutes is easy } \\
\text { to understand }\end{array}$ & $\begin{array}{l}\text { Large positive and negative } \\
\text { errors cancel each other, } \\
\text { providing a misleading } \\
\text { estimate of the error magnitude } \\
\text { When used for travel time, it } \\
\text { provides misleading results } \\
\text { when comparing different } \\
\text { segment lengths }\end{array}$ \\
\hline $\begin{array}{l}\text { Average Percent Difference } \\
(\%) \\
\text { [also called bias] }\end{array}$ & $\begin{array}{l}\text { Simple measure, easy to } \\
\text { calculate } \\
\text { Indicates whether there is } \\
\text { consistent bias } \\
\text { Percentage value permits } \\
\text { comparison of accuracy on } \\
\text { different segment lengths }\end{array}$ & $\begin{array}{l}\text { Large positive and negative } \\
\text { errors cancel each other, } \\
\text { providing a misleading } \\
\text { estimate of the error magnitude } \\
\text { If low speeds are being } \\
\text { evaluated, small changes in } \\
\text { magnitude can create large } \\
\text { changes in percent difference. }\end{array}$ \\
\hline $\begin{array}{l}\text { Average Absolute } \\
\text { Difference } \\
\text { (mph or minutes) }\end{array}$ & $\begin{array}{l}\text { - Simple measure, easy to } \\
\text { calculate } \\
\text { Conveys the magnitude of the } \\
\text { error, whether positive or } \\
\text { negative }\end{array}$ & $\begin{array}{l}\text { When used for travel time, it } \\
\text { provides misleading results } \\
\text { when comparing different } \\
\text { segment lengths }\end{array}$ \\
\hline $\begin{array}{l}\text { Average Absolute } \\
\text { Difference, Normalized by } \\
\text { Segment Length } \\
\text { (seconds per mile) }\end{array}$ & $\begin{array}{l}\text { Normalizes by segment length } \\
\text { and permits comparisons across } \\
\text { different segment lengths } \\
\text { Conveys the magnitude of the } \\
\text { error, whether positive or } \\
\text { negative }\end{array}$ & $\begin{array}{l}\text { Not a lot of intuitive meaning } \\
\text { to non-professionals }\end{array}$ \\
\hline $\begin{array}{l}\text { Average Absolute Percent } \\
\text { Difference (\%) }\end{array}$ & $\begin{array}{l}\text { Simple measure, easy to } \\
\text { calculate } \\
\text { Conveys the magnitude of the } \\
\text { error, whether positive or } \\
\text { negative }\end{array}$ & $\begin{array}{l}\text { If low speeds are being } \\
\text { evaluated, small changes in } \\
\text { magnitude can create large } \\
\text { changes in percent difference. }\end{array}$ \\
\hline $\begin{array}{l}\text { Root Mean Square Error } \\
\text { (RMSE) }\end{array}$ & $\begin{array}{l}\text { Relatively easy to calculate, } \\
\text { standard output for data analysis } \\
\text { software } \\
\text { Provides greater weight to higher } \\
\text { magnitude error, even in a } \\
\text { limited quantity }\end{array}$ & $\begin{array}{l}\text { Underlying concept not well } \\
\text { understood or related to by } \\
\text { non-technical audiences }\end{array}$ \\
\hline $\begin{array}{l}\text { Percent of values within } \\
\{X\} \text { of benchmark, where } \\
\{X\} \text { is a specified margin } \\
\text { of error (mph, \%, or } \\
\text { confidence interval) }\end{array}$ & $\begin{array}{l}\text { A percentage value is fairly easy } \\
\text { to understand } \\
\text { Provides capability to vary the } \\
\text { margin of error on different } \\
\text { roads or area types (urban vs. } \\
\text { rural) yet still report a consistent } \\
\text { measure }\end{array}$ & $\begin{array}{l}\text { Calculation details more } \\
\text { difficult to communicate } \\
\text { concisely } \\
\text { Confidence intervals not } \\
\text { available with single test } \\
\text { vehicle data collection }\end{array}$ \\
\hline
\end{tabular}


To appropriately evaluate TIS accuracy and avoid inconsistencies in absolute speed error impact at different speeds, TIS accuracy should be calculated and reported separately in different traffic conditions, based on speeds categories[15]. The Pooled Fund Study recommended the following traffic speed ranges for computing and reporting accuracy statistics [15]:

- Freeways: less than $30 \mathrm{mph}, 30-45 \mathrm{mph}, 45-60 \mathrm{mph}$, and over $60 \mathrm{mph}$.

- Arterials: less than $20 \mathrm{mph}, 20-30 \mathrm{mph}, 30-40 \mathrm{mph}$, and over $40 \mathrm{mph}$.

\subsubsection{Bluetooth data}

The University of Maryland (UMD) developed a portable Bluetooth monitoring system to obtain ground truth data as an alternative to using the floating car method [16]. Although the floating car method may provide good benchmark data, the quantity of data is often not sufficient due to its high cost and limited agency funds [17]. In order to provide a vigorous validation of probe data for I-95 corridor, UMD needed a high density of probe data [17].

Bluetooth data collection works by re-identifying media access control (MAC) addresses for Bluetooth devices that are in discoverable mode in a vehicle. A MAC address is a unique identifying number assigned to a device. Even though the MAC address for each device is unique, the MAC address is not linked to any kind of personal information database $[16,18]$. Bluetooth readers can be used to determine the arrival of vehicles by detecting MAC address of an electrical device in a vehicle [19]. The two Bluetooth detectors in Figure 2-1 are located at a known distance apart and match a 
device's MAC address. Once the Bluetooth MAC address matched, travel times between the detectors can be determined. Bluetooth will collect only the match time, travel time, and speed of vehicles. The ground truth data from the Bluetooth are collected 24 hours a day, using vehicle probe techniques to be consistent with how INRIX produces their travel time data.

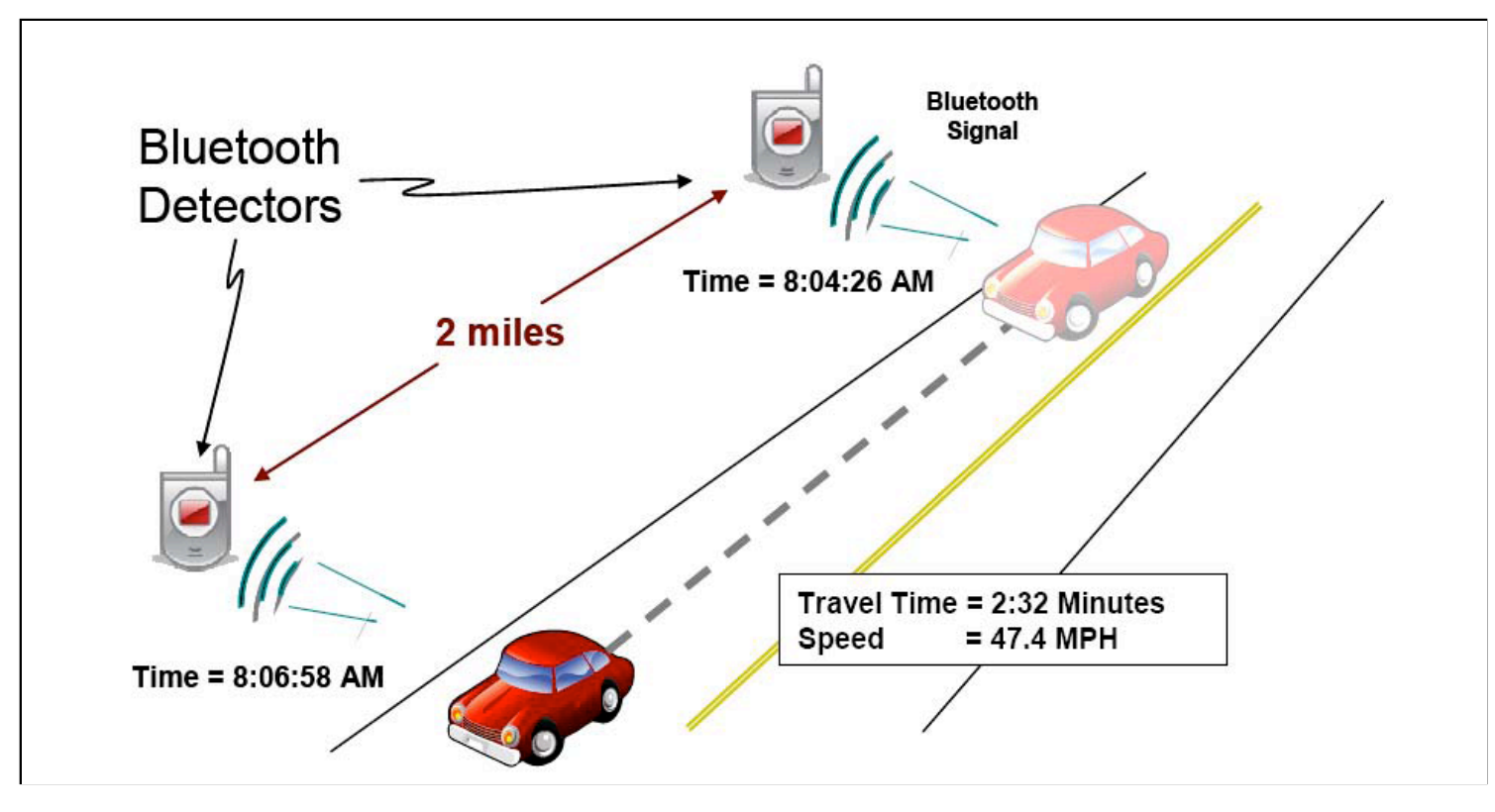

Figure 2-1 Bluetooth Data Collection Method [16]

\subsubsection{Bluetooth Case Study from I-95 Corridor Coalition}

In 2008, the I-95 Corridor Coalition signed a contract with INRIX and initiated the Vehicle Probe Project (VPP). The VPP enhances traveler information by providing access to real-time traffic information via a website, DMSs, and other public information sites. Moreover, the I-95 Corridor Coalition also disseminates vehicle probe data by 
making it available to member agencies, starting from New Jersey down to Florida, covering over 20,000 centerline freeway and arterial miles [20].

To ensure the accuracy of INRIX data, the I-95 Corridor Coalition signed an agreement with the University of Maryland (UMD). UMD is responsible for evaluating the travel time quality for I-95 Corridor Coalition by comparing INRIX data to Bluetooth data, which serves as ground truth. UMD assessed the accuracy of the data in each speed category as defined in the contract (0-30 mph, 30-45 mph, 45-60 mph, and >60 mph). Since Bluetooth monitoring was a new technology at the time, the researchers had to establish the validity of the Bluetooth method prior to using it as the benchmark.

In June 2008, UMD collected the data on the Washington Beltway (I-495) and compared it against INRIX data [16]. In the sample validation data, there were four floating car sample data points included [16]. The Figure 2-2 shown below demonstrates the difference between the floating car runs and the Bluetooth data [16]. Generally speaking, the Bluetooth data tracked well with the floating car data. Also, Bluetooth traffic monitoring had the additional advantage of generating a much higher number of data points than the floating car method as shown in Figure 2-2. 


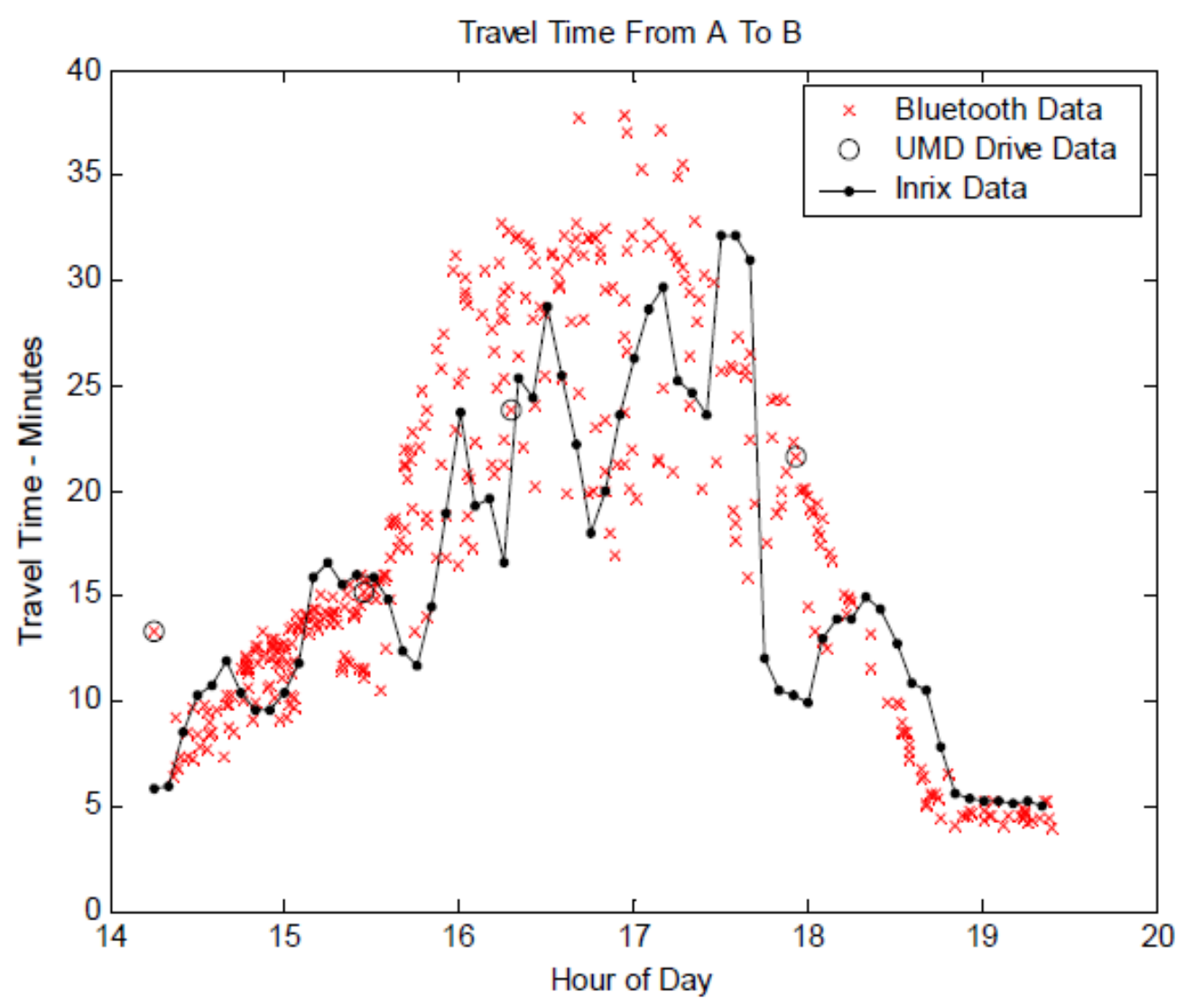

Figure 2-2 Sample validation data on I-495 in D.C. [16]

\subsubsection{Bluetooth Case Study from Ohio DOT}

The University of Akron, sponsored by the Ohio DOT, verified the travel times provided by a data service vendor, using different data collection methods. In one of the studies, the research team studied Bluetooth performance by comparing it to the floating car method under different scenarios: high volume interstates, lower volume roads, different times of day, and within a work zone area. The research team found that the Bluetooth method has the ability to reproduce floating car data, while providing a much greater quantity of data points (see Figure 2-3) [18].

An example from one of the studies from the University of Akron [18] occurred during congestion caused by a heavy rain around $5 \mathrm{PM}$. Both data points from the 
floating cars and Bluetooth devices detect the change in the average vehicle speeds, as shown in Figure 2-3. After the rain subsides, the average vehicle speeds increase back to free-flow speed. The following results are also illustrated in Figure 2-3 below [18].

- During a congested period due to rain, the results for both data collection methods were similar. Both showed a decrease in the average vehicle speeds during a period of rain.

- During free-flow, Bluetooth data points show higher frequency of speeds above the speed limit. Note that the floating cars were instructed to drive within the speed limits.

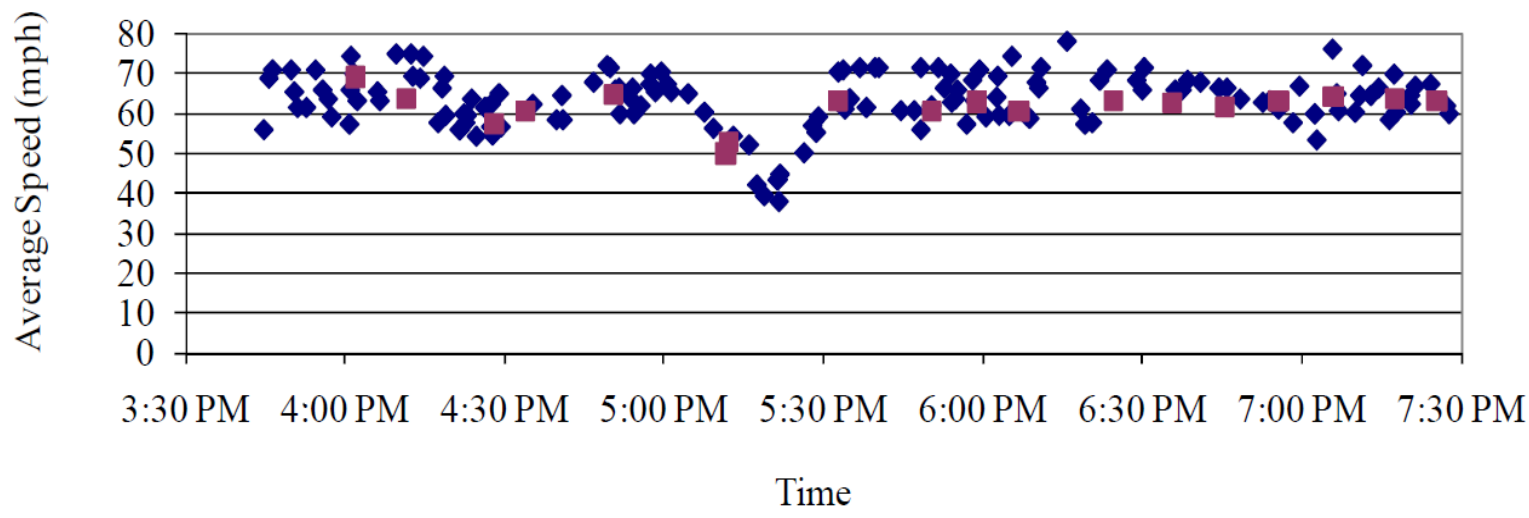

$\bullet$ Bluetooth $\quad$ Floating Car

Figure 2-3 Data Collection from a highway 2.6 miles segment on I-75, 7/29/2009 [18]

The University of Akron studied Bluetooth performance as compared to the floating car method in different scenarios (e.g. high volume road, smaller road, different time of day and work zone). The following are the major concerns regarding to the nature of Bluetooth data, based on the study done by the University of Akron [18]. 
- Bluetooth matches may decrease due to one of the two following factors.

- Distance between readers: If the distance between Bluetooth detectors on a highway is too long, some vehicles may take an exit after passing the first detector and do not pass the second detector. On the other hand, if those vehicles decide to get back on the highway and pass the second detector, this will significantly increase the reported travel time, which can misrepresent the actual traffic condition.

- Time of Day: Bluetooth matches at nighttime may be a lot lower than daytime due to lower traffic volumes.

- Local road network: The traffic lights in a local road network between Bluetooth detectors may cause a decrease in the number of Bluetooth matches due to a lower volume of traffic. However, it is possible that traffic lights will increase the number of Bluetooth matches when a platoon of vehicles commonly associated with signals passes the readers. These two cases were shown in the University of Akron's study.

The previous case studies illustrate that Bluetooth data is an appropriate data source to be used as the ground truth data for providing travel time estimates in real-time. Bluetooth data can reproduce floating car data with a much greater quantity of data points. Moreover, the Bluetooth method is more cost effective: the cost for one data point of floating cars method is equivalent to the cost of 500 to 2,500 data points from the Bluetooth method [16]. 


\subsection{INRIX DATA}

INRIX provides historical and real-time traffic information. Two of the most important technologies, which enable INRIX to provide real-time and historical traffic information, are the INRIX "Smart Dust Network" and the INRIX "Traffic Fusion Engine." The INRIX Smart Dust Network includes not only hundreds of public and private road sensors, but also uses real-time GPS probe data from more than 650,000 commercial fleet, delivery, and taxi vehicles [21]. The INRIX Traffic Fusion Engine combines traffic flow and incident information from multiple data sources [21]. To generate real-time and historical travel time information, the INRIX Traffic Fusion Engine utilizes sophisticated Bayesian modeling and proprietary error detection and correction techniques [21].

With traffic information from INRIX, public agencies can provide travel time data at a lower cost as compared to traditional approaches. On average, I-95 Corridor Coalition found that state DOTs can get the same coverage, if not more, from INRIX data at around $25 \%$ of the cost for traditional approaches [22, 23].

\subsubsection{INRIX Case Study from I-95 Corridor Coalition}

UMD evaluated INRIX data on monthly basis for all the member states in the I-95 Corridor Coalition, using Bluetooth as a benchmark. To compare INRIX data with Bluetooth data, the standard error of the mean (SEM) (see Equation 4) was used to represent the uncertainty in the definition of the ground truth and travel times [24]. SEM represents the speed and travel time variation depending on driver, vehicle, and roadway characteristics [24]. The narrower the SEM band, the more confident the data. Besides 
SEM, another measure of error used to evaluate the accuracy of the INRIX data is the ground truth mean. Equations 4, 5, and 6 show how SEM can be computed.

$$
\begin{gathered}
\text { Standard Error of the Mean }(S E M)=\frac{S}{\sqrt{N}} \\
\text { Standard Deviation }(\mathrm{S})=\sqrt{\frac{\sum_{i=1}^{n}\left(\text { Speed }_{I N R I X}-{\text { mean })_{i}^{2}}^{2}\right.}{N}} \\
\text { Mean Speed (mean) }=\frac{\sum_{i=1}^{n}\left(\text { Speed }_{B T}\right)_{i}}{N}
\end{gathered}
$$

UMD followed the accuracy standards of the I-95 Corridor Coalition, which required certain speed error bias and average absolute speed error thresholds. These standards are listed below in Equations 7 and 8.

$$
\begin{aligned}
& \text { Speed_error_bias }(\operatorname{SEB})=\frac{\sum_{i=1}^{n}\left(\left(\operatorname{Speed}_{B T}\right)_{i}-\left(\operatorname{Speed}_{I N R I X}\right)_{i}\right)}{N} \\
& \text { Average_absolute_speed_error }(\text { AASE })=\frac{\sum_{i=1}^{n} \mid\left(\text { Speed }_{i}\right)_{B T}-\left(\text { Speed }_{i}\right)_{\text {INRIX }} \mid}{N}
\end{aligned}
$$

To appropriately characterize TIS accuracy, the I-95 Corridor Coalition requires UMD to measure the accuracy of the INRIX data, using the above equations, and provide the validation of INRIX data for each of the following speed ranges $[4,15]$ :

\section{0-30 MPH}

$30-45 \mathrm{MPH}$ 
45-60 MPH

$>>60 \mathrm{MPH}$

The maximum average error for AASE (referred to as Average Absolute Difference in Table 2-1) and SEB (referred to as Average Difference in Table 2-1) in each speed bin should not exceed $10 \mathrm{mph}$ and +/- $5 \mathrm{mph}$, respectively. If the AASE and SEB for each speed bin do not fall outside of these ranges, UMD determines INRIX data to be accurate.

Since the beginning of the VPP until June 2011, UMD had collected the data from 30 test sites in seven states (New Jersey, Pennsylvania, Delaware, Maryland, Virginia, South Carolina and North Carolina), producing monthly reports using a total of nearly 35,000 hours of data across more than 650 miles [20]. When a roadway has a flow above 500 vehicles per hour, the VPP requires the quality check [15]. To maximize the likelihood of observing congestion, the data were collected during the following periods: rush hours for commuter routes, weekends and holidays for recreational routes, and during major events such as sporting events and concerts [17].

Based on the Two-Year Summary Report July 2008-June 2010 [25], the INRIX data, generally satisfied the contract requirements. Some monthly reports showed that the speed requirements in low speed ranges had not met the standards due to congestion, snow storms, overnight work zones, etc.

For example, the validation of INRIX data April 2010 monthly report [11] used travel time samples collected by Bluetooth technology on 14 miles on ten freeway segments on the Route 42 freeway in New Jersey. The data consisted of over 1980 hours 
of observations during a two week period. The results show that INRIX data did not meet the contract specification for the speed bins less than $45 \mathrm{mph}$ [11]. The averages of AASE and SEB for the lower two speed bins are approximately $13 \mathrm{mph}$ and $10 \mathrm{mph}$, respectively [11]. The report specified the cause of the failure of INRIX data as being due to nighttime construction and road maintenance activities on Route 42 during the validation period [11].

Based on the results during the two-year validation of INRIX data, it can be concluded that the data quality improves as more INRIX data is acquired. For example, the average absolute speed error (AASE) in the 0-30 mph speed bin were significantly improved after the amount of data collected increased from 790 (February 2009) to 1190 hours (August 2010) [25].

\subsection{DRIVER RESPONSE}

Assessing the benefits of providing travel time information in terms of improving traffic conditions and mitigating congestion is complicated and difficult to measure. One of the expected responses, which will be beneficial to the traffic network, is diversion. This section illustrates previous studies on drivers' responses by categorizing them into two groups based on the information presented to the driver: travel time information and nontravel time information.

\subsubsection{Travel time information}

There are several ways to assess driver responses due to travel time information. First, driver responses can be studied through a survey with a set of questions from a sample of 
drivers. A survey is commonly used because the responses come directly from drivers, plus it is quite straightforward to conduct. Second, the study can be done through a field experiment to collect the field data (i.e. diversion volumes). The field data represent the actual traffic pattern and how drivers respond to the system. Lastly, researchers can use a simulation with several assumptions to create a virtual traffic network and then obtain the results from there. Previous studies in this section will be separated based on their study methods: surveys, field data, and simulation.

\subsubsection{Surveys}

In Houston, TX, travel time information was determined using toll tag transponder readers placed at 1 to 5 mile intervals along freeways and HOV lanes [27]. Travel times were updated every 10 minutes and displayed on overhead DMSs. Between April and May 2004, the Texas Department of Transportation (TxDOT) conducted a survey to assess customer satisfaction. The survey showed that 85 percent of the respondents changed their routes due to information on a DMS sign [27]. Out of this 85 percent, 66 percent said that it resulted in travel time savings [27].

TxDOT initiated another study to examine how commuters' behaviors and traffic operations were affected by traveler information [28]. The survey was distributed as an online questionnaire accessible through an online survey provider. There were 706 survey participants by the end of October 2005. These participants lived in the urban and suburban areas of Austin, including seven counties. The alternative route for this study was a toll road, and the main routes are the highways which used most often by 
participants for their commute trips. The benefits from enhancing the diversion to toll roads are to increase toll road usage and reduce congestion on non-tolled roads [28]. The participants' responses on how traveler information has an impact on travel behavior showed that $67 \%$ stated that they would select an alternate route, followed by $18 \%$ who said they would leave earlier than planned, and 3\% reporting no impact on travel decisions [28].

There are more significant findings from this study survey, which are listed below [28].

- Most respondents, $91 \%$, expected to save 5 to 15 minutes by using an alternate route. About $40 \%$ of respondents indicated they were willing to pay for travel time savings; the average amount is $\$ 2.07$ with an average anticipated time saving of 12.5 minutes.

- About $46 \%$ of respondents said they would choose a toll road if traveler information indicated that they could save time. It was also confirmed that income level and gender have effects on commuters' willingness to choose toll roads. For example, the survey shows women (i.e., 49\%) are more likely to choose a toll road than men (i.e., 41\%). Also, when the income level is over $\$ 75,000$, the percentage of respondents willing to choose a toll road is 51 percent. On the other hand, the percentage could go as low as 39 percent if a respondent's income level is between $\$ 25,000$ and $\$ 34,000$.

Another study from Texas Transportation Institute used a survey to study how commuters respond to real-time information from a radio advisory [8]. A homogeneous group of 
workers, who regularly make Home-Based Work (HBW) trips between North Central Expressway in Dallas, TX and the Dallas Central Business District (CBD), were selected. The survey was conducted via phone calls. The participants were asked to imagine that they were driving on the highway and heard an advisory message from the radio providing the following information: where the accident occurred, where congestion begins, what the alternate route is, and how much time is saved if they divert. Each question provides different time saving values. Participant will choose the time saved value which influences them to consider diversion. The main finding from the study is that the characteristics of an alternate route have an impact on commuters' decisions on whether or not to divert [8]. For example, some subjects needed much higher time saved values in order to divert to an alternate route because of the large numbers of traffic lights and stop signs [8]. On the other hand, other subjects had higher time saved values for the Tollway because they do not want to pay the fee [8].

Lerner et al used two methods, driver logs and focus groups, to examine actual experiences of drivers who normally encounter en route travel time information [29]. The study took place in three different urban areas: Atlanta, GA, Milwaukee, WI, and Seattle, WA. There were 15 participants in each location, for a total of 45 focus group participants. The same individuals completed the driver log portion of the study, however complete driver logs for a two-week period were only received from 42 participants [29]. In the focus group, many drivers believed that travel time information is useful in terms of reducing frustration and uncertainty [29]. Based on the individual driver log data, 56\% of drivers reported that travel time information encouraged them to divert [29]. Once they 
were provided with travel time information, they believed that an alternate route would be faster or about the same as the current route [29].

$\mathrm{Lu}$ et al examined the average number of route switches comparing two scenarios (termed the incident and information scenarios) to study how information impacts travelers' route choice behaviors [30]. This study was done using surveys in a laboratory setting. There were a total of eight experimental sessions performed: four sessions for each scenario, and each session had a total of 16 participants [30]. The difference between the incident and information scenario is that the incident scenario has no realtime information for participants to improve their choice, unlike information scenario. Participants were instructed to make route choices from work to home on a day-to-day basis. The network consists of a risky route (highways), a safe route (arterials) and a detour route (local roads). The risky route has a $25 \%$ chance of an incident which may cause significant congestion [30]. First each participant was required to choose between the safe branch and the risky branch. If participants chose the risky branch, they would have to decide whether they want to take the detour route or the risky route. Only participants in the information scenario, who chose the risky branch in the first bifurcation, will have an access to real-time travel time information for the experimental day. Once all 16 subjects made their route choice for one day, the travel time for a participant's chosen route was given, and they could proceed to the next day's route selection. The subjects from both scenarios would only see their own travel time for the chosen route in the previous day. Subjects made route selections for a total of 120 days. The result suggests that the real-time information significantly reduces the level of 
uncertainty [30]. Moreover, the average trip time improved by $30 \%$ when real-time information exists [30].

Ramsay et al., 1997 conducted vehicle count surveys to observe how diversion changes after an incident due to the Drive Time System on Melbourne's South Eastern Arterial, which provided dynamic freeway information, such as displaying real-time trip time information, current traffic conditions (e.g. LIGHT, MEDIUM, HEAVY, or CLOSED) and details of incidents and roadwork [31]. The Drive Time System information was provided via DMSs, dial-in telephone, fax, and radio/TV broadcasting [31]. The research team conducted three surveys via telephone and diversion counts. The initial telephone survey had 300 respondents. The questions covered awareness of the system, legibility of the signs, perceived usefulness of Drive Time information, etc. Some respondents were willing to be contacted in follow-up surveys. With the help from the VicRoads Traffic Control and Communication Centre, the research team was notified immediately when an incident occurred. The first incident follow-up survey was conducted on the same day as an incident on September 14, 1995. The blockage lasted approximately 26 minutes during the morning peak. The survey had 60 respondents. The second incident follow-up survey was conducted on October 24, 1995, which was 2 days after the incident. The blockage lasted approximately 36 minutes during the afternoon peak. The survey had 72 respondents. Between 70 to 90 percent of drivers considered the Drive Time System Signs to be useful [31]. 
Zhang and Levinson studied the determinants of route choice and the value of traveler information, using both a stated preference survey and a field experiment using randomly selected subjects [10]. The field experiment consisted of five routes between the University of Minnesota East Bank Campus and Downtown Saint Paul. Subjects had to choose two of the selected routes to travel between the origin and the destination points in the field experiment, and then make another trip using two new routes. About half of the subjects were informed about the expected travel time before their trips. After the subjects finished their trips, they were asked about the usefulness of knowing estimated travel time prior to the trips and the value of having such information. The results suggest that drivers are more likely to divert to a route that has lower travel time, higher speed, and better aesthetics. The factors which influence drivers' decisions in this study included trip purpose, travel time information, aesthetics, commercial development, characteristics of the routes (e.g. easiness), pleasure (based on a scale of 1-7), and familiarity. The information variable had the highest value. However, when the trip purpose was changed to other trip purposes (e.g. shopping, recreation), the variable for commercial development became higher than the variable for accurate information. Therefore, travel time information is just one of the factors affecting route choice behavior [10].

Researchers also found that there are several factors, such as trip purpose, characteristics of alternative routes, previous network knowledge, and demographics that influence drivers to make a decision whether or not to divert $[10,12,33]$. It is difficult to compare how important these factors are relative to travel time information because each factor can be related to other factors under examination. The study done by Zhang and Levinson showed that the influence from travel time information factor was decreased 
when the trip purpose was changed from commute trips to shopping or recreations trips [10]. Based on their findings, it is safe to say that travel time information encourages diversion under the following conditions [10].

- Commute trips during rush hours

- Alternative routes have a few stop signs, traffic lights, speed bumps, etc.

- Drivers are familiar with the network

The findings about related factors influencing diversion are important because there will be no operational benefits to the network without diversion or trip cancelation/rescheduling.

\subsubsection{Simulation}

Lam and Chan analyzed the effects of dynamic travel time information provided via DMSs on the expressway network in Hong Kong [2]. Even though the expressway network represents a small proportion of the total length of the roadway network, the expressway network is an important key to improving traffic conditions in Hong Kong because it carries a disproportionately high amount of traffic. The network in this study is the network of the Tuen Mun Road Corridor which connects Tuen Mun (a new town in the outlying area) and Kowloon (the urban area in Hong Kong) [2]. The network consisted of 3 zones and 10 links. The total network time is the sum of the network time for different time intervals in the study period, which was two hours [2]. A timedependent traffic assignment model was used to assess the effects of travel time information [2]. The effect of dynamic travel time information provided via DMS was 
evaluated using the ratio of total network time network time with DMSs and detectors divided by a total network time without DMSs and detectors [2]. Ratios with smaller values indicates more improvement. After the two-hour study period in recurrent and non-recurrent congestion situations, the study found that the effectiveness of the DMS system during non-recurrent congestion (the ratio of 0.7 ) is more significant than recurrent congestion (the ratio of 0.94 ) [2]. Note the model was not calibrated or validated.

TxDOT also used the DYNASMART-P program to simulate the network in Travis, Williamson, and Hays Counties in Texas and analyze the impacts of TIS (i.e. DMS) on link performance. Prior to the simulation process, a number of assumptions had to be made. Some were based on the online survey discussed in section 2.6.1, which was conducted by TxDOT. For example, the value of time for Austin commuters was estimated to be $\$ 10$ based on the survey, and TIS was active throughout the simulation period (i.e., 100 minutes) [28]. The DYNASMART-P simulation provides users with network performance and link performance data in terms of speed, density, and volume information. The results illustrate that the traffic volume diverting to the toll road link increases by about $50 \%$ on average, and in some links goes as high as $110 \%$ [28]. A possible explanation is that providing traveler information to inform commuters how much travel time they can save by using toll roads can encourage their route choice decision [28]. Note that the model was not calibrated or validated. 


\subsubsection{Field Data}

Brownstone and Small conducted a study to measure commuters' value of time (VOT) and reliability using two road pricing corridors in southern California: SR91 and I-15 [32]. They analyzed several datasets and results from SR91 and I-15 corridors based on both revealed preference (RP) lane-choice data and stated preference (SP) surveys. SR91 has preset time-varying pricing structure, where prices vary hour by hour. I-15 has a dynamic pricing structure, where prices vary based on real-time traffic conditions. Even though the congestion pricing schemes for both corridors are different, the VOT on the morning commute for both corridors are very similar and quite high, between $\$ 20$ and $\$ 40$ per hour [32]. Knowing commuters' VOT is important because VOT helps explain drivers' responses to travel time information.

\subsubsection{Non-travel time information}

Another study conducted by Schroeder and Demetsky evaluated driver reactions and investigated the impacts of existing messages on DMSs [34]. The data came from I-95 (e.g. main route) and I-295 (e.g. alternate route) in Richmond, VA. The performance measure studied was the percent of traffic diverting. During the study, there were four types of messages: no incident, incident with no guidance provided, incident with an alternate route recommended, and incident with I-295 recommended as the alternate route. These messages were displayed on I-95 DMSs before the I-295 interchange along with additional information (e.g. different word choice, information about lanes closed, incident type) in order to inform commuters about an incident downstream. Then the research team observed how diversion has changed. The results show that messages on 
DMSs encourage diversion. For example, the percent of traffic exiting to I-295 for the no incident message type was $29.9 \%$, which is less than other message types. The percent of diversion increased to $35.4 \%$ and $38.3 \%$ when alternate routes were recommended with the message types "ACCIDENT" and "MAJOR ACCIDENT," respectively [34]. One of the recommendations, without any supporting data, is that it is beneficial to provide estimates of travel times on DMS, if they can be reasonably accurate, to encourage diversion [34].

Table 2-2 summarizes the findings related to how drivers response to travel time information. 
Table 2-2 Driver responses to travel time information

\begin{tabular}{|c|c|c|}
\hline Author(s) & Methodology & Key Findings \\
\hline $\begin{array}{c}\text { TxDOT } \\
\text { (Houston) [27] }\end{array}$ & Survey (SP) & $\begin{array}{l}66 \% \text { out of } 85 \% \text { who change their routes said } \\
\text { they did so because of travel time saving }\end{array}$ \\
\hline TxDOT [28] & $\begin{array}{l}\text { Online survey, } 706 \text { participants }(\mathrm{SP}) \\
\text { [alternate route is toll road] }\end{array}$ & $\begin{array}{l}50 \% \text { increase on toll road due to the provision } \\
\text { of traveler information } \\
91 \% \text { expect to save } 5 \text { to } 15 \text { minutes by } \\
\text { changing their routes } \\
67 \% \text { would select an alternate route } \\
\text { VOT } \$ 10 \text { per hour }\end{array}$ \\
\hline $\begin{array}{c}\text { Texas } \\
\text { Transportation } \\
\text { Institute [8] }\end{array}$ & Survey (SP) & $\begin{array}{l}\text { Corridor characteristics of alternate } \\
\text { (e.g. Tollway) route have an impact on } \\
\text { drivers' decisions }\end{array}$ \\
\hline $\begin{array}{l}\text { Lerner et al } \\
\quad[29]\end{array}$ & Focus group of 45 participants (RP) & $\begin{array}{l}56 \% \text { of drivers reported that travel time } \\
\text { information encouraged them to divert }\end{array}$ \\
\hline $\begin{array}{c}\text { Zhang et al } \\
{[10]}\end{array}$ & $\begin{array}{c}\text { Field experience stated } \\
\text { preference survey (FESP) \& } \\
\text { Discrete choice model (Logit model) }\end{array}$ & $\begin{array}{l}\text { Accurate information variable is } 0.81 \text { which } \\
\text { has the highest value for commute trips } \\
\text { Diversion influence by trip purpose, } \\
\text { information, distance, number of stops, etc. }\end{array}$ \\
\hline Lu et al. [30] & Survey in a laboratory setting (SP) & $\begin{array}{l}\text { Real-time information reduces the level of } \\
\text { uncertainty and improves the average travel } \\
\text { time trip by } 30 \%\end{array}$ \\
\hline $\begin{array}{c}\text { Ramsay et al } \\
{[31]}\end{array}$ & Vehicle count survey (RP) & $\begin{array}{l}28 \% \text { and } 22 \% \text { increased in diversion after an } \\
\text { incident during A.M. and P.M. peak }\end{array}$ \\
\hline $\begin{array}{c}\text { Brownstone } \\
\text { and Small [32] }\end{array}$ & $\begin{array}{l}\text { Lane-choice data (RP) } \\
\text { And survey (SP) }\end{array}$ & $\begin{array}{l}\text { VOT } \$ 20-\$ 40 \text { per hour on the morning commute } \\
\text { for road pricing on SR91 and I- } 15 \text { corridors }\end{array}$ \\
\hline $\begin{array}{c}\text { Lam and Chan } \\
{[2]}\end{array}$ & Two-hour study period (RP) & $\begin{array}{l}\text { Dynamic travel time information on DMS is } \\
\text { more effective during non-recurrent than } \\
\text { recurrent congestion }\end{array}$ \\
\hline
\end{tabular}

$\mathrm{SP}=$ Stated Preference

$\mathrm{RP}=$ Revealed Preference 


\subsection{SUMMARY}

The literature review produced the following major findings:

The Bluetooth method has been tested by both UMD and University of Akron, and found to be consistent and able to reproduce floating car data.

UMD has evaluated INRIX data along I-95 corridor and found that INRIX data has met the accuracy requirements from I-95 Corridor Coalition. However, INRIX data, which is based on probe data, is sensitive to several factors, such as location, the length of the segment, and the geometry of a highway. It is essential to re-evaluate the INRIX data quality prior to implementing the data in a new location to ensure the data is credible.

Although there are many factors that influence drivers' responses, such as travel time information, trip purpose, corridor characteristics, VOT, etc., studies showed that travel time information has a significant impact on the diversion decision. 


\section{CHAPTER 3. METHODOLOGY}

The following tasks were conducted to achieve the study objectives:

1. Validation Segment Selection

2. Process Ground Truth Data

3. Determine Data Quality Measures

4. INRIX Data Analysis

5. Analyze Factors Impacting Data Quality

6. Diversion Analysis

The methodology began by selecting the segments on the corridor where INRIX travel times will be evaluated. Then ground truth data were collected and processed, and data quality measures were selected based on the literature review. The next step was to analyze INRIX data for both site locations (i.e., I-95 and the Hampton Roads Area). Lastly, the diversion analyses were performed on select sites before and after the implementation of DMS travel time information using data from existing detectors. The following sections of this chapter detail each step of the methodology.

\subsection{VALIDATION SEGMENT SELECTION}

One of the first tasks was to determine the segments where travel time information will be posted and evaluated. For the Northern Virginia sections, the segments were defined by VDOT using the endpoints of the DMS travel time messages. Since the VDOT travel 
time project's goal is to better inform commuters and improve traffic flow, especially during peak hours, it is important to select the right locations where travel times will be most useful to commuters.

Therefore, VDOT selected total of 8 DMSs locations on the I-95 corridor to post travel time information. Table 3-1 shows the locations and distances of each segment. In this paper, each of these segments will be referred by its direction and distance (e.g., NB18, SB33).

Table 3-1 Bluetooth locations and distances of each segment on I-95 corridor

\begin{tabular}{|c|l|c|}
\hline Segment & \multicolumn{1}{|c|}{ Location } & $\begin{array}{c}\text { Distance } \\
\text { (miles) }\end{array}$ \\
\hline NB18 & MM 151.10 to MM170 @ 495/395 Springfield Interchange (Northbound) & 18.4 \\
\hline NB10 & MM 159.9 to MM 170 @ Springfield Interchange (Northbound) & 9.5 \\
\hline SB14 & MM 165.65 to DC Line (Northbound) & 14.5 \\
\hline SB15 & MM 168.15 to SR 234 (Southbound) & 15.06 \\
\hline SB12 & MM 2.41 to I-95 SB MM 161.3 (Southbound) & 11.6 \\
\hline SB8 & I-395 DC to I-495 (Southbound) & 8.09 \\
\hline SB33 & MM 162.7 to Route 3 at exit 130 (Southbound) & 31.95 \\
\hline SB19 & MM 162.7 to Route 610 at exit 143 (Southbound) & 18.8 \\
\hline
\end{tabular}

On the I-64 corridor, the segments were validated and selected based on available Bluetooth sample size since DMS travel times had not yet been implemented. VDOT had defined a total of 27 possible corridors to be investigated, as shown in Table 3-2. Only segments with sufficient of Bluetooth sample sizes were selected for a formal evaluation. The segments that were subjected to validation in the Hampton Roads area are listed in Table 3-2. More details on how these segments were selected are provided in section 3.4.2. 
Table 3-2 Locations of all 27 selected segments for validation on Hampton Roads Area

\begin{tabular}{|c|c|c|}
\hline Station & Segments & $\begin{array}{c}\mathrm{BT} \\
\text { (miles) }\end{array}$ \\
\hline 4121 & EB I-264 before Ingleside (u421) to I-64W @ I-664 Pole \#270403 (u434) & 22 \\
\hline 4122 & WB I-264 before Witchduck Rd (u439) to I-64W @ I-664 Pole \#270403 (u434) & 22.1 \\
\hline 4123 & WB I-264 before Independence (u444) to I-64W @ I-664 Pole \#270403 (u434) & 23.1 \\
\hline 4124 & $\begin{array}{l}\text { EB I-264 at Pine Chapel (u420) to I-64 prior to I-264 Square I-Beam Sign Structure } \\
(\mathrm{u} 427)\end{array}$ & 19.8 \\
\hline 4125 & $\begin{array}{l}\text { EB I-264 at Magruder, MP262 (u433) to I-64 prior to I-264 Square I-Beam Sign } \\
\text { Structure (u427) }\end{array}$ & 21.6 \\
\hline 4126 & $\begin{array}{l}\text { WB I-64 at Denbigh (u424) to I-64 prior to I-264 Square I-Beam Sign Structure } \\
(\mathrm{u} 427)\end{array}$ & 30.2 \\
\hline 4127 & $\begin{array}{l}\text { Outer Loop I-64 Between Greenbrier Pkwy and Indian River Rd (u426) to I-64W @ I- } \\
664 \text { Pole \#270403 (u434) }\end{array}$ & 23.5 \\
\hline 4128 & $\begin{array}{l}\text { Outer Loop I-64 before I-264 interchange (u438) to I-64W @ I-664 Pole \#270403 } \\
\text { (u434) }\end{array}$ & 20 \\
\hline 4129 & $\begin{array}{l}\text { Inner Loop I-664 South of Queen St Overpass (u440) to I-64 prior to I-264 Square I- } \\
\text { Beam Sign Structure (u427) }\end{array}$ & 19.5 \\
\hline 5840 & WB I-64 at Denbigh (u424) to EB I-64 at Magruder, MP262 EB (u433) & 8.7 \\
\hline 5841 & EB I-64 at Magruder, MP262 EB (u433) to WB I-64 at Denbigh (u424) & 8.7 \\
\hline 5842 & EB I-64 at Magruder, MP262 EB (u433) to EB I-64 at Pine Chapel (u420) & 1.8 \\
\hline 5843 & EB I-64 at Pine Chapel (u420) to EB I-64 at Magruder, MP262 EB (u433) & 1.8 \\
\hline 5844 & $\begin{array}{l}\text { EB I-64 at Pine Chapel (u420) to Inner Loop I-664 South of Queen St Overpass } \\
(\mathrm{u} 440)\end{array}$ & 1 \\
\hline 5845 & $\begin{array}{l}\text { Inner Loop I-664 South of Queen St Overpass (u440) to EB I-64 at Pine Chapel } \\
(\mathrm{u} 420)\end{array}$ & 1 \\
\hline 5846 & EB I-64 at Pine Chapel (u420) to I-64W @ I-664 Pole \#270403 (u434) & 0.9 \\
\hline 5847 & I-64W @ I-664 Pole \#270403 (u434) to EB I-64 at Pine Chapel (u420) & 0.9 \\
\hline 5848 & I-64W @ I-664 Pole \#270403 (u434) to I-264 Square I-Beam Sign Structure (u427) & 18.8 \\
\hline 5849 & I-264 Square I-Beam Sign Structure (u427) to I-64W @ I-664 Pole \#270403 (u434) & 18.8 \\
\hline 5850 & $\begin{array}{l}\text { I-264 Square I-Beam Sign Structure (u427) to Outer Loop I-64 before I-264 } \\
\text { interchange (u438) }\end{array}$ & 1.2 \\
\hline 5851 & $\begin{array}{l}\text { Outer Loop I-64 before I-264 interchange (u438) to I-264 Square I-Beam Sign } \\
\text { Structure (u427) }\end{array}$ & 1.2 \\
\hline 5852 & $\begin{array}{l}\text { Outer Loop I-64 before I-264 interchange (u438) to Outer Loop I-64 Between } \\
\text { Greenbrier Pkwy and Indian River Rd (u426) }\end{array}$ & 3.5 \\
\hline 5853 & $\begin{array}{l}\text { Outer Loop I-64 Between Greenbrier Pkwy and Indian River Rd (u426) to Outer Loop } \\
\text { I-64 before I-264 interchange (u438) }\end{array}$ & 3.5 \\
\hline 5854 & EB I-264 before Ingleside (u421) to WB I-264 before Witchduck Rd (u439) & 5.4 \\
\hline 5855 & WB I-264 before Witchduck Rd (u439) to EB I-264 before Ingleside (u421) & 5.4 \\
\hline 5856 & WB I-264 before Witchduck Rd (u439) to WB I-264 before Independence (u444) & 1 \\
\hline 5857 & WB I-264 before Independence (u444) to WB I-264 before Witchduck Rd (u439) & 1 \\
\hline
\end{tabular}




\subsection{PROCESS GROUND TRUTH DATA}

To evaluate the INRIX travel time data quality, there is a need to have another set of data, which can be trusted, available for comparison. The literature review highlighted two methods to collect probe data which can be used as the ground truth data. The first method was the floating car and the second was Bluetooth reidentification. Both methods provided good quality data. However, the literature review also demonstrated that Bluetooth data is more cost effective than the floating car method for generating a large volume of data points. Therefore, Bluetooth data is used as ground truth data for this study.

Bluetooth data was obtained from TrafficCast. This data provided timestamps, travel times, and speeds of matched vehicles, as shown in Table 3-3. The Bluetooth data is generated from the vehicles that traveled the entire Bluetooth section and passed Bluetooth readers at either end of the validation segment. It is possible that outliers may occur due to vehicles stopping between those two points. To mitigate this effect, the Excel program was used to filter out the outliers. The outliers were defined as any data point that has vehicle speed of $20 \mathrm{mph}$ higher or lower than the average speed of the five vehicles before and after it. Besides filtering out the outliers, the Excel program was used to reformat Bluetooth data timestamp to be in 5-minute intervals and average the sum of travel times and speeds for each interval. The data outside of the operational hours were also discarded. 
Table 3-3 Example of Bluetooth data provided by TrafficCast

\begin{tabular}{|c|c|c|}
\hline Match time & Travel time $(\mathrm{s})$ & Speed $(\mathrm{mph})$ \\
\hline $11 / 9 / 20115: 20$ & 1204 & 55.02 \\
\hline $11 / 9 / 20115: 22$ & 1288 & 51.43 \\
\hline $11 / 9 / 20115: 25$ & 1073 & 61.73 \\
\hline $11 / 9 / 20115: 28$ & 1042 & 63.57 \\
\hline $11 / 9 / 20115: 29$ & 1042 & 63.57 \\
\hline
\end{tabular}

\subsection{SELECT DATA QUALITY MEASURES}

The literature review identified six fundamental measures of traffic data quality, based on the Federal Highway Administration [14]. This study uses only three measures, including accuracy, completeness, and validity because the other three measures (i.e., timeliness, coverage, and accessibility) were already represented in some extent. For example, the fact that INRIX data can be obtained for the analyses in this study by itself is a way to express the accessibility of the INRIX data. The accuracy, completeness, and validity measures selected for this evaluation were:

\section{- Accuracy Measures}

- In this study, there are three accuracy measures used to evaluate INRIX data accuracy relative to Bluetooth data: bias, absolute error, and RMSE. Although there are many accuracy measures highlighted in literature review (Table 2-1), bias, absolute error and RMSE were selected because they are simple to calculate, easy to understand, and relate directly to 
VDOT quality requirements. The equations for these accuracy measures will be demonstrated in the section 3.4.1.

- Completeness Measure

- Completeness of the data is another important factor for VDOT because the absence of travel time information during operational hours may create questions on the reliability of the system and possibly complaints. The measure for completeness in this study is the percent of intervals where the sign is blanked out during the operational period. A blank-out occurs when the VDOT requirements for posting are not met. The most relevant requirement is that at least $85 \%$ of TMCs must report real-time travel times before data will be posted to the DMS [4].

- Validity Measure

- As discussed in the literature review, an average absolute speed error less than $10 \mathrm{mph}$ and speed error bias within $+/-5 \mathrm{mph}$ are the speed accuracy requirements for the VDOT travel time project. The percentage of intervals that pass the validity check (i.e., passes the speed requirements) is used as validity measure. The percentages of both speed errors provide a quick understanding of the data. 


\subsection{INRIX DATA ANALYSIS}

This section has two subsections since the data analysis took place at two different locations. The first subsection analyzed the data from the I-95 corridor starting from Fredericksburg, VA to Washington D.C., and the second subsection was in the Hampton Roads area, which includes the I-64 and I-264 corridors. The following shows details on each subsection.

\subsubsection{Quality Assessment of INRIX Data on Interstate 95}

VDOT identified which segments on I-95 with existing DMSs will be evaluated and then installed Bluetooth readers to coincide with DMS endpoints. There are two major parties involved in providing Bluetooth and travel time estimates using INRIX data. VDOT has a contract with a private company, TrafficCast, to deliver Bluetooth data for the analysis. Therefore, the Bluetooth data in this study was downloaded from the TrafficCast website. The estimated travel times from INRIX are processed by the Statewide Advanced Traffic Management System (ATMS) Operating Platform to develop estimated travel times for posting on DMSs. The ATMS aggregates the INRIX data on multiple TMCs to develop an estimated path travel time. The ATMS operating platform, developed by Open Roads Consulting Inc., gathers the TMC code, disseminates and archives the INRIX information [35]. Therefore, the Bluetooth data and the raw travel time data for this study on I-95 come from TrafficCast and Open Roads, respectively.

There are total of eight segments on I-95 that were selected for travel time data quality evaluation, as shown in Figure 3-1. The data evaluations started on November $9^{\text {th }}$, 
2011 and lasted until January $31^{\text {st }}, 2012$ (some of the days were not tested). The first travel time information was posted on overhead DMSs on Dec $5^{\text {th }}, 2011$.

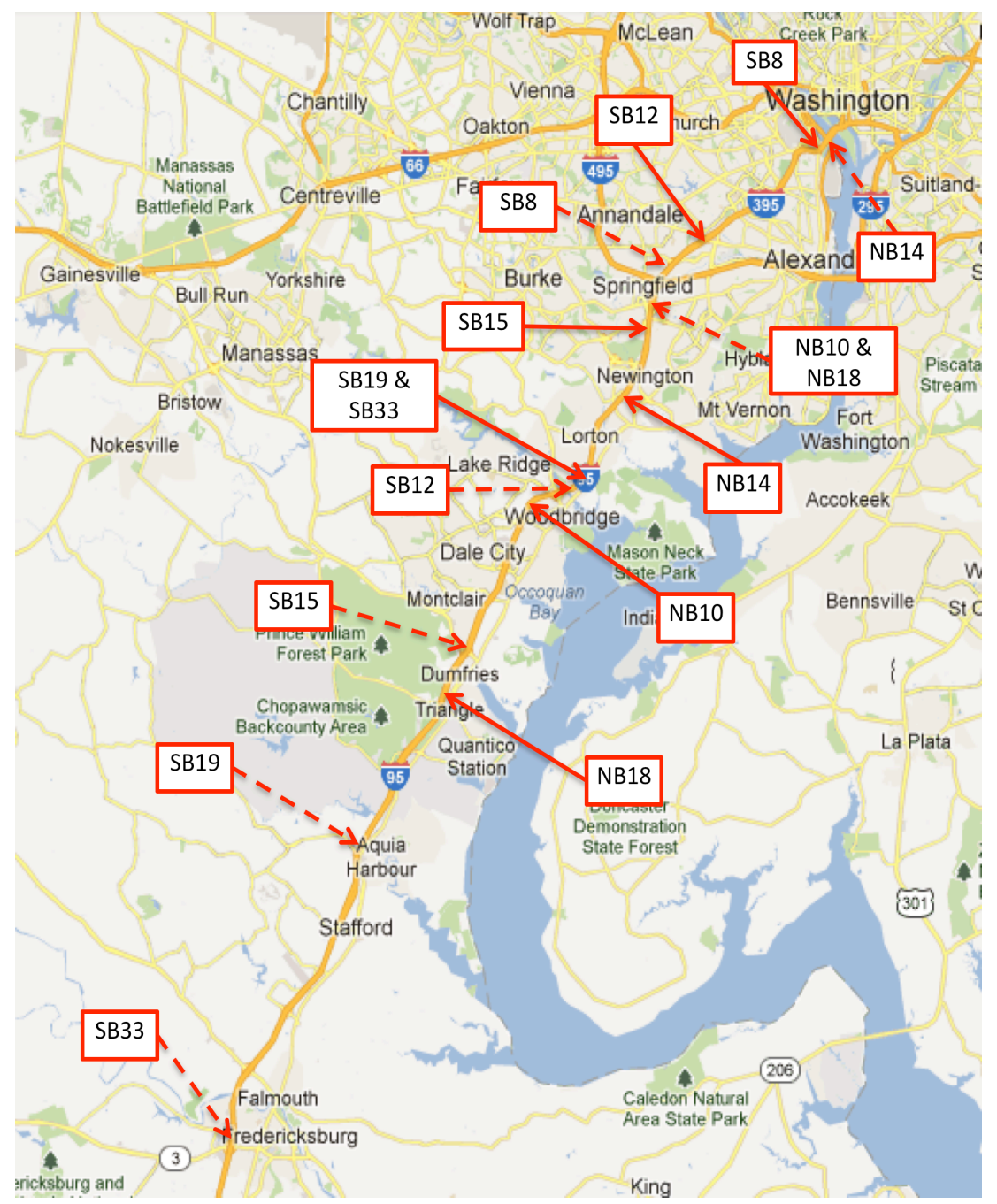

Figure 3-1 Location of DMS travel time messages on I-95 corridor (Solid arrow is the start of the segment, and dashed arrow is the end of the segment)

It is also important to note that there is some inconsistency in the Bluetooth locations and the actual INRIX travel time segments. Because of this inconsistency, the results may have some bias. With the goal of assessing the quality of INRIX data, the Bluetooth data needs to be located as close to the endpoints of the travel time segment as possible. To avoid this problem, Bluetooth speeds were recalculated using the actual 
distances and travel times between two Bluetooth readers. Table 3-4 demonstrates the inconsistency between the two distances.

Table 3-4 Difference between INRIX and Bluetooth distances on I-95 corridor

\begin{tabular}{|c|c|c|c|c|c|}
\hline \multirow{2}{*}{ Segment } & \multirow{2}{*}{ Link } & \multicolumn{2}{|c|}{ Distance (miles) } & \multirow{2}{*}{$\begin{array}{c}\text { Differences } \\
\text { (miles) }\end{array}$} & \% Differences \\
\cline { 3 - 4 } & & INRIX & Bluetooth & & \\
\hline NB18 & 52814 & 18.9 & 18.4 & 0.5 & $2.6 \%$ \\
\hline NB10 & 52818 & 10.1 & 9.5 & 0.6 & $5.9 \%$ \\
\hline NB14 & 52819 & 15.43 & 14.5 & 0.93 & $6.0 \%$ \\
\hline SB33 & 52823 & 32.7 & 31.95 & 0.75 & $2.3 \%$ \\
\hline SB15 & 52824 & 15.06 & 15.06 & 0 & $0 \%$ \\
\hline SB12 & 52825 & 12.2 & 11.6 & 0.6 & $4.9 \%$ \\
\hline SB8 & 52826 & 9.3 & 8.09 & 1.21 & $13.0 \%$ \\
\hline SB19 & 254425 & 19.7 & 18.8 & 0.9 & $4.6 \%$ \\
\hline
\end{tabular}

Once both data sources were received, these data need to be reformatted prior to the analysis. To capture the accuracy of the real-time travel time information, Bluetooth and INRIX data must be compared at the same time period during the operational hours (5 AM to 9 PM on weekdays and 8 AM to 8 PM on weekends).

Raw data from Open Roads provided timestamps, raw travel times, reported travel time, and historical travel time, as shown in Table 3-5. There is no need to reformat these raw data because the data were already set to be at 5-mintue intervals. However, the historical data, where raw travel times were not available, needed to be filtered out. VDOT does not post historical travel times because that will defeat the purpose of providing real-time information. Therefore, when there are no raw travel times available, DMSs will be left blank (also called a blank-out). Thus, it is important to keep a record of how many blank-outs occurs for each section on each day to evaluate INRIX completeness. 
Table 3-5 Example of raw travel time data provided by Open Roads

\begin{tabular}{|c|c|c|c|c|c|c|}
\hline Link & Timestamp & Raw TT & Smooth TT & Historical TT & Reported TT & Quality \\
\hline 52814 & 1/11/2012 5:00:10 AM & 983.00 & 983.00 & 981.00 & $1,020.00$ & 0 \\
\hline 52814 & 1/11/2012 5:05:20 AM & 973.00 & 973.00 & 981.00 & $1,020.00$ & 0 \\
\hline 52814 & 1/11/2012 5:10:30 AM & 985.00 & 985.00 & 981.00 & $1,020.00$ & 0 \\
\hline 52814 & 1/11/2012 5:15:40 AM & 977.00 & 977.00 & 985.00 & $1,020.00$ & 0 \\
\hline 52814 & 1/11/2012 5:20:50 AM & 973.00 & 973.00 & 985.00 & $1,020.00$ & 0 \\
\hline
\end{tabular}

Note that the raw travel times are the actual estimated travel times, and the reported travel times are the travel times posted on DMS signs (rounded up to nearest minute). The quality column has two values " 0 " or " 2 ". If the reported travel time derived from raw travel times, the quality column shows " 0 ", otherwise "2".

Once Bluetooth data and INRIX data were ready to be analyzed, both data were integrated into one table based on their timestamps. The Bluetooth timestamps were matched to the closest timestamps in the raw data. Then the combined table was used to generate bias, absolute error, and RMSE to evaluate the accuracy quality of INRIX data.

All bias and RMSE equations can be calculated using the following equations:

Average_TravelTime_Error_Bias $_{-} \frac{\sum_{i}^{N}\left(\left(\text { TravelTime }_{B T}\right)_{i}-\left(\text { TravelTime }_{\text {INRIX }}\right)_{i}\right)}{N}$

Average_Absolute_TravelTime_error $=\frac{\sum_{i=1}^{n} \mid\left(\text { TravelTime }_{B T}\right)_{i}-\left(\text { TravelTime }_{\text {INRIX }}\right)_{i} \mid}{N}$

$$
\text { Average_Speed_Error_Bias }(S E B)=\frac{\sum_{i=1}^{n}\left(\left(\text { Speed }_{B T}\right)_{i}-\left(\operatorname{Speed}_{I N R I X}\right)_{i}\right)}{N}
$$

Average_Absolute_Speed_Error $(A A S E)=\frac{\sum_{i=1}^{n} \mid\left(\text { Speed }_{i}\right)_{B T}-\left(\text { Speed }_{i}\right)_{I N R I X} \mid}{N}$ 


$$
R o o t_{-} \text {Mean_Square_Error }(R M S E)=\sqrt{\frac{\sum_{i=1}^{n}\left(\operatorname{Speed}_{B T}-\operatorname{Speed}_{I N R L X}\right)_{i}{ }^{2}}{N}}
$$

Where $\quad \mathrm{N}=$ the total data points

Travel time $(\mathrm{BT})=$ Bluetooth travel time

Travel time $($ INRIX) $=$ Raw travel time

Speed $(\mathrm{BT})=$ Bluetooth speed based on Bluetooth distance and travel time Speed $($ INRIX) $=$ Raw speed based on INRIX distance and raw travel time

The results from the calculations above were put together in one table, which has the following columns: timestamps (5-minute interval), raw travel times, reported travel times, average Bluetooth travel times, average Bluetooth speeds, raw travel time errors, reported travel time errors, absolute raw travel time differences, absolute reported travel time differences, raw INRIX speeds, speed differences, speed differences square, absolute speed differences, and the true/false columns to determine a value that has speed error less than $10 \mathrm{mph}$, and within $+/-5 \mathrm{mph}$.

With the calculated data above, the travel times and speeds of Bluetooth and INRIX data can be compared and analyzed. After the comparison, the final table was generated, which include the following columns; the travel time error bias, absolute travel time error, mean travel time, raw speed error bias, absolute raw speed error, the percent of raw error thresholds (i.e. $+/-5 \mathrm{mph}$ and $10 \mathrm{mph}$ ), and root mean square error of the raw data.

Then graphs were created in order to observe trends in how the data changes over time on each segment. Lastly, the INRIX data performance was analyzed by the level of 
congestion at the site based on the speed distributions (i.e., 0-30 mph, 30-45 mph, 45-60 $\mathrm{mph}$ and over $60 \mathrm{mph})$.

\subsubsection{Quality Assessment of INRIX Data in the Hampton Roads Area}

For the INRIX data quality assessment in the Hampton Roads Area, the process is different from the I-95 corridor, especially during the process of acquiring the data. Although Bluetooth data was available for download from the TrafficCast website, some of the readers were not functioning properly. Therefore, there was a need to conduct a preliminary test on the Bluetooth data. For the INRIX raw travel time data, the ATMS did not provide raw data for the Hampton Roads Area because it was an exploratory assessment. Therefore, the INRIX raw travel times needed to be extracted from INRIX TMC codes, which can be downloaded from the Regional Integrated Transportation Information System (RITIS) system developed by the University of Maryland Center for Advanced Transportation Technology.

Since the TrafficCast BlueTOAD data was used as a ground truth, it is important to ensure the quality of BlueTOAD data. A preliminary test on all TrafficCast BlueTOAD (Bluetooth Travel-time Origination And Destination) sensors was conducted to investigate which BlueTOAD stations seemed to provide reasonable results based on the average number of matched vehicles. To determine the number of matched vehicles needed to produce an adequate sample, the Central Limit Theorem was used. Assuming a standard deviation of speed of $5 \mathrm{mph}$ and an acceptable error term to be $+/-5 \mathrm{mph}$ with 
$95 \%$ confidence level, the minimum sample size comes out to be 3.84 , based on the Equation (14) shown below [36].

$$
\mathrm{N}=\left(\frac{\mathrm{Z \sigma}}{\mathrm{d}}\right)^{2}
$$

Where $\quad \mathrm{N}=$ minimum sample size

$\mathrm{Z}=$ number of standard deviations corresponding to the required Confidence (for $95 \%$ confidence level, $\mathrm{z}=1.96$ ) $\sigma=$ standard deviation (mph)

$\mathrm{d}=$ limit of acceptable error in the average speed estimate $(\mathrm{mph})$ Speed $(\mathrm{BT})=$ Bluetooth speed based on Bluetooth distance and travel time Speed $($ INRIX) $=$ Raw speed based on INRIX distance and raw travel time

To balance data availability in this study (by increasing the error term to be $+/$ $5.66 \mathrm{mph}$ ), a minimum sample size of 3 vehicles per 5 minutes was selected as the standard for the average number of matched vehicles. Therefore, the BlueTOAD links, which were selected for the analysis, must have the average number of matches greater or equal to "3" per 5 minutes.

Upon the completion of the preliminary test of the 27 BlueTOAD links on I-64 and I-264 in the Hampton Roads area, there were 10 links that could be compared with the INRIX data based on available sample size. Figure 3-2 is the map showing each qualifying BlueTOAD link locations using labels A to $\mathrm{H}$. The locations for all 10 BlueTOAD links are listed below in Table 3-6 along with the letters defining its endpoints on the map. The data quality assessment for these links started from July $16^{\text {th }}$, 2012 to Aug $19^{\text {th }}$, 2012. In this thesis, each of these segments will be referred by its link number (e.g., Link 5840) 


\section{Table 3-6 Bluetooth locations and distances of each segment on I-64 and I-264} corridors

\begin{tabular}{|c|c|c|}
\hline Station & Locations & $\begin{array}{c}\text { BT distance } \\
\text { (miles) }\end{array}$ \\
\hline 5840 & WB I-64 at Denbigh (u424) to EB I-64 at Magruder, MP262 EB (u433) & 8.7 (A to B) \\
\hline 5841 & EB I-64 at Magruder, MP262 EB (u433) to WB I-64 at Denbigh (u424) & 8.7 (B to A) \\
\hline 5842 & EB I-64 at Magruder, MP262 EB (u433) to EB I-64 at Pine Chapel (u420) & 1.8 (B to C) \\
\hline 5843 & EB I-64 at Pine Chapel (u420) to EB I-64 at Magruder, MP262 EB (u433) & 1.8 (C to B) \\
\hline 5846 & EB I-64 at Pine Chapel (u420) to I-64W @ I-664 Pole \#270403 (u434) & 0.9 (C to D) \\
\hline 5847 & I-64W @ I-664 Pole \#270403 (u434) to EB I-64 at Pine Chapel (u420) & 0.9 (D to C) \\
\hline 5850 & I-264 Square I-Beam Sign Structure (u427) to Outer Loop I-64 before & 1.2 (E to F) \\
\hline 5853 & Outer Loop I-64 Between Greenbrier Pkwy and Indian River Rd (u426) to Outer & 3.5 (G to F) \\
\hline 5856 & WB I-264 before Witchduck Rd (u439) to WB I-264 before Independence (u444) & 1 (H to I) \\
\hline 5857 & WB I-264 before Independence (u444) to WB I-264 before Witchduck Rd (u439) & 1 (I to H) \\
\hline
\end{tabular}

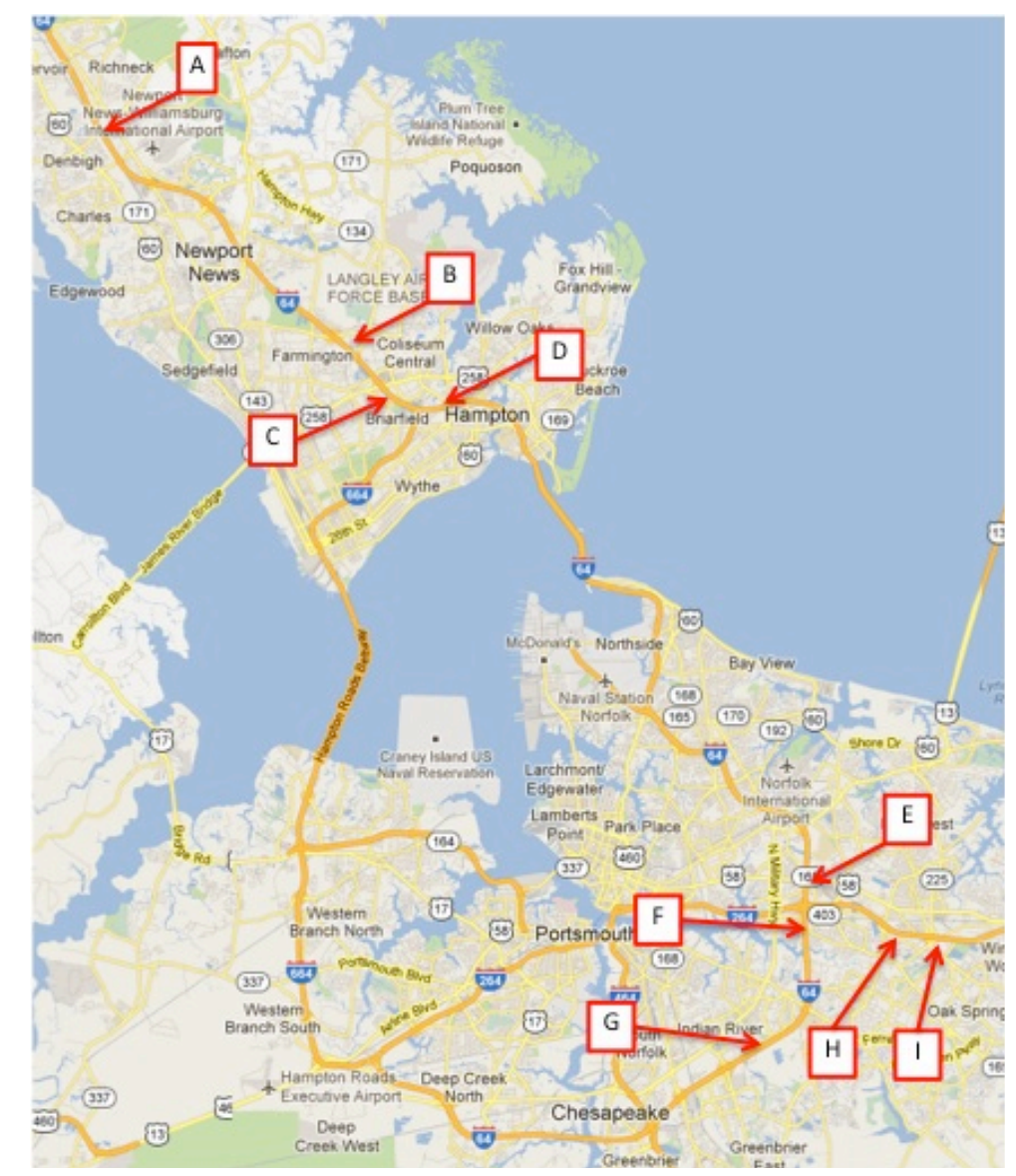

Figure 3-2 Location of DMS travel time messages on I-64 and I-264 corridors 
To match each BlueTOAD link with INRIX TMC codes, the latitude and longitude from each BlueTOAD pair was used to identify the location where the TMC codes need to be downloaded from RITIS. Generally, the TMC length used for analysis was greater than the BlueTOAD length in this study. There were only some exceptions which will be discussed further in the results chapter.

Prior to comparing BlueTOAD and TMC data, it is important to understand how TMC speed data was computed. For this study, each travel time path is composed of more than one TMC code. Each TMC code has confidence level score of 0, 10, 20, or 30 . Each score level was defined as follows [37].

- “30” provides high confidence, based on real-time time data for that specific segment

- " 20 " provides medium confidence, based on the real-time data and/or the historical data

- “10” provides low confidence, based primarily on historical data

Based on the Business Rules from Northern Region, a blank-out occurs when less than $85 \%$ of TMCs report real-time data [4]. Therefore, only TMC speeds which have a confidence level of " 30 " on more than $85 \%$ of all TMCs were used to compare with BlueTOAD speeds. For example, if there are 6 TMCs in a travel time link, the number of TMCs with a confidence score of 30 must be greater than 5.1 TMCs (85\% of 6 TMCs). In other words, all six TMCs must have a confidence score of 30 to be qualified to compare to BlueTOAD data. 
Due to large discrepancies between TMC and BlueTOAD distances (see Table 37) travel times were not used for the analysis. Using travel times may provide misleading results because a higher distance will have a higher travel time, and that has nothing to do with the data quality of the INRIX data. Therefore, travel time was not use in the accuracy analysis in Hampton Road area. Speeds were used instead. Although it would have been ideal to have TMC and Bluetooth endpoints coincide exactly, Bluetooth sensor locations were defined by field concerns like locations where sensors could be mounted and availability of power.

Table 3-7 Difference between INRIX and Bluetooth distances on I-64 and I-264 corridors

\begin{tabular}{|c|c|c|c|}
\cline { 2 - 4 } \multicolumn{1}{c|}{} & \multicolumn{3}{c|}{ Distance (miles) } \\
\hline link & TMC & Bluetooth & Diff. \\
\hline 5840 & 11.88 & 8.7 & 3.18 \\
\hline 5841 & 11.87 or 7.9 & 8.7 & -0.8 \\
\hline 5842 & 2.3 & 1.8 & 0.5 \\
\hline 5843 & 2.37 & 1.8 & 0.57 \\
\hline 5846 & 1.37 & 0.9 & 0.47 \\
\hline 5847 & 1.09 & 0.9 & 0.19 \\
\hline 5850 & 4.03 & 1.2 & 2.83 \\
\hline 5853 & 4.35 & 3.5 & 0.85 \\
\hline 5856 & 3.28 or 1.5 & 1 & 0.5 \\
\hline 5857 & 3.20 or 1.4 & 1 & 0.40 \\
\hline
\end{tabular}

Note: Link 5841, 5856, and 5857 have 2 TMC distances because their original distances were suspected to be too long, which may cause disagreement in speeds with Bluetooth data. Therefore, TMC distances on these segments were decreased. The distance differences on these segments were calculated based on new (shorter) TMC distances.

Once TMC speeds have been calculated (using the sum of TMC travel times and distances), both data were ready to be compared and analyzed. The equations which were used in this study were the bias equations (Equations 6-10). The final table which was generated for this study had the following columns: raw speed error bias, absolute raw 
speed error, the percent of raw error thresholds (i.e. $+/-5 \mathrm{mph}$ and $10 \mathrm{mph}$ ), and the percent of intervals where the DMS was blanked out. Then the graphs were generated to show the relationship between TMC speeds versus BlueTOAD speeds during the operational period.

\subsection{ANALYZE FACTORS IMPACTING DATA QUALITY}

The results of the INRIX data quality from the I-95 corridor and the Hampton Roads area in the previous sections were used to analyze and investigate the factors which may impact variations in INRIX data quality. Each segment in both locations is different in terms of geometric characteristics, distances, and traffic characteristics. This task investigated these factors to determine which ones may or may not affect the INRIX data quality. The results (e.g., the final tables and graphs) from both location sites will be observed to determine whether the INRIX data quality is impacted by any particular characteristic of a site. In order to integrate the results across multiple sites, the major data quality measures (i.e., accuracy, validity, and completeness) were used.

The overall results were analyzed based on their speed errors, percentages of bias within $10 \mathrm{mph}$, and travel times availability. With these criteria, segments with disagreements between INRIX and Bluetooth data can be identified based on the created diagrams. Each diagram represents each criterion versus the segment distance. The analysis will be based on the trends shown in the diagrams and the results from sections 3.4. This analysis will be used to provide recommendations to VDOT on how future DMS travel time deployments should be set up. 


\subsection{DIVERSION ANALYSIS}

To evaluate the impacts of DMS travel time messages, this study used the number and percent diversion as measurements of drivers' responses to travel time information. Segments on the I-95 corridor for diversion analysis were identified based the quality and quantity of available volume data. The diversion analysis was performed on the I-95 corridor only, because only the I-95 corridor had travel time DMSs active during the study period. The study was divided into two set of data. The first set of data is the before period, which lasted from 10/26/11 to $12 / 04 / 11$. The second set of data is the after period, which lasted from $12 / 05 / 11$ to $03 / 31 / 12$ because travel time information was activated on existing DMSs on Dec $5^{\text {th }}, 2011$. To analyze the diversions in the before and after periods, linear regression and analysis of variance (ANOVA) tests were performed. Linear regression, including single linear and multivariable regressions, was used to analyze correlations between the response variable (i.e., number and percent diverting) and each individual independent variable (i.e., travel time and mainline volume) and both variables together. The ANOVA test was performed to determine whether there is a significant difference between the mean diversion before and after the implementation of DMS travel times, without correcting for covariates. The confidence level in this study was set at $95 \%$ for each statistical test. The detailed steps of diversion analysis are discussed below:

- Preliminary Screen

The purpose of preliminary screen was to determine count stations that had good volume data for both the mainline and off ramp volumes within each studied segment. The preliminary screen was conducted on all detectors and was 
used to identify sites that provided good and reasonable volume data. The initial screen looked for volume data which is not equal to zero or has the same volume throughout the day. The volume data in this study came from Archived Data Management System (ADMS). After analyzing the data from each detector, there were only two pairs of detectors in northbound direction, which provided both the mainline volume and off ramp volumes. The mileposts of Mainline and off ramp locations for the first pair (NB18) are on mile 152.98 (i.e., station 337) and 153 (i.e., station 339), which is the exit 152B to Dumfries Road. The milepost for the second pair (NB14) has both locations on mile 166.98 (i.e., station 229 and 230), which is the exit 166B to Fairfax County Parkway.

- Validate Volume Data

Prior to assessing the impact of the travel time information, volume data from ADMS were compared to vehicle count from the VDOT Traffic Monitoring System (TMS) to ensure the consistency of the data. Even though TMS vehicle counts are reliable, there only limited data are available since neither site had a continuous count station present. The VDOT TMS had coverage count data for two days that occurred during the study period (e.g. November $1^{\text {st }}$ and $2^{\text {nd }}, 2011$ ) for station 337 . For station 229 , the available data was in 2006 , which was almost 5 years older. Based on the available data, Wednesday and Thursday data (November $2^{\text {nd }}$ and $3^{\text {rd }}, 2011$ ) from ADMS were compared to the same days VDOT vehicle counts from October $11^{\text {th }}$ and $12^{\text {th }}, 2006$. 
During the weekday operational hours (5 AM - 9 PM), the percent differences in volume data for station 337 (NB18) are 3\% and 3\% for Tuesday and Wednesday, respectively. The percent differences for station 229 (NB14) are $6 \%$ and $7 \%$ for Wednesday and Thursday, respectively. The TMS volumes were higher than ADMS volumes for both segments. The ADMS volume data on NB 18 segment is consistent with VDOT vehicles count data. Although the percentage of volume discrepancies on NB 14 segment is double the one on NB 18 segment, both segments were used for diversion analysis because only these two segments had reliable off ramp data.

- Raw travel time data from the data quality analysis was then matched to volume data during the same time period for each day and each segment in order to check whether travel times and volumes have any impact on commuters' decisions.

Volume data from ADMS were matched with raw travel times based on the timestamp for both before and after periods. Diversion was calculated from the mainline and off ramp volumes as shown in the following equation.

Equation 11:

$$
\begin{aligned}
& \text { Percent_of_diverting _vehicles }=\frac{\text { Off_Ramp }}{\text { Mainline }+ \text { Off } f_{-} \text {Ramp }} * 100 \% \\
& \text { Where } \quad \text { Off Ramp }=\text { the number of diverting vehicles } \\
& \text { Mainline }=\text { the number of vehicles on the mainline }
\end{aligned}
$$

- Average Data Graphs 
Individual data for the same days of the week were averaged. These averaged data were used to graph and observe how each data element (e.g., off ramp volumes and percentage of diverting vehicles) changes over time of day. Each day has 4 graphs comparing before and after data. The x-axis is time of day. The y-axis for each graph is travel times, mainline volume, the percent of diversion, and the number of diversion. There are total of 28 graphs (i.e., 7 days) for NB14 and another 28 graphs for NB18.

- Regression analysis for the individual data during operational periods (5AM-9PM and $8 \mathrm{AM}-8 \mathrm{PM})$

To assess the impacts of travel time messages, regression analysis and ANOVA analysis were conducted on using data from the before and after periods. For each period, each individual time interval was used to develop regression models for each day of the week, for all weekdays, and for weekends. Then the adjusted R-squares and P-values for each data set were collected.

- Regression analysis for the individual interval data during congested periods (i.e., vehicles speeds below $40 \mathrm{mph}$ )

This step was similar to the prior step, but only intervals with speeds below $40 \mathrm{mph}$ were examined. In this study, congested periods were assumed when vehicle travel speeds were lower than $40 \mathrm{mph}$. Since drivers may be more likely to divert from the freeway during congested periods, behavior during these periods were examined separately. 


\section{CHAPTER 4. RESULTS}

This chapter summarizes the INRIX data quality analysis of sections of I-95, I-64, and I-264 and the diversion analysis on the I-95 corridor section. The results for each section will be discussed on an individual segment basis, and then trends across sites will be reviewed.

\subsection{INRIX DATA QUALITY ANALYSIS}

\subsubsection{I-95 corridor}

Five different time periods were analyzed on the I-95 corridor as part of this study, based on the timeline of data quality reports required by VDOT. The results were regularly reported to VDOT so they can make changes in system operation in response to evaluation results. The time periods and the segments covered for each report varied and also listed below in Table 4-1.

Table 4-1 Analyzed periods for each segment on I-95 corridor

\begin{tabular}{|c|c|c|c|c|c|c|c|c|c|}
\hline Time Periods & Missing Dates & NB18 & NB10 & NB14 & SB8 & SB12 & SB15 & SB19 & SB33 \\
\hline $\begin{array}{c}\text { November 9-16, } \\
2011\end{array}$ & 16-Nov & - & & & & & & & \\
\hline $\begin{array}{c}\text { November 17-20, } \\
2011\end{array}$ & 11/20 (NB14) & - & • & • & & & & & \\
\hline $\begin{array}{c}\text { November } 20-27 \text {, } \\
2011\end{array}$ & $\begin{array}{c}11 / 20(\mathrm{NB} 14), \\
11 / 21(\mathrm{NB} 14 \\
\text { and all SB), } \\
11 / 27\end{array}$ & $\bullet$ & $\bullet$ & • & • & $\bullet^{\circ}$ & $\bullet$ & & \\
\hline $\begin{array}{l}\text { December 7-13, } \\
2011\end{array}$ & none & - & - & • & • & - & • & & • \\
\hline January 2-31, 2012 & $\begin{array}{c}1 / 11,1 / 28 \text {, and } \\
\text { Jan } 24-31 \\
\text { (SB19) }\end{array}$ & • & & • & - & • & • & • & • \\
\hline \multirow{3}{*}{ Total days analyzed } & Weekdays & 38 & 15 & 32 & 30 & 30 & 30 & 15 & 26 \\
\hline & Weekends & 14 & 5 & 11 & 10 & 10 & 10 & 5 & 9 \\
\hline & Total days & 52 & 20 & 43 & 40 & 40 & 40 & 20 & 35 \\
\hline
\end{tabular}

Note that some days were not analyzed due to missing data. The missing date column shows the dates when the segments were not analyzed due to either missing Bluetooth or unavailability of travel time data from the OpenRoads Travel Time Engine. These missing days were not caused by INRIX data gaps. 
This study analyzed eight segments on I-95 corridor. The DMSs in the northbound direction were analyzed before the ones on the southbound direction. Therefore, the numbers of days analyzed on the northbound segments were greater than on the southbound segments, with the exception of the NB10 segment. The NB10 segment was not analyzed for the last two reports because Bluetooth data were not available for that segment in January.

The following sections will discuss the data quality results of each segment on the I-95 corridor in the direction of travel. The results below (Table 4-2 - Table 4-17) were calculated from all the days that each segment was analyzed. The detailed performances of each evaluated day of each segment on I-95 corridor are available in Appendix A. It is important to note that each segment generally provided consistent results throughout the analysis periods.

\subsubsection{I-95 NB from MM 151.10 to MM170 (NB18)}

The NB18 segment on I-95 is located from MM 151.1 to 170.0 , which is before the Springfield Interchange. NB 18 has bias errors lower than $5 \mathrm{mph}$ for both weekdays and weekends. Also, it has a high percentage of raw travel times within the error threshold of $10 \mathrm{mph}$ and almost zero blank outs, as shown in Table 4-2. Overall, the estimated travel time data on NB18 segment has a high degree of agreement with Bluetooth data since the speed errors satisfy the business rules. Moreover, the percent of blank outs was low, while the percent of raw travel time within the error threshold of $10 \mathrm{mph}$ were high. 
Table 4-2 Performance measures during operational periods, NB18

\begin{tabular}{|c|c|c|c|c|c|c|c|}
\hline \multirow[t]{2}{*}{ Date } & \multirow{2}{*}{$\begin{array}{l}\text { Number } \\
\text { of } \\
\text { Intervals } \\
\text { Analyzed }\end{array}$} & \multirow{2}{*}{$\begin{array}{c}\text { Raw } \\
\text { Speed } \\
\text { Error Bias } \\
(\mathrm{mph})\end{array}$} & \multirow{2}{*}{$\begin{array}{l}\text { Raw Speed } \\
\text { Absolute } \\
\text { Error (mph) }\end{array}$} & \multicolumn{2}{|c|}{$\begin{array}{c}\% \text { of Raw Travel } \\
\text { Time within Error } \\
\text { Thresholds }\end{array}$} & \multirow[t]{2}{*}{$\begin{array}{l}\text { RMSE } \\
(\mathrm{mph})\end{array}$} & \multirow[t]{2}{*}{$\begin{array}{c}\text { Blank } \\
\text { Out }(\%)\end{array}$} \\
\hline & & & & $\pm 10 \mathrm{mph}$ & $\pm 5 \mathrm{mph}$ & & \\
\hline Weekdays & 6745 & 4.4 & 4.9 & 90.8 & 58.4 & 6.2 & 0.4 \\
\hline Weekends & 1950 & 2.5 & 3.7 & 96.4 & 71.9 & 4.6 & 0.2 \\
\hline
\end{tabular}

The speed error distribution in Table 4-3 demonstrates that slightly higher errors were observed during weekdays. Generally speaking, the errors increase as speeds increase. There is no substantial difference between speed categories because the errors of each adjacent category are similar. The weekday results indicate more congestion and bias than the weekends. Lastly, the majority speeds were over $60 \mathrm{mph}$.

Table 4-3 Speed error distributions during operational periods, NB18

\begin{tabular}{|c|c|c|c|c|c|c|}
\hline \multirow{2}{*}{$\begin{array}{c}\text { Speed Bin } \\
(\mathrm{mph})\end{array}$} & \multicolumn{3}{|c|}{ Weekdays (5 AM to 9PM) } & \multicolumn{3}{c|}{ Weekends (8 AM to 8 PM) } \\
\cline { 2 - 7 } & $\begin{array}{c}\text { Error } \\
\text { Bias } \\
(\mathrm{mph})\end{array}$ & $\begin{array}{c}\text { Absolute Average } \\
\text { Speed Error (mph) }\end{array}$ & $\begin{array}{c}\text { Avg. } \\
\text { Interval } \\
\text { Count } \\
\text { per Day }\end{array}$ & $\begin{array}{c}\text { Error } \\
\text { Bias } \\
(\mathrm{mph})\end{array}$ & $\begin{array}{c}\text { Absolute Average } \\
\text { Speed Error (mph) }\end{array}$ & $\begin{array}{c}\text { Avg. } \\
\text { Interval } \\
\text { Count } \\
\text { per Day }\end{array}$ \\
\hline $0-30$ & -0.5 & 1.4 & 3.5 & 0 & 0 & 0 \\
\hline $30-45$ & 2.9 & 3.8 & 12.0 & -0.8 & 0.8 & 0.3 \\
\hline $45-60$ & 5.1 & 5.4 & 21.0 & 0.2 & 0.9 & 7.5 \\
\hline 60 or more & 4.6 & 4.8 & 141.0 & 2.8 & 3.7 & 131.5 \\
\hline
\end{tabular}

\subsubsection{I-95 NB from MM 159.9 to MM 170 (NB10)}

The NB10 segment on I-95 extends from MM 159.9 to 170.0 , which is before the Springfield Interchange. This segment has a speed bias error below $5 \mathrm{mph}$ on weekdays, but for weekends it was over $5 \mathrm{mph}$ and failed to meet VDOT requirements. The percentages of raw travel times within error thresholds of $10 \mathrm{mph}$ were high, and the blank outs were almost zero, as shown in Table 4-4. Therefore, the weekday data quality 
met VDOT requirements, but the weekend data quality did not. These deviations may be attributable to inconsistencies between the travel time segments and the Bluetooth segments.

Although NB10 is a subsection of NB18 segment, the endpoint discrepancy on NB10 (i.e., 5.9\%) is greater than NB18 segment (i.e., 2.6\%). That could be a factor causing different performance between the two segments. There is no other obvious explanation for disagreements on the NB10 segment for the weekend results,. It is possible that errors from one of the TMCs in a segment may be averaged out when the segment gets longer, and the added TMCs have higher speeds. The results from Table 4-3 and 4-5 demonstrate that speeds on NB18 are higher than NB14, which could have caused some errors to be averaged out on NB18. The fact that HOV lanes cover the entire NB 10 segment should not affect the results because northbound HOV lanes are open to all traffic on weekends.

Table 4-4 Performance measures during operational periods, NB10

\begin{tabular}{|c|c|c|c|c|c|c|c|}
\hline \multirow[t]{2}{*}{ Date } & \multirow{2}{*}{$\begin{array}{l}\text { Number } \\
\text { of } \\
\text { Intervals } \\
\text { Analyzed } \\
\end{array}$} & \multirow{2}{*}{$\begin{array}{c}\text { Raw } \\
\text { Speed } \\
\text { Error Bias } \\
(\mathrm{mph}) \\
\end{array}$} & \multirow{2}{*}{$\begin{array}{l}\text { Raw Speed } \\
\text { Absolute } \\
\text { Error (mph) }\end{array}$} & \multicolumn{2}{|c|}{$\begin{array}{c}\% \text { of Raw Travel } \\
\text { Time within Error } \\
\text { Thresholds }\end{array}$} & \multirow[t]{2}{*}{$\begin{array}{l}\text { RMSE } \\
\text { (mph) }\end{array}$} & \multirow[t]{2}{*}{$\begin{array}{c}\text { Blank } \\
\text { Out (\%) }\end{array}$} \\
\hline & & & & $\pm 10 \mathrm{mph}$ & $\pm 5 \mathrm{mph}$ & & \\
\hline Weekdays & 2758 & -4.5 & 5.2 & 94.2 & 49.4 & 6.0 & 0.9 \\
\hline Weekends & 698 & -7.2 & 7.3 & 82.0 & 22.8 & 7.7 & 0.0 \\
\hline
\end{tabular}

The speed error distribution in Table 4-5 demonstrates no substantial difference between speed categories. The majority speeds were between 45 and $60 \mathrm{mph}$ for both weekdays and weekends, but the weekend bias was larger. 
Table 4-5 Speed error distributions during operational periods, NB10

\begin{tabular}{|c|c|c|c|c|c|c|}
\hline \multirow{2}{*}{$\begin{array}{c}\text { Speed Bin } \\
(\mathrm{mph})\end{array}$} & \multicolumn{3}{|c|}{ Weekdays (5 AM to 9PM) } & \multicolumn{3}{c|}{ Weekends (8 AM to 8 PM) } \\
\cline { 2 - 7 } & $\begin{array}{c}\text { Error } \\
\text { Bias } \\
(\mathrm{mph})\end{array}$ & $\begin{array}{c}\text { Absolute Average } \\
\text { Speed Error (mph) }\end{array}$ & $\begin{array}{c}\text { Avg. } \\
\text { Interval } \\
\text { Count } \\
\text { per Day }\end{array}$ & $\begin{array}{c}\text { Error } \\
\text { Bias } \\
\text { (mph) }\end{array}$ & $\begin{array}{c}\text { Absolute Average } \\
\text { Speed Error (mph) }\end{array}$ & $\begin{array}{c}\text { Avg. } \\
\text { Interval } \\
\text { Count } \\
\text { per Day }\end{array}$ \\
\hline $0-30$ & -1.3 & 1.5 & 13.4 & 0 & 0 & 0 \\
\hline $30-45$ & -0.8 & 2.1 & 13.9 & -1.2 & 1.2 & 0.2 \\
\hline $45-60$ & -5.2 & 5.7 & 132.4 & -7.3 & 7.4 & 118.5 \\
\hline 60 or more & -3.6 & 3.7 & 24.2 & -3.6 & 3.7 & 21.0 \\
\hline
\end{tabular}

\subsubsection{I-95/I-395 NB from MM 165.65 to the DC Line (NB14)}

The NB14 segment has the Springfield Interchange located within the segment. The speed bias error on both weekdays and weekends were almost zero. The percentages of raw travel times within error thresholds of $10 \mathrm{mph}$ were high, and the blank outs were approximately at 1\%, as shown in Table 4-6. Overall, the degree of agreement between raw travel time data and Bluetooth data on NB10 segment was high due to the low values of speeds errors and blank out percentages.

Table 4-6 Performance measures during operational periods, NB14

\begin{tabular}{|c|c|c|c|c|c|c|c|}
\hline \multirow[t]{2}{*}{ Date } & \multirow{2}{*}{$\begin{array}{c}\text { Number } \\
\text { of } \\
\text { Intervals } \\
\text { Analyzed }\end{array}$} & \multirow{2}{*}{$\begin{array}{c}\text { Raw } \\
\text { Speed } \\
\text { Error Bias } \\
(\mathrm{mph})\end{array}$} & \multirow{2}{*}{$\begin{array}{l}\text { Raw Speed } \\
\text { Absolute } \\
\text { Error (mph) }\end{array}$} & \multicolumn{2}{|c|}{$\begin{array}{c}\% \text { of Raw Travel } \\
\text { Time within Error } \\
\text { Thresholds }\end{array}$} & \multirow[t]{2}{*}{$\begin{array}{l}\text { RMSE } \\
(\mathrm{mph})\end{array}$} & \multirow[t]{2}{*}{$\begin{array}{l}\text { Blank } \\
\text { Out (\%) }\end{array}$} \\
\hline & & & & $\pm 10 \mathrm{mph}$ & $\pm 5 \mathrm{mph}$ & & \\
\hline Weekdays & 5280 & -0.9 & 3.9 & 88.1 & 69.1 & 5.2 & 1.1 \\
\hline Weekends & 1390 & -1.8 & 4.0 & 94.5 & 70.1 & 5.3 & 1.3 \\
\hline
\end{tabular}

The speed bias errors from all speed ranges were small (i.e., less than $2.5 \mathrm{mph}$ ) and close to each other, as shown in Table 4-7. The majority speeds were in high speed bins: 45-60 mph and over $60 \mathrm{mph}$. 
Table 4-7 Speed error distributions during operational periods, NB14

\begin{tabular}{|c|c|c|c|c|c|c|}
\hline \multirow{2}{*}{$\begin{array}{c}\text { Speed Bin } \\
(\mathrm{mph})\end{array}$} & \multicolumn{3}{|c|}{ Weekdays (5 AM to 9PM) } & \multicolumn{3}{c|}{ Weekends (8 AM to 8 PM) } \\
\cline { 2 - 7 } & $\begin{array}{c}\text { Error } \\
\text { Bias } \\
(\mathrm{mph})\end{array}$ & $\begin{array}{c}\text { Absolute Average } \\
\text { Speed Error (mph) }\end{array}$ & $\begin{array}{c}\text { Avg. } \\
\text { Interval } \\
\text { Count } \\
\text { per Day }\end{array}$ & $\begin{array}{c}\text { Error } \\
\text { Bias } \\
(\mathrm{mph})\end{array}$ & $\begin{array}{c}\text { Absolute Average } \\
\text { Speed Error (mph) }\end{array}$ & $\begin{array}{c}\text { Avg. } \\
\text { Interval } \\
\text { Count } \\
\text { per Day }\end{array}$ \\
\hline $0-30$ & 0.1 & 3.1 & 22.0 & -1.2 & 1.2 & 0.3 \\
\hline $30-45$ & -0.2 & 5.6 & 18.5 & 0.6 & 4.8 & 8.2 \\
\hline $45-60$ & -1.7 & 4.4 & 92.0 & -2.5 & 4.7 & 73.0 \\
\hline 60 or more & -1.7 & 3.7 & 42.5 & -2.0 & 3.6 & 49.5 \\
\hline
\end{tabular}

\subsubsection{I-395 SB from MM 9.3 to 0.0 (SB8)}

The SB8 segment was the shortest segment in this study, and ended before the Springfield Interchange. It also has the largest distance discrepancy between Bluetooth and INRIX endpoints. The Bluetooth endpoints were 13\% shorter than INRIX travel time endpoints, as shown in Table 3-4 in the Methodology. The difference in endpoints occurred near the Springfield interchange. The speed error biases in Table 4-8 satisfied the VDOT requirements. The blank outs on this segment (especially on weekends with blank outs of $8.2 \%$ ) occurred more often than other segments, as shown in Table 4-8.

Table 4-8 Performance measures during operational periods, SB8

\begin{tabular}{|c|c|c|c|c|c|c|c|}
\hline \multirow[t]{2}{*}{ Date } & \multirow{2}{*}{$\begin{array}{l}\text { Number } \\
\text { of } \\
\text { Intervals } \\
\text { Analyzed } \\
\end{array}$} & \multirow{2}{*}{$\begin{array}{c}\text { Raw } \\
\text { Speed } \\
\text { Error Bias } \\
(\mathrm{mph}) \\
\end{array}$} & \multirow{2}{*}{$\begin{array}{l}\text { Raw Speed } \\
\text { Absolute } \\
\text { Error (mph) }\end{array}$} & \multicolumn{2}{|c|}{$\begin{array}{c}\% \text { of Raw Travel } \\
\text { Time within Error } \\
\text { Thresholds }\end{array}$} & \multirow[t]{2}{*}{$\begin{array}{l}\text { RMSE } \\
(\mathrm{mph})\end{array}$} & \multirow[t]{2}{*}{$\begin{array}{c}\text { Blank } \\
\text { Out (\%) }\end{array}$} \\
\hline & & & & $\pm 10 \mathrm{mph}$ & $\pm 5 \mathrm{mph}$ & & \\
\hline Weekdays & 5385 & -3.6 & 4.8 & 88.3 & 58.7 & 6.8 & 4.6 \\
\hline Weekends & 1271 & -4.8 & 5.3 & 90.1 & 50.4 & 6.9 & 8.2 \\
\hline
\end{tabular}

The speed error distributions in Tables 4.9 suggest that the high speeds (i.e., $45-60 \mathrm{mph}$ range) have the largest errors, and the weekend bias was more severe. Since the speed limit is $55 \mathrm{mph}$ on this section, that may explain why there are few intervals in the over 
60 mph range. Over 15 percent of intervals (i.e., 29 out of 176 vehicles from Table 4-9)

on weekdays are in the low speed bin, which is a sign of congestion in the segment.

Table 4-9 Speed error distributions during operational periods, SB8

\begin{tabular}{|c|c|c|c|c|c|c|}
\hline \multirow{2}{*}{$\begin{array}{c}\text { Speed Bin } \\
(\mathrm{mph})\end{array}$} & \multicolumn{3}{|c|}{ Weekdays (5 AM to 9PM) } & \multicolumn{3}{c|}{ Weekends (8 AM to 8 PM) } \\
\cline { 2 - 7 } & $\begin{array}{c}\text { Error } \\
\text { Bias } \\
(\mathrm{mph})\end{array}$ & $\begin{array}{c}\text { Absolute Average } \\
\text { Speed Error (mph) }\end{array}$ & $\begin{array}{c}\text { Avg. } \\
\text { Interval } \\
\text { Count } \\
\text { per Day }\end{array}$ & $\begin{array}{c}\text { Error } \\
\text { Bias } \\
(\mathrm{mph})\end{array}$ & $\begin{array}{c}\text { Absolute Average } \\
\text { Speed Error (mph) }\end{array}$ & $\begin{array}{c}\text { Interval } \\
\text { Count } \\
\text { per Day }\end{array}$ \\
\hline $0-30$ & -1.6 & 3.3 & 29.0 & 0 & 0 & 0 \\
\hline $30-45$ & -2.6 & 5.5 & 19.5 & -2.7 & 2.7 & 15.0 \\
\hline $45-60$ & -5.7 & 6.1 & 127.5 & -6.2 & 6.4 & 110.0 \\
\hline 60 or more & -0.1 & 0.8 & 0.3 & 0.4 & 0.4 & 0.1 \\
\hline
\end{tabular}

\subsubsection{I-395/I-95 SB from MM 2.2 to I-95 SB MM 160 (SB12)}

The SB12 results in Table 4-10 have speed bias errors well above VDOT requirements, but these results could be impacted by factors that impact the Bluetooth benchmark data.

This segment has the Springfield Interchange located within the segment. The percentage of raw travel time within the $10 \mathrm{mph}$ error threshold was approximately $50 \%$, as shown in Table 4-10. This suggests a low degree of agreement between two sources. .

Table 4-10 Performance measures during operational periods, SB12

\begin{tabular}{|c|c|c|c|c|c|c|c|}
\hline \multirow{2}{*}{ Date } & $\begin{array}{c}\text { Number } \\
\text { of } \\
\text { Intervals } \\
\text { Analyzed }\end{array}$ & $\begin{array}{c}\text { Raw } \\
\text { Error Bias } \\
(\mathrm{mph})\end{array}$ & $\begin{array}{c}\text { Raw Speed } \\
\text { Absolute } \\
\text { Error }(\mathrm{mph})\end{array}$ & \multicolumn{2}{|c|}{$\begin{array}{c}\text { \% of Raw Travel } \\
\text { Time within Error } \\
\text { Thresholds }\end{array}$} & \multirow{2}{*}{$\begin{array}{c}\text { RMSE } \\
(\mathrm{mph})\end{array}$} & $\begin{array}{c}\text { Blank } \\
\text { Out (\%) }\end{array}$ \\
\cline { 5 - 7 } Weekdays & 5391 & -8.7 & 9.2 & 57.3 & 20.7 & 10.4 & 2.6 \\
\hline Weekends & 1367 & -10.9 & 10.9 & 43.5 & 5.0 & 11.5 & 1.7 \\
\hline
\end{tabular}


Speeds were mostly in the 45 to $60 \mathrm{mph}$ range. The speed error distribution in Table 4-11 also suggests that the largest bias occurred during congested periods (i.e., in low speed ranges) and the transitional regime from 45-60 $\mathrm{mph}$.

Table 4-11 Speed error distributions during operational periods, SB12

\begin{tabular}{|c|c|c|c|c|c|c|}
\hline \multirow{2}{*}{$\begin{array}{c}\text { Speed Bin } \\
(\mathrm{mph})\end{array}$} & $\begin{array}{c}\text { Error } \\
\text { Bias } \\
(\mathrm{mph})\end{array}$ & $\begin{array}{c}\text { Absolute Average } \\
\text { Speed Error (mph) }\end{array}$ & $\begin{array}{c}\text { Avg. } \\
\text { Interval } \\
\text { Count } \\
\text { per Day }\end{array}$ & $\begin{array}{c}\text { Error } \\
\text { Bias } \\
(\mathrm{mph})\end{array}$ & $\begin{array}{c}\text { Absolute Average } \\
\text { Speed Error (mph) }\end{array}$ & $\begin{array}{c}\text { Avg. } \\
\text { Interval } \\
\text { Count } \\
\text { per Day }\end{array}$ \\
\hline $0-30$ & -13.7 & 13.5 & 19.5 & 0 & 0 & 0 \\
\hline $30-45$ & -7.6 & 9.0 & 20.5 & -11.3 & 11.3 & 27.5 \\
\hline $45-60$ & -10.1 & 10.5 & 140.5 & -12.3 & 12.3 & 107.5 \\
\hline 60 or more & -1.3 & 1.4 & 0.5 & -4.4 & 5.1 & 0.6 \\
\hline
\end{tabular}

A possible explanation for the difference between the INRIX and Bluetooth speeds on this segment is the site location. The location of SB12 segment may have caused the bias because within the segment there is the Springfield Interchange where the I-495 Capital Beltway crosses with the I-95 corridor, as shown in Figure 3-1 in the Methodology. The segments before (i.e., SB8) and after (i.e., SB15) the Springfield Interchange did not have significant differences between Bluetooth and INRIX data. Therefore, it is reasonable to suspect that the Springfield Interchange may be one of the factors causing these large errors, especially if the merging volume at the intersection is high. For example, when the volume of vehicles entering the freeway is high, the Bluetooth data may not pick up the congestion at the merging area if vehicles are in the median lanes while INRIX data (e.g., trucks running on slow lanes) does. It is impossible to say for certain which data set is responsible for the differences in the speed data. 
Another possible explanation is the discrepancies between Bluetooth and INRIX endpoints (i.e., $4.6 \%$ shorter than INRIX endpoints). If a bottleneck situation occurs before the start of the Bluetooth segment, the endpoint discrepancies near the Springfield interchange will be a major factor. In such a scenario, INRIX speeds will be less than Bluetooth speeds due to a slow traffic prior to the bottleneck area.

Figure 4-1 demonstrates that the speed travel time data on SB12 were generally underestimated throughout the day on Wednesday, January $4^{\text {th }}$. These underestimated results are typical on the SB12 segment during weekdays. There are high fluctuations during evening peak hours. Generally speaking, however, the trends in the speeds were similar between the two data sources even though there was a bias present.

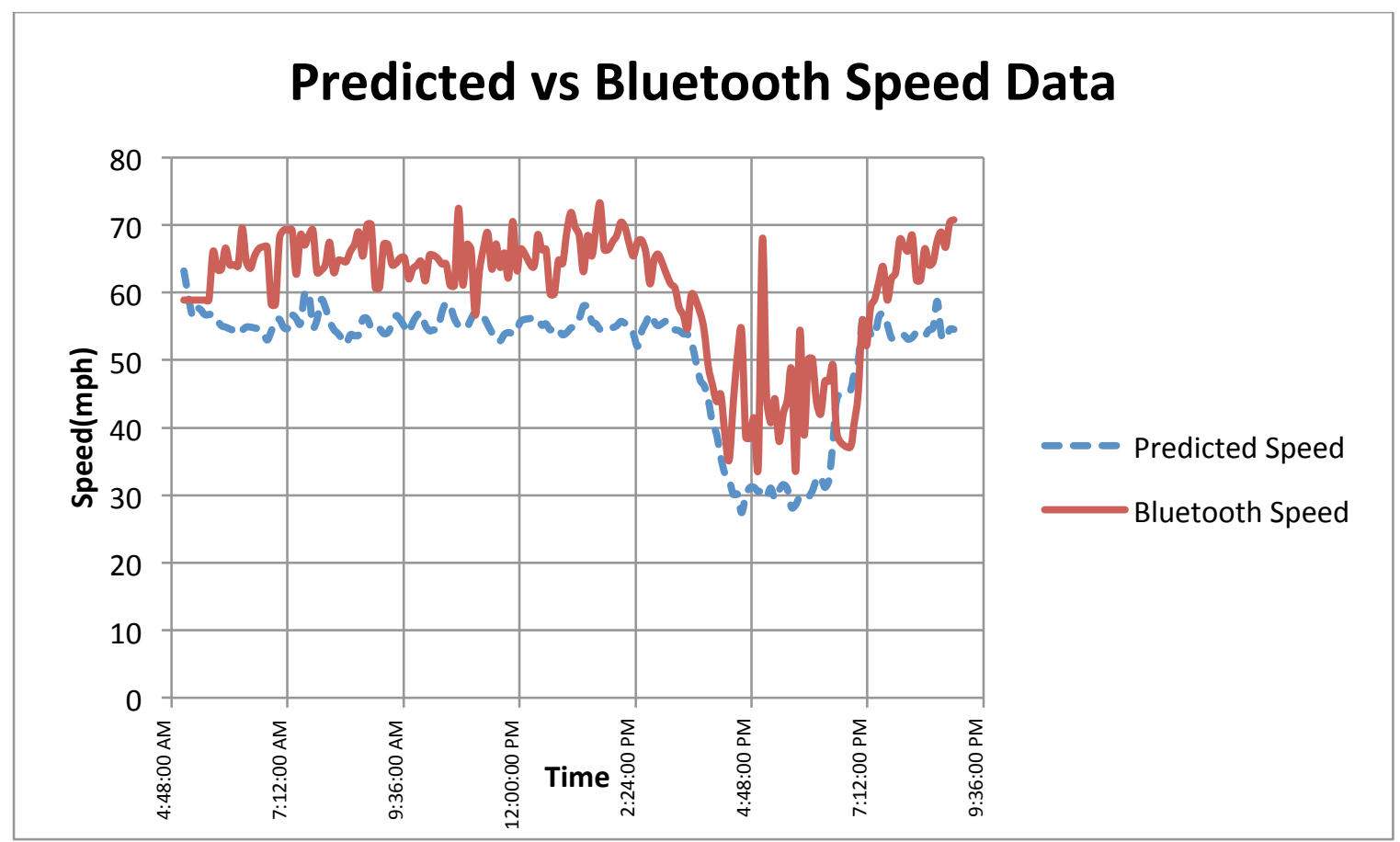

Figure 4-1 SB12, predicted speeds compared with Bluetooth "Ground Truth" Data, on weekday, January $4^{\text {th }}$ 


\subsubsection{I-95 SB from MM 168.1 to SR 234 (SB15)}

This segment started after the Springfield Interchange at MM168.1 to MM152. The raw speed errors on segment SB15 were below $5 \mathrm{mph}$ and passed the VDOT requirements.

The percentages of raw travel time within error thresholds were high, especially on weekends, as shown in Table 4-12. Overall, the SB15 segment has a high degree of agreement between Bluetooth and INRIX data sets.

Table 4-12 Performance measures during operational periods, SB15

\begin{tabular}{|c|c|c|c|c|c|c|c|}
\hline \multirow[t]{2}{*}{ Date } & \multirow{2}{*}{$\begin{array}{l}\text { Number } \\
\quad \text { of } \\
\text { Intervals } \\
\text { Analyzed }\end{array}$} & \multirow{2}{*}{$\begin{array}{c}\text { Raw } \\
\text { Speed } \\
\text { Error Bias } \\
\text { (mph) }\end{array}$} & \multirow{2}{*}{$\begin{array}{l}\text { Raw Speed } \\
\text { Absolute } \\
\text { Error (mph) }\end{array}$} & \multicolumn{2}{|c|}{$\begin{array}{c}\% \text { of Raw Travel } \\
\text { Time within Error } \\
\text { Thresholds }\end{array}$} & \multirow[t]{2}{*}{$\begin{array}{l}\text { RMSE } \\
(\mathrm{mph})\end{array}$} & \multirow[t]{2}{*}{$\begin{array}{c}\text { Blank } \\
\text { Out (\%) }\end{array}$} \\
\hline & & & & $\pm 10 \mathrm{mph}$ & $\pm 5 \mathrm{mph}$ & & \\
\hline Weekdays & 5520 & 3.7 & 4.8 & 88.9 & 59.2 & 6.1 & 1.0 \\
\hline Weekends & 1387 & 2.9 & 4.3 & 95.4 & 63.7 & 5.3 & 0.7 \\
\hline
\end{tabular}

The speed error distribution in Table 4-13 demonstrates no substantial difference between speed categories, and the majority speeds were over $60 \mathrm{mph}$. The weekday errors decrease as speeds decrease.

Table 4-13 Speed error distributions during operational periods, SB15

\begin{tabular}{|c|c|c|c|c|c|c|}
\hline \multirow{2}{*}{$\begin{array}{c}\text { Speed Bin } \\
(\mathrm{mph})\end{array}$} & $\begin{array}{c}|c| \\
\text { Error } \\
\text { Bias } \\
(\mathrm{mph})\end{array}$ & $\begin{array}{c}\text { Absolute Average } \\
\text { Speed Error (mph) }\end{array}$ & $\begin{array}{c}\text { Avg. } \\
\text { Interval } \\
\text { Count } \\
\text { per Day }\end{array}$ & $\begin{array}{c}\text { Error } \\
\text { Bias } \\
(\mathrm{mph})\end{array}$ & $\begin{array}{c}\text { Absolute Average } \\
\text { Speed Error (mph) }\end{array}$ & $\begin{array}{c}\text { Avg. } \\
\text { Interval } \\
\text { Count } \\
\text { per Day }\end{array}$ \\
\hline $0-30$ & 0.1 & 3.2 & 18.0 & 0 & 0 & 0 \\
\hline $30-45$ & 1.3 & 4.5 & 20.5 & -3.6 & 5.0 & 4.1 \\
\hline $45-60$ & 2.1 & 4.8 & 13.5 & 0.8 & 5.8 & 31.5 \\
\hline 60 or more & 4.9 & 5.4 & 133.0 & 3.0 & 4.1 & 103.0 \\
\hline
\end{tabular}




\subsubsection{I-95 SB from MM 162.7 to MM 130 (SB33)}

As might be expected with a long segment, the SB33 segment had large deviations between the INRIX and Bluetooth data during the study period. The average speed error biases on weekdays and weekends were $10.7 \mathrm{mph}$ and $10.5 \mathrm{mph}$, as shown in Table 4-14. These results violated the business rules requirements. The data completeness on SB33 segment was really high, and had the smallest percent of blank outs in all segments. The raw travel times were available for almost $100 \%$ during the operational periods. These differences are likely influenced by characteristics of the Bluetooth benchmark, however.

Table 4-14 Performance measures during operational periods, SB33

\begin{tabular}{|c|c|c|c|c|c|c|c|}
\hline \multirow[t]{2}{*}{ Date } & \multirow{2}{*}{$\begin{array}{l}\text { Number } \\
\text { of } \\
\text { Intervals } \\
\text { Analyzed }\end{array}$} & \multirow{2}{*}{$\begin{array}{c}\text { Raw } \\
\text { Speed } \\
\text { Error Bias } \\
\text { (mph) }\end{array}$} & \multirow{2}{*}{$\begin{array}{l}\text { Raw Speed } \\
\text { Absolute } \\
\text { Error (mph) }\end{array}$} & \multicolumn{2}{|c|}{$\begin{array}{c}\% \text { of Raw Travel } \\
\text { Time within Error } \\
\text { Thresholds }\end{array}$} & \multirow[t]{2}{*}{$\begin{array}{l}\text { RMSE } \\
(\mathrm{mph})\end{array}$} & \multirow[t]{2}{*}{$\begin{array}{c}\text { Blank } \\
\text { Out (\%) }\end{array}$} \\
\hline & & & & $\pm 10 \mathrm{mph}$ & $\pm 5 \mathrm{mph}$ & & \\
\hline Weekdays & 4846 & 10.7 & 10.8 & 45.9 & 12.6 & 12.1 & 0.0 \\
\hline Weekends & 1258 & 10.5 & 10.6 & 48.7 & 11.5 & 11.7 & 0.0 \\
\hline
\end{tabular}

As shown in Table 4-15, speeds higher than $60 \mathrm{mph}$ have greater error bias than the lower speed bins, especially during weekdays. These high speed bin errors failed the business rules requirements.

Table 4-15 Speed error distributions during operational periods, SB33

\begin{tabular}{|c|c|c|c|c|c|c|}
\hline \multirow{2}{*}{$\begin{array}{c}\text { Speed Bin } \\
(\mathrm{mph})\end{array}$} & \multicolumn{3}{|c|}{ Weekdays (5 AM to 9PM) } & \multicolumn{3}{c|}{ Weekends (8 AM to 8 PM) } \\
\cline { 2 - 7 } & $\begin{array}{c}\text { Error } \\
\text { Bias }\end{array}$ & $\begin{array}{c}\text { Absolute Average } \\
\text { Speed Error (mph) }\end{array}$ & $\begin{array}{c}\text { Avg. } \\
\text { Interval } \\
\text { Count } \\
\text { per Day }\end{array}$ & $\begin{array}{c}\text { Error } \\
\text { Bias } \\
(\mathrm{mph})\end{array}$ & $\begin{array}{c}\text { Avg. } \\
\text { Speed Error (mph) }\end{array}$ & $\begin{array}{c}\text { Interval } \\
\text { Count } \\
\text { per Day }\end{array}$ \\
\hline $0-30$ & 0.4 & 0.6 & 0.4 & 0 & 0 & 0 \\
\hline $30-45$ & 4.2 & 4.4 & 15.0 & -0.9 & 0.9 & 0.4 \\
\hline $45-60$ & 8.8 & 9.0 & 20.0 & -0.6 & 5.2 & 1.4 \\
\hline 60 or more & 11.5 & 11.5 & 151.0 & 10.7 & 10.7 & 138.0 \\
\hline
\end{tabular}


The raw speeds were consistently over-predicted throughout the days. These overestimations of raw speeds may be caused by several reasons, including the characteristics of Bluetooth and/or the distance discrepancy. First, a long SB33 segment may significantly affect the travel time data quality due to the characteristics of Bluetooth. Bluetooth data points are collected from any vehicles that are identified by the Bluetooth detectors at the segment endpoints, regardless of time spent travelling the segment. With this characteristic, the outliers may be likely to occur. Although the outliers were filtered out, there may still be some outliers that were not captured in the process. A more sophisticated filtering process may be helpful.

Secondly, a small discrepancy in endpoints locations (i.e., Bluetooth segments were $2.3 \%$ shorter than INRIX endpoints) may be another factor causing the predicted speeds to be overpredicted. However, the assumption that the data quality for this segment is not good may not be applicable in this case because the raw data showed the same trends as the Bluetooth data, as shown in Figure 4-2. Although a bias is present, both data sources show similar trends. As a result, the travel time data would appear to be appropriate for most business applications.

Lastly, the HOV lanes could be another factor if the speeds of vehicles on HOV lanes were included in INRIX data since the HOV lanes ended at Dumfries (approximately at MM 153). 


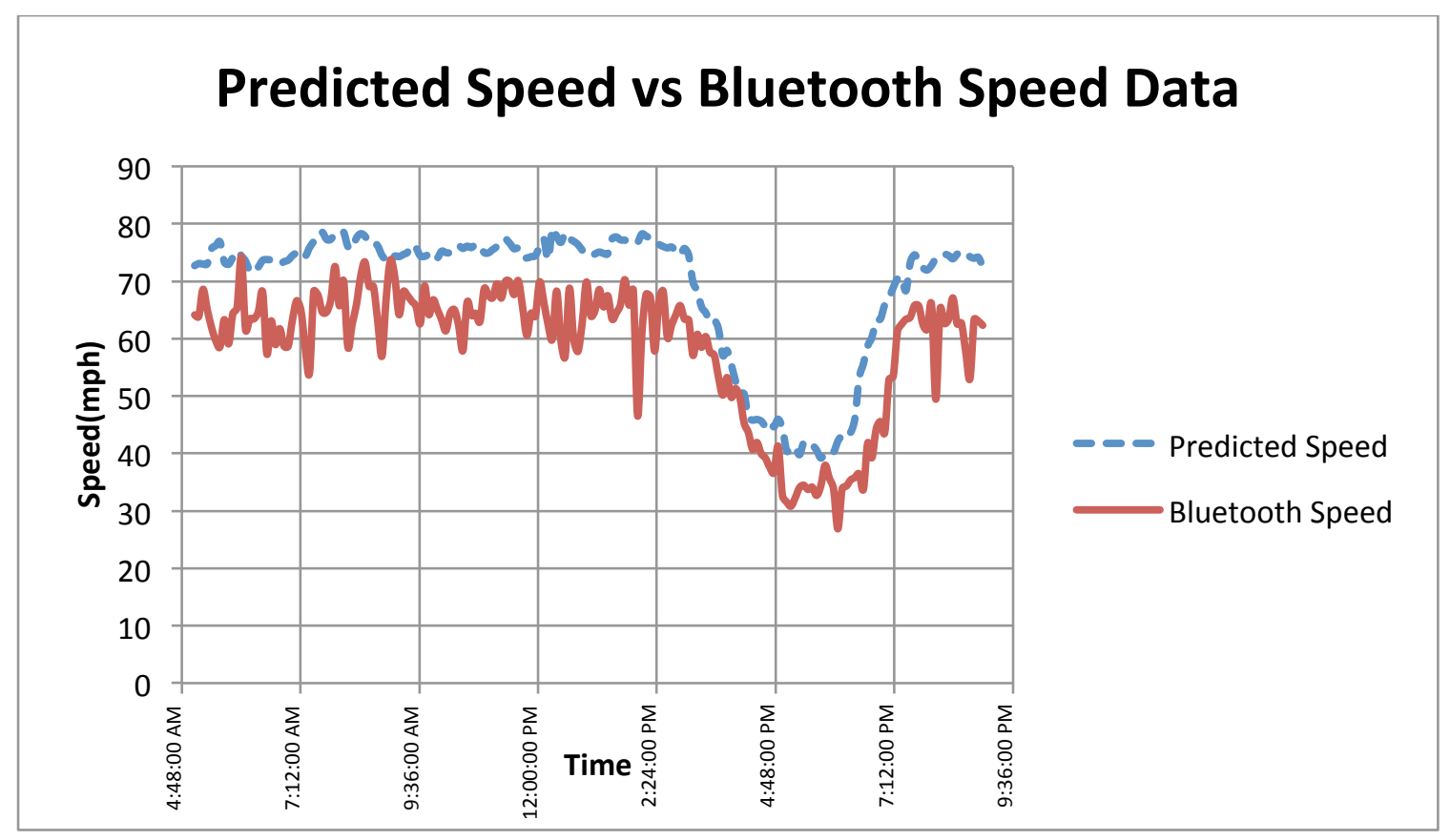

Figure 4-2 SB33, predicted speeds compared with Bluetooth "Ground Truth" Data, on weekday, January $4^{\text {th }}$

\subsubsection{I-95 SB from MM 162.7 to MM 143 (SB19)}

Since the INRIX and Bluetooth data did not agree on SB33, VDOT shortened the length of the segment to determine if performance could be improved. The SB19 segment was evaluated one time in January. As expected, the performance on SB19 segment was better than the SB33 segment, but still did not satisfy the business rule requirements, as shown in Table 4-16. The average blank out was less than $1 \%$ during the operational periods.

Similar to SB33 segment, the predicted speeds on the SB19 segment were consistently overestimated with a smaller bias error than the SB33 segment, as shown in Figure 4-3. Both sources in the figure clearly shows the same speed trends throughout the day, which is still useful for VDOT, even though some of VDOT requirements had not been met. 
Even though this segment overlapped with a well performing segment, SB15, SB19 does not show as much agreement between the Bluetooth and INRIX data as SB15. A possible factor, which may be responsible for the lower degree of agreement on SB19, is Bluetooth characteristics. Similar to SB33 segment, Bluetooth characteristics of a longer distance, comparing SB15 and SB19 segments, may impact a quality data due to the influence of low speed vehicles on Bluetooth data speed.

Table 4-16 Performance measures during operational periods, SB19

\begin{tabular}{|c|c|c|c|c|c|c|c|}
\hline \multirow[t]{2}{*}{ Date } & \multirow{2}{*}{$\begin{array}{l}\text { Number } \\
\text { of } \\
\text { Intervals } \\
\text { Analyzed }\end{array}$} & \multirow{2}{*}{$\begin{array}{c}\text { Raw } \\
\text { Speed } \\
\text { Error Bias } \\
(\mathrm{mph})\end{array}$} & \multirow{2}{*}{$\begin{array}{l}\text { Raw Speed } \\
\text { Absolute } \\
\text { Error (mph) }\end{array}$} & \multicolumn{2}{|c|}{$\begin{array}{c}\% \text { of Raw Travel } \\
\text { Time within Error } \\
\text { Thresholds }\end{array}$} & \multirow[t]{2}{*}{$\begin{array}{l}\text { RMSE } \\
(\mathrm{mph})\end{array}$} & \multirow[t]{2}{*}{$\begin{array}{c}\text { Blank } \\
\text { Out }(\%)\end{array}$} \\
\hline & & & & $\pm 10 \mathrm{mph}$ & $\pm 5 \mathrm{mph}$ & & \\
\hline Weekdays & 2790 & 8.0 & 8.2 & 69.7 & 21.6 & 9.2 & 0.4 \\
\hline Weekends & 697 & 7.4 & 7.7 & 75.6 & 23.8 & 8.6 & 0.2 \\
\hline
\end{tabular}

Speeds were mostly over $60 \mathrm{mph}$, and the errors were high in the high speed bins, as shown in Table 4-17. The speed over $60 \mathrm{mph}$ range had the highest error, which failed the business rules requirements.

Table 4-17 Speed error distributions during operational periods, SB19

\begin{tabular}{|c|c|c|c|c|c|c|}
\hline \multirow{2}{*}{$\begin{array}{c}\text { Speed Bin } \\
(\mathrm{mph})\end{array}$} & $\begin{array}{c}\text { Error } \\
\text { Bias } \\
(\mathrm{mph})\end{array}$ & $\begin{array}{c}\text { Absolute Average } \\
\text { Speed Error (mph) }\end{array}$ & $\begin{array}{c}\text { Avg. } \\
\text { Interval } \\
\text { Count } \\
\text { per Day }\end{array}$ & $\begin{array}{c}\text { Error } \\
\text { Bias } \\
(\mathrm{mph})\end{array}$ & $\begin{array}{c}\text { Absolute Average } \\
\text { Speed Error (mph) }\end{array}$ & $\begin{array}{c}\text { Avg. } \\
\text { Interval } \\
\text { Count } \\
\text { per Day }\end{array}$ \\
\hline $0-30$ & 2.1 & 2.5 & 8.5 & 0 & 0 & 0 \\
\hline $30-45$ & 5.1 & 5.9 & 27.0 & -2.5 & 2.5 & 0.1 \\
\hline $45-60$ & 8.3 & 8.5 & 19.0 & 0.1 & 5.7 & 4.6 \\
\hline 60 or more & 9.3 & 9.4 & 131.5 & 8.5 & 8.6 & 134.5 \\
\hline
\end{tabular}




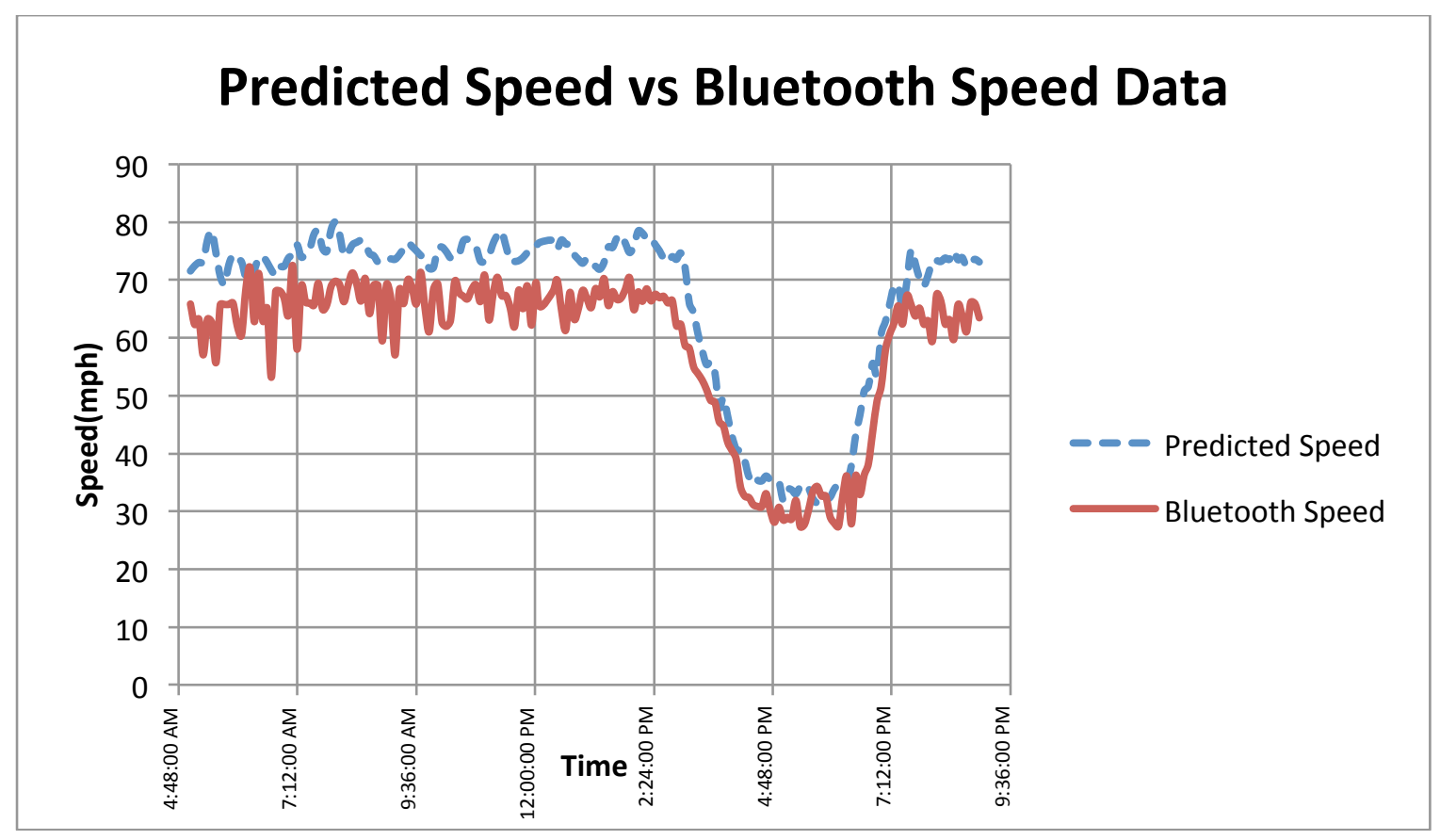

Figure 4-3 SB19, predicted speeds compared with Bluetooth "Ground Truth" Data, on weekday, January $4^{\text {th }}$

\subsubsection{Overall Performance on I-95 Corridor}

From a total of 8 evaluated segments, there were 3 segments that showed disagreement between Bluetooth data and the OpenRoads estimated travel time data (i.e., SB12, SB19, and SB33). Table 4-18 summarizes overall performance measures on I-95 corridor. This table averages the performance measures of all the segments with the same weight for each day. The overall performance measures table indicated that $78 \%$ of the raw data were within $10 \mathrm{mph}$, mainly because of the results from the segments where INRIX and Bluetooth data disagreed. The percentage of the data within $10 \mathrm{mph}$ from segments with reliable benchmark data were over $85 \%$. The speed error bias in the table was low (i.e., $0.5 \mathrm{mph}$ ) because the positive and negative errors cancel each other. 
Table 4-18 Overall performance measures on I-95 Corridor

\begin{tabular}{|c|c|}
\hline ERROR METRIC & MEASURE \\
\hline Speed error bias - raw travel time $(\mathrm{mph})$ & 0.5 \\
\hline Average absolute speed error - raw travel time $(\mathrm{mph})$ & 6.6 \\
\hline$\%$ within $\pm 10 \mathrm{mph}$ (raw travel time) & $78.1 \%$ \\
\hline$\%$ within $\pm 5 \mathrm{mph}$ (raw travel time) & $41.8 \%$ \\
\hline Root mean square error - raw travel time $(\mathrm{mph})$ & 7.7 \\
\hline$\%$ of operational period blanked out & $1.5 \%$ \\
\hline
\end{tabular}

The lessons learned from data quality evaluation on I-95 corridor are listed below.

The completeness of Open Roads travel time data, which based on INRIX data, is high because the blank outs were low for all segments during the operational periods.

Based on the analysis results, sites with the following characteristics seem to have high levels of agreement between the Bluetooth data and the travel time estimates.

$\circ$ Less severe congestion. Based on the results from the eight segments on the I-95 corridor, all northbound segments have good agreement. It may be just a coincidence, or the time of congestion may result in better estimated travel times. Normally, the congestion during the morning peak hours is less severe than the evening peak hours. Since the most challenging hours for estimating travel times is during peak hours, being able to provide more accurate travel time information during peak hours can improve data quality of a segment. Therefore, Open Roads may be able to estimate travel times more accurately during less severe congestion 
(i.e., morning peak hours), using raw INRIX travel time data.

Alternatively, it is possible that Bluetooth data was more reliable in less congested regimes as well. However, it is just a hypothesis. With only 3 northbound segments, it may be too soon to conclude that Open Roads can provide better estimated travel times during morning peak hours on I-95 corridor.

- Short segment lengths. When a segment distance is less than 15 miles, the results generally have a good agreement. Figure 4-4 demonstrates how well short distance segments perform over long distance segments, with the exception of the SB12 segment. It is intuitive that predicted travel times over a short distance would be more accurate than a long distance because human behavior and other unpredicted events (e.g., an incident) have less affect over a short distance. This also is confounded with severity of congestion since the two longest links were located on I-95 SB. The plots of INRIX distance versus speed error bias and absolute error bias in Figure 4-4 and 4.5 seem to show the same trends. Both plots generally demonstrate increasing trend of biases as the distance increases. For Figure 4-4, the error bias goes from underprediction to overprediction as length increases. The shifting of the bias sign may caused by the characteristics of Bluetooth data with a long distance segment. As shown in Figure 4-4, over short distance segments, the bias values were all negative, showing slower speeds of INRIX data. Since INRIX probe data 
mainly comes from trucks, this may explain slow speed data comparing to a general traffic.

However, as the distance increases, the characteristics of Bluetooth may cause Bluetooth speeds to be slower. At some point, the Bluetooth speeds may become slower than INRIX speeds and results in overprediction bias. Looking at Figure 4-4, the bias switches when the segment length goes beyond 15 miles. To minimize the impacts of Bluetooth's characteristics, the evaluated segment length should not exceed 15 miles to be conservative based on the results in this study.

The absolute error bias in Figure 4-5 captures the actual magnitude of errors. Therefore, the bias in Figure 4-5 is larger than the ones in Figure 4-4. For example, SB12 segment, where the magnitudes from both plots are almost the same, indicates that almost all the biases occurred on SB12 were underpredicted.

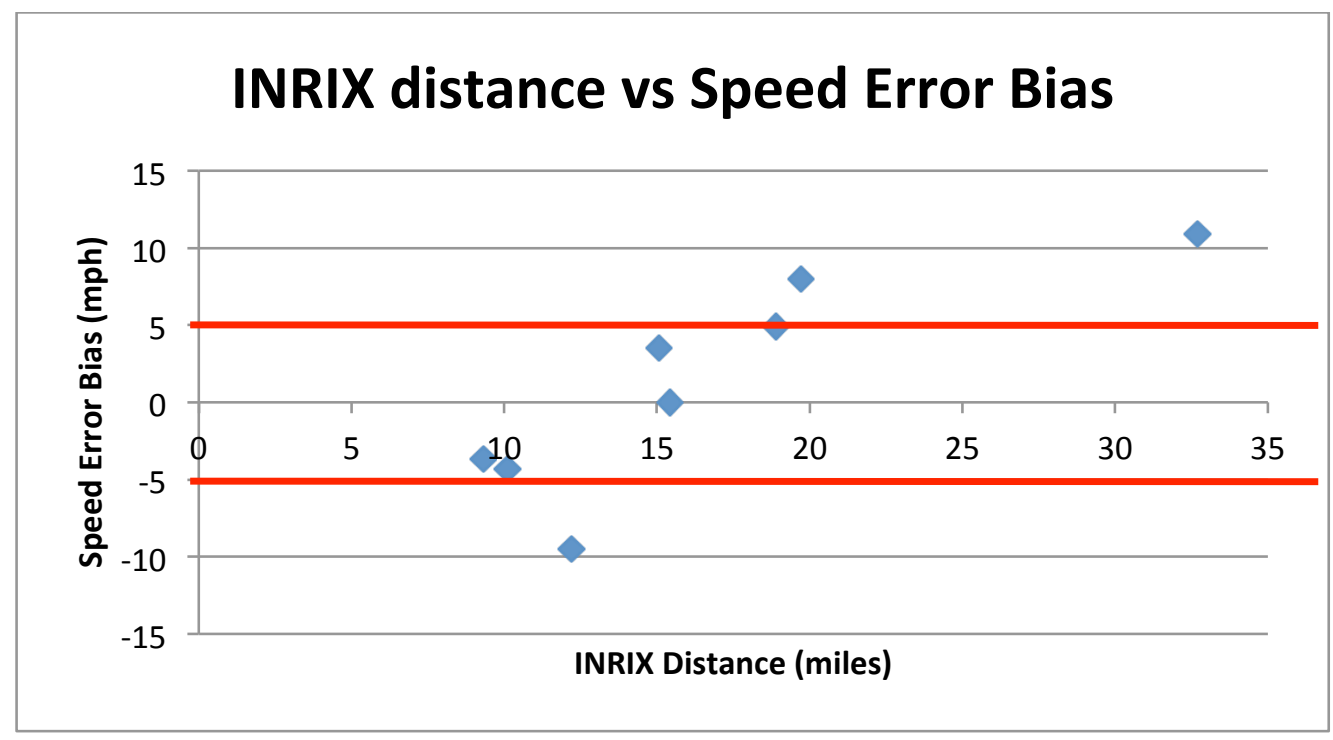

Figure 4-4 INRIX distances compared to speed error biases of each segment on I-95 corridor 


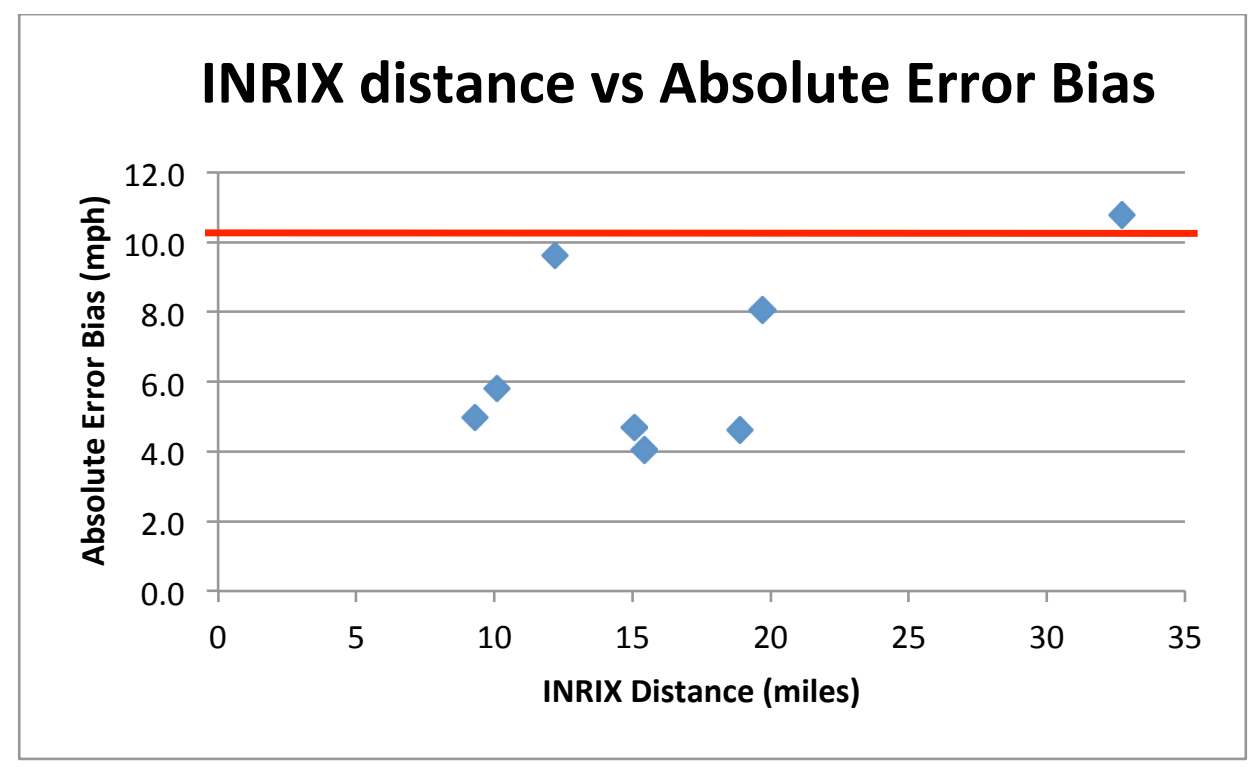

Figure 4-5 INRIX distances compared to absolute error biases of each segment on I95 corridor

Based on the analysis results, sites with the following characteristics may contribute to a degree of disagreement in travel time data quality results.

$\circ$ A major intersection within the site location. The Springfield Interchange in the SB12 segment is an example. With such an interchange on a major urban freeway, there may be a large number of vehicles entering the freeway and slowing down the traffic at the merging area. If that is the case, this could affect both INRIX and Bluetooth data. For INRIX data, it depends on the locations of INRIX probe data. If majority of INRIX probe data were trucks running on the slow lanes experiencing congestion at the merging area, INRIX speeds would be low. On the other hand, through vehicles detected by Bluetooth at the start and end of the corridor may be traveling in the far left lane to avoid merging vehicles, thereby experiencing less traffic and resulting in higher speeds. 
- Distance discrepancies between Benchmark and TIS data. Almost all the Bluetooth distances were shorter than INRIX distances, except SB15. Since Bluetooth did not fully cover the INRIX distance, this may cause errors in certain situations, such as when bottlenecks occur near the segment boundaries. If, for instance, a bottleneck situation occurs towards the end of Bluetooth distance, the predicted speeds from INRIX may be overestimated because of the higher speeds after the bottleneck, which were not captured by Bluetooth detectors.

\subsubsection{Data Quality Evaluation in Hampton Roads}

The data quality analysis was conducted on the I-64 and I-264 corridors between July 16 and August 19, 2012. A total of 27 BlueTOAD links were initially examined to determine if the sample size was sufficient to conduct the evaluation. To have fair results, BlueTOAD data needs to be reliable. As described in Methodology, the evaluated BlueTOAD links needed to have an average of at least 3 matched vehicles per 5 minutes. After the BlueTOAD data screening, only 10 out of 27 links had a sufficient number of matched vehicles to be used for data quality analysis, as shown in Table 4-19.

Only two out of these ten links (i.e., Link 5856 and 5857) are on I-264 corridor. The rest of the BlueTOAD links are on I-64 corridor. Table 4-20 demonstrates the BlueTOAD distances from TrafficCast website and INRIX distances determined from integrating TMC codes. Also, it includes the estimated mileposts and distances using VDOT GIS Integrator. Based on the results from the analysis on I-95 corridor where the 
distance discrepancies seem to cause a quality issue, the Integrator was also used to ensure both Bluetooth and INRIX distances on Hampton Roads Area.

Table 4-19. Bluetooth Preliminary Test In Hampton Roads

\begin{tabular}{|c|c|c|c|}
\hline Station & $\begin{array}{c}\text { Mean of Avg \# } \\
\text { matches per } 5 \\
\text { minutes }\end{array}$ & $\begin{array}{c}\% \text { of intervals } \\
\text { with at least } 3 \\
\text { matches }\end{array}$ & $\begin{array}{l}\text { BT } \\
\text { Miles }\end{array}$ \\
\hline 4121 & 1.13 & $17.30 \%$ & 22 \\
\hline 4122 & 2.18 & $76.90 \%$ & 22.1 \\
\hline 4123 & 1.64 & $56.10 \%$ & 23.1 \\
\hline 4124 & 2.38 & $79.20 \%$ & 19.8 \\
\hline 4125 & 2.22 & $75.80 \%$ & 21.6 \\
\hline 4126 & 1.73 & $59.60 \%$ & 30.2 \\
\hline 4127 & 1.28 & $28.70 \%$ & 23.5 \\
\hline 4128 & 1.54 & $54.70 \%$ & 20 \\
\hline 4129 & 1.11 & $11.10 \%$ & 19.5 \\
\hline 5840 & 3.45 & $92.30 \%$ & 8.7 \\
\hline 5841 & 3.34 & $91.90 \%$ & 8.7 \\
\hline 5842 & 6.47 & $99.00 \%$ & 1.8 \\
\hline 5843 & 3.25 & $92.10 \%$ & 1.8 \\
\hline 5844 & 2.32 & $82.80 \%$ & 1 \\
\hline 5845 & 2.03 & $71.60 \%$ & 1 \\
\hline 5846 & 4.06 & $95.10 \%$ & 0.9 \\
\hline 5847 & 3.11 & $90.40 \%$ & 0.9 \\
\hline 5848 & 2.11 & $75.70 \%$ & 18.8 \\
\hline 5849 & 1.59 & $57.40 \%$ & 18.8 \\
\hline 5850 & 4.01 & $95.40 \%$ & 1.2 \\
\hline 5851 & 1.95 & $73.00 \%$ & 1.2 \\
\hline 5852 & 2.83 & $88.20 \%$ & 3.5 \\
\hline 5853 & 6.51 & $99.60 \%$ & 3.5 \\
\hline 5854 & 2.31 & $80.10 \%$ & 5.4 \\
\hline 5855 & 1.56 & $59.00 \%$ & 5.4 \\
\hline 5856 & 3.42 & $90.50 \%$ & 1 \\
\hline 5857 & 7.78 & $99.50 \%$ & 1 \\
\hline
\end{tabular}


Table 4-20 Details information on each link on Hampton Road area

\begin{tabular}{|c|c|c|c|c|c|c|c|c|c|c|c|}
\hline & & & & & & & & ttegrator & & & \\
\hline & & & & & $\mathrm{BT} \mathrm{mi}$ & lepost & & $\mathrm{TMC}_{1}$ & ilepost & & \\
\hline Link & $\begin{array}{c}\text { Number of } \\
\text { TMCs }\end{array}$ & $\begin{array}{c}\text { BT } \\
\text { Miles } \\
\end{array}$ & $\begin{array}{l}\text { TMC } \\
\text { Miles } \\
\end{array}$ & Diff. & Start & End & Dist & Start & End & Dist & Diff \\
\hline 5840 & 9 & 8.7 & 11.88 & 3.18 & 253.39 & 262.02 & 8.63 & 250.49 & 262.35 & 11.9 & 3.23 \\
\hline 5841 & 8 & 8.7 & 7.91 & -0.79 & 262.02 & 253.39 & 8.63 & 262.35 & 254.35 & 8 & -0.63 \\
\hline 5842 & 5 & 1.8 & 2.3 & 0.5 & 262.02 & 263.82 & 1.8 & 261.9 & 264.21 & 2.31 & 0.51 \\
\hline 5843 & 5 & 1.8 & 2.37 & 0.57 & 263.82 & 262.02 & 1.8 & 264.02 & 261.7 & 2.32 & 0.52 \\
\hline 5846 & 3 & 0.9 & 1.37 & 0.47 & 263.82 & 264.79 & 0.97 & 263.56 & 264.96 & 1.4 & 0.43 \\
\hline 5847 & 2 & 0.9 & 1.09 & 0.19 & 264.79 & 263.82 & 0.97 & 264.93 & 263.8 & 1.13 & 0.16 \\
\hline 5850 & 3 & 1.2 & 4.03 & 2.83 & 283.66 & 284.63 & 0.97 & 282.07 & 286.28 & 4.21 & 3.24 \\
\hline 5853 & 3 & 3.5 & 4.35 & 0.85 & 288.12 & 284.63 & 3.49 & 288.67 & 284.38 & 4.29 & 0.8 \\
\hline 5856 & 2 & 1 & 1.51 & 0.51 & N/A & N/A & N/A & N/A & N/A & N/A & N/A \\
\hline 5857 & 2 & 1 & 1.4 & 0.4 & N/A & N/A & N/A & N/A & N/A & N/A & N/A \\
\hline
\end{tabular}

Note: the Integrator did not have mileposts for the I-264 corridor.

\subsubsection{I-64 Corridor, Hampton Roads Area}

The following sections will discuss the data quality results of each segment on the I-64 corridor in each direction of travel. The results in this section (Table 4-21 - Table 4-45) were the average results from July 16 to August 19, 2012. The detailed performances on each day of each evaluated segment in the Hampton Roads Area are available in Appendix B. The speed error distributions on each link were averaged from the entire evaluation periods using equal weights for each day. 


\subsubsection{Link 5840 WB I 64 at Denbigh (u424) to EB I 64 At Magruder, MP262 EB (u433)}

Link 5840 started from WB I-64 at Denbigh to EB I-64 at Magruder, and has bias errors lower than $5 \mathrm{mph}$ for both weekdays and weekends. Also, it has a high percentage of raw travel times within the $10 \mathrm{mph}$ error threshold, Table 4-21. Overall, the raw travel times on link 5840 have a good agreement with Bluetooth data. Even though weekend quality is worse than weekday quality, both results satisfy the VDOT speed bias requirements.

Table 4-21 Performance measures during operational periods on I-64, link 5840

\begin{tabular}{|c|c|c|c|c|c|c|c|}
\hline \multirow[t]{2}{*}{ Date } & \multirow{2}{*}{$\begin{array}{l}\text { Number } \\
\text { of } \\
\text { Intervals } \\
\text { Analyzed }\end{array}$} & \multirow{2}{*}{$\begin{array}{c}\text { Raw } \\
\text { Speed } \\
\text { Error Bias } \\
(\mathrm{mph})\end{array}$} & \multirow{2}{*}{$\begin{array}{l}\text { Raw Speed } \\
\text { Absolute } \\
\text { Error (mph) }\end{array}$} & \multicolumn{2}{|c|}{$\begin{array}{c}\% \text { of Raw Travel } \\
\text { Time within Error } \\
\text { Thresholds }\end{array}$} & \multirow[t]{2}{*}{$\begin{array}{l}\text { RMSE } \\
(\mathrm{mph})\end{array}$} & \multirow[t]{2}{*}{$\begin{array}{c}\text { Blank } \\
\text { Out (\%) }\end{array}$} \\
\hline & & & & $\pm 10 \mathrm{mph}$ & $\pm 5 \mathrm{mph}$ & & \\
\hline Weekdays & 4336 & -1.7 & 3.7 & $93 \%$ & $76 \%$ & 4.5 & $0.8 \%$ \\
\hline Weekends & 1337 & -4.0 & 5.6 & $83 \%$ & $62 \%$ & 5.4 & $3.8 \%$ \\
\hline
\end{tabular}

The speed error distribution in Table 4-22 demonstrates no substantial difference between speed categories, and the majority speeds were over $60 \mathrm{mph}$.

Table 4-22 Speed error distributions during operational periods on I-64, link 5840

\begin{tabular}{|c|c|c|c|c|c|c|}
\hline \multirow{2}{*}{$\begin{array}{c}\text { Speed Bin } \\
(\mathrm{mph})\end{array}$} & \multicolumn{3}{|c|}{ Weekdays (5 AM to 9PM) } & \multicolumn{3}{c|}{ Weekends (8 AM to 8 PM) } \\
\cline { 2 - 7 } & $\begin{array}{c}\text { Error } \\
\text { Bias } \\
(\mathrm{mph})\end{array}$ & $\begin{array}{c}\text { Absolute Average } \\
\text { Speed Error } \\
(\mathrm{mph})\end{array}$ & $\begin{array}{c}\text { Avg. } \\
\text { Interval } \\
\text { Count } \\
\text { per Day }\end{array}$ & $\begin{array}{c}\text { Error Bias } \\
\text { (mph) }\end{array}$ & $\begin{array}{c}\text { Absolute Average } \\
\text { Speed Error } \\
\text { (mph) }\end{array}$ & $\begin{array}{c}\text { Avg. } \\
\text { Interval } \\
\text { Count } \\
\text { per Day }\end{array}$ \\
\hline $0-30$ & 1.70 & 1.70 & 0.08 & 7.17 & 7.17 & 0.1 \\
\hline $30-45$ & 1.24 & 1.24 & 0.28 & -0.46 & 0.53 & 1.3 \\
\hline $45-60$ & 3.00 & 6.70 & 5.84 & 0.90 & 6.71 & 4.9 \\
\hline 60 or more & -1.88 & 3.63 & 167.24 & -4.19 & 5.74 & 127.4 \\
\hline
\end{tabular}




\subsubsection{Link 5841 EB I 64 At Magruder, MP 262 EB (u433) to WB I 64 at Denbigh (u424)}

Table 4-23 demonstrates the results on link 5841 with both 8 and 9 TMC codes.

Originally, link 5841 was analyzed using a total of 9 TMC codes to cover the entire Bluetooth distance. As shown in Table 3-7 (in Methodology), the TMC distance for link 5841 with 9 TMC was 11.87 miles, compared to the Bluetooth distance of 8.7 miles. The weekday results with 9 TMC codes satisfied the business rules requirements, but the weekend results failed. With 9 TMC codes, the speed error bias (i.e., $2.8 \mathrm{mph}$ ) and the absolute speed error (i.e., $18.5 \mathrm{mph}$ ) on weekends were substantially different. As a result, the weekend data on link 5841 was reanalyzed with a shorter distance of TMC codes by taking out the longest TMC code at the endpoint. With 8 TMCs, the TMC distance for link 5841 was reduced to 7.91 miles and the absolute speed error on weekend was improved to $7.5 \mathrm{mph}$, as shown in Table 4-23. However, the Bluetooth distance that was not covered by TMC was 1.06 miles, not 0.79 miles $(8.7-7.91=0.79)$ because none of Bluetooth and TMC endpoints were the same.

Table 4-23 Performance measures during operational periods on I-64, link 5841

\begin{tabular}{|c|c|c|c|c|c|c|c|c|}
\hline & \multirow[t]{2}{*}{ Date } & \multirow{2}{*}{$\begin{array}{l}\text { Number } \\
\text { of } \\
\text { Intervals } \\
\text { Analyzed }\end{array}$} & \multirow{2}{*}{$\begin{array}{l}\text { Raw } \\
\text { Speed } \\
\text { Error } \\
\text { Bias } \\
(\mathrm{mph}) \\
\end{array}$} & \multirow{2}{*}{$\begin{array}{c}\text { Raw } \\
\text { Speed } \\
\text { Absolute } \\
\text { Error } \\
\text { (mph) }\end{array}$} & \multicolumn{2}{|c|}{$\begin{array}{c}\% \text { of Raw Travel } \\
\text { Time within Error } \\
\text { Thresholds }\end{array}$} & \multirow{2}{*}{$\begin{array}{l}\text { RMSE } \\
\text { (mph) }\end{array}$} & \multirow{2}{*}{$\begin{array}{c}\text { Blank } \\
\text { Out } \\
(\%)\end{array}$} \\
\hline & & & & & $\begin{array}{l} \pm 10 \\
\mathrm{mph}\end{array}$ & $\begin{array}{c} \pm 5 \\
\mathrm{mph} \\
\end{array}$ & & \\
\hline \multirow{2}{*}{$\begin{array}{c}8 \\
\text { TMC }\end{array}$} & Weekdays & 4309 & 1.7 & 4.1 & $91 \%$ & $76 \%$ & 5.4 & $1.3 \%$ \\
\hline & Weekends & 1296 & 5.1 & 7.5 & $72 \%$ & $48 \%$ & 6.1 & $2.8 \%$ \\
\hline \multirow{2}{*}{$\begin{array}{c}9 \\
\text { TMC }\end{array}$} & Weekdays & 4321 & 0.7 & 3.6 & $92 \%$ & $79 \%$ & 8.2 & $1 \%$ \\
\hline & Weekends & 1310 & 2.8 & 18.5 & $43 \%$ & $30 \%$ & 5.4 & $3 \%$ \\
\hline
\end{tabular}


The weekend results from both sets of TMC codes are worse than the weekday results. Based on the speed distribution results in Table 4-24 and 4-25, the higher values of average vehicle counts in the speed ranges below $60 \mathrm{mph}$ in the weekends indicate a more severe congestion over weekends, compared to weekday traffic. There are two possible reasons for a higher congestion during weekends. First, recreational trips (i.e., trips to Busch Gardens in Williamsburg) during the summer cause congestion in westbound segment in the morning hours. Second, a decreased number of lanes from 4 to 2 lanes within a mile distance in the segment create significant backs up.

Weekend results with 8 TMC codes show a much better fit between INRIX and Bluetooth speeds, compared to 9 TMC results, as shown in Figure 4-6 and 4-7.

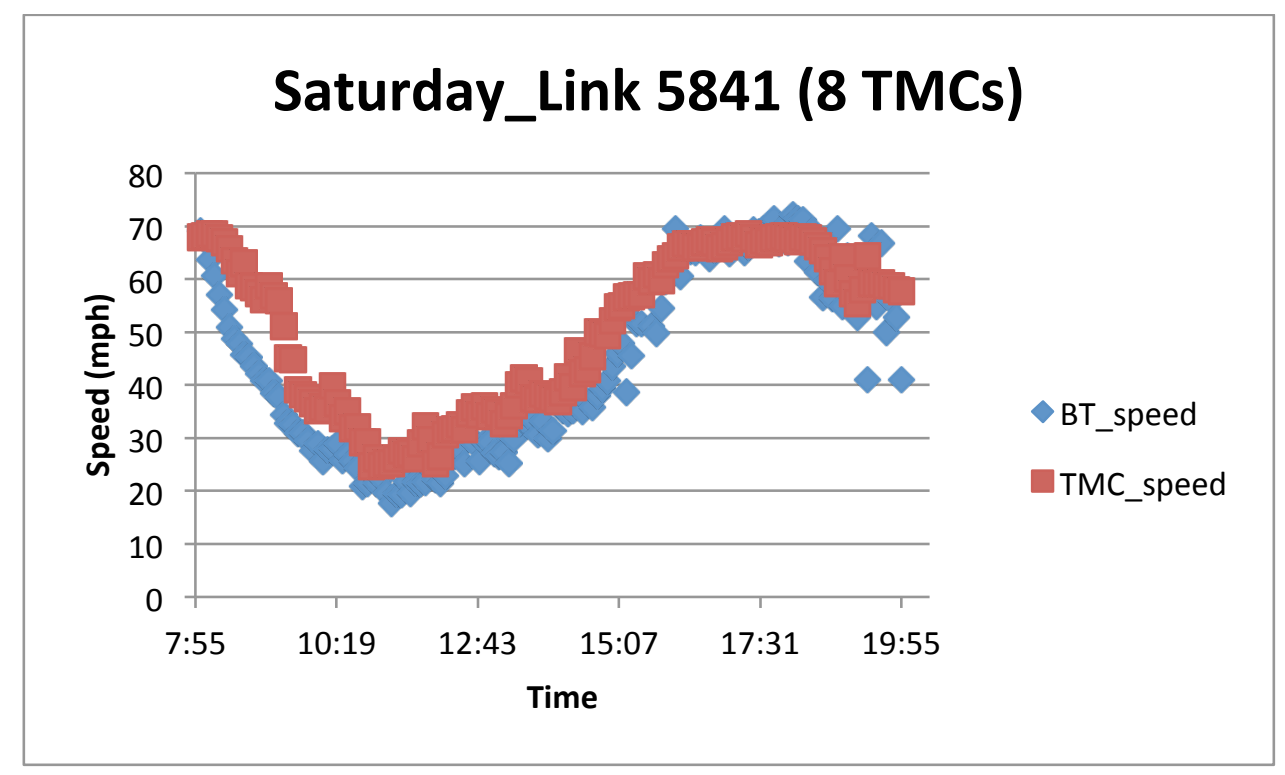

Figure 4-6 Link 5841, the average predicted speed from the entire weekend data compared with Bluetooth "Ground Truth" Data with 8 TMCs 


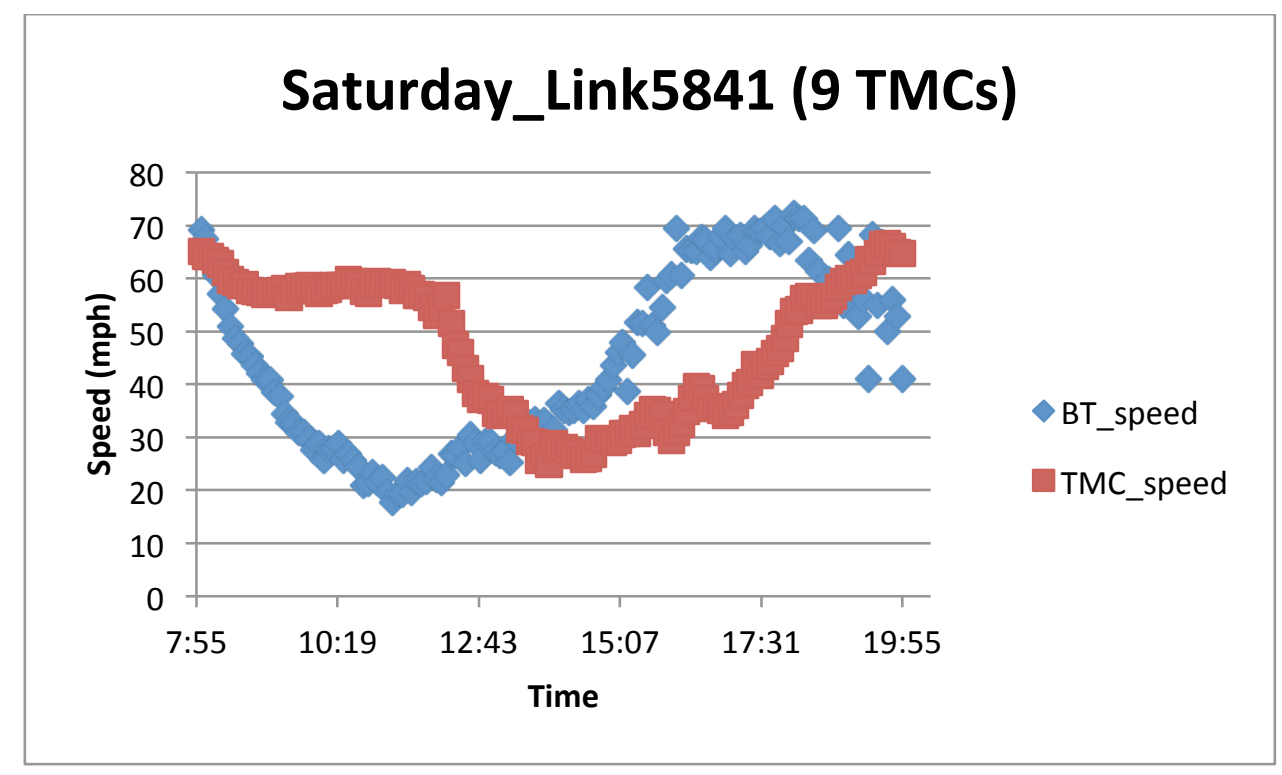

Figure 4-7 Link 5841, the average predicted speed from the entire weekend data compared with Bluetooth "Ground Truth" Data with 9 TMCs

With 9 TMCs, the INRIX speeds on weekends were greatly overestimated in the morning hours, as shown in Figure 4-7. This was likely due to the differences in the endpoints between the Bluetooth and INRIX data. These errors suggest that the TMC which taken out has shifted INRIX speeds to be higher than the true speeds. This makes sense since the link that was removed occurs after the transition from 4 lanes to 2 lanes, and speeds increase past the bottleneck, The results in Table 4-24 and 4-25 also indicate smaller bias in all speed ranges (except the 45-60 mph speed range) after taking out the TMC.

Especially in the range when vehicle speeds below $30 \mathrm{mph}$, the weekend speed bias was improved from $26.6 \mathrm{mph}$ to $10.48 \mathrm{mph}$, as shown in Table 4-24 and 4-25.

The speed error biases on each speed category suggest that errors increased as speeds decrease for both 8 TMCs and 9 TMCs, as shown in Table 4-24 and 4-25. With 8 TMCs, the weekend errors were notably improved. 
Table 4-24 Speed error distributions during operational periods on I-64, link 5841(8 TMCs)

\begin{tabular}{|c|c|c|c|c|c|c|}
\hline \multirow{2}{*}{$\begin{array}{c}\text { Speed Bin } \\
(\mathrm{mph})\end{array}$} & \multicolumn{3}{|c|}{ Weekdays (5 AM to 9PM) } & \multicolumn{3}{c|}{ Weekends (8 AM to 8 PM) } \\
\cline { 2 - 7 } & $\begin{array}{c}\text { Error } \\
\text { Bias } \\
(\mathrm{mph})\end{array}$ & $\begin{array}{c}\text { Absolute Average } \\
\text { Speed Error } \\
(\mathrm{mph})\end{array}$ & $\begin{array}{c}\text { Avg. } \\
\text { Interval } \\
\text { Count } \\
\text { per Day }\end{array}$ & $\begin{array}{c}\text { Error Bias } \\
(\mathrm{mph})\end{array}$ & $\begin{array}{c}\text { Absolute Average } \\
\text { Speed Error } \\
(\mathrm{mph})\end{array}$ & $\begin{array}{c}\text { Avg. } \\
\text { Interval } \\
\text { Count } \\
\text { per Day }\end{array}$ \\
\hline $0-30$ & 7.19 & 8.61 & 7.6 & 10.48 & 10.67 & 30.1 \\
\hline $30-45$ & 5.65 & 8.01 & 9.36 & 6.55 & 9.66 & 29.3 \\
\hline $45-60$ & 4.58 & 6.01 & 17.28 & 9.00 & 11.20 & 18.7 \\
\hline 60 or more & -0.53 & 2.63 & 138.12 & -0.08 & 3.04 & 51.5 \\
\hline
\end{tabular}

Table 4-25 Speed error distributions during operational periods on I-64, link 5841 (9 TMCs)

\begin{tabular}{|c|c|c|c|c|c|c|}
\hline \multirow[b]{2}{*}{$\begin{array}{l}\text { Speed Bin } \\
\text { (mph) }\end{array}$} & \multicolumn{3}{|c|}{ Weekdays (5 AM to 9PM) } & \multicolumn{3}{|c|}{ Weekends (8 AM to 8 PM) } \\
\hline & $\begin{array}{l}\text { Error } \\
\text { Bias } \\
(\mathrm{mph})\end{array}$ & $\begin{array}{l}\text { Absolute Average } \\
\text { Speed Error } \\
\text { (mph) }\end{array}$ & $\begin{array}{c}\text { Avg. } \\
\text { Interval } \\
\text { Count } \\
\text { per Day }\end{array}$ & $\begin{array}{l}\text { Error Bias } \\
\quad(\mathrm{mph})\end{array}$ & $\begin{array}{l}\text { Absolute Average } \\
\text { Speed Error } \\
\text { (mph) }\end{array}$ & $\begin{array}{c}\text { Avg. } \\
\text { Interval } \\
\text { Count } \\
\text { per Day }\end{array}$ \\
\hline $0-30$ & 10.32 & 11.86 & 7.1 & 26.60 & 26.85 & 30.2 \\
\hline $30-45$ & 6.87 & 9.63 & 8.2 & 11.90 & 18.09 & 29.5 \\
\hline $45-60$ & 4.80 & 6.81 & 15.7 & -5.63 & 16.15 & 18.8 \\
\hline 60 or more & -1.20 & 3.27 & 141.9 & -13.62 & 14.60 & 52.5 \\
\hline
\end{tabular}

\subsubsection{Link 5842 EB I 64 At Magruder, MP262 EB (u433) to EB I 64 At Pine}

\section{Chapel(u420)}

Link 5842 started from EB I-64 at Magruder to EB I-64 at Pine Chapel, and has bias errors lower than $5 \mathrm{mph}$ for both weekdays and weekends. Also, it has almost a hundred percent of raw travel times within error thresholds of $10 \mathrm{mph}$ and almost zero blank out signs during weekdays, as shown in Table 4-26. Overall, the travel time data on link 5842 have a good agreement with Bluetooth data. 
Table 4-26 Performance measures during operational periods on I-64, link 5842

\begin{tabular}{|c|c|c|c|c|c|c|c|}
\hline \multirow[t]{2}{*}{ Date } & \multirow{2}{*}{$\begin{array}{l}\text { Number } \\
\text { of } \\
\text { Intervals } \\
\text { Analyzed }\end{array}$} & \multirow{2}{*}{$\begin{array}{c}\text { Raw } \\
\text { Speed } \\
\text { Error Bias } \\
(\mathrm{mph})\end{array}$} & \multirow{2}{*}{$\begin{array}{l}\text { Raw Speed } \\
\text { Absolute } \\
\text { Error (mph) }\end{array}$} & \multicolumn{2}{|c|}{$\begin{array}{c}\text { \% of Raw Travel } \\
\text { Time within Error } \\
\text { Thresholds }\end{array}$} & \multirow[t]{2}{*}{$\begin{array}{l}\text { RMSE } \\
\text { (mph) }\end{array}$} & \multirow[t]{2}{*}{$\begin{array}{c}\text { Blank } \\
\text { Out (\%) }\end{array}$} \\
\hline & & & & $\pm 10 \mathrm{mph}$ & $\pm 5 \mathrm{mph}$ & & \\
\hline Weekdays & 4710 & -0.7 & 2.5 & $99 \%$ & $89 \%$ & 2.2 & $0.8 \%$ \\
\hline Weekends & 1393 & -1.0 & 3.0 & $98 \%$ & $83 \%$ & 3.4 & $2.9 \%$ \\
\hline
\end{tabular}

The speed error distribution in Table 4-27 shows that the majority speeds were over 60 mph.

Table 4-27 Speed error distributions during operational periods on I-64, link 5842

\begin{tabular}{|c|c|c|c|c|c|c|}
\hline \multirow[b]{2}{*}{$\begin{array}{l}\text { Speed Bin } \\
(\mathrm{mph})\end{array}$} & \multicolumn{3}{|c|}{ Weekdays (5 AM to 9PM) } & \multicolumn{3}{|c|}{ Weekends (8 AM to 8 PM) } \\
\hline & $\begin{array}{l}\text { Error } \\
\text { Bias } \\
(\mathrm{mph})\end{array}$ & $\begin{array}{l}\text { Absolute Average } \\
\text { Speed Error } \\
\text { (mph) }\end{array}$ & $\begin{array}{c}\text { Avg. } \\
\text { Interval } \\
\text { Count } \\
\text { per Day }\end{array}$ & $\begin{array}{l}\text { Error Bias } \\
\quad(\mathrm{mph})\end{array}$ & $\begin{array}{l}\text { Absolute Average } \\
\text { Speed Error } \\
\text { (mph) }\end{array}$ & $\begin{array}{c}\text { Avg. } \\
\text { Interval } \\
\text { Count } \\
\text { per Day }\end{array}$ \\
\hline $0-30$ & 4.82 & 4.82 & 0.1 & 0 & 0 & 0 \\
\hline $30-45$ & 7.19 & 7.19 & 0.2 & 2.37 & 2.37 & 0.7 \\
\hline $45-60$ & 5.02 & 6.64 & 2.2 & -1.21 & 4.68 & 5 \\
\hline 60 or more & -0.79 & 2.42 & 185.9 & -0.98 & 2.78 & 133.6 \\
\hline
\end{tabular}

\subsubsection{Link 5843 EB I 64 At Pine Chapel (u420) to EB I 64 At Magruder, MP262}

EB (u433)

Link 5843 started from EB I-64 at Pine Chapel to EB I-64 at Magruder and has bias errors lower than $5 \mathrm{mph}$ for both weekdays and weekends. Also, it has almost a hundred percent of raw travel times within the error thresholds of $10 \mathrm{mph}$, as shown in Table 4-28. Overall, the travel time data on link 5843 have a high degree of agreement with Bluetooth data. 
Table 4-28 Performance measures during operational periods on I-64, link 5843

\begin{tabular}{|c|c|c|c|c|c|c|c|}
\hline \multirow[t]{2}{*}{ Date } & \multirow{2}{*}{$\begin{array}{l}\text { Number } \\
\text { of } \\
\text { Intervals } \\
\text { Analyzed }\end{array}$} & \multirow{2}{*}{$\begin{array}{c}\text { Raw } \\
\text { Speed } \\
\text { Error Bias } \\
(\mathrm{mph})\end{array}$} & \multirow{2}{*}{$\begin{array}{l}\text { Raw Speed } \\
\text { Absolute } \\
\text { Error (mph) }\end{array}$} & \multicolumn{2}{|c|}{$\begin{array}{c}\% \text { of Raw Travel } \\
\text { Time within Error } \\
\text { Thresholds }\end{array}$} & \multirow[t]{2}{*}{$\begin{array}{l}\text { RMSE } \\
(\mathrm{mph})\end{array}$} & \multirow[t]{2}{*}{$\begin{array}{c}\text { Blank } \\
\text { Out (\%) }\end{array}$} \\
\hline & & & & $\pm 10 \mathrm{mph}$ & $\pm 5 \mathrm{mph}$ & & \\
\hline Weekdays & 4259 & -0.7 & 2.9 & $98 \%$ & $84 \%$ & 2.5 & $1.4 \%$ \\
\hline Weekends & 1305 & -2.2 & 3.7 & $97 \%$ & $73 \%$ & 4.0 & $4.0 \%$ \\
\hline
\end{tabular}

The majority speeds were over $60 \mathrm{mph}$, and the results suggest worse performance below $60 \mathrm{mph}$, as shown in Table 4-29. Speeds below $60 \mathrm{mph}$ occurred relatively infrequently, however.

Table 4-29 Speed error distributions during operational periods on I-64, link 5843

\begin{tabular}{|c|c|c|c|c|c|c|}
\hline \multirow{2}{*}{$\begin{array}{c}\text { Speed Bin } \\
(\mathrm{mph})\end{array}$} & \multicolumn{3}{|c|}{ Weekdays (5 AM to 9PM) } & \multicolumn{3}{c|}{ Weekends (8 AM to 8 PM) } \\
\cline { 2 - 7 } & $\begin{array}{c}\text { Error } \\
\text { Bias }\end{array}$ & $\begin{array}{c}\text { Absolute Average } \\
\text { Speed Error } \\
(\mathrm{mph})\end{array}$ & $\begin{array}{c}\text { Avg. } \\
\text { Interval } \\
\text { Count } \\
\text { per Day }\end{array}$ & $\begin{array}{c}\text { Error Bias } \\
(\mathrm{mph})\end{array}$ & $\begin{array}{c}\text { Absolute Average } \\
\text { Speed Error } \\
\text { (mph) }\end{array}$ & $\begin{array}{c}\text { Avg. } \\
\text { Interval } \\
\text { Count } \\
\text { per Day }\end{array}$ \\
\hline $0-30$ & 0.31 & 0.56 & 0.4 & 2.35 & 2.35 & 0.3 \\
\hline $30-45$ & 3.48 & 7.55 & 0.5 & 0.94 & 1.24 & 1.7 \\
\hline $45-60$ & 5.52 & 6.38 & 5.5 & 3.34 & 4.01 & 3.1 \\
\hline 60 or more & -0.94 & 2.77 & 164 & -2.40 & 3.60 & 125.4 \\
\hline
\end{tabular}

\subsubsection{Link 5846 EB I 64 At Pine Chapel (u420) to I-64W@ I-664 Pole \#270403} (u434)

The link 5846 started from EB I-64 at Pine Chapel to I-64 WB @ I-664 Pole \#270403 and has bias errors lower than $5 \mathrm{mph}$ for both weekdays and weekends. Also, it has over 90 percent of raw travel times within error thresholds of $10 \mathrm{mph}$. Overall, the link 5846 does not have any data quality issues based on the performance measures in Table 4-30. 
Table 4-30 Performance measures during operational periods on I-64, link 5846

\begin{tabular}{|c|c|c|c|c|c|c|c|}
\hline \multirow[t]{2}{*}{ Date } & \multirow{2}{*}{$\begin{array}{l}\text { Number } \\
\text { of } \\
\text { Intervals } \\
\text { Analyzed }\end{array}$} & \multirow{2}{*}{$\begin{array}{c}\text { Raw } \\
\text { Speed } \\
\text { Error Bias } \\
(\mathrm{mph})\end{array}$} & \multirow{2}{*}{$\begin{array}{l}\text { Raw Speed } \\
\text { Absolute } \\
\text { Error (mph) }\end{array}$} & \multicolumn{2}{|c|}{$\begin{array}{c}\text { \% of Raw Travel } \\
\text { Time within Error } \\
\text { Thresholds }\end{array}$} & \multirow[t]{2}{*}{$\begin{array}{l}\text { RMSE } \\
\text { (mph) }\end{array}$} & \multirow[t]{2}{*}{$\begin{array}{c}\text { Blank } \\
\text { Out (\%) }\end{array}$} \\
\hline & & & & $\pm 10 \mathrm{mph}$ & $\pm 5 \mathrm{mph}$ & & \\
\hline Weekdays & 4336 & 4.1 & 4.9 & $93 \%$ & $57 \%$ & 3.3 & $1.4 \%$ \\
\hline Weekends & 1277 & 4.0 & 4.8 & $92 \%$ & $59 \%$ & 6.0 & $4.6 \%$ \\
\hline
\end{tabular}

The speed error distribution in Table 4-31 suggests that weekday errors increase as speeds decrease, and the majority speeds were in 45-60 mph and over $60 \mathrm{mph}$ ranges.

Table 4-31 Speed error distributions during operational periods on I-64, link 5846

\begin{tabular}{|c|c|c|c|c|c|c|}
\hline \multirow[b]{2}{*}{$\begin{array}{l}\text { Speed Bin } \\
(\mathrm{mph})\end{array}$} & \multicolumn{3}{|c|}{ Weekdays (5 AM to 9PM) } & \multicolumn{3}{|c|}{ Weekends (8 AM to 8 PM) } \\
\hline & $\begin{array}{c}\text { Error } \\
\text { Bias } \\
(\mathrm{mph})\end{array}$ & $\begin{array}{l}\text { Absolute Average } \\
\text { Speed Error } \\
\text { (mph) }\end{array}$ & $\begin{array}{c}\text { Avg. } \\
\text { Interval } \\
\text { Count } \\
\text { per Day }\end{array}$ & $\begin{array}{l}\text { Error Bias } \\
\quad(\mathrm{mph})\end{array}$ & $\begin{array}{l}\text { Absolute Average } \\
\text { Speed Error } \\
\text { (mph) }\end{array}$ & $\begin{array}{c}\text { Avg. } \\
\text { Interval } \\
\text { Count } \\
\text { per Day }\end{array}$ \\
\hline $0-30$ & 9.06 & 9.41 & 0.9 & 3.79 & 4.39 & 2.9 \\
\hline $30-45$ & 5.81 & 11.47 & 1.3 & 3.84 & 3.84 & 0.4 \\
\hline $45-60$ & 7.08 & 7.48 & 64.2 & 6.84 & 7.36 & 36.9 \\
\hline 60 or more & 2.24 & 3.20 & 107.0 & 2.47 & 3.46 & 87.5 \\
\hline
\end{tabular}

\subsubsection{Link 5847 I-64W @ I-664 Pole \#270403 (u434) to EB I 64 At Pine Chapel} (u420)

Link 5847 started at I-64 WB at I-664 Pole \#270403 to EB I-64 at Pine Chapel and has a bias error a little over the speed requirement on weekdays. The weekday raw speeds were consistently underestimated as shown in Figure 4-8. There was no sign of congestion. A possible explanation for the error is the endpoint discrepancies. Not only there were discrepancies between BlueTOAD and TMC endpoints, but also the accuracy of BlueTOAD and TMC distances are questionable. Using VDOT GIS Integrator, mileposts and distances were estimated as shown in Table 4-20. The BlueTOAD and TMC 
distances from Integrator were $7.2 \%$ and $3.5 \%$ longer than its original lengths, respectively. If the BlueTOAD length were increased, the speed bias error will be decreased.

The bias switched from underprediction on weekdays to overpredition on weekends, as shown in Table 4-32, because of the increased INRIX speeds over weekends. The Bluetooth data were approximately at $60 \mathrm{mph}$ throughout the weeks during operational periods. Again, these differences may be attributable to inaccuracies in the definition of the Bluetooth reader locations.

Table 4-32 Performance measures during operational periods on I-64, link 5847

\begin{tabular}{|c|c|c|c|c|c|c|c|}
\hline \multirow{2}{*}{ Date } & $\begin{array}{c}\text { Number } \\
\text { of } \\
\text { Intervals } \\
\text { Analyzed }\end{array}$ & $\begin{array}{c}\text { Raw } \\
\text { Error Bias } \\
(\mathrm{mph})\end{array}$ & $\begin{array}{c}\text { Raw Speed } \\
\text { Absolute } \\
\text { Error }(\mathrm{mph})\end{array}$ & \multicolumn{2}{|c|}{$\begin{array}{c}\text { \% of Raw Travel } \\
\text { Time within Error } \\
\text { Threshold }\end{array}$} & \multirow{2}{*}{$\begin{array}{c}\text { RMSE } \\
(\mathrm{mph})\end{array}$} & $\begin{array}{c}\text { Blank } \\
\text { Out (\%) }\end{array}$ \\
\cline { 5 - 6 } Weekdays & 3951 & -5.5 & 5.7 & $89 \%$ & $46 \%$ & 3.6 & $1.8 \%$ \\
\hline Weekends & 1237 & 2.7 & 5.7 & $87 \%$ & $46 \%$ & 6.6 & $4.1 \%$ \\
\hline
\end{tabular}

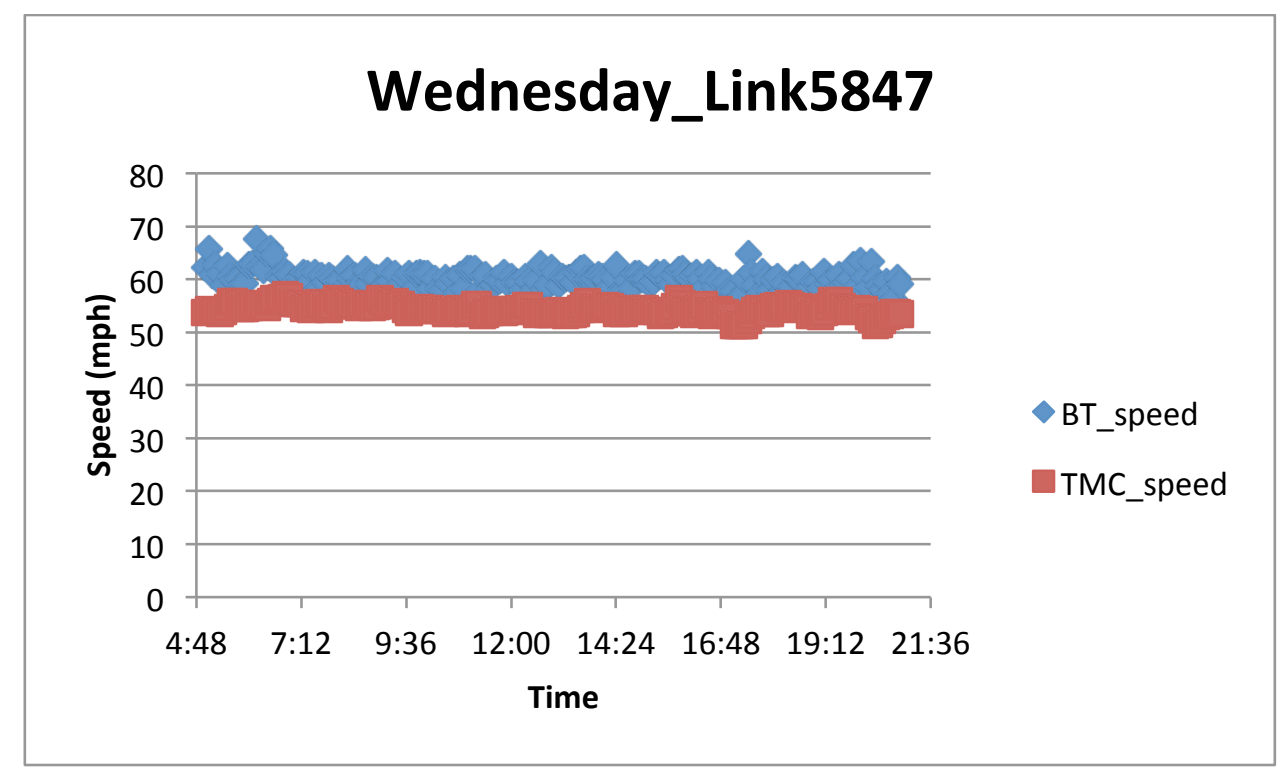

Figure 4-8 Link 5847, the average predicted speed from all the Wednesday data compared with Bluetooth "Ground Truth" Data 
The majority speeds were in high-speed ranges (i.e., 45-60 mph and over $60 \mathrm{mph}$ ), as shown in Table 4-33. Also, the speed error distribution suggests that errors increase as speeds increase.

Table 4-33 Speed error distributions during operational periods on I-64, link 5847

\begin{tabular}{|c|c|c|c|c|c|c|}
\hline \multirow{2}{*}{$\begin{array}{c}\text { Speed Bin } \\
(\mathrm{mph})\end{array}$} & \multicolumn{3}{|c|}{ Weekdays (5 AM to 9PM) } & \multicolumn{3}{c|}{ Weekends (8 AM to 8 PM) } \\
\cline { 2 - 7 } & $\begin{array}{c}\text { Error } \\
\text { Bias } \\
(\mathrm{mph})\end{array}$ & $\begin{array}{c}\text { Absolute Average } \\
\text { Speed Error } \\
(\mathrm{mph})\end{array}$ & $\begin{array}{c}\text { Avg. } \\
\text { Interval } \\
\text { Count } \\
\text { per Day }\end{array}$ & $\begin{array}{c}\text { Error Bias } \\
(\mathrm{mph})\end{array}$ & $\begin{array}{c}\text { Absolute Average } \\
\text { Speed Error } \\
(\mathrm{mph})\end{array}$ & $\begin{array}{c}\text { Avg. } \\
\text { Interval } \\
\text { Count } \\
\text { per Day }\end{array}$ \\
\hline $0-30$ & 0 & 0 & 0 & 2.47 & 2.47 & 0.1 \\
\hline $30-45$ & 1.21 & 1.23 & 0.16 & -0.04 & 1.43 & 1.3 \\
\hline $45-60$ & -2.96 & 3.42 & 85.84 & 5.47 & 7.10 & 54 \\
\hline 60 or more & -8.45 & 8.45 & 72.04 & 0.30 & 4.76 & 68.3 \\
\hline
\end{tabular}

\subsubsection{Link 5850 I-64 prior to I-264 Square I-Beam Sign Structure (u427) to Outer}

\section{Loop I 64 before I 264 interchange (u438)}

Link 5850 extended from I-64 EB at the I-264 Square I-Beam Sign Structure to I-64 EB before the I-264 Interchange. This link had bias errors lower than $5 \mathrm{mph}$ for both weekdays and weekends. The blank outs were over $10 \%$ during weekends, but only $3 \%$ during weekdays, as shown in Table 4-34. The main reason causing a high percentage of blank outs over weekends, especially on Sunday, was the insufficient numbers of TMCs reporting real-time travel time data. Since link5850 has 3 TMCs, a blank out will occur if only one of these TMCs does not report travel time data with a high confidence level score of " 30 ". The blank outs on weekends tend to occur more often between morning hours and late afternoon, 4 PM. There was one weekend day (Aug 4, 2012) that had no INRIX data available for 45 minutes. It is worth noting that this segment contains the 
Hampton Roads Bridge Tunnel, which may cause gaps in reporting GPS data used by INRIX to estimate travel times.

Table 4-34 Performance measures during operational periods on I-64, link 5850

\begin{tabular}{|c|c|c|c|c|c|c|c|}
\hline \multirow[t]{2}{*}{ Date } & \multirow{2}{*}{$\begin{array}{l}\text { Number } \\
\text { of } \\
\text { Intervals } \\
\text { Analyzed }\end{array}$} & \multirow{2}{*}{$\begin{array}{c}\text { Raw } \\
\text { Speed } \\
\text { Error Bias } \\
(\mathrm{mph})\end{array}$} & \multirow{2}{*}{$\begin{array}{c}\text { Raw Speed } \\
\text { Absolute } \\
\text { Error (mph) }\end{array}$} & \multicolumn{2}{|c|}{$\begin{array}{c}\% \text { of Raw Travel } \\
\text { Time within Error } \\
\text { Thresholds }\end{array}$} & \multirow[t]{2}{*}{$\begin{array}{l}\text { RMSE } \\
(\mathrm{mph})\end{array}$} & \multirow[t]{2}{*}{$\begin{array}{c}\text { Blank } \\
\text { Out (\%) }\end{array}$} \\
\hline & & & & $\pm 10 \mathrm{mph}$ & $\pm 5 \mathrm{mph}$ & & \\
\hline Weekday & 4331 & -4.0 & 5 & $86 \%$ & $58 \%$ & 3.4 & $3.0 \%$ \\
\hline Weekends & 1194 & -3.9 & 5.0 & $89 \%$ & $62 \%$ & 7.7 & $13.3 \%$ \\
\hline
\end{tabular}

The speed error distribution in Table 4-35 suggests underprediction in the high speed bins and overprediction in the low speed bins. The majority speeds were in 45-60 mph and over 60 mph ranges.

Table 4-35 Speed error distributions during operational periods on I-64, link 5850

\begin{tabular}{|c|c|c|c|c|c|c|}
\hline \multirow{2}{*}{$\begin{array}{c}\text { Speed Bin } \\
(\mathrm{mph})\end{array}$} & \multicolumn{3}{|c|}{ Weekdays (5 AM to 9PM) } & \multicolumn{3}{c|}{ Weekends (8 AM to 8 PM) } \\
\cline { 2 - 7 } & $\begin{array}{c}\text { Error } \\
\text { Bias }\end{array}$ & $\begin{array}{c}\text { Absolute Average } \\
\text { Speed Error } \\
(\mathrm{mph})\end{array}$ & $\begin{array}{c}\text { Avg. } \\
\text { Interval } \\
\text { Count } \\
\text { per Day }\end{array}$ & $\begin{array}{c}\text { Error Bias } \\
(\mathrm{mph})\end{array}$ & $\begin{array}{c}\text { Absolute Average } \\
\text { Speed Error } \\
\text { (mph) }\end{array}$ & $\begin{array}{c}\text { Avg. } \\
\text { Interval } \\
\text { Count } \\
\text { per Day }\end{array}$ \\
\hline $0-30$ & 8.00 & 8.20 & 2.4 & 3.99 & 3.99 & 1 \\
\hline $30-45$ & 3.67 & 8.78 & 5.2 & 3.33 & 3.33 & 0.1 \\
\hline $45-60$ & -1.48 & 5.49 & 30.3 & 0.73 & 3.85 & 9.6 \\
\hline 60 or more & -5.15 & 5.41 & 135.3 & -4.38 & 4.89 & 108.7 \\
\hline
\end{tabular}

\subsubsection{Link 5853 Outer Loop I 64 Between Greenbrier Pkwy and Indian River Rd (u426) to Outer Loop I 64 before I 264 interchange (u438)}

Link 5853 started from the Outer Loop of I-64 Between Greenbrier Pkwy and Indian River Rd to the Outer Loop of I-64 before I-264 Interchange. The segment had bias errors lower than $5 \mathrm{mph}$ for both weekdays and weekends. Also, it has a high percentage 
of raw travel times within error thresholds within10 mph, as shown in Table 4-36.

Overall, the results from link 5853 demonstrate a high degree of agreement. .

Table 4-36 Performance measures during operational periods on I-64, link 5853

\begin{tabular}{|c|c|c|c|c|c|c|c|}
\hline \multirow[t]{2}{*}{ Date } & \multirow{2}{*}{$\begin{array}{l}\text { Number } \\
\text { of } \\
\text { Intervals } \\
\text { Analyzed }\end{array}$} & \multirow{2}{*}{$\begin{array}{c}\text { Raw } \\
\text { Speed } \\
\text { Error Bias } \\
(\mathrm{mph})\end{array}$} & \multirow{2}{*}{$\begin{array}{c}\text { Raw Speed } \\
\text { Absolute } \\
\text { Error (mph) }\end{array}$} & \multicolumn{2}{|c|}{$\begin{array}{c}\% \text { of Raw Travel } \\
\text { Time within Error } \\
\text { Thresholds }\end{array}$} & \multirow[t]{2}{*}{$\begin{array}{l}\text { RMSE } \\
(\mathrm{mph})\end{array}$} & \multirow[t]{2}{*}{$\begin{array}{c}\text { Blank } \\
\text { Out (\%) }\end{array}$} \\
\hline & & & & $\pm 10 \mathrm{mph}$ & $\pm 5 \mathrm{mph}$ & & \\
\hline Weekday & 4612 & 2.9 & 3. & $95 \%$ & $75 \%$ & 2.2 & $2.6 \%$ \\
\hline Weekends & 1325 & 2.6 & 3.2 & $98 \%$ & $80 \%$ & 5.3 & $5.5 \%$ \\
\hline
\end{tabular}

The speed error distribution in Table 4-37 suggests the highest errors in the speed range of 30-45 mph during weekday operation. Also, the results table suggests more congestion in the weekday. The majority speeds were in 45-60 mph and over $60 \mathrm{mph}$ ranges.

Table 4-37 Speed error distributions during operational periods on I-64, link 5853

\begin{tabular}{|c|c|c|c|c|c|c|}
\hline \multirow[b]{2}{*}{$\begin{array}{l}\text { Speed Bin } \\
\quad(\mathrm{mph})\end{array}$} & \multicolumn{3}{|c|}{ Weekdays (5 AM to 9PM) } & \multicolumn{3}{|c|}{ Weekends (8 AM to 8 PM) } \\
\hline & $\begin{array}{l}\text { Error } \\
\text { Bias } \\
(\mathrm{mph})\end{array}$ & $\begin{array}{l}\text { Absolute Average } \\
\text { Speed Error } \\
(\mathrm{mph})\end{array}$ & $\begin{array}{l}\text { Avg. } \\
\text { Interval } \\
\text { Count } \\
\text { per Day }\end{array}$ & $\begin{array}{l}\text { Error Bias } \\
\quad(\mathrm{mph})\end{array}$ & $\begin{array}{l}\text { Absolute Average } \\
\text { Speed Error } \\
\text { (mph) }\end{array}$ & $\begin{array}{c}\text { Avg. } \\
\text { Interval } \\
\text { Count } \\
\text { per Day }\end{array}$ \\
\hline $0-30$ & 2.84 & 4.56 & 1.2 & 0 & 0 & 0 \\
\hline $30-45$ & 8.08 & 9.94 & 7.9 & 0 & 0 & 0 \\
\hline $45-60$ & 3.57 & 4.44 & 120.5 & 4.4 & 4.4 & 48.6 \\
\hline 60 or more & 0.79 & 1.97 & 54.8 & 1.6 & 2.5 & 83.9 \\
\hline
\end{tabular}

\subsubsection{Overall Performance on the I-64 Corridor}

There were total of 8 links evaluated on I-64 corridor. All links satisfied the business rule requirements, except link 5841 and link 5847.

The overall performance of all 8 links on I-64 corridor between July 16 and August 19, provided satisfactory results, which passed the business rule requirements, 
and the blank outs were small, as shown in Table 4-38. Note that this table averages the performance measures of all the segments with the same weight for each day.

Table 4-38 Overall performance measures on I-64 Corridor

\begin{tabular}{|c|c|}
\hline ERROR METRIC & MEASURE \\
\hline Speed error bias - raw travel time $(\mathrm{mph})$ & -0.2 \\
\hline Average absolute speed error - raw travel time $(\mathrm{mph})$ & 4.4 \\
\hline$\%$ Within $\pm 10 \mathrm{mph}$ (raw travel time) & $92 \%$ \\
\hline$\%$ Within $\pm 5 \mathrm{mph}$ (raw travel time) & $68 \%$ \\
\hline RMSE (mph) & $2.6 \%$ \\
\hline$\%$ Of operational period blanked out
\end{tabular}

The lessons learned from data quality evaluation on I-64 corridor are listed below.

The validity and completeness measures of data quality on I-64 corridor are high because of a low percentage of blank outs (i.e., 2.6\%) and a high percentage of speed error within thresholds of $10 \mathrm{mph}$ (i.e., 92\%).

Based on the analysis results, the travel time data from sites with a short and precise distance from both sources seem to have a good agreement with Bluetooth data. Using link 5842 and link 5843 as examples, each BlueTOAD distance is 1.8 miles. The distances from these two links are almost the same with the estimated distances from Integrator. As a result, these links have low speed error biases (i.e., $-0.7 \mathrm{mph}$ weekdays and less than $-2.2 \mathrm{mph}$ weekends) and high percentages of raw travel times within error thresholds of $10 \mathrm{mph}$ (i.e., over 97\%).

Based on the analysis results, the raw travel time results show a good agreement with Bluetooth data when the benchmark is reliable. For the sites with poor 
agreement, the benchmarks were unreliable. Link 5841 during weekends is a good example.

\subsubsection{I-264 Corridor, Hampton Roads Area}

Both links 5856 and 5857 on I-264 corridor had INRIX data that disagree with the Bluetooth data. Similar to link 5841, the TMC codes on links 5856 and 5857 were reduced from 3 TMCs to 2 TMCs. The purpose of reducing the TMC distance to be closer to the BlueTOAD distance and allowing both sources to focus on a similar location is to improve the performance on these links. However, there was not much improvement on speed bias in each speed category. The results of each link from both 2 TMCs and 3 TMCs are summarized and discussed below.

\subsubsection{Link 5856 WB I 264 before Witchduck Rd (u439) to WB I 264 before Independence Blvd (u444)}

Link5856 started from WB I-264 before Witchduck Rd to WB I-264 before Independence Blvd. With $2 \mathrm{TMCs}$, the bias error and the average absolute error failed to meet the business rules requirements. The blank outs on weekends were over $10 \%$. The agreement between INRIX and Bluetooth data for both weekdays and weekends was low, as shown Table 4-39. The raw speeds on link 5856 were consistently underestimated, and the Bluetooth speeds were surprisingly high (approximately $80 \mathrm{mph}$ ), as shown in Figure 4-9. This extremely high speed of Bluetooth suggests problems with how TrafficCast set 
their validation segments. The high percentages of blank outs over weekends were much higher than the blank outs on weekdays, as shown in Table 4-39.

These weekend blank outs, especially on Sunday, were due to the insufficient numbers of TMCs reporting travel time data. Since link5856 has only a few TMCs, a blank out will occur if any of these TMCs does not report real-time travel time data with a high confidence level score of " 30 ".

Table 4-39 Performance measures during operational periods on I-264, link 5856

\begin{tabular}{|c|c|c|c|c|c|c|c|c|}
\hline & \multirow[t]{2}{*}{ Date } & \multirow{2}{*}{$\begin{array}{l}\text { Number } \\
\text { of } \\
\text { Intervals } \\
\text { Analyzed }\end{array}$} & \multirow{2}{*}{$\begin{array}{l}\text { Raw } \\
\text { Speed } \\
\text { Error } \\
\text { Bias } \\
(\mathrm{mph})\end{array}$} & \multirow{2}{*}{$\begin{array}{c}\text { Raw } \\
\text { Speed } \\
\text { Absolute } \\
\text { Error } \\
\text { (mph) }\end{array}$} & \multicolumn{2}{|c|}{$\begin{array}{c}\% \text { of Raw Travel } \\
\text { Time within Error } \\
\text { Thresholds }\end{array}$} & \multirow{2}{*}{$\begin{array}{l}\text { RMSE } \\
(\mathrm{mph})\end{array}$} & \multirow{2}{*}{$\begin{array}{c}\text { Blank } \\
\text { Out (\%) }\end{array}$} \\
\hline & & & & & $\begin{array}{l} \pm 10 \\
\mathrm{mph}\end{array}$ & $\begin{array}{l} \pm 5 \\
\mathrm{mph}\end{array}$ & & \\
\hline \multirow{2}{*}{$\begin{array}{c}2 \\
\text { TMC }\end{array}$} & Weekdays & 4332 & -12.8 & 12.9 & $32 \%$ & $8 \%$ & 8.0 & $3.6 \%$ \\
\hline & Weekends & 1270 & -13.5 & 13.6 & $28 \%$ & $8 \%$ & 14.2 & $15.0 \%$ \\
\hline \multirow{2}{*}{$\begin{array}{c}3 \\
\text { TMC }\end{array}$} & Weekdays & 4306 & -12.4 & 12.6 & $34 \%$ & $9 \%$ & 13.8 & $3 \%$ \\
\hline & Weekends & 1256 & -13.3 & 13.3 & $30 \%$ & $8 \%$ & 7.7 & $15 \%$ \\
\hline
\end{tabular}

The speed error distribution in Table 4-40 and 4-41 suggests that errors increase as Bluetooth speeds increase, and the majority of speeds were over $60 \mathrm{mph}$. Both tables also indicate the accuracy issue in the over $60 \mathrm{mph}$ speed bin, which is likely attributable to problems with the benchmark data. 
Table 4-40 Speed error distributions during operational periods on I-264, link 5856 (2 TMCs)

\begin{tabular}{|c|c|c|c|c|c|c|}
\hline \multirow{2}{*}{$\begin{array}{c}\text { Speed Bin } \\
(\mathrm{mph})\end{array}$} & \multicolumn{3}{|c|}{ Weekdays (5 AM to 9PM) } & \multicolumn{3}{c|}{ Weekends (8 AM to 8 PM) } \\
\cline { 2 - 7 } & $\begin{array}{c}\text { Error } \\
\text { Bias } \\
(\mathrm{mph})\end{array}$ & $\begin{array}{c}\text { Absolute Average } \\
\text { Speed Error } \\
(\mathrm{mph})\end{array}$ & $\begin{array}{c}\text { Avg. } \\
\text { Interval } \\
\text { Count } \\
\text { per Day }\end{array}$ & $\begin{array}{c}\text { Error Bias } \\
(\mathrm{mph})\end{array}$ & $\begin{array}{c}\text { Absolute Average } \\
\text { Speed Error } \\
(\mathrm{mph})\end{array}$ & $\begin{array}{c}\text { Avg. } \\
\text { Interval } \\
\text { Count } \\
\text { per Day }\end{array}$ \\
\hline $0-30$ & 1.77 & 1.77 & 0.1 & 0 & 0 & 0 \\
\hline $30-45$ & -1.89 & 3.05 & 0.4 & 0 & 0 & 0 \\
\hline $45-60$ & -5.41 & 7.92 & 1.8 & -4.0 & 4.7 & 0.4 \\
\hline 60 or more & -12.92 & 12.99 & 171.0 & -13.6 & 13.6 & 126.6 \\
\hline
\end{tabular}

Table 4-41 Speed error distributions during operational periods on I-264, link 5856 (3 TMCs)

\begin{tabular}{|c|c|c|c|c|c|c|}
\hline \multirow[b]{2}{*}{$\begin{array}{l}\text { Speed Bin } \\
\text { (mph) }\end{array}$} & \multicolumn{3}{|c|}{ Weekdays (5 AM to 9PM) } & \multicolumn{3}{|c|}{ Weekends (8 AM to 8 PM) } \\
\hline & $\begin{array}{l}\text { Error } \\
\text { Bias } \\
(\mathrm{mph})\end{array}$ & $\begin{array}{l}\text { Absolute Average } \\
\text { Speed Error } \\
\text { (mph) }\end{array}$ & $\begin{array}{c}\text { Avg. } \\
\text { Interval } \\
\text { Count } \\
\text { per Day }\end{array}$ & $\begin{array}{l}\text { Error Bias } \\
\quad(\mathrm{mph})\end{array}$ & $\begin{array}{l}\text { Absolute Average } \\
\text { Speed Error } \\
\text { (mph) }\end{array}$ & $\begin{array}{c}\text { Avg. } \\
\text { Interval } \\
\text { Count } \\
\text { per Day }\end{array}$ \\
\hline $0-30$ & 1.58 & 1.58 & 0.12 & 0 & 0 & 0 \\
\hline $30-45$ & -1.32 & 3.12 & 0.36 & 0 & 0 & 0 \\
\hline $45-60$ & -6.58 & 9.11 & 1.84 & -4.18 & 4.97 & 0.4 \\
\hline 60 or more & -12.60 & 12.66 & 169.92 & -13.33 & 13.36 & 125.2 \\
\hline
\end{tabular}

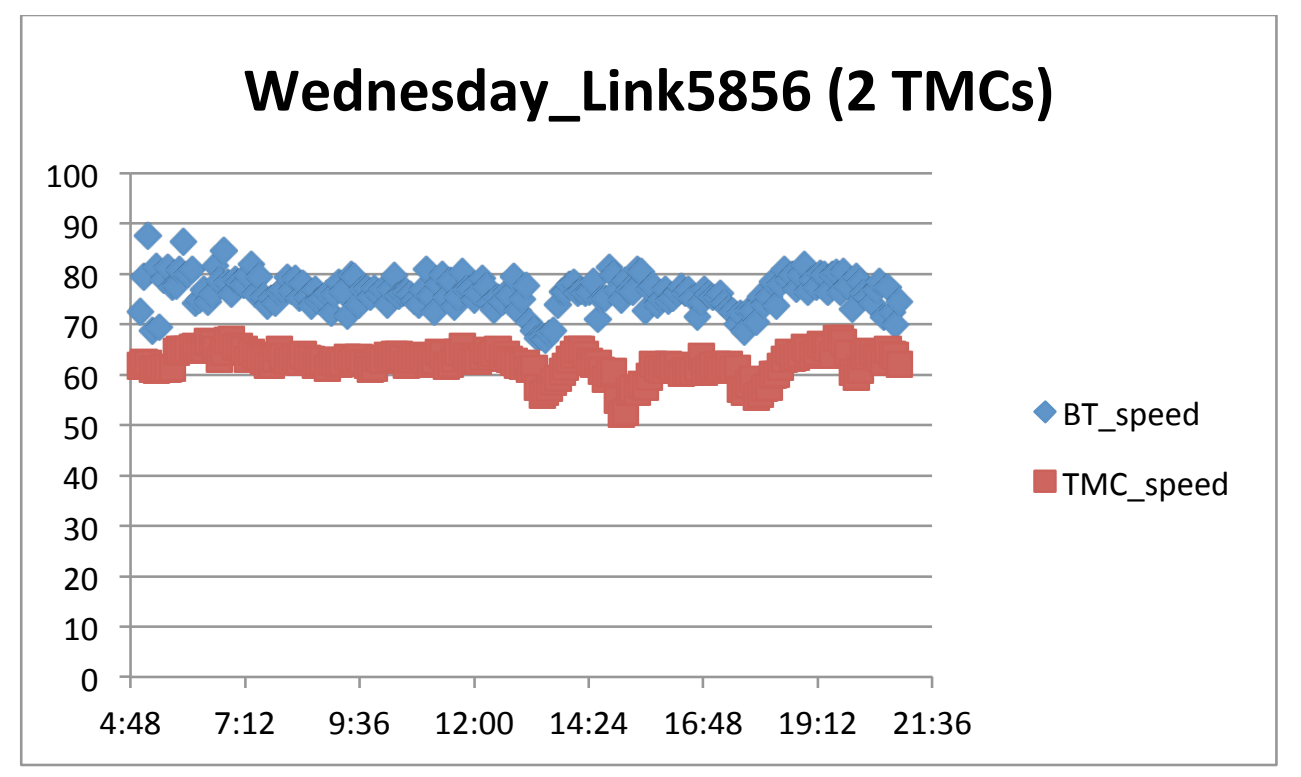

Figure 4-9 Link 5856, the average predicted speed from all the Wednesday data compared with Bluetooth "Ground Truth" Data with 2 TMCs 


\subsubsection{Link 5857 WB I 264 before Independence Blvd (u444) to WB I 264 before Witchduck Rd (u439)}

Link 5857 started from WB I-264 before Independence to WB I-264 before Witchduck Rd. The speed error biases on weekdays and weekends failed the VDOT requirements. The blank outs on weekends were over $10 \%$, as shown in Table 4-42. The high percentages of blank outs over weekends caused by the insufficient of TMCs travel time data, similar to link 5856.

Table 4-42 Performance measures during operational periods on I-264, link 5857

\begin{tabular}{|c|c|c|c|c|c|c|c|c|}
\hline & \multirow[t]{2}{*}{ Date } & \multirow{2}{*}{$\begin{array}{l}\text { Number } \\
\text { of } \\
\text { Intervals } \\
\text { Analyzed }\end{array}$} & \multirow{2}{*}{$\begin{array}{c}\text { Raw } \\
\text { Speed } \\
\text { Error } \\
\text { Bias } \\
(\mathrm{mph}) \\
\end{array}$} & \multirow{2}{*}{$\begin{array}{c}\text { Raw } \\
\text { Speed } \\
\text { Absolute } \\
\text { Error } \\
(\mathrm{mph}) \\
\end{array}$} & \multicolumn{2}{|c|}{$\begin{array}{c}\% \text { of Raw Travel } \\
\text { Time within Error } \\
\text { Thresholds }\end{array}$} & \multirow{2}{*}{$\begin{array}{l}\text { RMSE } \\
(\mathrm{mph})\end{array}$} & \multirow{2}{*}{$\begin{array}{c}\text { Blank } \\
\text { Out (\%) }\end{array}$} \\
\hline & & & & & $\begin{array}{l} \pm 10 \\
\mathrm{mph}\end{array}$ & $\begin{array}{c} \pm 5 \\
\mathrm{mph}\end{array}$ & & \\
\hline \multirow{2}{*}{$\begin{array}{c}2 \\
\text { TMC }\end{array}$} & Weekdays & 4703 & 7.7 & 8.0 & $75 \%$ & $20 \%$ & 4.6 & $1.8 \%$ \\
\hline & Weekends & 1353 & 7.7 & 7.8 & $75 \%$ & $22 \%$ & 8.8 & $11.5 \%$ \\
\hline \multirow{2}{*}{$\begin{array}{c}3 \\
\text { TMC }\end{array}$} & Weekdays & 4698 & 7.9 & 8.6 & $72 \%$ & $17 \%$ & 9.9 & $1 \%$ \\
\hline & Weekends & 1338 & 7.8 & 7.9 & $75 \%$ & $19 \%$ & 4.6 & $12 \%$ \\
\hline
\end{tabular}

Raw speeds on link 5857 were consistently overestimated, and the Bluetooth speeds were approximately $55 \mathrm{mph}$, as shown in Figure 4-10. The relatively low speeds of Bluetooth data in the westbound direction as compared to the eastbound speed on link 5856 emphasize problems about the validation of the Bluetooth data. The errors occur in speed ranges lower than $60 \mathrm{mph}$, as shown in Table 4-43 and Table 4-44. 
Table 4-43 Speed error distributions during operational periods on I-264, link 5857 (2 TMCs)

\begin{tabular}{|c|c|c|c|c|c|c|}
\hline \multirow{2}{*}{$\begin{array}{c}\text { Speed Bin } \\
(\mathrm{mph})\end{array}$} & \multicolumn{3}{|c|}{ Weekdays (5 AM to 9PM) } & \multicolumn{3}{c|}{ Weekends (8 AM to 8 PM) } \\
\cline { 2 - 7 } & $\begin{array}{c}\text { Error } \\
\text { Bias } \\
(\mathrm{mph})\end{array}$ & $\begin{array}{c}\text { Absolute Average } \\
\text { Speed Error } \\
(\mathrm{mph})\end{array}$ & $\begin{array}{c}\text { Avg. } \\
\text { Interval } \\
\text { Count } \\
\text { per Day }\end{array}$ & $\begin{array}{c}\text { Error Bias } \\
\text { (mph) }\end{array}$ & $\begin{array}{c}\text { Absolute Average } \\
\text { Speed Error } \\
\text { (mph) }\end{array}$ & $\begin{array}{c}\text { Avg. } \\
\text { Interval } \\
\text { Count } \\
\text { per Day }\end{array}$ \\
\hline $0-30$ & 6.63 & 7.07 & 3.76 & 0 & 0 & 0 \\
\hline $30-45$ & 10.42 & 12.47 & 3.12 & 5.47 & 5.48 & 1.3 \\
\hline $45-60$ & 7.96 & 8.10 & 172.44 & 8.09 & 8.13 & 124 \\
\hline 60 or more & 2.47 & 3.06 & 8.8 & 2.35 & 3.04 & 10 \\
\hline
\end{tabular}

Table 4-44 Speed error distributions during operational periods on I-264, link 5857 (3 TMCs)

\begin{tabular}{|c|c|c|c|c|c|c|}
\hline \multirow[b]{2}{*}{$\begin{array}{l}\text { Speed Bin } \\
\quad(\mathrm{mph})\end{array}$} & \multicolumn{3}{|c|}{ Weekdays (5 AM to 9PM) } & \multicolumn{3}{|c|}{ Weekends (8 AM to $8 \mathrm{PM})$} \\
\hline & $\begin{array}{l}\text { Error } \\
\text { Bias } \\
(\mathrm{mph})\end{array}$ & $\begin{array}{l}\text { Absolute Average } \\
\text { Speed Error } \\
\text { (mph) }\end{array}$ & $\begin{array}{c}\text { Avg. } \\
\text { Interval } \\
\text { Count } \\
\text { per Day }\end{array}$ & $\begin{array}{l}\text { Error Bias } \\
\quad(\mathrm{mph})\end{array}$ & $\begin{array}{l}\text { Absolute Average } \\
\text { Speed Error } \\
\text { (mph) }\end{array}$ & $\begin{array}{c}\text { Avg. } \\
\text { Interval } \\
\text { Count } \\
\text { per Day }\end{array}$ \\
\hline $0-30$ & 20.64 & 21.12 & 3.76 & 0 & 0 & 0 \\
\hline $30-45$ & 13.87 & 16.23 & 3.12 & 5.9 & 5.9 & 1.3 \\
\hline $45-60$ & 8.00 & 8.50 & 172.28 & 8.2 & 8.3 & 122.5 \\
\hline 60 or more & 0.83 & 3.43 & 8.76 & 2.5 & 3 & 10 \\
\hline
\end{tabular}

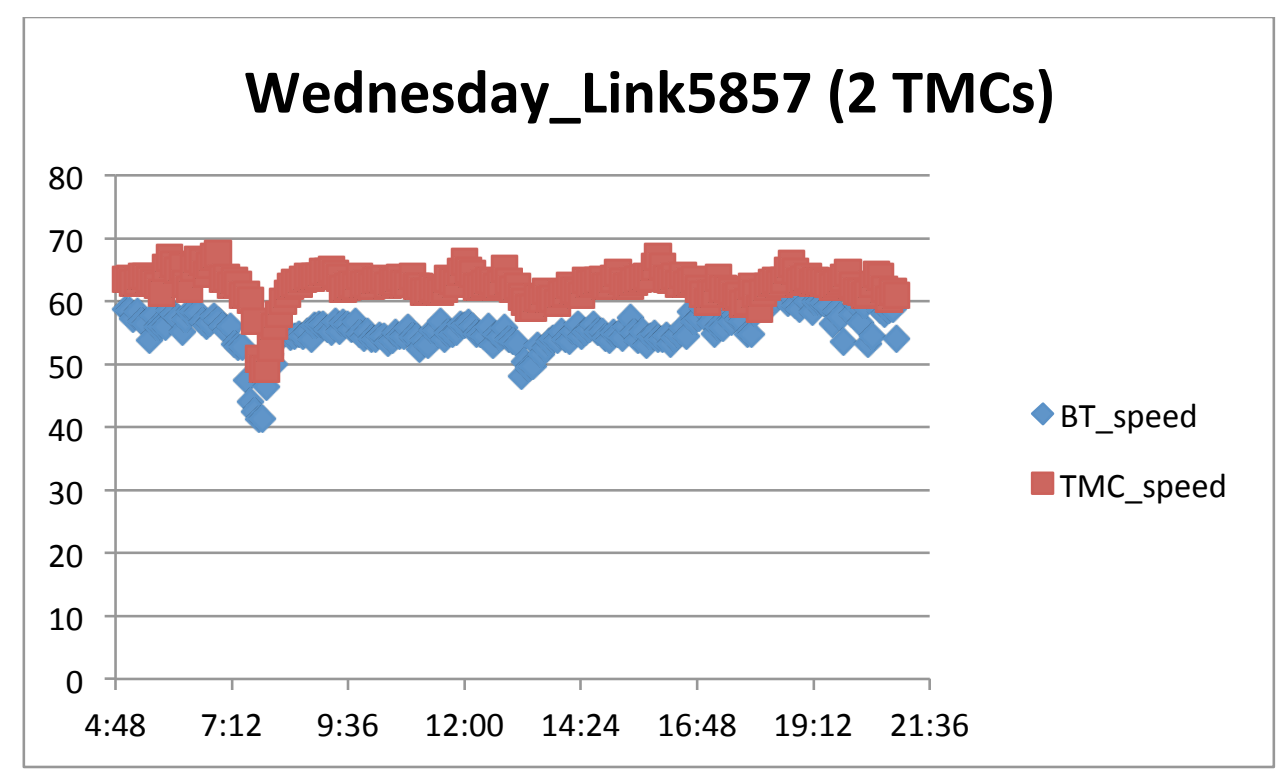

Figure 4-10 Link 5857, the average predicted speed from all the Wednesday data compared with Bluetooth "Ground Truth" Data with 2 TMCs 


\subsubsection{Overall Performance on I-264 Corridor}

Both links have BlueTOAD detectors at the same locations. The direction of travel for link 5856 is eastbound, and for link 5857 is westbound. The speed error bias in the overall performance table, shown in Table $4-45$, is lower than $5 \mathrm{mph}$ is only because the errors on both links have cancelled each other. Both links failed the business rules requirements.

Table 4-45 Overall performance measures on I-264 Corridor

\begin{tabular}{|c|c|}
\hline ERROR METRIC & MEASURE \\
\hline Speed error bias - raw travel time $(\mathrm{mph})$ & -2.65 \\
\hline Average absolute speed error - raw travel time $(\mathrm{mph})$ & 10.5 \\
\hline$\%$ within $\pm 10 \mathrm{mph}$ (raw travel time) & $53 \%$ \\
\hline$\%$ within $\pm 5 \mathrm{mph}$ (raw travel time) & $14 \%$ \\
\hline RMSE (mph) & 11.5 \\
\hline$\%$ of operational period blanked out & $5.7 \%$ \\
\hline
\end{tabular}

The following factors can be contributing factors for INRIX and Bluetooth Disagreement of the links on I-264 corridor.

Distance discrepancy - By reducing TMC codes to 2 TMCs, the TMC lengths for both links are still approximately 50\% longer than BlueToad distances. Moreover, none of the links can fully cover Bluetooth distances.

Disagreement in distances - As discussed in the overall performance on I-64 corridor, the distance disagreement may generate an error in data quality results. The average BlueTOAD speeds for link 5856 were extremely high (i.e., approximately $80 \mathrm{mph}$ ) while the average BlueTOAD speeds for link 5857 were 
relatively low (i.e., approximately $55 \mathrm{mph}$ ). The BlueTOAD locations for both links have been double check to be correct, based on its latitudes and longitudes. However, further investigation is needed because these extreme speeds indicate abnormality. TrafficCast has not been able to confirm the locations of the readers in time for the completion of this study.

\subsubsection{Overall Data Quality Performance Across Sites}

Using the three performance measures (i.e., accuracy, validity, and availability), the overall data quality performance seems to provide satisfactory results. The majority (12 out of 18 segments) of the evaluated segments are within the speed bias requirements, as shown in Figure 4-11. This generally indicates the accuracy of travel time data quality to be acceptable relative to the business rules requirements. Several potential explanations were identified that could explain why 6 segments violated the bias requirements:

- Distance discrepancies between the INRIX and Bluetooth data,

- Characteristics of Bluetooth when the evaluation segment is longer than 15 miles,

- Segment geometry (i.e., a major intersection within the segment or HOV facility)

- Disagreement in reported distances between the provided Bluetooth distances and the estimated Bluetooth distances using Integrator based on the latitude and longitude information.

- Severity of congestion (i.e., morning peak hours are less severe than evening peak hours). Therefore, the data quality of segments associated with evening peak hours may cause higher errors. 


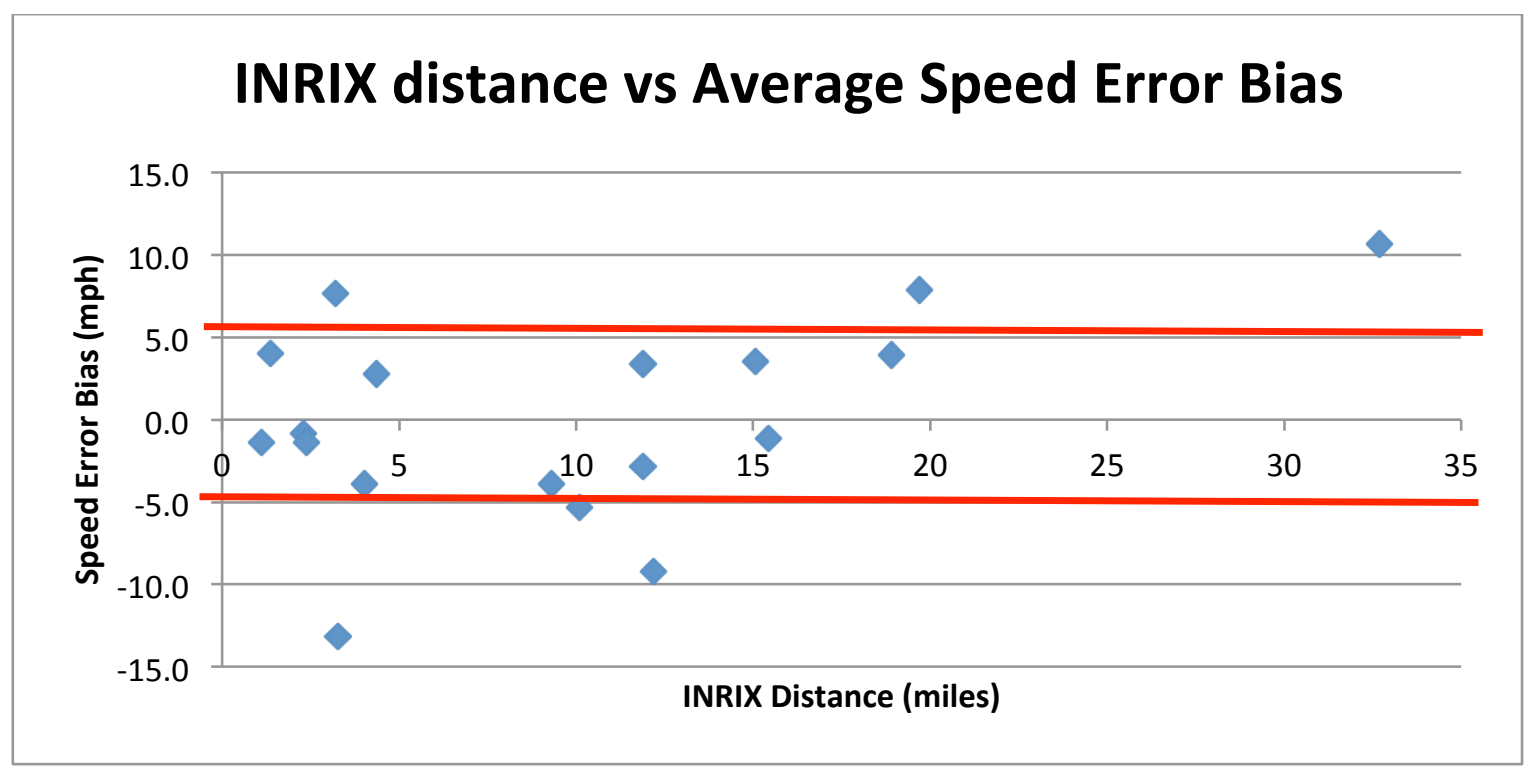

Figure 4-11 INRIX distances compared to average speed error biases of all evaluated segments

The majority (13 out of 18 segments) of the evaluated segments have over 80 percent of speed bias within $10 \mathrm{mph}$ threshold, as shown in Figure 4-12. This indicates that the INRIX travel times could be counted on 80 percent of the time to provide speeds within $10 \mathrm{mph}$ of the Bluetooth speeds. Again, discrepancies in the Bluetooth data could be attributable for some of these differences. 


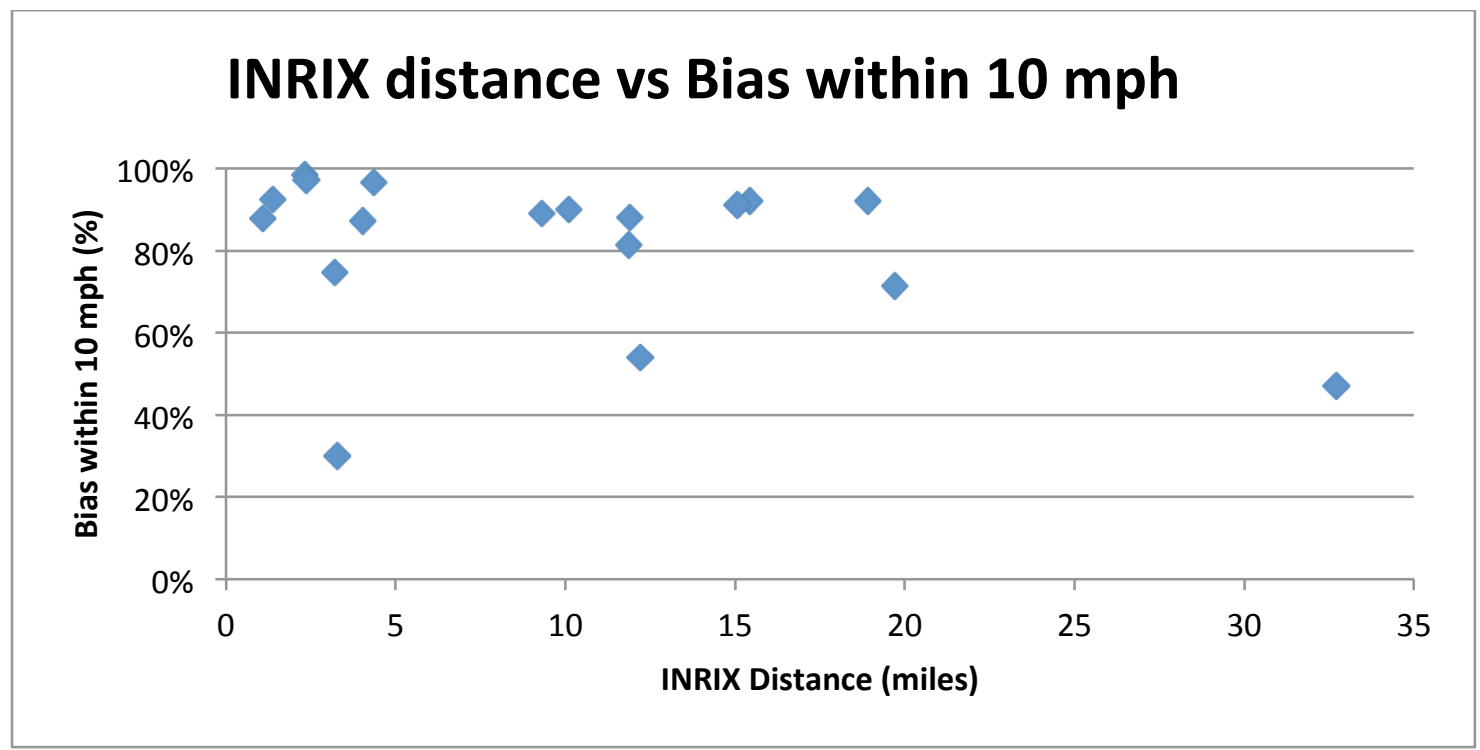

Figure 4-12 INRIX distances compared to percent of speed bias within $10 \mathrm{mph}$ threshold

The INRIX data proved to have a high degree of completeness. The business rules require a minimum availability of travel time information to be 90 percent. All evaluated segments provided over 90 percent of travel time availability, as shown in Figure 4-13. Note that the travel time availability in the y-axis starts from $90(\%)$, not $0(\%)$. 


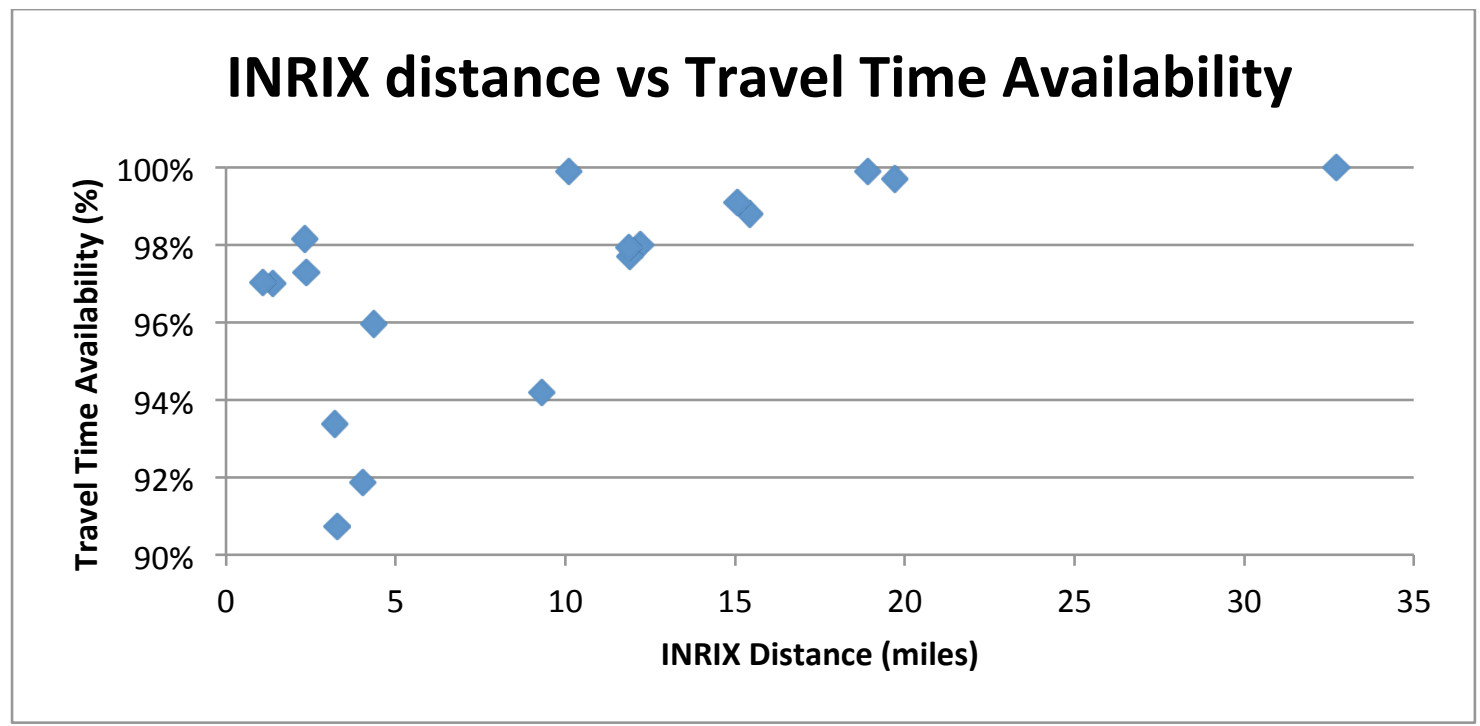

Figure 4-13 INRIX distances compared to INRIX travel times availability of all evaluated segments. (Note: Availability $(\%)=100$ - Percent of blank out)

\subsection{DIVERSION ANALYSIS}

After conducting the preliminary screen on volume and validating the volume data with TMS data, the NB 14 and NB 18 segments were selected for diversion analysis. To observe the impacts of travel time information, diversion analysis was conducted on data before and after posting travel times. The available before period data (10/26/11 $12 / 04 / 11)$ is significantly shorter than the after period data $(12 / 05 / 11-03 / 31 / 12)$, as shown in Table 4-46. Since this study uses 5-minute interval data, the total theoretical count of data points in Table 4-46 is 192 data points per weekday (5 AM to 9 PM) and 145 data points per weekend day ( $8 \mathrm{AM}$ to $8 \mathrm{PM})$. It is worth noting that each segment during before period has only one weekday day of Wednesday data (November 2 for NB14 and November 16 for NB18). 
Table 4-46. Theoretical number of data points during before and after periods on NB14 and NB18 segments

\begin{tabular}{|c|c|c|c|c|c|c|}
\hline & \multicolumn{3}{|c|}{ Before Period } & \multicolumn{3}{c|}{ After periods } \\
\hline Segment & Weekdays & Weekends & Data points & Weekdays & Weekends & Data points \\
\hline NB14 & 10 & 5 & 2645 & 68 & 26 & 16826 \\
\hline NB18 & 11 & 6 & 2982 & 77 & 31 & 19279 \\
\hline
\end{tabular}

Since diversion occurs due to several factors, it is necessary to make some assumptions:

- Diversion in this study refers to vehicles leaving the mainline, regardless of their purpose and action after diverting. For example, vehicles that leave the mainline for gas and then come back on the mainline are still counted as diverting vehicles.

- For the diversion models, only mainline volume and travel time were examined for their impact on diversion decisions. Socioeconomic factors were not considered.

The diversion analysis results for NB14 and NB18 segments on the I-95 corridor are analyzed using ANOVA and regression analyses. Each segment was analyzed for both travel time operational periods and congested periods in order to investigate if diversion occurs more frequently during congestion. Detailed discussions on both links are shown below. 


\subsubsection{Diversion Analysis for NB14 segment}

\subsubsection{Operational Period}

Table 4-47 shows the results of regression analysis for diversion on NB 14 during the operational period. Table 4-47 suggests that the correlation between travel time and volume and the number of diverting vehicles is higher than the percent diversion. Moreover, the adjusted R-square values for percent diversion and travel time and volume are generally low (i.e., less than 0.6) which indicates that the percent of vehicles diverting does not have a strong linear correlation with travel time or the mainline volume.

The adjusted R-square in the far right column for all weekdays (excluding except Friday) shows high adjusted R-square values, suggesting that there are some correlations between the three factors (i.e., number diverting, travel time, and mainline volume). The Friday results were separated from other weekdays because the traffic pattern on Friday is often different from the other weekdays.

It is important to note that travel time data in the before period is sometimes limited. For example, November 2 was the only Wednesday on before period data. Using the data from one day to represent a weekday during the whole period may misrepresent the results. 
Table 4-47 ANOVA results (adjusted R-squares) during operational periods on NB14 segment

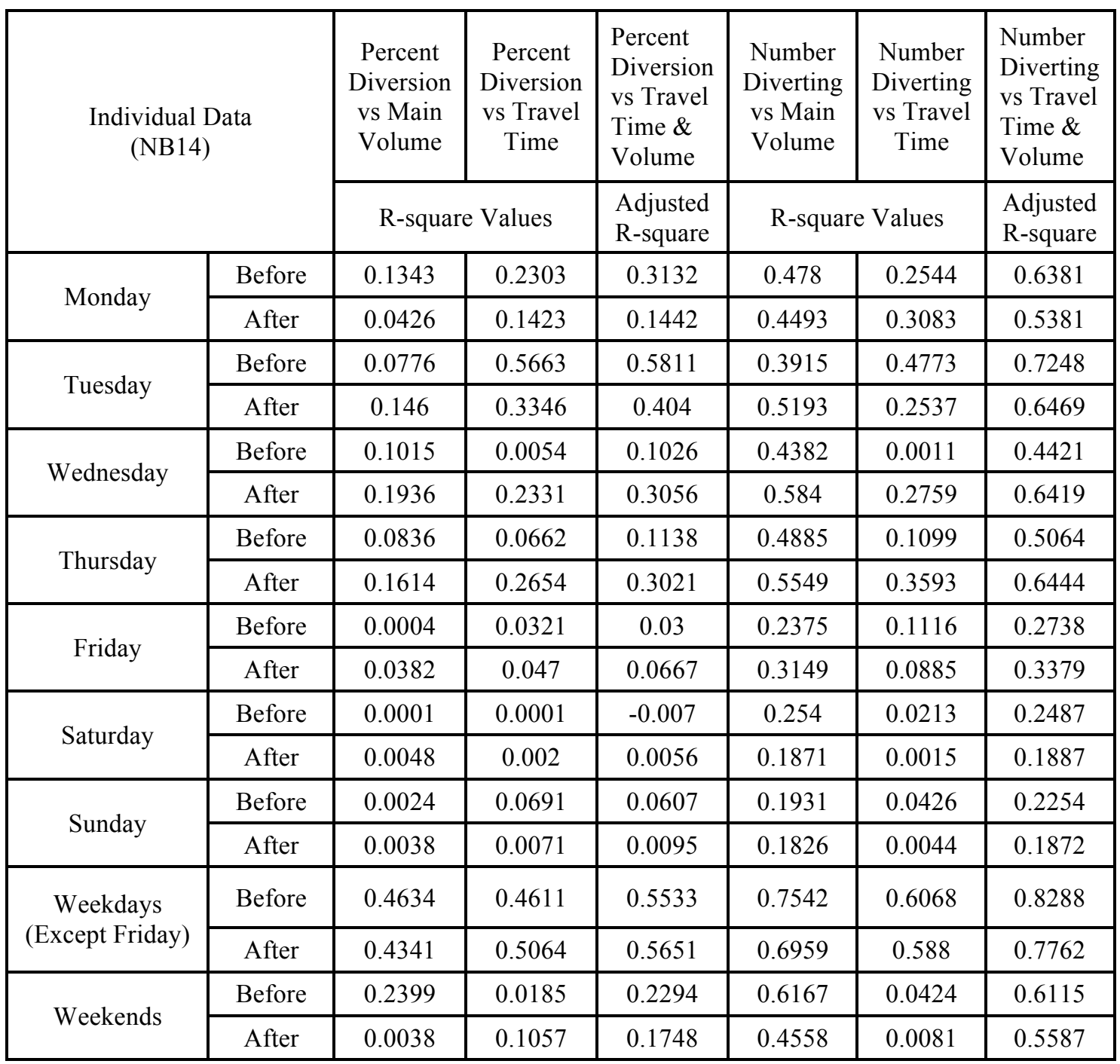

The models provided a reasonable fit $\left(\mathrm{R}^{2} \mathrm{a}-0.6\right)$ are weekday before, weekday after, and weekend before. To observe the actual impacts of each independent variable, the standardized regression models were created, using the SPSS program. The weekday standardized regression models (listed below) show that mainline volume has a greater impact on diversion decision than travel times.

Weekday_Before: Number Diverting $=0.612 *$ Volume $+0.328 *$ Travel Time -23.23 
Weekday_After: Number Diverting $=0.627 *$ Volume $+0.314 *$ Travel Time -24.46

Although commuters did not have the actual knowledge of volume, besides their visual estimations, it is clear from such high volume normalized coefficients in the models that the mainline volume influenced diversion decisions more than travel times. To investigate how the impacts of mainline volume and travel times changed in the after period, the unstandardized model equations were created and shown below.

Weekday_Before: Number Diverting $=0.109 *$ Volume $+0.008 *$ Travel Time -23.23

Weekday_After: Number Diverting $=0.114 *$ Volume $+0.009 *$ Travel Time -24.46

With these unstandardized coefficients, the travel time coefficients between before and after periods are significantly different at $95 \%$ confidence level, but the volume coefficients are not significantly different. Thus, diversions influenced by mainline volume do not change after travel times were posted. The constant in the after periods is pretty much the same as the before periods. Thus, mainline volume and travel times seem to be highly correlated with the number of vehicles leaving the freeway. On the other hand, travel times encourage commuters to divert more during operational periods because of the increasing in travel time coefficients in the after periods.

Both weekday models were plotted, as shown in Figure 4-14 and 4.15. The plots below show a slightly increased number of diverting vehicles after travel time messages were posted on DMS. The increase is more obvious at the high end of the plots, which show an increased number of diverting vehicles (i.e., a wider strip of 40-50 diverting vehicles per 5 minutes). 


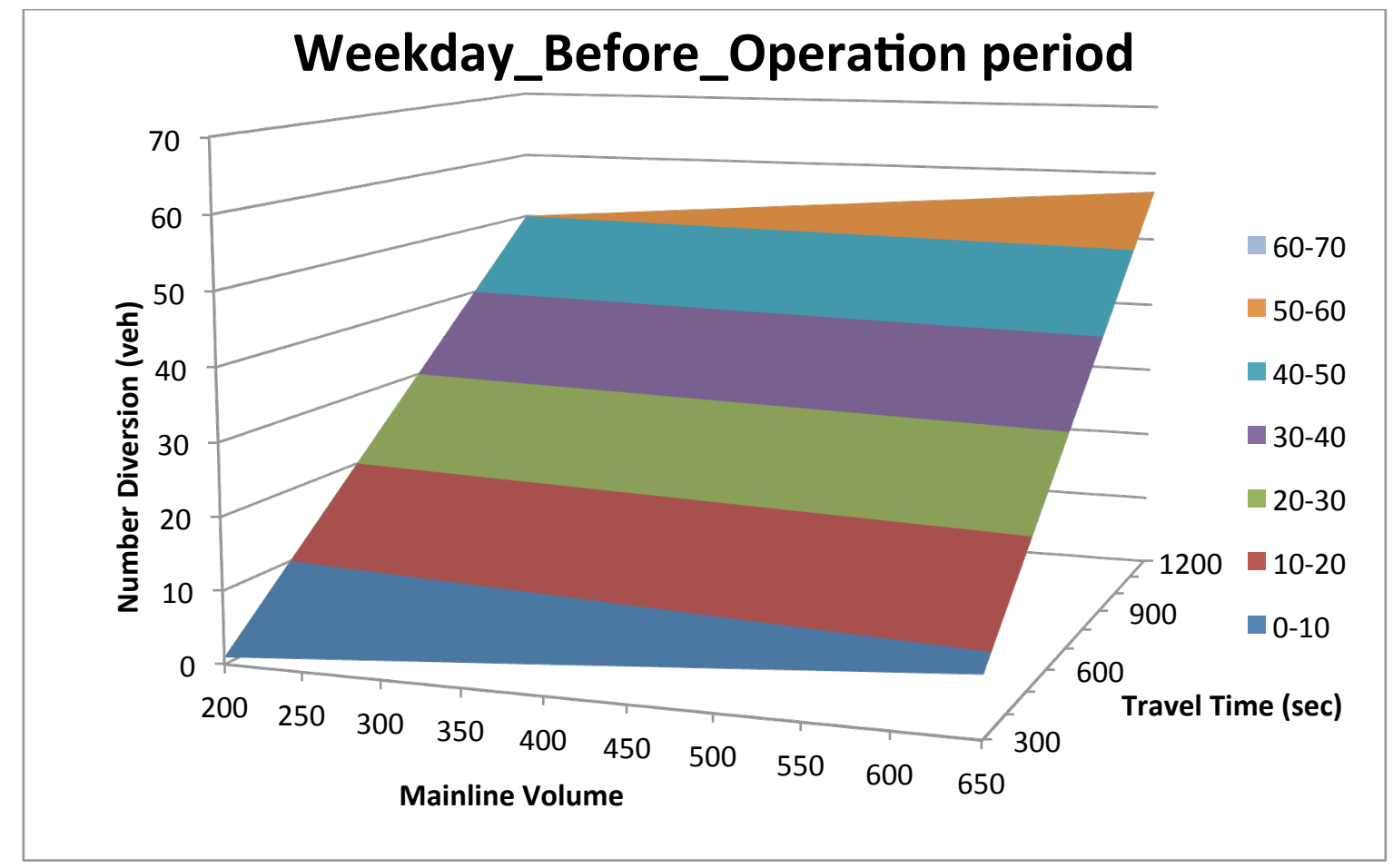

Figure 4-14 Number diversion versus mainline volume and travel time on weekdays, NB14, during operational periods based on regression equation - Before period

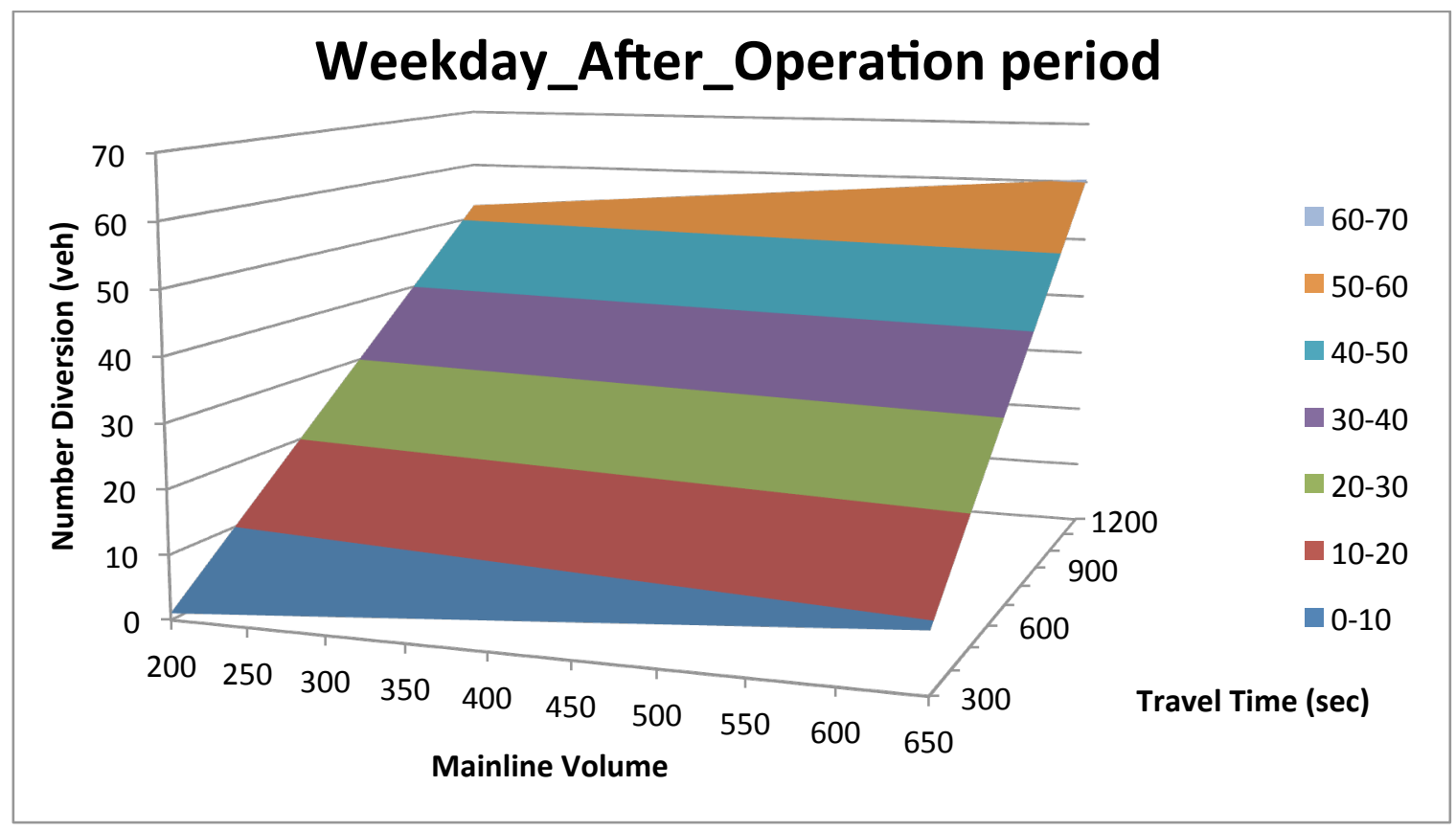

Figure 4-15 Number diversion versus mainline volume and travel time on weekdays, NB14, during operational periods based on regression equation - After period 
As expected for a northbound segment, the diversion graph on Tuesday demonstrates the high diversion trend in the morning peak hours and decreased diversions during the day, as shown in Figure 4-16. This trend is the same for all weekdays on NB14 segment. The weekends' diversions are more consistent throughout the day, and the diversion on Saturday is higher than Sunday.

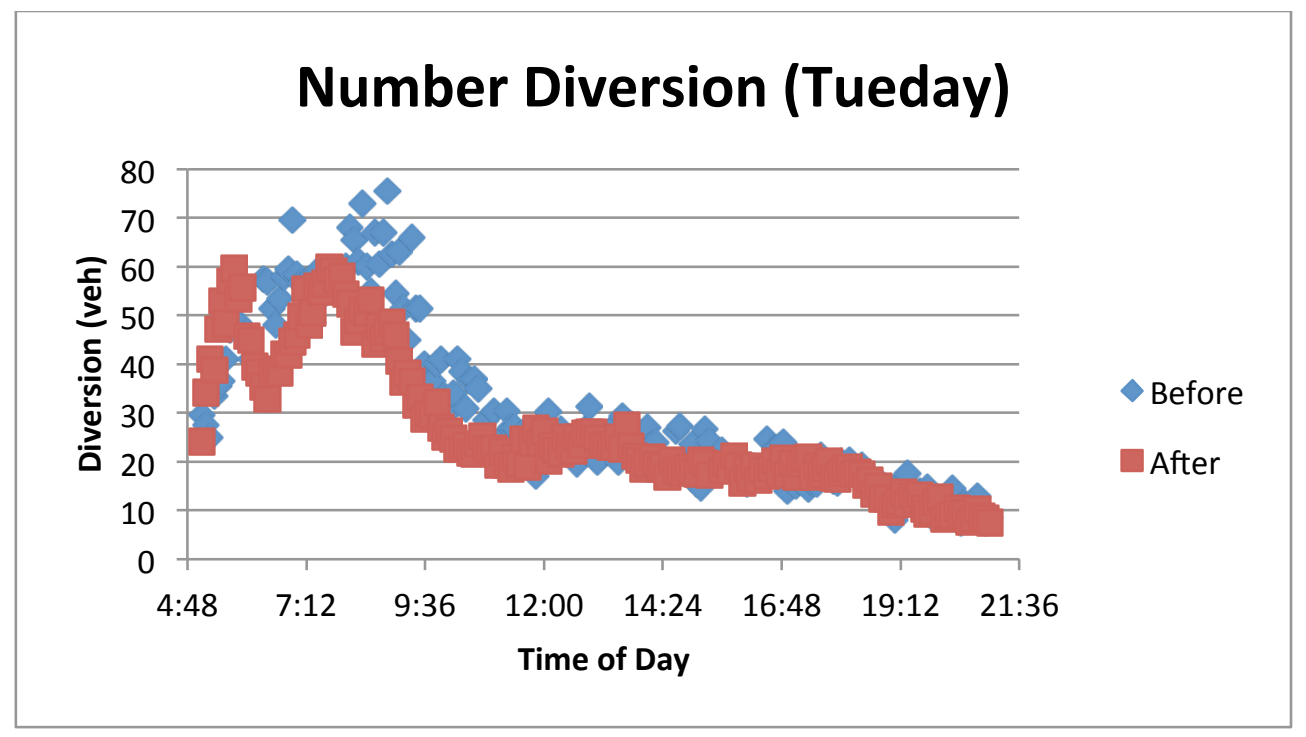

\section{Figure 4-16 Number of vehicle diverting on Tuesday, NB14 segment, in the before and after periods}

In the ANOVA analysis, the p-value on weekdays (except Friday) indicates a difference in the number of vehicles diverting between the before and after periods with $95 \%$ confidence level. Table 4-48 also demonstrates the counts of how many data points being evaluated, comparing before and after periods. The data in the after period is approximately 10 times larger than the before period data. The "Average" column demonstrates the average numbers of vehicle diverting from the freeway. Based on the "Average" column, the trend of vehicles diverting from the freeway seems to be increased in the after period during the operational period, similar to the model equations. 
Table 4-48 ANOVA results (P-values) during operational periods due to number diversions on NB14 segment

\begin{tabular}{|c|c|c|c|c|c|c|}
\hline \multirow{2}{*}{\multicolumn{2}{|c|}{$\begin{array}{l}\text { Individual Data } \\
\text { (NB14) }\end{array}$}} & \multicolumn{5}{|c|}{ Number of Vehicle Diverting (veh) } \\
\hline & & \multirow{2}{*}{$\frac{\text { Count }}{270}$} & \multirow{2}{*}{$\begin{array}{c}\text { Average } \\
28.51\end{array}$} & \multirow{2}{*}{$\frac{\text { Variance }}{265.34}$} & \multirow{2}{*}{$\begin{array}{c}\mathrm{F} \\
0.01\end{array}$} & \multirow{2}{*}{$\frac{P \text {-value }}{0.94}$} \\
\hline \multirow{2}{*}{ Monday } & Before & & & & & \\
\hline & After & 2625 & 28.42 & 301.94 & & \\
\hline \multirow{2}{*}{ Tuesday } & Before & 287 & 26.48 & 276.94 & 16.28 & 0.00 \\
\hline & After & 2454 & 31.69 & 446.8 & & \\
\hline \multirow{2}{*}{ Wednesday } & Before & 176 & 17.01 & 57.04 & 80.04 & 0.00 \\
\hline & After & 2622 & 30.41 & 390.59 & & \\
\hline \multirow{2}{*}{ Thursday } & Before & 501 & 28.44 & 269.97 & 5.24 & 0.02 \\
\hline & After & 2629 & 30.4 & 318.91 & & \\
\hline \multirow{2}{*}{ Friday } & Before & 570 & 27.81 & 261.3 & 13.97 & 0.00 \\
\hline & After & 2589 & 30.86 & 323.14 & & \\
\hline \multirow{2}{*}{ Saturday } & Before & 284 & 19.67 & 44.61 & 0.46 & 0.5 \\
\hline & After & 1859 & 20.01 & 67.39 & & \\
\hline \multirow{2}{*}{ Sunday } & Before & 178 & 14.86 & 40.92 & 0.67 & 0.41 \\
\hline & After & 1705 & 15.32 & 51.81 & & \\
\hline \multirow{2}{*}{$\begin{array}{l}\text { Weekday } \\
\text { (Except F) }\end{array}$} & Before & 1234 & 26.37 & 254.94 & 46.1 & 0.00 \\
\hline & After & 10330 & 30.21 & 364.43 & & \\
\hline \multirow{2}{*}{ Weekend } & Before & 462 & 17.81 & 48.58 & 0.01 & 0.91 \\
\hline & After & 3564 & 17.77 & 65.42 & & \\
\hline
\end{tabular}

\subsubsection{Congested Period}

There are no results for weekend data because there was not much congested data on the weekends. The adjusted R-square values between number diverting versus travel time and mainline volume on weekdays are high for both before and after data $(0.7373$ and 0.8663, respectively). This indicates some relationship between number of diversion and the two variables in both periods. 
Although the combined weekday after period has a higher correlation of 0.8663 , as shown in Table 4-49, it is worth noting that none of each individual weekdays has adjusted R-square values that increased in the after period.

Table 4-49 ANOVA results (adjusted R-squares) during congested periods on NB14 segment

\begin{tabular}{|c|c|c|c|c|c|c|c|}
\hline \multirow{2}{*}{\multicolumn{2}{|c|}{$\begin{array}{c}\text { Individual Data } \\
\text { (NB14_Below 40mph) }\end{array}$}} & $\begin{array}{c}\text { Percent } \\
\text { Diversion } \\
\text { vs Main } \\
\text { Volume }\end{array}$ & $\begin{array}{c}\text { Percent } \\
\text { Diversion } \\
\text { vs Travel } \\
\text { Time }\end{array}$ & $\begin{array}{l}\text { Percent } \\
\text { Diversion } \\
\text { vs Travel } \\
\text { Time \& } \\
\text { Volume }\end{array}$ & $\begin{array}{l}\text { Number } \\
\text { Diversion } \\
\text { vs Main } \\
\text { Volume }\end{array}$ & $\begin{array}{c}\text { Number } \\
\text { Diversion } \\
\text { vs Travel } \\
\text { Time }\end{array}$ & \multirow{2}{*}{$\begin{array}{l}\text { Number } \\
\text { Diversion } \\
\text { vs Travel } \\
\text { Time \& } \\
\text { Volume } \\
\text { Adjusted } \\
\text { R-square }\end{array}$} \\
\hline & & \multicolumn{2}{|c|}{ R-square Values } & $\begin{array}{l}\text { Adjusted } \\
\text { R-square }\end{array}$ & \multicolumn{2}{|c|}{ R-square Values } & \\
\hline \multirow{2}{*}{ Monday } & Before & 0.0585 & 0.7069 & 0.7813 & 0.2953 & 0.4978 & 0.8367 \\
\hline & After & 0.0073 & 0.0554 & 0.0554 & 0.3118 & 0.0453 & 0.347 \\
\hline \multirow{2}{*}{ Tuesday } & Before & 0.4409 & 0.7388 & 0.7986 & 0.0224 & 0.5823 & 0.6413 \\
\hline & After & 0.0748 & 0.1647 & 0.1817 & 0.1739 & 0.0092 & 0.2346 \\
\hline \multirow{2}{*}{ Wednesday } & Before & $\mathrm{n} / \mathrm{a}$ & $\mathrm{n} / \mathrm{a}$ & $\mathrm{n} / \mathrm{a}$ & $\mathrm{n} / \mathrm{a}$ & $\mathrm{n} / \mathrm{a}$ & $\mathrm{n} / \mathrm{a}$ \\
\hline & After & 0.0135 & 0.1614 & 0.1717 & 0.3698 & 0.0823 & 0.4496 \\
\hline \multirow{2}{*}{ Thursday } & Before & 0.3893 & 0.146 & 0.4874 & 0.6818 & 0.0662 & 0.7100 \\
\hline & After & 0.0055 & 0.1369 & 0.1368 & 0.2883 & 0.0739 & 0.3759 \\
\hline \multirow{2}{*}{ Friday } & Before & 0.3581 & 0.0005 & 0.3293 & 0.5488 & 0.001 & 0.5262 \\
\hline & After & 0.0113 & 0.0422 & 0.0397 & 0.2832 & 0.0741 & 0.3028 \\
\hline \multirow{2}{*}{$\begin{array}{l}\text { Weekday } \\
\text { (Except F) }\end{array}$} & Before & 0.0189 & 0.6077 & 0.5865 & 0.4447 & 0.4419 & 0.7373 \\
\hline & After & 0.0059 & 0.8378 & 0.8288 & 0.3784 & 0.5863 & 0.8663 \\
\hline
\end{tabular}

The models that provided a reasonable fit are weekday before and weekday after. To observe the actual impacts of each independent variable, the standardized regression models were created. The weekday standardized regression models (listed below) show that mainline volume has a greater impact on diversion decision than travel times during congested periods.

Weekday Before Number Diverting $=0.626^{*}$ Volume $+0.476^{*}$ Travel Time -39.50 
Weekday After $\quad$ Number Diverting $=0.561 *$ Volume $+0.312 *$ Travel Time -9.84

Due to the higher normalized coefficients of mainline volume, it is clear that the mainline volume influenced diversion decisions more than travel times. To investigate how the impacts of mainline volume and travel times changed after posted travel time, the unstandardized model equations are created and shown below.

Weekday Before $\quad$ Number Diverting $=0.132 *$ Volume $+0.010 *$ Travel Time -39.5

Weekday After $\quad$ Number Diverting $=0.105 *$ Volume $+0.006 *$ Travel Time -9.84

During congestion, both volume and travel time unstandardized coefficients significantly decreased with a $95 \%$ confidence level after travel time messages were posted. However, the constants in the models were substantially reduced in magnitude from -39.5 to -9.84 , which results in increased diversion in the after periods. That explains the increase in diversion in the after period, as shown in Figure 4-17 and 4.18, regardless of the decrease in coefficients of both variables. This increase may be influenced by other factors which were not covered in this study, like conditions on the alternate route. Even though diversion increased in the congested periods, it does not appear that it was linearly related to travel time.

Both weekday models during congested periods were plotted, as shown in Figure 4-17 and 4.18. The plots below demonstrate a substantial increase in the number of diverting vehicles during congestion on NB14 segment.

In the ANOVA analysis, the p-value for number of vehicle diverting on weekdays is significant at $95 \%$ confidence level. But in all the weekdays, only one p-value from 
Thursday is at a significant level, as shown in Table 4-50. The "Average" column for weekday suggests an increase in diversion (i.e., from 40.35 to 54.94 diverting vehicles per 5 minutes) after travel time messages were posted on weekdays. This suggestion also agrees with the model plots.

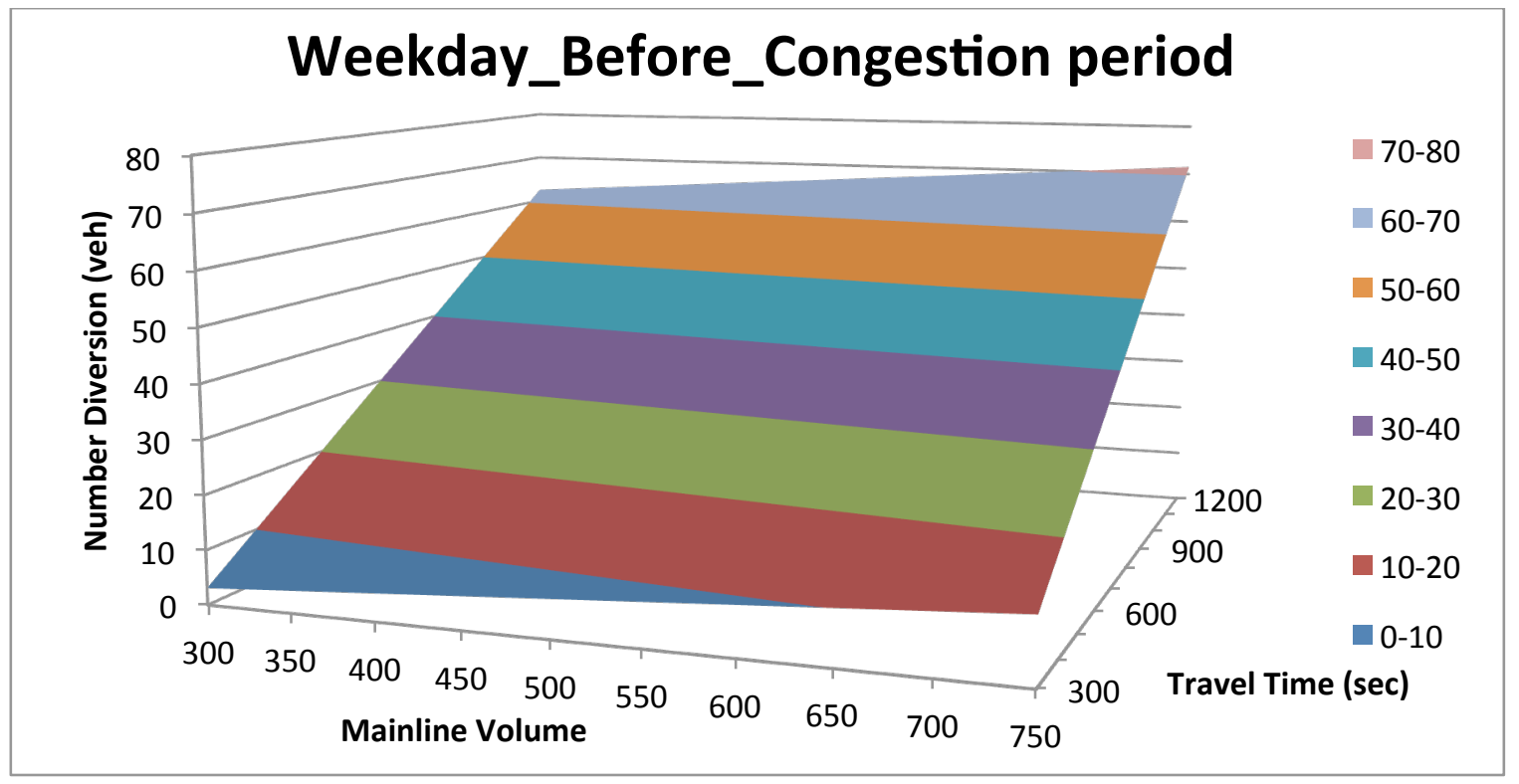

Figure 4-17 Number diversion versus mainline volume and travel time on weekdays, NB14, during congested periods based on regression equation - Before period

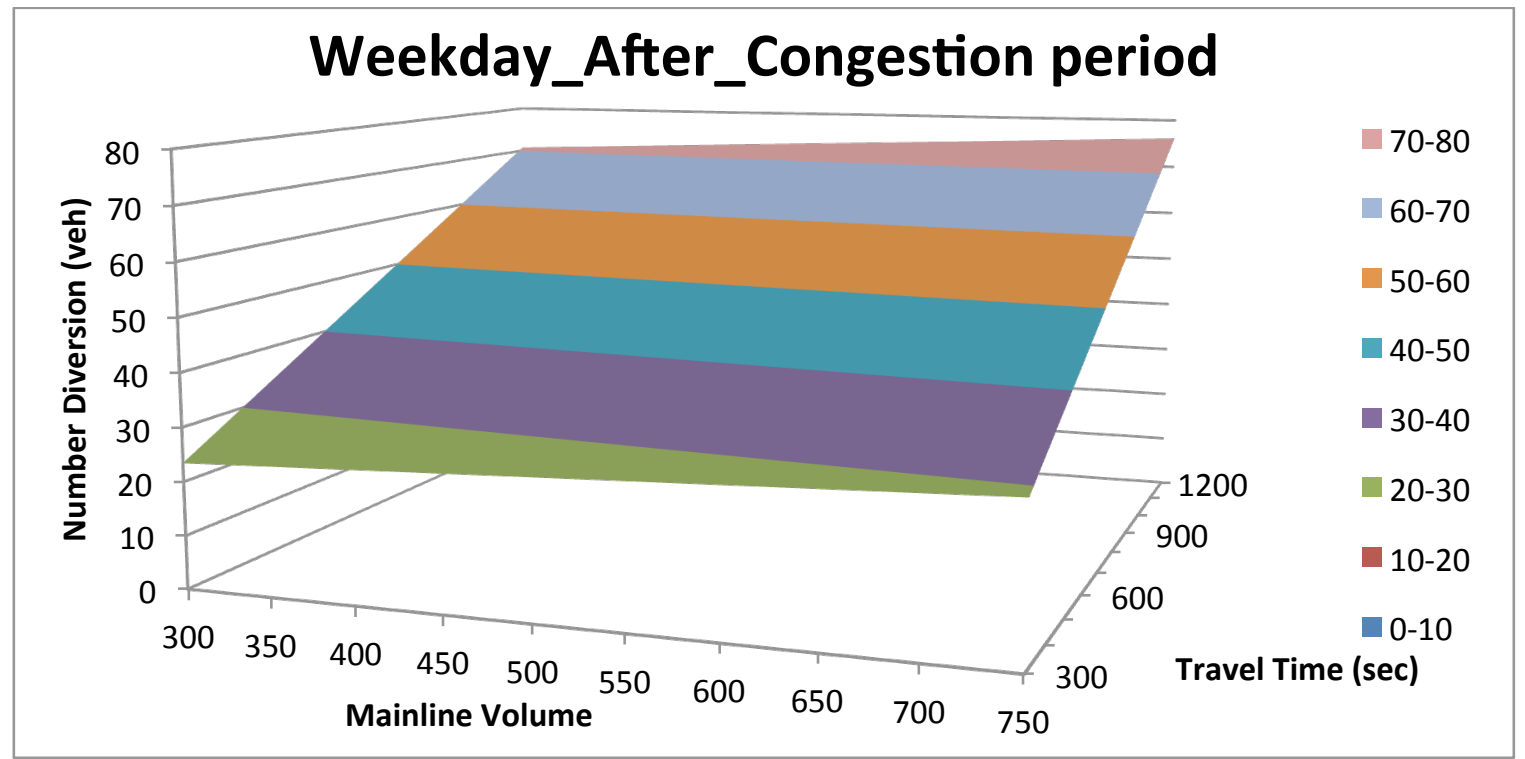

Figure 4-18 Number diversion versus mainline volume and travel time on weekdays, NB14, during congested periods based on regression equation - After period 
Table 4-50 ANOVA results (P-values) during congested periods due to number diversions on NB14 segment

\begin{tabular}{|c|c|c|c|c|c|c|}
\hline \multirow{2}{*}{\multicolumn{2}{|c|}{$\begin{array}{l}\text { Individual Data } \\
\text { (NB14_Below 40) }\end{array}$}} & \multicolumn{5}{|c|}{ Number of Vehicle Diverting (veh) } \\
\hline & & \multirow{2}{*}{$\begin{array}{c}\text { Count } \\
31\end{array}$} & \multirow{2}{*}{$\begin{array}{c}\text { Average } \\
49.55\end{array}$} & \multirow{2}{*}{$\begin{array}{c}\text { Variance } \\
595.79\end{array}$} & \multirow{2}{*}{$\frac{F}{2.14}$} & \multirow{2}{*}{$\frac{P \text {-value }}{0.14}$} \\
\hline \multirow{2}{*}{ Monday } & Before & & & & & \\
\hline & After & 234 & 54.44 & 267.66 & & \\
\hline \multirow{2}{*}{ Tuesday } & Before & 42 & 52.98 & 220.61 & 2.51 & 0.11 \\
\hline & After & 448 & 58.42 & 474.73 & & \\
\hline \multirow{2}{*}{ Wednesday } & Before & $\mathrm{n} / \mathrm{a}$ & $\mathrm{n} / \mathrm{a}$ & $\mathrm{n} / \mathrm{a}$ & $\mathrm{n} / \mathrm{a}$ & $\mathrm{n} / \mathrm{a}$ \\
\hline & After & $\mathrm{n} / \mathrm{a}$ & $\mathrm{n} / \mathrm{a}$ & $\mathrm{n} / \mathrm{a}$ & & \\
\hline \multirow{2}{*}{ Thursday } & Before & 147 & 34.93 & 438.26 & 131.32 & 0.00 \\
\hline & After & 543 & 52.31 & 219.94 & & \\
\hline \multirow{2}{*}{ Friday } & Before & 32 & 44.41 & 658.06 & 1.87 & 0.17 \\
\hline & After & 309 & 39.54 & 338.72 & & \\
\hline \multirow{2}{*}{ Saturday } & Before & $\mathrm{n} / \mathrm{a}$ & $\mathrm{n} / \mathrm{a}$ & $\mathrm{n} / \mathrm{a}$ & $\mathrm{n} / \mathrm{a}$ & $\mathrm{n} / \mathrm{a}$ \\
\hline & After & $\mathrm{n} / \mathrm{a}$ & $\mathrm{n} / \mathrm{a}$ & $\mathrm{n} / \mathrm{a}$ & & \\
\hline \multirow{2}{*}{ Sunday } & Before & $\mathrm{n} / \mathrm{a}$ & $\mathrm{n} / \mathrm{a}$ & $\mathrm{n} / \mathrm{a}$ & $\mathrm{n} / \mathrm{a}$ & $\mathrm{n} / \mathrm{a}$ \\
\hline & After & $\mathrm{n} / \mathrm{a}$ & $\mathrm{n} / \mathrm{a}$ & $\mathrm{n} / \mathrm{a}$ & & \\
\hline \multirow{2}{*}{$\begin{array}{l}\text { Weekday } \\
\text { (Except F) }\end{array}$} & Before & 220 & 40.35 & 478.16 & 112.4 & 0.00 \\
\hline & After & 1225 & 54.94 & 329.45 & & \\
\hline \multirow{2}{*}{ Weekend } & Before & $\mathrm{n} / \mathrm{a}$ & $\mathrm{n} / \mathrm{a}$ & $\mathrm{n} / \mathrm{a}$ & $\mathrm{n} / \mathrm{a}$ & $\mathrm{n} / \mathrm{a}$ \\
\hline & After & $\mathrm{n} / \mathrm{a}$ & $\mathrm{n} / \mathrm{a}$ & $\mathrm{n} / \mathrm{a}$ & & \\
\hline
\end{tabular}

The results from the coefficient table, Table 4-51, can be summarized as follows:

○ During operational periods, weekday travel time coefficients generally increase in the after period, which indicates an increase in impact of DMS travel time messages on diversion. During congested periods, both volume and travel time coefficients generally decrease. This indicates that drivers do not rely heavily on travel times to make their diversion decisions during congested periods. During congestion, travel time information on the current route may not be sufficient to encourage drivers to risk by 
diverting to other alternative routes without knowing the predicted travel times of the new route.

Table 4-51 Summary of unstandardized coefficients during operational and congested periods of NB14 segment

\begin{tabular}{|c|c|c|c|c|c|c|c|c|}
\hline \multirow{2}{*}{ NB14 } & \multicolumn{4}{|c|}{ Operational period } & \multicolumn{4}{c|}{ Congested period } \\
\cline { 2 - 9 } & \multicolumn{2}{|c|}{ Volume Coeff. } & \multicolumn{2}{|c|}{ Travel Time Coeff. } & \multicolumn{2}{c|}{ Volume Coeff. } & \multicolumn{2}{c|}{ Travel Time Coeff. } \\
\cline { 2 - 9 } & Before & After & Before & After & Before & After & Before & After \\
\hline Monday & 0.117 & 0.086 & 0.019 & 0.026 & 0.111 & 0.093 & 0.040 & 0.016 \\
\hline Tuesday & 0.095 & 0.123 & 0.009 & 0.008 & 0.045 & 0.100 & 0.010 & 0.004 \\
\hline Wednesday & 0.076 & 0.129 & -0.008 & 0.008 & $\mathrm{n} / \mathrm{a}$ & 0.118 & $\mathrm{n} / \mathrm{a}$ & 0.007 \\
\hline Thursday & 0.120 & 0.107 & 0.004 & 0.010 & 0.174 & 0.095 & 0.005 & 0.007 \\
\hline Friday & 0.076 & 0.103 & 0.019 & 0.008 & 0.280 & 0.114 & 0.014 & 0.006 \\
\hline $\begin{array}{c}\text { Weekday } \\
\text { Except Friday) }\end{array}$ & 0.109 & 0.114 & 0.008 & 0.009 & 0.132 & 0.105 & 0.014 & 0.006 \\
\hline
\end{tabular}

\subsubsection{Diversion Analysis on NB18 segment}

\subsubsection{Operational Period}

None of the R-square values are significant enough to be meaningful, except the after period on weekdays with adjusted R-square of 0.753 , as shown in Table 4-52. With these low adjusted R-square values for NB18 segment, it suggests that neither travel time information nor mainline volume have linear relationships with drivers' diversion decisions. 
Table 4-52 ANOVA results (adjusted R-squares) during operational periods on NB18 segment

\begin{tabular}{|c|c|c|c|c|c|c|c|}
\hline \multicolumn{2}{|c|}{$\begin{array}{l}\text { Individual Data } \\
\text { (NB18) }\end{array}$} & $\begin{array}{l}\text { Percent } \\
\text { Diversion } \\
\text { vs Main } \\
\text { Volume }\end{array}$ & $\begin{array}{l}\text { Percent } \\
\text { Diversion } \\
\text { vs Travel } \\
\text { Time }\end{array}$ & $\begin{array}{l}\text { Percent } \\
\text { Diversion } \\
\text { vs Travel } \\
\text { Time \& } \\
\text { Volume }\end{array}$ & $\begin{array}{l}\text { Number } \\
\text { Diversion } \\
\text { vs Main } \\
\text { Volume }\end{array}$ & $\begin{array}{c}\text { Number } \\
\text { Diversion } \\
\text { vs Travel } \\
\text { Time }\end{array}$ & \multirow{2}{*}{$\begin{array}{l}\text { Number } \\
\text { Diversion } \\
\text { vs Travel } \\
\text { Time \& } \\
\text { Volume } \\
\text { Adjusted } \\
\text { R-square }\end{array}$} \\
\hline & & \multicolumn{2}{|c|}{ R-square Values } & $\begin{array}{l}\text { Adjusted } \\
\text { R-square }\end{array}$ & \multicolumn{2}{|c|}{ R-square Values } & \\
\hline \multirow{2}{*}{ Monday } & Before & 0.0085 & 0.0125 & 0.0276 & 0.3327 & 0.1316 & 0.3526 \\
\hline & After & 0.0047 & 0.0049 & 0.0117 & 0.2499 & 0.041 & 0.2578 \\
\hline \multirow{2}{*}{ Tuesday } & Before & 0.0216 & 0.0141 & 0.0431 & 0.2632 & 0.0959 & 0.2872 \\
\hline & After & 0.0157 & 0.0109 & 0.0364 & 0.2529 & 0.077 & 0.2719 \\
\hline \multirow{2}{*}{ Wednesday } & Before & 0.0359 & 0.047 & 0.0552 & 0.3225 & 0.0002 & 0.3346 \\
\hline & After & 0.0329 & 0.0155 & 0.065 & 0.2635 & 0.1189 & 0.3082 \\
\hline \multirow{2}{*}{ Thursday } & Before & 0.0059 & 0.0529 & 0.0687 & 0.1716 & 0.1355 & 0.2422 \\
\hline & After & 0.019 & 0.1063 & 0.1519 & 0.1738 & 0.1776 & 0.2876 \\
\hline \multirow{2}{*}{ Friday } & Before & 0.2532 & 0.1216 & 0.2977 & 0.0135 & 0.1446 & 0.1417 \\
\hline & After & 0.0187 & 0.0182 & 0.0397 & 0.1408 & 0.0268 & 0.1578 \\
\hline \multirow{2}{*}{ Saturday } & Before & 0.0364 & 0.0008 & 0.0302 & 0.1205 & 0.0125 & 0.1147 \\
\hline & After & 0.0609 & 0.0237 & 0.1112 & 0.0872 & 0.0903 & 0.1400 \\
\hline \multirow{2}{*}{ Sunday } & Before & 0.1505 & 0.1713 & 0.2187 & 0.2391 & 0.0087 & 0.2459 \\
\hline & After & 0.0051 & 0.0025 & 0.0067 & 0.3614 & 0.003 & 0.3626 \\
\hline \multirow{2}{*}{$\begin{array}{l}\text { Weekday } \\
\text { (Except F) }\end{array}$} & Before & 0.0302 & 0.0376 & 0.039 & 0.4161 & 0.3397 & 0.5430 \\
\hline & After & 0.0013 & 0.2998 & 0.3429 & 0.5477 & 0.5356 & 0.7532 \\
\hline \multirow{2}{*}{ Weekend } & Before & 0.0019 & 0.012 & -0.0019 & 0.3988 & 0.1685 & 0.4472 \\
\hline & After & 0.0003 & 0.0601 & 0.0793 & 0.5173 & 0.1656 & 0.1597 \\
\hline
\end{tabular}

The diversion graph on Tuesday, Figure 4-19, demonstrates high diversion trends in the morning peak hours and the evening peak hours. This trend is true for all weekdays on NB18 segment. Similar to NB14, the diversion on Saturday is higher than Sunday. 


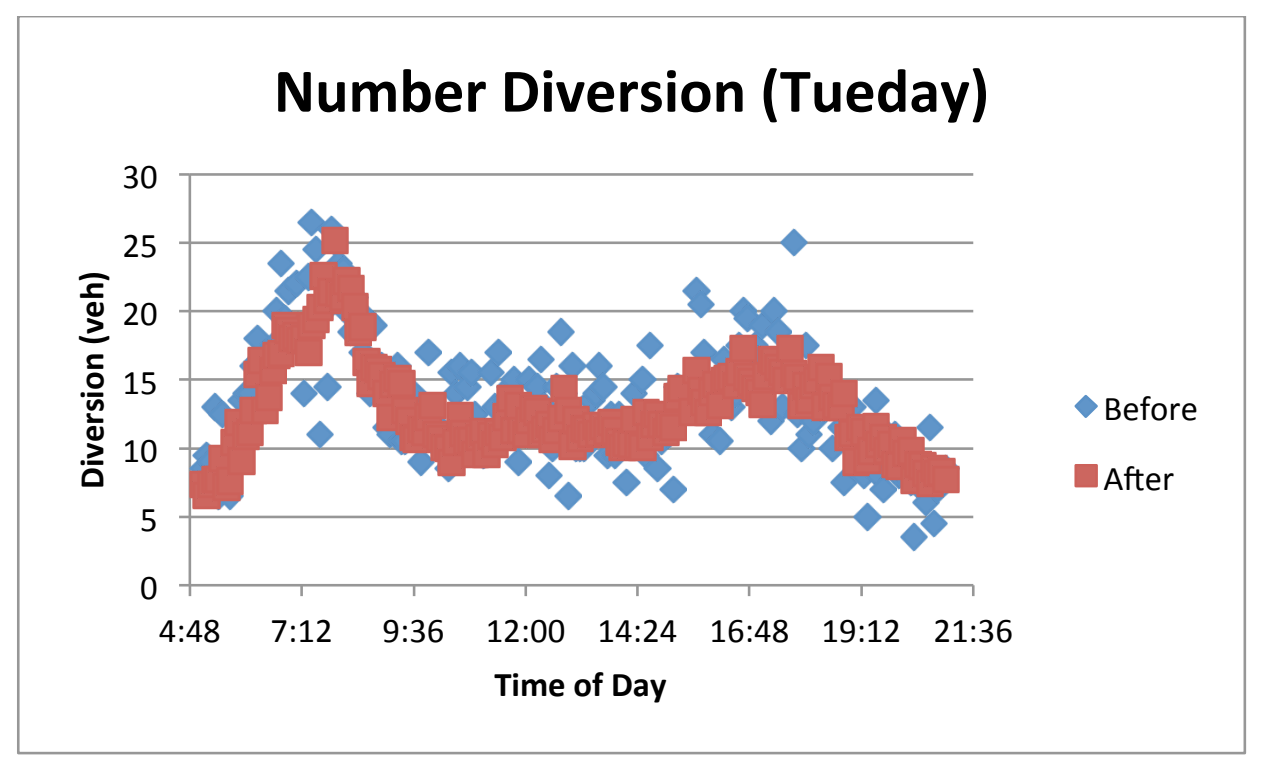

Figure 4-19 Number of vehicle diverting on Tuesday, NB18 segment, during operational periods

In the ANOVA analysis, Table 4-53, the p-value on weekdays (except Friday) indicates a difference in number of vehicle diverting between before and after periods with $95 \%$ confidence level. On weekdays, the "Average" column shows a decreasing trend of vehicles diverting from the freeway in the after period during the operational period. A possible explanation, besides the insufficient data in the before period, is the ability of travel time information to reduce anxiety [1]. By knowing estimated travel times and decreasing drivers' anxiety, it may result in increasing drivers' patient to be a little more willing to cope with the traffic. However, the further research is needed before this hypothesis can be concluded. 
Table 4-53 ANOVA results (P-values) during operational periods due to number diversions on NB18 segment

\begin{tabular}{|c|c|c|c|c|c|c|}
\hline \multirow{2}{*}{\multicolumn{2}{|c|}{$\begin{array}{l}\text { Individual Data } \\
\text { (NB18) }\end{array}$}} & \multicolumn{5}{|c|}{ Number of Vehicle Diverting (veh) } \\
\hline & & \multirow{2}{*}{$\frac{\text { Count }}{322}$} & \multirow{2}{*}{$\begin{array}{c}\text { Average } \\
12.76\end{array}$} & \multirow{2}{*}{$\begin{array}{c}\text { Variance } \\
20.58\end{array}$} & \multirow{2}{*}{$\frac{F}{0.27}$} & \multirow{2}{*}{$\frac{\text { P-value }}{0.60}$} \\
\hline$T_{0} \mathrm{~d}$ & Before & & & & & \\
\hline & After & 2799 & 12.6 & 26.98 & & \\
\hline \multirow{2}{*}{ Tuesday } & Before & 291 & 13.16 & 24.52 & 1.28 & 0.26 \\
\hline & After & 2970 & 12.8 & 27.32 & & \\
\hline \multirow{2}{*}{ Wednesday } & Before & 176 & 11.88 & 22.53 & 7.23 & 0.01 \\
\hline & After & 2771 & 13.01 & 29.85 & & \\
\hline \multirow{2}{*}{ Thursday } & Before & 501 & 13.3 & 25.39 & 0.25 & 0.62 \\
\hline & After & 3014 & 13.43 & 32.45 & & \\
\hline \multirow{2}{*}{ Friday } & Before & 568 & 14.85 & 66.81 & 23.33 & 0.00 \\
\hline & After & 3164 & 13.59 & 26.37 & & \\
\hline \multirow{2}{*}{ Saturday } & Before & 288 & 13.39 & 18.2 & 0.09 & 0.76 \\
\hline & After & 2303 & 13.48 & 27.61 & & \\
\hline \multirow{2}{*}{ Sunday } & Before & 184 & 10.08 & 17.8 & 10.81 & 0.00 \\
\hline & After & 2012 & 11.24 & 21.55 & & \\
\hline \multirow{2}{*}{$\begin{array}{l}\text { Weekday } \\
\text { (Except F) }\end{array}$} & Before & 1858 & 13.52 & 37.67 & 9.81 & 0.00 \\
\hline & After & 14718 & 13.1 & 28.71 & & \\
\hline \multirow{2}{*}{ Weekend } & Before & 472 & 12.1 & 20.61 & 1.97 & 0.16 \\
\hline & After & 4315 & 12.44 & 26.03 & & \\
\hline
\end{tabular}

\subsubsection{Congested Period}

Since there is no congested data on Sunday, the R-square values on weekends were not available. None of the R-square is significant enough to be meaningful, as shown in Table 4-54. With low adjusted R-squares, it suggests that neither travel time information nor mainline volume have a linear relationship with diversion decisions. 
Table 4-54 ANOVA results (adjusted R-squares) during congested periods on NB18 segment

\begin{tabular}{|c|c|c|c|c|c|c|c|}
\hline \multirow{2}{*}{\multicolumn{2}{|c|}{$\begin{array}{c}\text { Individual Data } \\
\text { (NB18_Below40mph) }\end{array}$}} & $\begin{array}{l}\text { Percent } \\
\text { Diversion } \\
\text { vs Main } \\
\text { Volume }\end{array}$ & $\begin{array}{c}\text { Percent } \\
\text { Diversion } \\
\text { vs Travel } \\
\text { Time }\end{array}$ & $\begin{array}{l}\text { Percent } \\
\text { Diversion } \\
\text { vs Travel } \\
\text { Time \& } \\
\text { Volume }\end{array}$ & $\begin{array}{l}\text { Number } \\
\text { Diversion } \\
\text { vs Main } \\
\text { Volume }\end{array}$ & $\begin{array}{c}\text { Number } \\
\text { Diversion } \\
\text { vs Travel } \\
\text { Time }\end{array}$ & \multirow{2}{*}{$\begin{array}{l}\text { Number } \\
\text { Diversion } \\
\text { vs Travel } \\
\text { Time \& } \\
\text { Volume } \\
\text { Adjusted } \\
\text { R-square }\end{array}$} \\
\hline & & \multicolumn{2}{|c|}{ R-square Values } & $\begin{array}{l}\text { Adjusted } \\
\text { R-square }\end{array}$ & \multicolumn{2}{|c|}{ R-square Values } & \\
\hline \multirow{2}{*}{ Monday } & Before & 0.0238 & 0.0591 & 0.0191 & 0.0131 & 0.0928 & 0.009 \\
\hline & After & 0.0003 & 0.004 & -0.0101 & 0.1302 & 0.0239 & 0.1217 \\
\hline \multirow{2}{*}{ Tuesday } & Before & 0.1715 & 0.1863 & 0.1932 & 0.4323 & 0.1991 & 0.4392 \\
\hline & After & 0.0264 & 0.0411 & 0.0534 & 0.061 & 0.0236 & 0.0893 \\
\hline \multirow{2}{*}{ Wednesday } & Before & $\mathrm{n} / \mathrm{a}$ & $\mathrm{n} / \mathrm{a}$ & $\mathrm{n} / \mathrm{a}$ & $\mathrm{n} / \mathrm{a}$ & $\mathrm{n} / \mathrm{a}$ & $\mathrm{n} / \mathrm{a}$ \\
\hline & After & 0.0505 & 0.0765 & 0.1186 & 0.007 & 0.0911 & 0.0875 \\
\hline \multirow{2}{*}{ Thursday } & Before & 0.0128 & 0.0102 & -0.0108 & 0.1953 & 0.0042 & 0.1771 \\
\hline & After & 0.2676 & 0.1516 & 0.3629 & 0.0443 & 0.1324 & 0.1506 \\
\hline \multirow{2}{*}{ Friday } & Before & 0.6295 & 0.0048 & 0.6717 & 0.4252 & 0.0002 & 0.4619 \\
\hline & After & 0.2564 & 0.0436 & 0.2454 & 0.0584 & 0.0246 & 0.0491 \\
\hline \multirow{2}{*}{ Saturday } & Before & 0.2916 & 0.1387 & 0.2888 & 0.0482 & 0.1721 & 0.0403 \\
\hline & After & 0.5707 & 0.0124 & 0.5678 & 0.3996 & 0.0097 & 0.3876 \\
\hline \multirow{2}{*}{ Sunday } & Before & $\mathrm{n} / \mathrm{a}$ & $\mathrm{n} / \mathrm{a}$ & $\mathrm{n} / \mathrm{a}$ & $\mathrm{n} / \mathrm{a}$ & $\mathrm{n} / \mathrm{a}$ & $\mathrm{n} / \mathrm{a}$ \\
\hline & After & $\mathrm{n} / \mathrm{a}$ & $\mathrm{n} / \mathrm{a}$ & $\mathrm{n} / \mathrm{a}$ & $\mathrm{n} / \mathrm{a}$ & $\mathrm{n} / \mathrm{a}$ & $\mathrm{n} / \mathrm{a}$ \\
\hline \multirow{2}{*}{$\begin{array}{l}\text { Weekday } \\
\text { (Except F) }\end{array}$} & Before & 0.285 & 0.0513 & 0.2693 & 0.0037 & 0.1254 & 0.0287 \\
\hline & After & 0.1293 & 0.0597 & 0.1921 & 0.0009 & 0.0694 & 0.0676 \\
\hline \multirow{2}{*}{ Weekend } & Before & $\mathrm{n} / \mathrm{a}$ & $\mathrm{n} / \mathrm{a}$ & $\mathrm{n} / \mathrm{a}$ & $\mathrm{n} / \mathrm{a}$ & $\mathrm{n} / \mathrm{a}$ & $\mathrm{n} / \mathrm{a}$ \\
\hline & After & $\mathrm{n} / \mathrm{a}$ & $\mathrm{n} / \mathrm{a}$ & $\mathrm{n} / \mathrm{a}$ & $\mathrm{n} / \mathrm{a}$ & $\mathrm{n} / \mathrm{a}$ & $\mathrm{n} / \mathrm{a}$ \\
\hline
\end{tabular}

The p-values for number of vehicle diverting on Friday and Saturday are significant at 95\% confidence level. On Wednesday and Sunday, there are no congested data to be analyzed. The others p-values are insignificant, as shown in Table 4-55. 
Table 4-55 ANOVA results (P-values) during congested periods due to number diversions on NB18 segment

\begin{tabular}{|c|c|c|c|c|c|c|}
\hline \multirow{2}{*}{\multicolumn{2}{|c|}{$\begin{array}{l}\text { Individual Data } \\
\text { (NB18_Below40) }\end{array}$}} & \multicolumn{5}{|c|}{ Number of Vehicle Diverting (veh) } \\
\hline & & \multirow{2}{*}{$\frac{\text { Count }}{24}$} & \multirow{2}{*}{$\begin{array}{c}\text { Average } \\
17.83\end{array}$} & \multirow{2}{*}{$\begin{array}{c}\text { Variance } \\
25.88\end{array}$} & \multirow{2}{*}{$\begin{array}{c}\mathrm{F} \\
2.81\end{array}$} & \multirow{2}{*}{$\frac{P \text {-value }}{0.10}$} \\
\hline \multirow{2}{*}{ Monday } & Before & & & & & \\
\hline & After & 144 & 15.64 & 36.72 & & \\
\hline \multirow{2}{*}{ Tuesday } & Before & 22 & 17.59 & 26.92 & 2.84 & 0.09 \\
\hline & After & 280 & 15.55 & 30.11 & & \\
\hline \multirow{2}{*}{ Wednesday } & Before & $\mathrm{n} / \mathrm{a}$ & $\mathrm{n} / \mathrm{a}$ & $\mathrm{n} / \mathrm{a}$ & $\mathrm{n} / \mathrm{a}$ & $\mathrm{n} / \mathrm{a}$ \\
\hline & After & $\mathrm{n} / \mathrm{a}$ & $\mathrm{n} / \mathrm{a}$ & $\mathrm{n} / \mathrm{a}$ & & \\
\hline \multirow{2}{*}{ Thursday } & Before & 57 & 18.16 & 34.71 & 1.11 & 0.29 \\
\hline & After & 239 & 19.5 & 84.49 & & \\
\hline \multirow{2}{*}{ Friday } & Before & 52 & 26.25 & 240.15 & 31.28 & 0.00 \\
\hline & After & 127 & 16.79 & 51.17 & & \\
\hline \multirow{2}{*}{ Saturday } & Before & 12 & 14.17 & 10.88 & 4.15 & 0.04 \\
\hline & After & 70 & 21.34 & 145.47 & & \\
\hline \multirow{2}{*}{ Sunday } & Before & $\mathrm{n} / \mathrm{a}$ & $\mathrm{n} / \mathrm{a}$ & $\mathrm{n} / \mathrm{a}$ & $\mathrm{n} / \mathrm{a}$ & $\mathrm{n} / \mathrm{a}$ \\
\hline & After & $\mathrm{n} / \mathrm{a}$ & $\mathrm{n} / \mathrm{a}$ & $\mathrm{n} / \mathrm{a}$ & & \\
\hline \multirow{2}{*}{$\begin{array}{l}\text { Weekday } \\
\text { (Except F) }\end{array}$} & Before & 103 & 17.96 & 30.49 & 1.62 & 0.20 \\
\hline & After & 663 & 16.99 & 54.55 & & \\
\hline \multirow{2}{*}{ Weekend } & Before & $\mathrm{n} / \mathrm{a}$ & $\mathrm{n} / \mathrm{a}$ & $\mathrm{n} / \mathrm{a}$ & $\mathrm{n} / \mathrm{a}$ & $\mathrm{n} / \mathrm{a}$ \\
\hline & After & $\mathrm{n} / \mathrm{a}$ & $\mathrm{n} / \mathrm{a}$ & $\mathrm{n} / \mathrm{a}$ & & \\
\hline
\end{tabular}

\subsubsection{Overall diversion analysis on I-95 corridor (i.e., NB14 and NB18)}

The key results from the diversion analysis are the following.

The regression analysis results suggest that travel time information and mainline volume influence diversion due to high adjusted R-squares (i.e., over 0.6) during the operational and congested periods on NB14, but not NB18. With much larger magnitude of normalized mainline volume coefficients in all normalized model 
equations, the mainline volume seems to have greater impacts on commuters' diversion decisions than travel time messages.

$>$ The ANOVA analysis results (i.e., P-values) from both segments suggest that before and after diversions are significantly different with $95 \%$ confidence level, especially during weekday operation and congested periods on NB14. Based on the unstandardized coefficients, travel time messages increase diversion during operational periods and decrease diversion during congested period. This indicates that commuters are less likely to risk changing their route when travel time information shows a regular delay during congested periods.

Based on the P-value tables in the NB14 section where the adjusted R-squares are high, the following can be concluded.

- The congested period has a higher number of diverting vehicles than operational period.

- After posted travel time information, diversion increases during the operational period and congested period, relative to the average number of diverting vehicles before posting travel time messages. 


\section{CHAPTER 5. CONCLUSIONS \& RECOMMENDATIONS}

The INRIX probe data satisfied business rule requirements on many evaluated segments on both the I-95 corridor and in the Hampton Roads area. Out of 18 segments on the I-95, I-64 and I-264 corridors, there were 6 segments (i.e., SB12, SB19, SB33, 5841, 5847, 5856, and 5857) where INRIX and Bluetooth data had some disagreement either on weekdays, weekends or both. Many of the cases where the two data sources differed also had suspect ground truth data. Although in the literature review Bluetooth data had been proved to be accurate, this study suggests some scenarios where Bluetooth may not act as an accurate ground truth data due to limitations in the characteristics of Bluetooth or poor deployment decisions.

In the literature review, studies showed travel time information has an impact on route choice decisions. After implementing DMS travel time information, the diversion analysis in this study shows a slight increase in diversion at one of the two evaluated sites, NB14. As mentioned in the literature review, the human decision-making process is complex, and there are many factors influence diversion decisions. Based on the data quality results in this study, the detailed conclusions on INRIX data quality and diversion analysis are discussed below.

\subsection{INRIX DATA QUALITY}

The conclusions on INRIX data quality are as follows: 
The INRIX estimated travel times provided high data availability. Blank outs averaged $3.2 \%$ over all evaluated segments.

$>$ The segments with travel time messages posted by VDOT generally have good agreement with the Bluetooth benchmark when the distance of the segment was not in excess 15 miles.

The following conditions appear to impact the degree of data agreement or adversely impact the ability of Bluetooth to serve as a valid benchmark:

$\circ$ The segment is too long.

As previously discussed, long segments cannot be easily evaluated due to the characteristics of Bluetooth. Vehicles departing the highway for gas or food may result in low Bluetooth speeds. That could be a factor causing the overestimated speed bias on SB19 and SB33. Problems with long segments are most likely due to the limitations of the Bluetooth data because of low Bluetooth speeds in long segments. Since the ground truth is suspected not to be trustworthy for long segments, the quality of INRIX data cannot be accurately evaluated in such segments. To minimize the impact of the Bluetooth's limitation, the segment should not be too long to satisfy the VDOT speed requirements. Some guidelines suggest a freeway benchmark link should be as short as 1 or 2 miles in length [15]. Based on the results in this 
study, it is suggested to keep the length segment within 15 miles, which also agrees with VDOT Business Rules (i.e., the minimum distance for travel times is 10 miles) [4]. If feasible, deploying multiple Bluetooth devices to generate Bluetooth data within a long segment should provide even better Bluetooth data quality than limiting the length to 15 miles.

It is also important to note that INRIX data on long segments, which violate the speed requirements, may still be used for other VDOT traffic operations since they are consistent with Bluetooth data and identify congested periods, as shown in Figure 4-2 and Figure 4-3.

- Poor spatial agreement between validation segment and travel time segment.

- Distance discrepancies between Bluetooth and TMC codes can act as a barrier to conducting fair evaluations of the INRIX data quality. The majority of the evaluated segments do not have data quality issues, even ones with large distance discrepancies (i.e., NB15 where Bluetooth distance is $6 \%$ shorter than INRIX). However, some segment with smaller discrepancies show large differences between the data sources (i.e., SB33 where Bluetooth distance is $2.3 \%$ shorter than INRIX). This factor should not cause much impact on the data quality results if the traffic flow is consistent along the segment. However, a bottleneck or an incident 
causes the traffic flow to change within a segment then this could be an issue. If a bottleneck occurs near one of the endpoints of the segment, the fact that distances of both sources are different may significantly impact the data quality assessment.

○ The segment contains major interchanges.

- From the results, a major intersection (i.e., the Springfield Interchange) within a segment may affect segment data quality. The segment geometry is considered as another factor because the segments before and after the intersection have good agreement. The segment geometry could be an issue for both the INRIX data and the Bluetooth data, as described below.

- INRIX data could be affected when there is a lot of traffic at the merging area. Since INRIX probe data is mainly based on trucks, merging trucks may have to spend more time trying to merge into the freeway. Also, the mainline trucks, which normally are on a slow lane where merging occurs, may be slowing down as well due to merging vehicles. These may result in slow INRIX speeds.

- Bluetooth data could be affected when majority of detected vehicles were on the far left lane, avoiding the traffic at merging area. In that case, the Bluetooth speeds will be higher than the actual traffic because these detected 
vehicles may not experience the slow traffic on the right lanes at the merging area.

However, further investigation is needed for SB12 segment. If the volume data of vehicles entering the intersection is available and show a significant on ramp volumes, that will increase the confidence of labeling the segment geometry as a factor impacting the travel time data quality. It is uncertain at this time whether the benchmark or the INRIX data is correct on this segment.

\subsection{DIVERSION}

Due to limited travel time data, only 10 and 11 weekdays were analyzed on NB14 and NB18 segments, respectively, during before period. As a result, travel time information does not seem to consistently increase diversion as expected. The diversion on NB14 segment has increased, but NB18 segment has decreased. For example, the average number of diverting vehicles on weekdays had slightly increased from 26.37 to 30.21 vehicles (see Table 4-48) on NB14 segment and decreased from 37.67 to 28.71 vehicles (see Table 4-53) on NB18 segment during operational periods.

Therefore, travel times, in this case, may be used to relieve commuters' anxieties more than encouraging diversion because of several possible reasons. First, commuters may expect congestion everywhere on I-95 corridor during the morning peak hours.

Second, some commuters who travel on the I-95 corridor may not familiar with the local network enough to take a detour. Third, diversion on NB 14 at station 230 and NB 18 at 
station 339 may not represent all the vehicles that choose to divert from the freeway after passing the DMS travel time information. Some drivers may decide to divert after these evaluated stations. With limited volume data, the impacts of travel time messages may not be fully captured. Lastly, there is no travel time information on alternate routes. The travel time information on an alternate route is, especially, important for the work trip because many people may not be willing to risk and divert on an unknown travel time route. With these reasons, commuters may not be encouraged to divert even if the travel time information showed a slightly higher travel time than typical travel time.

The number of diverting vehicles on NB14 seems to correlate with travel time and mainline volume based on the high adjusted R-squares of 0.83 before periods and 0.78 after periods on overall weekdays. This correlation, however, does not happen on NB18 segment based on low adjusted R-squares from each weekday. A possible explanation for NB18 segment is that the analyzed exit did not represent the main alternate route on this segment. Therefore, both mainline volume and travel time did not affect numbers of diversion on NB18 segment.

There was not much congestion during weekends. When there is congestion, drivers are more likely to divert based on higher average numbers of diverting vehicles on both NB14 and NB18 segments, as compared to operational periods.

\subsection{RECOMMENDATIONS}

Based on literature review and the results of this research, the following recommendations are categorized into three subsections as shown below. 


\subsubsection{Recommendations on using INRIX data for posting travel times data}

If INRIX travel time information will be posted on an existing DMS, the following factors should be carefully considered.

- Due to Bluetooth limitations in collecting data, a site survey during peak hours may be needed to better understand the site geometry and possible affect, which it may have on Bluetooth data. Using SB12 segment as an example, a site survey during peak hours may help to identify whether vehicles merging onto the freeway slow down or impact the traffic flow in anyway. Moreover, a site survey during peak hours may help identifying a segment where a bottleneck occurs.

- To avoid future issues regarding data quality analysis, the Bluetooth and TMC endpoints need to be clearly confirmed prior to the analysis. If it is possible, the endpoints from both sources should be the same to avoid data quality issue where a bottleneck occurs.

\subsubsection{Recommendations on evaluating data quality}

Besides the distance discrepancies, the precision of Bluetooth lengths may be another factor causing an error. From Table 1.2, the discrepancies in lengths between the provided lengths and the estimated lengths, using Integrator, may responsible for some of the bias results on link 5846 and 5847. It is encouraged to investigate the locations of these Bluetooth readers. It is critical to have the correct Bluetooth distances because Bluetooth speeds were calculated based on its distances. Therefore, the Bluetooth endpoints need to be confirmed. 
Distance seems to be a factor affecting the quality of Bluetooth data. To ensure the quality of Bluetooth data, Bluetooth should not be deployed on such a long segment. It is important for the data analysis to ensure that the benchmark data is reliable. The results from this study have demonstrated that the segments with reliable benchmarks have a good agreement. Based on the previous results, it is recommended that Bluetooth readers should not be spaced more than 15 miles apart.

\subsubsection{Recommendations for Future Research}

$>$ To better analyze diversion due to travel time information, it is necessary to analyze data from more sites. Unfortunately, this research had limited data due to insufficient volume data at other sites. Only two northbound sites were analyzed in this research. For future study, more site locations should be included in the diversion analysis. Moreover, comparison sites are encouraged, such as using a control site. A control site does not have an access to travel time information, and its location geometry, traffic pattern and volume should be similar to a testing site. It would be ideal to investigate the impact of travel time information if a control site is available as an option.

Due to volume data limitations on I-95 corridor, there was only one alternate route available for diversion analysis on each segment. This route may or may not represent the most popular route for I-95 corridor's commuters. Therefore, 
more routes should be analyzed and compared to capture the actual impacts of travel time information.

Drivers generally did not respond to the travel time information based on small changes in diversions between before and after periods. However, there may be other benefits from travel time information, which was not covered within this study. The literature review highlighted other benefits from travel time information, such as reduced anxiety. To better measure the impact of travel time information, further investigation in terms of anxiety level, or even, driver aggressiveness (which can be indicated by number of incidents) is recommended.

Both before and after time periods for diversion analysis should have sufficient data points. This research had only one and a half months worth of before data, while the after period had three months worth of data. Moreover some weekday during before period has only a day worth of data to represent a weekday of the whole operational period (i.e., Wednesday). The results basing on only a day worth of data may not be as accurate as expected. The future research should avoid this situation because having sufficient before posting travel time data may provide more insight results. 


\section{REFERENCES}

1. D. Schrank, T. Lomax, and B. Eisele. “TTI's 2011 Urban Mobility Report Powered by INRIX Traffic Data.” Technical Report, Texas Transportation Institute, September 2011.

2. W. H. K. Lam and K.S. Chan. "A Model for Assessing the Effects of Dynamic Travel Time Information Via Variable Message Signs.” Journal of Transportation, 28 (1):79-99, 2001.

3. J. C. Herrera, Daniel B. Work, Ryan Herring, Xuegang (Jeff) Ban, Quinn Jacobson, and Alexandre M. Bayen. "Evaluation of Traffic Data Obtained via GPS-enabled mobile phones: The Mobile Century Field Experiment.” Transportation Research Part C, pp. 568-583, 2010.

4. J. Sorensen and Catherine Winter. "Business Rules and Standard Operating Procedures fro Travel Time Dissemination on Dynamic Message Signs.” Virginia Department of Transportation, June 2010.

5. A. J. Khattak, Youngbin Yim, and Linda S. Prokopy. "Willingness to Pay for Travel Information.” Transportation Research Part C, pp. 137-159, 2003.

6. A. J. Khattak, Xiaohong Pan, Billy Williams, Nagui Rouphail, and Yingling Fan. "Traveler Information Delivery Mechanisms: Impact on Consumer Behavior." Journal of Transportation Research Board, pp. 77-84, 2008.

7. U.S. Department of Transportation, "Intelligent Transportation Systems for Travel Information.” January 2007.

8. Virginia Department of Transportation, "Major Initiatives: I-66 Travel Times Pilot Project.” November 2011. 
9. Y. Yin, Siriphong Lawphongpanich, Fang He, and Xiao Chen. "Effective and Efficient Development of Dynamic Message Signs to Display Travel Time Information.” Technical Report, July 2011.

10. L. Zhang and David Levinson. "Determinants of Route Choice and the Value of Traveler Information: A Field Experiment.” 2006.

11. A. Haghani, Masoud Hamedi, and Kaveh F. Sadabadi. "I-95 Corridor Coalition Vehicle Probe Project: Validation of INRIX Data March 2010.” Technical Report, I-95 Corridor Coalition, April 2010.

12. G. L. Ullman, Conrad L. Dudek, and Kevin N. Balke. "Effect of Freeway Corridor Attributes upon Motorists Diversion Response to Real-Time Travel Time Traffic Information.” Texas Transportation Institute, October 1992.

13. D. Middleton, Rajat Rajbhandari, Robert Brydia, Praprut Songchitruksa, Edgar Kraus, Salvador Hernandez, Kelvin Cheu, Vichika Iragavarapu, and Shawn Turner. "Synthesis of TXDOT Uses of Real-Time Commercial Traffic Data." Technical Report, Texas Transportation Institute, January 2012.

14. U.S. Department of Transportation. "Framework for Data Quality Measurement." October 2012.

15. S. Turner, James Richardson, Michael Fontaine, and Brian Smith. "Guidelines for Evaluating the Accuracy of Travel Time and Speed Data." Technical Report, June 2011.

16. Center for Advance Transportation Technology, University of Maryland. "Bluetooth Traffic Monitoring Technology.” Technical Report, September 2008. 
17. I-95 Corridor Coalition. "Data Validation Plan I-95 Vehicle Probe Project." June 2008.

18. W. H. Schneider IV, Shawn Turner, Jennifer Roth, and John Wikander. "Statistical Validation of Speeds and Travel Times Provided by a Data Services Vendor." Technical Report, the University of Akron, January 2010.

19. "Northern Region Operations Dynamic Message Sign Travel Time Pilot Project: Operation Concept and High-Level Requirement.” Technical Report, Virginia Department of Transportation, February 2009.

20. The I-95 Corridor Coalition. "Vehicle Probe Project: Acquiring Travel Times and Speeds using Probe Technology.” September 2011.

21. Inc. INRIX. "Traffic Data and Associated Services along the I-95 Corridor." Request for Proposal, June 2007.

22. The I-95 Corridor Coalition. "Project Database: Vehicle Probe Project.” 2011.

23. The I-95 Corridor Coalition. "Vehicle Probe Project General Benefits White Paper.” August 2010.

24. The I-95 Corridor Coalition. "Summary Report for I-95 Corridor Coalition Vehicle Probe Project: Validation of INRIX Data July-September 2008.” Technical Report, January 2009.

25. I-95 Corridor Coalition. "Validation of INRIX data: Two-Year Summary Report July2008-June2010.” Technical Report, September 2010.

26. The Oregon Department of Transportation. "Travel Time Messaging on Dynamic Message Signs - Portland, OR.” May 2005. 
27. The Texas Department of Transportation. "Travel Time Messaging on Dynamic Message Signs - Houston, TX.” May 2005.

28. C. M. Walton, Khali Persad, and Zhong Wang. "Use of Traveler Information to Improve Texas Transportation Network Operations in the Context of Toll Roads." Technical Report, Center of Transportation Research, the University of Texas at Austin, October 2006.

29. N. Lerner, Jeremiah Singer, Emanuel Robinson, Richard Huey, and James Jenness. "Driver Use of En Route Real-Time Travel Time Information." Technical report, July 2009.

30. X. Lu, Song Gao, Eran Ben-Elia, and Ryan Pothering. "Information Impacts on Travelers' Route Choice Behavior in a Congested Risky Network.” 2011.

31. E. D. Ramsay, John E. Catchpole, and James Y.K. Luk. "An Evaluation of VicRoads' Drive Time System.” Technical report, 1997.

32. D. Brownstone and Kenneth A. Small. "Valuing Time and Reliability: Assessing the Evidence from Road Pricing Demonstrations." Transportation Research Part A, pp. 279-293, 2005.

33. K. Chatterjee, N.B. Hounsell, P.E. Firmin, and P.W. Bonsall. "Driver Response to Variable Message Sign Information in London.” Transportation Research Part C, pp.149-169, July 2002.

34. J. L. Schroeder. "Evaluation of Driver Reactions for Effective Use of Dynamic Message Signs in Richmond, Virginia.” Technical Report, Virginia Transportation Research Council, February 2010. 
35. Statewide ATMS Operation Platform: Concept of Operations. Technical report, Virginia Department of Transportation, December 2011.

36. N. J. Garber and Lester A. Hoel. "Traffic \& Highway Engineering, Fourth Edition.” Cengage Learning, 2009.

37. Vehicle Probe Project Data Use and Application Guide. Technical report, The University of Maryland, April 2011.

38. S. K. Asare. "Pilot Travel Time Evaluation on I-66 corridor." July to September, 2011. 


\section{APPENDIX A}

\section{DATA QUALITY ASSESSMENT ON I-95 CORRIDOR}

Table A-1 Summary of Speed Error Bias (mph) on each segment on I-95 corridor for each report period

\begin{tabular}{|c|c|c|c|c|c|c|c|c|c|c|c|c|}
\hline & \multicolumn{2}{|c|}{ Nov 9-16 } & \multicolumn{2}{|c|}{ Nov $17-20$} & \multicolumn{2}{|c|}{ Nov $17-26$} & \multicolumn{2}{|c|}{ Dec 7-13 } & \multicolumn{2}{|c|}{ Jan 2-8 } & \multicolumn{2}{|c|}{ Jan 2-31 } \\
\hline & WKD & WKE & WKD & WKE & WKD & WKE & WKD & WKE & WKD & WKE & WKD & WKE \\
\hline NB18 & 3.6 & 1.2 & 3.9 & -0.1 & 3.5 & 2.6 & 3.5 & 1.5 & 4.7 & 3.8 & 4.9 & 3.9 \\
\hline NB10 & & & -4.7 & -8 & -4.7 & -5.7 & -4.3 & -7.2 & & & & \\
\hline NB14 & & & -2.7 & -3 & -3 & -3.6 & -2.5 & -2.9 & -1.4 & -1.3 & 0 & -0.9 \\
\hline SB33 & & & & & & & 9.8 & 10.5 & 11.2 & 11.3 & 10.9 & 10.6 \\
\hline SB15 & & & & & 4.1 & 1.6 & 4.2 & 2.1 & 2.9 & 3.7 & 3.5 & 3.3 \\
\hline SB12 & & & & & -4.9 & -12.7 & -8.6 & -11 & -9.5 & -10.6 & -9.5 & -10.6 \\
\hline SB8 & & & & & -4.1 & -4.6 & -2.8 & -4.8 & -3.9 & -5.3 & -3.7 & -4.9 \\
\hline SB19 & & & & & & & & & 7.8 & 8.3 & 8 & 7.4 \\
\hline
\end{tabular}

a. The bold numbers indicate speeds that failed the business rules requirements

b. The segments with black highlights for certain report periods were evaluated because of either Bluetooth data or predicted travel time data were not available at the time.

Table A-2 Summary of Absolute Error Bias (mph) on each segment on I-95 corridor for each report period

\begin{tabular}{|c|c|c|c|c|c|c|c|c|c|c|c|c|c|}
\hline & \multicolumn{2}{|c|}{ Nov 9-16 } & \multicolumn{2}{|c|}{ Nov $17-20$} & \multicolumn{2}{|c|}{ Nov $17-26$} & \multicolumn{2}{|c|}{ Dec 7-13 } & \multicolumn{2}{|c|}{$\operatorname{Jan} 2-8$} & \multicolumn{2}{|c|}{ Jan 2-31 } \\
\hline & & WKD & WKE & WKD & WKE & WKD & WKE & WKD & WKE & WKD & WKE & WKD & WKE \\
\hline \multirow{3}{*}{ NB } & NB18 & 5.2 & 2.9 & 4.2 & 3.4 & 4.3 & 3.3 & 4.3 & 2.7 & 4.9 & 4.2 & 5.2 & 4.5 \\
\hline & NB10 & & & 5 & 8.1 & 5.5 & 7.3 & 4.8 & 7.2 & & & & \\
\hline & NB14 & & & 4.4 & 4.3 & 5 & 4.6 & 4.7 & 5.9 & 3.8 & 3 & 3.6 & 3.3 \\
\hline \multirow{5}{*}{ SB } & SB33 & & & & & & & 10 & 10.6 & 11.3 & 11.3 & 11 & 10.7 \\
\hline & SB15 & & & & & 4.8 & 4.5 & 5.4 & 4.3 & 4.4 & 4.3 & 4.7 & 4.3 \\
\hline & SB12 & & & & & 5.4 & 12.7 & 9.5 & 11 & 10 & 10.6 & 9.9 & 10.6 \\
\hline & SB8 & & & & & 5 & 5.2 & 4.5 & 5.5 & 4.8 & 5.7 & 4.9 & 5.3 \\
\hline & SB19 & & & & & & & & & 8 & 8.3 & 8.2 & 7.7 \\
\hline
\end{tabular}

a. The bold numbers indicate speeds that failed the business rules requirements

b. The segments with black highlights for certain report periods were evaluated because of either Bluetooth data or predicted travel time data were not available at the time. 
Table A-3 Summary of Speed Error Bias (mph) on each segment on I-64 and I-264 corridors

\begin{tabular}{|c|c|c|c|}
\hline \multirow{2}{*}{ Segment } & \multirow{2}{*}{ Corridor } & \multicolumn{2}{|c|}{ July16 - Aug19 } \\
\cline { 3 - 4 } & & WKD & WKE \\
\hline 5840 & I-64 & -1.7 & -4 \\
\hline 5841 & I-64 & 1.7 & $\mathbf{5 . 1}$ \\
\hline 5842 & I-64 & -1 & -1 \\
\hline 5843 & I-64 & -0.7 & -2.1 \\
\hline 5846 & I-64 & 4.1 & 3.9 \\
\hline 5847 & I-64 & $\mathbf{- 5 . 5}$ & 2.7 \\
\hline 5850 & I-64 & -4 & -3.9 \\
\hline 5853 & I-64 & -4 & -3.9 \\
\hline 5856 & I-264 & $\mathbf{- 1 2 . 8}$ & $\mathbf{- 1 3 . 6}$ \\
\hline 5857 & I-264 & $\mathbf{7 . 7}$ & $\mathbf{7 . 7}$ \\
\hline
\end{tabular}

a. The bold numbers in highlights indicate speeds that failed the business rules requirements

Table A-4 Final tables and percent blank out of INRIX data analysis on I-95 corridor, NB10 segment

\begin{tabular}{|c|c|c|c|c|c|c|c|c|c|c|c|}
\hline \multirow[t]{3}{*}{ Date } & \multicolumn{2}{|c|}{$\begin{array}{c}\text { Travel Time } \\
\text { Error Bias (sec) }\end{array}$} & \multicolumn{2}{|c|}{$\begin{array}{l}\text { Absolute Travel } \\
\text { Time Error (sec) }\end{array}$} & \multirow{3}{*}{$\begin{array}{l}\text { Mean } \\
\text { Travel } \\
\text { Time } \\
(\mathrm{sec}) \\
\end{array}$} & \multirow{3}{*}{$\begin{array}{c}\text { Raw } \\
\text { Speed } \\
\text { Error } \\
\text { Bias } \\
\\
(\mathrm{mph}) \\
\end{array}$} & \multirow{3}{*}{$\begin{array}{c}\text { Raw } \\
\text { Speed } \\
\text { Absolute } \\
\text { Error } \\
(\mathrm{mph}) \\
\end{array}$} & \multirow{2}{*}{\multicolumn{2}{|c|}{$\begin{array}{c}\% \text { of Raw } \\
\text { Travel } \\
\text { Time within } \\
\text { Error } \\
\text { Thresholds } \\
\end{array}$}} & \multirow{3}{*}{$\begin{array}{c}\text { Raw } \\
\text { Data } \\
\text { RMSE } \\
(\mathrm{mph}) \\
\end{array}$} & \multirow{3}{*}{$\begin{array}{c}\text { Blank } \\
\text { Out } \\
(\%) \\
\end{array}$} \\
\hline & \multirow{2}{*}{$\begin{array}{l}\text { Raw } \\
\text { Time } \\
\end{array}$} & \multirow{2}{*}{$\begin{array}{c}\text { Reported } \\
\text { Time } \\
\end{array}$} & \multirow{2}{*}{$\begin{array}{l}\text { Raw } \\
\text { Time } \\
\end{array}$} & \multirow{2}{*}{$\begin{array}{c}\text { Reported } \\
\text { Time } \\
\end{array}$} & & & & & & & \\
\hline & & & & & & & & $\begin{array}{l} \pm 10 \\
\mathrm{mph}\end{array}$ & $\begin{array}{c} \pm 5 \\
\mathrm{mph}\end{array}$ & & \\
\hline 17-Nov & 50 & 76 & 55 & 79 & 675 & -4.7 & 5 & 96.8 & 45.2 & 5.6 & 0 \\
\hline 18-Nov & 44 & 69 & 49 & 72 & 625 & -4.7 & 4.9 & 96.8 & 57 & 5.5 & 0 \\
\hline 19-Nov & 52 & 82 & 55 & 82 & 601 & -5.5 & 5.7 & 98.6 & 36.7 & 6.2 & 0 \\
\hline 20-Nov & 93 & 148 & 93 & 148 & 605 & -10.4 & 10.4 & 39.3 & 2.9 & 10.7 & 0 \\
\hline 21-Nov & 20 & 66 & 84 & 117 & 606 & -3.6 & 7.4 & 87.7 & 34.3 & 9 & 7.1 \\
\hline 22-Nov & 62 & 91 & 94 & 115 & 842 & -2.3 & 3.6 & 96.1 & 77.3 & 4.6 & 1.6 \\
\hline 23-Nov & 38 & 68 & 45 & 70 & 630 & -3.9 & 4.3 & 96.8 & 62.4 & 5 & 0 \\
\hline 24-Nov & 60 & 92 & 61 & 93 & 575 & -7 & 7.1 & 79.3 & 25 & 7.7 & 1.1 \\
\hline $25-\mathrm{Nov}$ & 59 & 90 & 59 & 90 & 589 & -6.4 & 6.5 & 92.5 & 30.1 & 6.9 & 0 \\
\hline 26-Nov & 55 & 87 & 56 & 87 & 600 & -5.8 & 5.9 & 95.7 & 33.6 & 6.4 & 0 \\
\hline 7-Dec & 124 & 152 & 168 & 188 & 1117 & -1.9 & 2.9 & 100 & 83.3 & 3.6 & 0 \\
\hline 8-Dec & 49 & 70 & 55 & 74 & 641 & -5.2 & 5.5 & 96.2 & 41.1 & 6 & 0 \\
\hline 9-Dec & 125 & 157 & 166 & 187.6 & 1236 & -4.3 & 5 & 93.1 & 49.4 & 6.2 & 1.1 \\
\hline 10-Dec & 68 & 93 & 68 & 93 & 597 & -7.3 & 7.3 & 87.1 & 16.5 & 7.7 & 0 \\
\hline
\end{tabular}




\begin{tabular}{|c|c|c|c|c|c|c|c|c|c|c|c|}
$11-D e c$ & 60 & 89 & 60 & 89 & 574 & -7 & 7 & 89.2 & 24.5 & 7.5 & 0 \\
\hline 12-Dec & 99.5 & 127 & 108 & 133 & 846 & -5.3 & 5.4 & 96.2 & 40.9 & 6 & 0 \\
\hline $13-D e c$ & 51.8 & 76 & 54.4 & 77 & 660 & -4.9 & 5.1 & 98.4 & 47.3 & 5.6 & 0 \\
\hline
\end{tabular}
a. The INRIX data quality evaluations on NB10 segment were between November 17 and December 13, excluding November 28 - December 6.
b. The missing dates were caused by the absent of Bluetooth or Raw data

Table A-5 Final tables and percent blank out of INRIX data analysis on I-95 corridor, NB14 segment

\begin{tabular}{|c|c|c|c|c|c|c|c|c|c|c|c|}
\hline \multirow[t]{3}{*}{ Date } & \multicolumn{2}{|c|}{$\begin{array}{c}\text { Travel Time } \\
\text { Error Bias (sec) } \\
\end{array}$} & \multicolumn{2}{|c|}{$\begin{array}{l}\text { Absolute Travel } \\
\text { Time Error (sec) }\end{array}$} & \multirow{3}{*}{$\begin{array}{l}\text { Mean } \\
\text { Travel } \\
\text { Time } \\
(\mathrm{sec}) \\
\end{array}$} & \multirow{3}{*}{$\begin{array}{c}\text { Raw } \\
\text { Speed } \\
\text { Error } \\
\text { Bias } \\
\\
\\
(\mathrm{mph}) \\
\end{array}$} & \multirow{3}{*}{$\begin{array}{c}\text { Raw } \\
\text { Speed } \\
\text { Absolute } \\
\text { Error } \\
(\mathrm{mph}) \\
\end{array}$} & \multirow{2}{*}{\multicolumn{2}{|c|}{$\begin{array}{c}\% \text { of Raw } \\
\text { Travel } \\
\text { Time within } \\
\text { Error } \\
\text { Thresholds }\end{array}$}} & \multirow{3}{*}{$\begin{array}{c}\text { Raw } \\
\text { Data } \\
\text { RMSE } \\
(\mathrm{mph}) \\
\end{array}$} & \multirow{3}{*}{$\begin{array}{c}\text { Blank } \\
\text { Out } \\
(\%) \\
\end{array}$} \\
\hline & \multirow{2}{*}{$\begin{array}{l}\text { Raw } \\
\text { Time } \\
\end{array}$} & \multirow{2}{*}{$\begin{array}{c}\text { Reported } \\
\text { Time } \\
\end{array}$} & \multirow{2}{*}{$\begin{array}{l}\text { Raw } \\
\text { Time }\end{array}$} & \multirow{2}{*}{$\begin{array}{c}\text { Reported } \\
\text { Time } \\
\end{array}$} & & & & & & & \\
\hline & & & & & & & & $\begin{array}{l} \pm 10 \\
\mathrm{mph}\end{array}$ & $\begin{array}{c} \pm 5 \\
\mathrm{mph}\end{array}$ & & \\
\hline 17-Nov & 17 & 49 & 137 & 159 & 1206 & -3 & 4.2 & 97.3 & 65.4 & 5.2 & 0.5 \\
\hline 18-Nov & 29 & 57 & 107 & 122 & 1104 & -2.3 & 4.6 & 92.4 & 62.2 & 6.3 & 0.5 \\
\hline 19-Nov & 39 & 65 & 68 & 89 & 917 & -3 & 4.3 & 97.1 & 64.7 & 5.3 & 0 \\
\hline 22-Nov & 56 & 84 & 178 & 187 & 1423 & -1.1 & 4.8 & 86 & 69.8 & 7.4 & 2.7 \\
\hline 23-Nov & 22 & 54 & 59 & 80.1 & 965 & -1.7 & 3.4 & 98.4 & 75.5 & 4.2 & 1.1 \\
\hline 24-Nov & 87 & 115 & 100 & 125 & 917 & -5.9 & 6.7 & 81.8 & 46.6 & 9.1 & 5.4 \\
\hline 25-Nov & 37 & 67 & 115 & 136 & 981 & -3.8 & 6 & 89 & 48.4 & 7.2 & 2.2 \\
\hline 26-Nov & 59 & 87 & 72 & 95 & 912 & -4.2 & 4.9 & 95.7 & 50 & 5.6 & 0.7 \\
\hline 7-Dec & -71 & -44 & 348 & 354 & 1868 & -0.4 & 3.9 & 97.8 & 69.2 & 5.2 & 1 \\
\hline 8-Dec & 1 & 34 & 137 & 161 & 1130 & -3.2 & 5 & 89.7 & 56.8 & 6.2 & 0 \\
\hline 9-Dec & 55 & 81 & 178.5 & 185.6 & 1361 & -1.6 & 4.5 & 94 & 62.5 & 5.7 & 1 \\
\hline 10-Dec & 34 & 61 & 102 & 121 & 1059 & -2.7 & 4.3 & 94.9 & 67.6 & 5.6 & 2 \\
\hline 11-Dec & -4 & 25 & 162 & 186 & 933 & -3.1 & 7.5 & 78.9 & 37.6 & 10.3 & 4 \\
\hline 12-Dec & 91.6 & 124 & 184.8 & 208.9 & 1285 & -4.2 & 5.2 & 93.5 & 51.4 & 6.3 & 1 \\
\hline 13-Dec & 15.7 & 47 & 128.1 & 150.8 & 1157 & -2.9 & 4.7 & 91.9 & 62.4 & 5.8 & 0 \\
\hline 2-Jan & 114 & 144 & 118 & 148 & 937 & -3.8 & 4.6 & 87.1 & 68 & 7 & 4.3 \\
\hline 3-Jan & 46 & 77 & 76 & 102 & 965 & 0.1 & 3.2 & 96.2 & 83.3 & 4.3 & 0 \\
\hline
\end{tabular}




\begin{tabular}{|c|c|c|c|c|c|c|c|c|c|c|c|}
\hline 4-Jan & 57 & 86 & 80.9 & 102.3 & 990 & -0.2 & 2.9 & 98.8 & 80.7 & 3.9 & 1.1 \\
\hline 5-Jan & 58.4 & 90 & 95.8 & 118.8 & 980 & -0.7 & 3.8 & 96.2 & 73.1 & 4.9 & 0 \\
\hline 6-Jan & 96.3 & 125 & 104.1 & 129.7 & 954 & -2.5 & 4.3 & 91.9 & 66.5 & 5.5 & 0.5 \\
\hline 7-Jan & 61 & 89 & 71 & 95 & 902 & -0.6 & 2.8 & 98.5 & 83.9 & 3.6 & 1.4 \\
\hline 8-Jan & 78 & 105 & 80 & 105 & 900 & -1.9 & 3.1 & 99.3 & 78.3 & 3.8 & 1.4 \\
\hline 9-Jan & -32 & -3 & 121.7 & 129.6 & 1077 & 3.1 & 5 & 85 & 65.4 & 7.2 & 2.7 \\
\hline 10-Jan & 35 & 65 & 94 & 112 & 1118 & 0.7 & 3.4 & 95.2 & 81 & 4.4 & 2.2 \\
\hline 12-Jan & -14 & 16 & 151.4 & 166 & 1210 & 1.4 & 4.4 & 91.6 & 72.5 & 6.6 & 1.1 \\
\hline 13-Jan & 52 & 83 & 87.8 & 107.9 & 1030 & 0 & 3.4 & 97.8 & 79.2 & 4.4 & 0.5 \\
\hline 14-Jan & 64 & 91 & 68.1 & 92.6 & 905 & -0.8 & 2.6 & 100 & 87.9 & 3.3 & 0 \\
\hline 15-Jan & 67 & 96 & 95 & 119.6 & 940 & -1.1 & 4.3 & 91.6 & 66.4 & 5.8 & 0 \\
\hline 16-Jan & 73 & 105 & 75.2 & 105.1 & 918 & -1.4 & 2.6 & 100 & 86.7 & 3.4 & 0.5 \\
\hline 17-Jan & 1 & 28 & 237.8 & 252.2 & 1495 & 0.9 & 3.8 & 93.6 & 78.3 & 5.5 & 0 \\
\hline 18-Jan & 22 & 53 & 303.7 & 323 & 1486 & -0.3 & 4.3 & 91.9 & 70.2 & 6.2 & 1.1 \\
\hline 19-Jan & 32 & 63 & 101.1 & 119.4 & 1118 & 0.3 & 3.7 & 95.5 & 75.8 & 4.8 & 1.6 \\
\hline 20-Jan & 49 & 80 & 67.1 & 91.2 & 972 & 0.1 & 2.6 & 98.2 & 90.2 & 3.4 & 0.5 \\
\hline 21-Jan & 47 & 78 & 60.5 & 85.1 & 934 & 0.5 & 2.6 & 98.4 & 89.1 & 3.4 & 2.9 \\
\hline 22-Jan & 45 & 75 & 86.3 & 108.1 & 907 & 0.1 & 4.2 & 92.4 & 75.6 & 5.7 & 2.1 \\
\hline 23-Jan & 29 & 59 & 56.7 & 75.5 & 973 & 1.4 & 3.2 & 97.4 & 82.1 & 4.2 & 0 \\
\hline 24-Jan & -81 & -49 & 312.6 & 332.7 & 1363 & 0.5 & 4.1 & 93.9 & 67.7 & 5.3 & 0.5 \\
\hline 25-Jan & 29 & 60 & 115.7 & 133.7 & 1133 & 0.1 & 3.6 & 96.1 & 79.1 & 4.8 & 1.1 \\
\hline 26-Jan & 40 & 73 & 128.3 & 153.5 & 1144 & -0.8 & 3.5 & 97.3 & 70.3 & 4.5 & 1.1 \\
\hline 27-Jan & -1 & 30 & 108.8 & 128.2 & 1139 & 1.5 & 3.5 & 93.4 & 79.5 & 5 & 0 \\
\hline 29-Jan & 82 & 113 & 89.4 & 118.2 & 905 & -2.2 & 3.5 & 98.3 & 75.9 & 4.4 & 2.1 \\
\hline 30-Jan & 68 & 95 & 81.3 & 104 & 1045 & -0.9 & 2.9 & 99.4 & 86.5 & 3.5 & 1.1 \\
\hline 31-Jan & 45 & 74 & 378.4 & 396.2 & 1558 & 1 & 3.8 & 0 & 74.1 & 5.4 & 1.1 \\
\hline
\end{tabular}

a. The INRIX data quality evaluations on NB14 segment were between November 17 and January 31 , excluding November 28 - December 6 and December 14 - January 1

b. The missing dates were caused by the absent of Bluetooth or Raw data 
Table A-6 Final tables and percent blank out of INRIX data analysis on I-95 corridor, NB18 segment

\begin{tabular}{|c|c|c|c|c|c|c|c|c|c|c|c|}
\hline \multirow[t]{3}{*}{ Date } & \multicolumn{2}{|c|}{$\begin{array}{c}\text { Travel Time } \\
\text { Error Bias (sec) }\end{array}$} & \multicolumn{2}{|c|}{$\begin{array}{l}\text { Absolute Travel } \\
\text { Time Error (sec) }\end{array}$} & \multirow{3}{*}{$\begin{array}{l}\text { Mean } \\
\text { Travel } \\
\text { Time } \\
(\mathrm{sec}) \\
\end{array}$} & \multirow{3}{*}{$\begin{array}{c}\text { Raw } \\
\text { Speed } \\
\text { Error } \\
\text { Bias } \\
\\
\\
(\mathrm{mph}) \\
\end{array}$} & \multirow{3}{*}{$\begin{array}{c}\text { Raw } \\
\text { Speed } \\
\text { Absolute } \\
\text { Error } \\
(\mathrm{mph}) \\
\end{array}$} & \multirow{2}{*}{\multicolumn{2}{|c|}{$\begin{array}{c}\% \text { of Raw } \\
\text { Travel } \\
\text { Time within } \\
\text { Error } \\
\text { Thresholds }\end{array}$}} & \multirow{3}{*}{$\begin{array}{c}\text { Raw } \\
\text { Data } \\
\text { RMSE } \\
(\mathrm{mph}) \\
\end{array}$} & \multirow{3}{*}{$\begin{array}{c}\text { Blank } \\
\text { Out } \\
(\%) \\
\end{array}$} \\
\hline & \multirow{2}{*}{$\begin{array}{l}\text { Raw } \\
\text { Time }\end{array}$} & \multirow{2}{*}{$\begin{array}{c}\text { Reported } \\
\text { Time } \\
\end{array}$} & \multirow{2}{*}{$\begin{array}{l}\text { Raw } \\
\text { Time }\end{array}$} & \multirow{2}{*}{$\begin{array}{c}\text { Reported } \\
\text { Time } \\
\end{array}$} & & & & & & & \\
\hline & & & & & & & & $\begin{array}{l} \pm 10 \\
\mathrm{mph}\end{array}$ & $\begin{array}{r} \pm 5 \\
\mathrm{mph} \\
\end{array}$ & & \\
\hline 9-Nov & -64 & -35 & 70 & 53 & 993 & 3.5 & 4 & 93.3 & 65 & 4.9 & 68 \\
\hline 10-Nov & -102 & -71 & 123 & 104 & 1242 & 3.6 & 4.3 & 94.9 & 62.1 & 5.4 & 0 \\
\hline 11-Nov & -178 & -147 & 362 & 354 & 1624 & 3.3 & 4.9 & 94.1 & 74.2 & 9.7 & 0 \\
\hline 12-Nov & -52 & -22 & 63 & 54 & 1072 & 2.4 & 3.1 & 99.3 & 79.9 & 3.8 & 0 \\
\hline 13-Nov & -8 & 36 & 40 & 55 & 976 & 0 & 2.6 & 100 & 85 & 3.3 & 0 \\
\hline 14-Nov & -99 & -55 & 110 & 99 & 976 & 4.7 & 5.6 & 84.4 & 69.4 & 8.9 & 0 \\
\hline $15-\mathrm{Nov}$ & -200 & -165 & 205 & 181 & 987 & 7.9 & 8.3 & 78.9 & 67.4 & 13.7 & 6 \\
\hline 16-Nov & -76 & -43 & 80 & 55 & 1012 & 4.1 & 4.3 & 99.1 & 65.5 & 4.9 & 0 \\
\hline 17-Nov & -84 & -51 & 90 & 71 & 1110 & 3.9 & 4.2 & 95.2 & 66.7 & 5.2 & 0 \\
\hline 18-Nov & -70 & -40 & 74 & 55 & 1033 & 3.8 & 4.1 & 97.3 & 67.2 & 4.9 & 0 \\
\hline 19-Nov & -54 & -24 & 84 & 77 & 1223 & 2.3 & 3.5 & 94.2 & 75.4 & 4.8 & 0.7 \\
\hline 20-Nov & 37 & 96 & 47 & 97 & 1021 & -2.5 & 3.2 & 100 & 78.6 & 3.9 & 0 \\
\hline 21-Nov & -95 & -49 & 110 & 101 & 1021 & 4.5 & 5.5 & 88.2 & 67.5 & 8.2 & 7.7 \\
\hline 22-Nov & -98 & -66 & 155 & 133 & 1331 & 4.3 & 5.1 & 92.9 & 52.5 & 6.3 & 0.5 \\
\hline 23-Nov & -97 & -68 & 105 & 85 & 1192 & 4.1 & 4.4 & 95.7 & 62.9 & 5.3 & 0 \\
\hline 24-Nov & -61 & -31 & 97 & 95 & 1014 & 2 & 3.9 & 94.1 & 79 & 6.3 & 0 \\
\hline 25-Nov & -34 & -3 & 49 & 43 & 1018 & 2.1 & 3 & 98.4 & 84.4 & 3.8 & 0 \\
\hline 26-Nov & -74 & -43 & 81 & 73 & 1180 & 2.8 & 3.2 & 96.4 & 81.3 & 4.4 & 0 \\
\hline 7-Dec & -114 & -83 & 275 & 251 & 1684 & 5 & 5.8 & 90.3 & 44.1 & 6.5 & 0 \\
\hline 8-Dec & -79 & -49 & 85 & 67 & 1062 & 3.8 & 4.1 & 97.8 & 67 & 5 & 0 \\
\hline 9-Dec & -41 & -10 & 209.1 & 201 & 1775 & 2.8 & 4.3 & 93.2 & 68.8 & 5.4 & 0 \\
\hline 10-Dec & -31 & 2 & 44 & 38 & 1042 & 1.8 & 2.6 & 100 & 88.4 & 3.2 & 1 \\
\hline 11-Dec & -17 & 12 & 42 & 41 & 972 & 1.1 & 2.8 & 97.8 & 82.7 & 3.6 & 0 \\
\hline 12-Dec & -33.2 & -2 & 96.7 & 93.2 & 1285 & 2.1 & 3.2 & 96.2 & 79.6 & 4.4 & 0 \\
\hline 13-Dec & -75.7 & -44 & 90.2 & 75.2 & 1099 & 3.6 & 4.1 & 95.7 & 65.6 & 5.2 & 0 \\
\hline 2-Jan & -17 & 11 & 34 & 34 & 964 & 3 & 3.5 & 98.9 & 78 & 4.1 & 0 \\
\hline 3-Jan & -51 & -21 & 66 & 58 & 1040 & 4.5 & 4.8 & 95.2 & 54.8 & 5.7 & 0 \\
\hline 4-Jan & -62 & -31 & 67.8 & 54.4 & 1005 & 5.3 & 5.4 & 88.7 & 50.5 & 6.3 & 0 \\
\hline 5-Jan & -70.4 & -40 & 78.8 & 62.1 & 1078 & 5.4 & 5.5 & 91.9 & 41.9 & 6.2 & 0 \\
\hline 6-Jan & -50.3 & -17 & 58.1 & 45.9 & 970 & 5.1 & 5.3 & 92.5 & 47.3 & 6.1 & 0 \\
\hline 7-Jan & -33 & -5 & 42 & 39 & 967 & 4.1 & 4.3 & 95.7 & 66.9 & 5.1 & 0 \\
\hline
\end{tabular}




\begin{tabular}{|c|c|c|c|c|c|c|c|c|c|c|c|} 
8-Jan & -24 & 4 & 47 & 42 & 961 & 3.5 & 4.1 & 97.1 & 63.6 & 4.9 & 0 \\
\hline 9-Jan & -84 & -54 & 93.8 & 78.8 & 1087 & 5.8 & 6 & 87 & 39.1 & 6.9 & 0.5 \\
\hline 10-Jan & -77 & -50 & 93.1 & 79.1 & 1050 & 5.7 & 6 & 89.8 & 39.2 & 6.9 & 0 \\
\hline 12-Jan & -62 & -31 & 71.2 & 57.9 & 1093 & 5 & 5.1 & 94.1 & 53.5 & 5.9 & 0 \\
\hline 13-Jan & -47 & -15 & 59.6 & 48.1 & 1002 & 4.8 & 5.1 & 94.6 & 51.6 & 5.8 & 0 \\
\hline 14-Jan & -46 & -16 & 51.5 & 38.1 & 948 & 5 & 5.2 & 97.1 & 45.7 & 5.8 & 0 \\
\hline 15-Jan & -13 & 17 & 34.6 & 41.7 & 967 & 2.7 & 3.3 & 97.9 & 80.7 & 4.2 & 0 \\
\hline 16-Jan & -39 & -8 & 45.7 & 39.2 & 988 & 4.3 & 4.4 & 98.9 & 61.3 & 5.1 & 0 \\
\hline 17-Jan & -63 & -35 & 101.3 & 89.2 & 1314 & 4.3 & 4.7 & 96.8 & 57 & 5.4 & 0 \\
\hline 18-Jan & -50 & -22 & 102.7 & 84.4 & 1252 & 4.9 & 5.3 & 95.1 & 44.9 & 5.9 & 0 \\
\hline 19-Jan & -70 & -41 & 78.5 & 64.2 & 1033 & 5.5 & 5.7 & 89.2 & 47.8 & 6.6 & 0 \\
\hline 20-Jan & -46 & -16 & 58 & 50.7 & 986 & 4.7 & 4.9 & 96.2 & 48.9 & 5.7 & 0 \\
\hline 21-Jan & -70 & -43 & 78.7 & 66.8 & 993 & 5.9 & 6.1 & 86.3 & 45.3 & 7.3 & 0 \\
\hline 22-Jan & -30 & 0 & 43.6 & 39.4 & 984 & 3.8 & 4.1 & 97.1 & 65.5 & 4.9 & 0.7 \\
\hline 23-Jan & -65 & -34 & 67.3 & 46.9 & 1008 & 5.6 & 5.6 & 93 & 47.8 & 6.3 & 0 \\
\hline 24-Jan & -38 & -8 & 72.7 & 61.3 & 1114 & 4.4 & 4.8 & 96.8 & 56.5 & 5.5 & 0 \\
\hline 25-Jan & -44 & -11 & 173.5 & 159.9 & 1226 & 5.1 & 6.3 & 82.8 & 39.8 & 7.5 & 0 \\
\hline 26-Jan & -81 & -50 & 87.2 & 68.8 & 1085 & 5.7 & 5.8 & 90.3 & 42.5 & 6.5 & 0 \\
\hline 27-Jan & -43 & -13 & 52.8 & 48.9 & 992 & 4.4 & 4.6 & 92.5 & 64 & 5.6 & 0 \\
\hline 29-Jan & -3 & 31 & 61.7 & 66.7 & 1007 & 2.3 & 4.3 & 90 & 67.1 & 5.7 & 0 \\
\hline 30-Jan & -47 & -16 & 55.3 & 44.2 & 1005 & 4.6 & 4.8 & 96.2 & 52.4 & 5.5 & 0.5 \\
\hline 31-Jan & -59 & -29 & 85.1 & 73.9 & 1106 & 5.2 & 5.7 & 0 & 51.6 & 6.7 & 0 \\
\hline
\end{tabular}

a. The INRIX data quality evaluations on NB18 segment were between November 9 and January 13, excluding November 28 - December 6 and December 14 - January 1

b. The missing dates were caused by the absent of Bluetooth or Raw data

Table A-7 Final tables and percent blank out of INRIX data analysis on I-95 corridor, SB8 segment

\begin{tabular}{|c|c|c|c|c|c|c|c|c|c|c|c|}
\hline \multirow[t]{3}{*}{ Date } & \multicolumn{2}{|c|}{$\begin{array}{c}\text { Travel Time } \\
\text { Error Bias (sec) }\end{array}$} & \multicolumn{2}{|c|}{$\begin{array}{l}\text { Absolute Travel } \\
\text { Time Error (sec) }\end{array}$} & \multirow{3}{*}{$\begin{array}{l}\text { Mean } \\
\text { Travel } \\
\text { Time } \\
(\mathrm{sec}) \\
\end{array}$} & \multirow{3}{*}{$\begin{array}{c}\text { Raw } \\
\text { Speed } \\
\text { Error } \\
\text { Bias } \\
\\
\\
(\mathrm{mph}) \\
\end{array}$} & \multirow{3}{*}{$\begin{array}{c}\text { Raw } \\
\text { Speed } \\
\text { Absolute } \\
\text { Error } \\
(\mathrm{mph}) \\
\end{array}$} & \multirow{2}{*}{\multicolumn{2}{|c|}{$\begin{array}{c}\% \text { of Raw } \\
\text { Travel } \\
\text { Time within } \\
\text { Error } \\
\text { Thresholds } \\
\end{array}$}} & \multirow{3}{*}{$\begin{array}{c}\text { Raw } \\
\text { Data } \\
\text { RMSE } \\
\text { (mph) } \\
\end{array}$} & \multirow{3}{*}{$\begin{array}{r}\text { Blank } \\
\text { Out } \\
(\%) \\
\end{array}$} \\
\hline & \multirow{2}{*}{$\begin{array}{l}\text { Raw } \\
\text { Time } \\
\end{array}$} & \multirow{2}{*}{$\begin{array}{c}\text { Reported } \\
\text { Time } \\
\end{array}$} & \multirow{2}{*}{$\begin{array}{l}\text { Raw } \\
\text { Time }\end{array}$} & \multirow{2}{*}{$\begin{array}{c}\text { Reported } \\
\text { Time } \\
\end{array}$} & & & & & & & \\
\hline & & & & & & & & $\begin{array}{l} \pm 10 \\
\mathrm{mph}\end{array}$ & $\begin{array}{c} \pm 5 \\
\mathrm{mph} \\
\end{array}$ & & \\
\hline 22-Nov & 119 & 150 & 140 & 167 & 905 & -1.8 & 3.5 & 97.4 & 74.5 & 9 & 4.4 \\
\hline 23-Nov & 120 & 153 & 120 & 153 & 649 & -3.7 & 4.2 & 96.6 & 66.3 & 11 & 5 \\
\hline 24-Nov & 139 & 167 & 139 & 167 & 628 & -6.2 & 6.4 & 89 & 33.1 & 13.6 & 7.1 \\
\hline
\end{tabular}




\begin{tabular}{|c|c|c|c|c|c|c|c|c|c|c|c|}
\hline 25-Nov & 120 & 153 & 126 & 156 & 628 & -4.7 & 5.7 & 89.2 & 41.8 & 12.6 & 6.6 \\
\hline 26-Nov & 121 & 152 & 121 & 152 & 621 & -4.6 & 5.2 & 90 & 55.4 & 12.3 & 6.2 \\
\hline 7-Dec & 98 & 128 & 117 & 144 & 795 & -0.6 & 3.1 & 98.3 & 79 & 4.1 & 5.4 \\
\hline 8-Dec & 117 & 151 & 133 & 164 & 810 & -3.2 & 4.6 & 88.1 & 65.9 & 5.9 & 1.9 \\
\hline 9-Dec & 128 & 161 & 133.4 & 165.1 & 784 & -3.6 & 4.8 & 90.8 & 60.3 & 6.1 & 6.5 \\
\hline 10-Dec & 123 & 154 & 123 & 154 & 652 & -4.2 & 5.1 & 87.1 & 53 & 6.2 & 5 \\
\hline 11-Dec & 132 & 160 & 132 & 160 & 639 & -5.3 & 5.8 & 87.7 & 44.7 & 6.6 & 18 \\
\hline 12-Dec & 107.8 & 138 & 149.7 & 172.8 & 856 & -2.7 & 5 & 92.4 & 54.7 & 6.7 & 7.5 \\
\hline 13-Dec & 119.2 & 153 & 143.4 & 173.1 & 851 & -3.8 & 5.1 & 89.9 & 53.3 & 6.2 & 9.1 \\
\hline 2-Jan & 125 & 155 & 125 & 155 & 626 & -4.7 & 5 & 90.2 & 55.2 & 6 & 6.5 \\
\hline 3-Jan & 137 & 170 & 137 & 170 & 711 & -4.5 & 5.1 & 89.9 & 51.1 & 6.2 & 4.3 \\
\hline 4-Jan & 124 & 159 & 129.5 & 162.3 & 708 & -3.4 & 4.7 & 92.6 & 56 & 5.7 & 5.9 \\
\hline 5-Jan & 133.2 & 168 & 138.3 & 171.9 & 781 & -3.5 & 4.5 & 93.4 & 62.1 & 5.6 & 2.2 \\
\hline 6-Jan & 125.1 & 160 & 150.8 & 182.7 & 811 & -3.5 & 4.8 & 92.1 & 57.6 & 5.9 & 4.8 \\
\hline 7-Jan & 117 & 151 & 117 & 151 & 623 & -4.1 & 4.7 & 90.8 & 60 & 6 & 6.5 \\
\hline 8-Jan & 139 & 169 & 139 & 169 & 627 & -6.4 & 6.6 & 82.5 & 39.2 & 7.4 & 5.7 \\
\hline 9-Jan & 115 & 145 & 162.1 & 188.4 & 871 & -2.7 & 4.4 & 92 & 64.4 & 5.4 & 6.5 \\
\hline 10-Jan & 133 & 167 & 160 & 188.6 & 852 & -3.4 & 5.7 & 89.4 & 55.3 & 8.6 & 3.8 \\
\hline 12-Jan & 121 & 155 & 143.6 & 173.4 & 893 & -3.5 & 4.4 & 90.8 & 65.2 & 5.6 & 1.1 \\
\hline 13-Jan & 132 & 164 & 132.3 & 164.4 & 760 & -3.4 & 4.3 & 92.8 & 66.1 & 5.4 & 3.2 \\
\hline 14-Jan & 128 & 157 & 128 & 157.4 & 629 & -5 & 5.2 & 93.1 & 53.1 & 6 & 7.1 \\
\hline 15-Jan & 123 & 151 & 123 & 151.6 & 635 & -4.3 & 5.2 & 94.5 & 44.9 & 6 & 9.3 \\
\hline 16-Jan & 118 & 152 & 117.9 & 152 & 623 & -4.1 & 4.5 & 96.6 & 57.1 & 5.4 & 4.8 \\
\hline 17-Jan & 185 & 216 & 186.2 & 216.7 & 708 & -6.7 & 7.5 & 78.3 & 53.3 & 10.9 & 3.2 \\
\hline 18-Jan & 143 & 178 & 146.4 & 179.2 & 794 & -3.9 & 5.1 & 85.8 & 60.2 & 6.8 & 5.4 \\
\hline 19-Jan & 134 & 171 & 157.9 & 191.4 & 835 & -4 & 5.3 & 90.1 & 51.1 & 6.5 & 2.2 \\
\hline 20-Jan & 124 & 156 & 127.3 & 158.2 & 664 & -4.5 & 5.3 & 87.2 & 52.8 & 6.4 & 3.2 \\
\hline 21-Jan & 115 & 148 & 115.4 & 147.8 & 636 & -3.5 & 4.2 & 95.6 & 62 & 5.3 & 1.4 \\
\hline 22-Jan & 134 & 167 & 134.1 & 167.2 & 626 & -6 & 6.2 & 84.7 & 42.4 & 7.4 & 15.7 \\
\hline 23-Jan & 114 & 150 & 138.6 & 170.9 & 742 & -3.6 & 4.9 & 90.8 & 58.9 & 6.1 & 2.2 \\
\hline 24-Jan & 113 & 143 & 121.9 & 150.6 & 764 & -2.4 & 3.8 & 94.5 & 71.4 & 4.9 & 3.8 \\
\hline 25-Jan & 114 & 143 & 151 & 177.8 & 805 & -3.5 & 4.5 & 93.3 & 62 & 5.5 & 0.5 \\
\hline 26-Jan & 108 & 139 & 119 & 147.6 & 687 & -2.6 & 4.5 & 94.9 & 61.8 & 5.4 & 4.3 \\
\hline 27-Jan & 111 & 147 & 124.8 & 157 & 741 & -2.8 & 4.9 & 93.8 & 56.8 & 5.9 & 5.4 \\
\hline 29-Jan & 130 & 158 & 129.5 & 157.7 & 641 & -4.9 & 5.2 & 95.4 & 49.2 & 6.1 & 7.1 \\
\hline 30-Jan & 114 & 147 & 144.5 & 174.7 & 791 & -3.2 & 4.8 & 89.1 & 62.3 & 6.1 & 5.9 \\
\hline 31-Jan & 126 & 160 & 133.9 & 166 & 759 & -3.8 & 5 & 0 & 51.1 & 5.8 & 4.3 \\
\hline
\end{tabular}


a. The INRIX data quality evaluations on SB8 segment were between November 20 and January 13, excluding November 28 - December 6 and December 14 - January 1

b. The missing dates were caused by the absent of Bluetooth or Raw data

Table A-8 Final tables and percent blank out of INRIX data analysis on I-95 corridor, SB12 segment

\begin{tabular}{|c|c|c|c|c|c|c|c|c|c|c|c|}
\hline \multirow[t]{3}{*}{ Date } & \multicolumn{2}{|c|}{$\begin{array}{c}\text { Travel Time } \\
\text { Error Bias (sec) } \\
\end{array}$} & \multicolumn{2}{|c|}{$\begin{array}{l}\text { Absolute Travel } \\
\text { Time Error (sec) }\end{array}$} & \multirow{3}{*}{$\begin{array}{c}\text { Mean } \\
\text { Travel } \\
\text { Time } \\
(\mathrm{sec}) \\
\end{array}$} & \multirow{3}{*}{$\begin{array}{c}\text { Raw } \\
\text { Speed } \\
\text { Error } \\
\text { Bias } \\
\\
\\
(\mathrm{mph}) \\
\end{array}$} & \multirow{3}{*}{$\begin{array}{c}\text { Raw } \\
\text { Speed } \\
\text { Absolute } \\
\text { Error } \\
(\mathrm{mph}) \\
\end{array}$} & \multirow{2}{*}{\multicolumn{2}{|c|}{$\begin{array}{c}\% \text { of Raw Travel } \\
\text { Time within } \\
\text { Error } \\
\text { Thresholds }\end{array}$}} & \multirow{3}{*}{$\begin{array}{c}\text { Raw } \\
\text { Data } \\
\text { RMSE } \\
(\mathrm{mph}) \\
\end{array}$} & \multirow{3}{*}{$\begin{array}{r}\text { Blank } \\
\text { Out } \\
(\%) \\
\end{array}$} \\
\hline & \multirow{2}{*}{$\begin{array}{l}\text { Raw } \\
\text { Time }\end{array}$} & \multirow{2}{*}{$\begin{array}{c}\text { Reported } \\
\text { Time } \\
\end{array}$} & \multirow{2}{*}{$\begin{array}{l}\text { Raw } \\
\text { Time } \\
\end{array}$} & \multirow{2}{*}{$\begin{array}{c}\text { Reported } \\
\text { Time } \\
\end{array}$} & & & & & & & \\
\hline & & & & & & & & $\begin{array}{l} \pm 10 \\
\mathrm{mph}\end{array}$ & $\begin{array}{c} \pm 5 \\
\mathrm{mph} \\
\end{array}$ & & \\
\hline 22-Nov & 62 & 91 & 94 & 115 & 842 & -2.3 & 3.6 & 96.1 & 77.3 & 4.6 & 3.8 \\
\hline 23-Nov & 38 & 68 & 45 & 70 & 630 & -3.9 & 4.3 & 96.8 & 62.4 & 5 & 4.3 \\
\hline 24-Nov & 60 & 92 & 61 & 93 & 575 & -7 & 7.1 & 79.3 & 25 & 7.7 & 1.1 \\
\hline 25-Nov & 59 & 90 & 59 & 90 & 589 & -6.4 & 6.5 & 92.5 & 30.1 & 6.9 & 1.6 \\
\hline 26-Nov & 189 & 217 & 189 & 217 & 895 & -12.7 & 12.7 & 26.5 & 0.7 & 13.2 & 2.9 \\
\hline 7-Dec & 163 & 192 & 206 & 231 & 982 & -6.4 & 8.3 & 69.1 & 28.7 & 9.7 & 3 \\
\hline 8-Dec & 261 & 293 & 264 & 295 & 1041 & -9.9 & 10.3 & 52.8 & 14.6 & 12 & 4 \\
\hline 9-Dec & 193 & 226 & 196.4 & 228.5 & 909 & -9.4 & 9.8 & 58.9 & 15.6 & 11.3 & 3 \\
\hline 10-Dec & 184 & 216 & 184 & 216 & 873 & -10.5 & 10.5 & 46.3 & 6.7 & 11.1 & 4 \\
\hline 11-Dec & 214 & 244 & 214 & 244 & 929 & -11.4 & 11.4 & 40 & 3.7 & 12.1 & 1 \\
\hline 12-Dec & 162.6 & 196 & 181.9 & 212 & 902 & -7.9 & 9.1 & 62.8 & 17.5 & 10.2 & 2 \\
\hline 13-Dec & 222.6 & 254 & 234.2 & 262.8 & 1009 & -9.2 & 9.8 & 51.1 & 15.6 & 10.8 & 0 \\
\hline 2-Jan & 188 & 216 & 188 & 216 & 1030 & -7.9 & 8 & 73.9 & 24.4 & 9 & 5.4 \\
\hline 3-Jan & 274 & 304 & 283 & 311 & 1028 & -11 & 11.6 & 46 & 12.5 & 13.5 & 5.4 \\
\hline 4-Jan & 192 & 223 & 197.4 & 226.4 & 903 & -9.7 & 10.1 & 50.8 & 15.1 & 11.2 & 3.8 \\
\hline 5-Jan & 199 & 232 & 211.1 & 242.6 & 944 & -9.2 & 9.8 & 53.3 & 9.9 & 10.8 & 2.2 \\
\hline 6-Jan & 243.2 & 276 & 247.2 & 279 & 1028 & -9.9 & 10.3 & 48.9 & 19.1 & 11.7 & 4.3 \\
\hline 7-Jan & 184 & 215 & 184 & 215 & 888 & -10 & 10 & 52.2 & 5.8 & 10.6 & 0.7 \\
\hline 8-Jan & 175 & 205 & 175 & 205 & 820 & -11.1 & 11.1 & 39.1 & 2.2 & 11.6 & 1.4 \\
\hline 9-Jan & 179 & 209 & 212.8 & 238.9 & 999 & -7.3 & 8.9 & 61.3 & 19.1 & 10.2 & 3.8 \\
\hline 10-Jan & 176 & 211 & 186.1 & 217.7 & 930 & -8.4 & 9.2 & 53.6 & 24 & 10.4 & 1.6 \\
\hline 12-Jan & 179 & 212 & 185.1 & 216.2 & 925 & -8.9 & 9.3 & 54.6 & 16.9 & 10.4 & 1.6 \\
\hline 13-Jan & 170 & 202 & 174.7 & 205.9 & 882 & -8.6 & 9.1 & 56.8 & 17.5 & 10.1 & 1.6 \\
\hline 14-Jan & 172 & 201 & 171.9 & 200.8 & 832 & -10.6 & 10.7 & 46 & 7.2 & 11.2 & 0.7 \\
\hline 15-Jan & 180 & 208 & 179.5 & 207.8 & 806 & -12.2 & 12.2 & 32.1 & 0.7 & 12.9 & 2.1 \\
\hline
\end{tabular}




\begin{tabular}{|l|c|c|c|c|c|c|c|c|c|c|c} 
16-Jan & 153 & 185 & 152.5 & 185.3 & 796 & -9.8 & 9.8 & 50 & 7.5 & 10.3 & 2.7 \\
\hline 17-Jan & 181 & 210 & 181.8 & 210.3 & 888 & -9.3 & 9.5 & 57 & 15.8 & 10.8 & 2.2 \\
\hline 18-Jan & 193 & 223 & 197.2 & 227.3 & 902 & -9.5 & 9.9 & 0 & 15.2 & 11.4 & 1.1 \\
\hline 19-Jan & 239 & 272 & 245.1 & 275 & 968 & -10.7 & 11.1 & 39.8 & 13.3 & 12.9 & 2.7 \\
\hline 20-Jan & 182 & 211 & 185.4 & 213.5 & 859 & -10.2 & 10.6 & 46.7 & 15.2 & 11.7 & 1.1 \\
\hline 21-Jan & 156 & 184 & 155.8 & 183.7 & 809 & -9.8 & 9.8 & 47.4 & 11.9 & 10.6 & 1.4 \\
\hline 22-Jan & 155 & 185 & 154.5 & 185.1 & 804 & -9.8 & 9.8 & 56.8 & 7.2 & 10.4 & 0.7 \\
\hline 23-Jan & 175 & 205 & 186.8 & 212.7 & 957 & -8 & 8.8 & 63 & 18.8 & 9.7 & 2.7 \\
\hline 24-Jan & 204 & 233 & 204.1 & 233.2 & 938 & -9.7 & 9.8 & 53.9 & 20.2 & 11.3 & 1.1 \\
\hline 25-Jan & 204 & 236 & 206.5 & 237.9 & 924 & -10 & 10.3 & 47.3 & 11.4 & 11.4 & 1.1 \\
\hline 26-Jan & 212 & 240 & 211.6 & 240 & 935 & -10 & 10 & 47.2 & 12.2 & 10.8 & 3.2 \\
\hline 27-Jan & 163 & 194 & 164.8 & 194.4 & 871 & -8.4 & 8.7 & 61.7 & 26.1 & 10 & 3.2 \\
\hline 29-Jan & 184 & 214 & 184.5 & 213.8 & 858 & -10.4 & 10.5 & 48.2 & 3.6 & 11.1 & 2.1 \\
\hline 30-Jan & 229 & 263 & 229.9 & 262.8 & 949 & -10.9 & 10.9 & 47.8 & 9.4 & 12 & 3.2 \\
\hline 31-Jan & 243 & 274 & 242.6 & 273.7 & 950 & -11.3 & 11.3 & 45.1 & 10.3 & 13 & 1.1 \\
\hline
\end{tabular}

a. The INRIX data quality evaluations on SB12 segment were between November 20 and January 31, excluding November 28 - December 6 and December 14 - January 1

b. The missing dates were caused by the absent of Bluetooth or Raw data

Table A-9 Final tables and percent blank out of INRIX data analysis on I-95 corridor, SB 15 segment

\begin{tabular}{|c|c|c|c|c|c|c|c|c|c|c|c|}
\hline \multirow[t]{3}{*}{ Date } & \multicolumn{2}{|c|}{$\begin{array}{c}\text { Travel Time } \\
\text { Error Bias (sec) } \\
\end{array}$} & \multicolumn{2}{|c|}{$\begin{array}{l}\text { Absolute Travel } \\
\text { Time Error (sec) }\end{array}$} & \multirow{3}{*}{$\begin{array}{l}\text { Mean } \\
\text { Travel } \\
\text { Time } \\
(\mathrm{sec}) \\
\end{array}$} & \multirow{3}{*}{$\begin{array}{l}\text { Raw } \\
\text { Speed } \\
\text { Error } \\
\text { Bias } \\
\\
\\
(\mathrm{mph}) \\
\end{array}$} & \multirow{3}{*}{$\begin{array}{c}\text { Raw } \\
\text { Speed } \\
\text { Absolute } \\
\text { Error } \\
(\mathrm{mph}) \\
\end{array}$} & \multirow{2}{*}{\multicolumn{2}{|c|}{$\begin{array}{l}\text { \% of Raw } \\
\text { Travel } \\
\text { Time within } \\
\text { Error } \\
\text { Thresholds }\end{array}$}} & \multirow{3}{*}{$\begin{array}{c}\text { Raw } \\
\text { Data } \\
\text { RMSE } \\
(\mathrm{mph}) \\
\end{array}$} & \multirow{3}{*}{$\begin{array}{c}\text { Blank } \\
\text { Out } \\
(\%) \\
\end{array}$} \\
\hline & \multirow{2}{*}{$\begin{array}{l}\text { Raw } \\
\text { Time }\end{array}$} & \multirow{2}{*}{$\begin{array}{c}\text { Reported } \\
\text { Time } \\
\end{array}$} & \multirow{2}{*}{$\begin{array}{l}\text { Raw } \\
\text { Time } \\
\end{array}$} & \multirow{2}{*}{$\begin{array}{c}\text { Reported } \\
\text { Time } \\
\end{array}$} & & & & & & & \\
\hline & & & & & & & & $\begin{array}{l} \pm 10 \\
\mathrm{mph}\end{array}$ & $\begin{array}{c} \pm 5 \\
\mathrm{mph}\end{array}$ & & \\
\hline 22-Nov & -263 & -233 & 370 & 356 & 2097 & 4.2 & 4.8 & 91.6 & 62.9 & 6.7 & 3.3 \\
\hline 23-Nov & -176 & -144 & 346 & 329 & 2066 & 3.4 & 4.4 & 95.1 & 61.2 & 5.4 & 1.6 \\
\hline 24-Nov & -71 & -41 & 85 & 68 & 886 & 4.3 & 5.1 & 93.5 & 50.3 & 6.1 & 0.5 \\
\hline 25-Nov & -58 & -28 & 61 & 42 & 790 & 4.5 & 4.7 & 93.5 & 58.1 & 5.6 & 0 \\
\hline 26-Nov & -31 & 2 & 77 & 69 & 928 & 1.6 & 4.5 & 97.8 & 58.3 & 5.3 & 0.7 \\
\hline 7-Dec & -216 & -187 & 270 & 253 & 1198 & 6.2 & 7.7 & 74.7 & 35.5 & 9.9 & 0 \\
\hline 8-Dec & -16 & 14 & 130 & 125 & 1146 & 2.7 & 4.9 & 88.6 & 59.2 & 6.6 & 1 \\
\hline 9-Dec & -54 & -25 & 79.6 & 71.6 & 976 & 3 & 4 & 95.2 & 67.2 & 4.9 & 0 \\
\hline 10-Dec & -24 & 4 & 71 & 68 & 892 & 1.6 & 4.4 & 92.8 & 65.2 & 5.7 & 1 \\
\hline
\end{tabular}




\begin{tabular}{|c|c|c|c|c|c|c|c|c|c|c|c|}
\hline 11-Dec & -47 & -19 & 72 & 62 & 918 & 2.6 & 4.2 & 96.4 & 63.3 & 5.1 & 0 \\
\hline 12-Dec & -50.3 & -20 & 88.5 & 79.4 & 937 & 4.3 & 5.3 & 89.8 & 53.2 & 6.9 & 0 \\
\hline 13-Dec & -128 & -100 & 157 & 142.1 & 1147 & 4.7 & 5.3 & 89.8 & 53.8 & 6.6 & 0 \\
\hline 2-Jan & -89 & -59 & 101 & 86 & 999 & 3.6 & 4.3 & 97.3 & 65 & 5.1 & 1.6 \\
\hline 3-Jan & -57 & -24 & 120 & 111 & 1086 & 2.8 & 4.3 & 92.9 & 66.7 & 5.6 & 1.6 \\
\hline 4-Jan & -24 & 9 & 69.5 & 60.1 & 973 & 2.7 & 3.8 & 97.3 & 69.6 & 4.8 & 1.1 \\
\hline 5-Jan & -50.5 & -21 & 77.7 & 69.5 & 1010 & 3.5 & 4.3 & 91.9 & 63.2 & 5.4 & 0.5 \\
\hline 6-Jan & -62.2 & -31 & 162.5 & 156.2 & 1172 & 2 & 5.1 & 90.3 & 62.2 & 7 & 0.5 \\
\hline 7-Jan & -57 & -27 & 65 & 54 & 873 & 3.6 & 4.2 & 94.9 & 68.1 & 5.3 & 0.7 \\
\hline 8-Jan & -49 & -18 & 56 & 42 & 802 & 3.7 & 4.4 & 93.6 & 65 & 5.2 & 0 \\
\hline 9-Jan & -99 & -69 & 134.7 & 121.2 & 1094 & 3.8 & 4.9 & 91.2 & 58.2 & 6.1 & 2.2 \\
\hline 10-Jan & -133 & -102 & 152.3 & 134.3 & 1032 & 5.5 & 6.2 & 84.9 & 54.1 & 9.3 & 0.5 \\
\hline 12-Jan & -86 & -56 & 131.1 & 119.8 & 1118 & 3.1 & 4.4 & 94.6 & 62.7 & 5.5 & 0.5 \\
\hline 13-Jan & -73 & -43 & 93.2 & 82.1 & 995 & 3.5 & 4.2 & 97.3 & 63.6 & 5.1 & 1.1 \\
\hline 14-Jan & -48 & -18 & 52.6 & 40.4 & 814 & 3.5 & 3.9 & 97.9 & 68.6 & 4.7 & 0 \\
\hline 15-Jan & -41 & -10 & 51.8 & 40.1 & 788 & 3.4 & 4.2 & 97.1 & 68.8 & 5.1 & 1.4 \\
\hline 16-Jan & -51 & -20 & 56.2 & 40.8 & 782 & 4.1 & 4.6 & 95.1 & 58.7 & 5.4 & 1.1 \\
\hline 17-Jan & -85 & -54 & 90.8 & 72.1 & 876 & 5.6 & 5.9 & 82.7 & 49.2 & 7.4 & 0.5 \\
\hline 18-Jan & -76 & -47 & 81.5 & 60.7 & 897 & 5 & 5.4 & 89.1 & 50 & 6.5 & 1.1 \\
\hline 19-Jan & -23 & 10 & 83.5 & 77.5 & 1006 & 2.7 & 4.3 & 96.2 & 63.2 & 5.3 & 0.5 \\
\hline 20-Jan & -31 & -1 & 100.2 & 95.5 & 1061 & 2.5 & 4.2 & 94.5 & 64.6 & 5.3 & 2.7 \\
\hline 21-Jan & -34 & -4 & 64.2 & 56.6 & 819 & 2.6 & 4.9 & 94.9 & 52.6 & 5.9 & 1.4 \\
\hline 22-Jan & -28 & -1 & 56.6 & 50.7 & 807 & 2.3 & 4.4 & 92.9 & 64.3 & 5.8 & 0 \\
\hline 23-Jan & -46 & -12 & 79.7 & 65.8 & 966 & 3.3 & 4.6 & 94.5 & 59 & 5.6 & 1.6 \\
\hline 24-Jan & -42 & -12 & 87.2 & 77.9 & 945 & 3.2 & 5 & 92.9 & 54.6 & 6.2 & 1.6 \\
\hline 25-Jan & -38 & -5 & 63.6 & 52.9 & 931 & 2.9 & 4.2 & 97.8 & 65.9 & 5 & 0.5 \\
\hline 26-Jan & -38 & -8 & 87.5 & 81.1 & 1003 & 3.3 & 4.7 & 91.3 & 57.6 & 5.8 & 1.1 \\
\hline 27-Jan & -53 & -24 & 77.5 & 65.1 & 946 & 4 & 4.7 & 92.5 & 58.6 & 5.9 & 0 \\
\hline 29-Jan & -52 & -20 & 62 & 47 & 847 & 3.7 & 4.3 & 95.7 & 63 & 5.2 & 1.4 \\
\hline 30-Jan & -53 & -22 & 73.6 & 64.4 & 936 & 3.6 & 4.5 & 89.7 & 61.4 & 5.8 & 1 \\
\hline 31-Jan & -49 & -16 & 84.5 & 74.8 & 966 & 3.6 & 4.5 & 0 & 67 & 5.9 & 1 \\
\hline
\end{tabular}

a. The INRIX data quality evaluations on SB15 segment were between November 20 and January 31, excluding November 28 - December 6 and December 14 - January 1

b. The missing dates were caused by the absent of Bluetooth or Raw data 
Table A-10 Final tables and percent blank out of INRIX data analysis on I-95 corridor, SB19 segment

\begin{tabular}{|c|c|c|c|c|c|c|c|c|c|c|c|}
\hline \multirow[t]{3}{*}{ Date } & \multicolumn{2}{|c|}{$\begin{array}{c}\text { Travel Time } \\
\text { Error Bias (sec) }\end{array}$} & \multicolumn{2}{|c|}{$\begin{array}{l}\text { Absolute Travel } \\
\text { Time Error (sec) }\end{array}$} & \multirow{3}{*}{$\begin{array}{l}\text { Mean } \\
\text { Travel } \\
\text { Time } \\
(\mathrm{sec}) \\
\end{array}$} & \multirow{3}{*}{$\begin{array}{c}\text { Raw } \\
\text { Speed } \\
\text { Error } \\
\text { Bias } \\
\\
(\mathrm{mph}) \\
\end{array}$} & \multirow{3}{*}{$\begin{array}{c}\text { Raw } \\
\text { Speed } \\
\text { Absolute } \\
\text { Error } \\
(\mathrm{mph}) \\
\end{array}$} & \multirow{2}{*}{\multicolumn{2}{|c|}{$\begin{array}{c}\% \text { of Raw } \\
\text { Travel } \\
\text { Time within } \\
\text { Error } \\
\text { Thresholds }\end{array}$}} & \multirow{3}{*}{$\begin{array}{l}\text { Raw } \\
\text { Data } \\
\text { RMSE } \\
(\mathrm{mph}) \\
\end{array}$} & \multirow{3}{*}{$\begin{array}{r}\text { Blank } \\
\text { Out } \\
(\%) \\
\end{array}$} \\
\hline & \multirow{2}{*}{$\begin{array}{l}\text { Raw } \\
\text { Time } \\
\end{array}$} & \multirow{2}{*}{$\begin{array}{c}\text { Reported } \\
\text { Time } \\
\end{array}$} & \multirow{2}{*}{$\begin{array}{l}\text { Raw } \\
\text { Time } \\
\end{array}$} & \multirow{2}{*}{$\begin{array}{c}\text { Reported } \\
\text { Time } \\
\end{array}$} & & & & & & & \\
\hline & & & & & & & & $\begin{array}{l} \pm 10 \\
\mathrm{mph}\end{array}$ & $\begin{array}{c} \pm 5 \\
\mathrm{mph}\end{array}$ & & \\
\hline 2-Jan & -115 & -85 & 120 & 101 & 1010 & 9.1 & 9.1 & 55.9 & 20.4 & 10.1 & 0 \\
\hline 3-Jan & -133 & -106 & 147 & 132 & 1168 & 7.6 & 7.8 & 74.5 & 28.3 & 8.9 & 1.1 \\
\hline 4-Jan & -109 & -76 & 113.4 & 89.1 & 1160 & 8.1 & 8.1 & 69.6 & 23.4 & 9 & 1.1 \\
\hline 5-Jan & 123.6 & -93 & 133.4 & 115.9 & 1183 & 7.4 & 7.5 & 75.3 & 24.2 & 8.3 & 0 \\
\hline 6-Jan & -171 & -140 & 214.3 & 196.5 & 1357 & 6.8 & 7.4 & 76.5 & 28.3 & 8.3 & 0 \\
\hline 7-Jan & -86 & -55 & 91 & 67 & 1002 & 8.4 & 8.4 & 70.5 & 15.8 & 9.2 & 0.7 \\
\hline 8-Jan & -70 & -40 & 73 & 54 & 956 & 8.1 & 8.1 & 74.8 & 18 & 8.8 & 0 \\
\hline 9-Jan & -155 & -125 & 166.6 & 147.8 & 1260 & 7.9 & 7.9 & 70.4 & 25.3 & 9 & 0 \\
\hline 10-Jan & -202 & -174 & 213.6 & 193.7 & 1210 & 9.7 & 9.9 & 59.8 & 16.8 & 11.8 & 1.1 \\
\hline 12-Jan & -162 & -131 & 206.7 & 190.8 & 1414 & 7.2 & 7.5 & 73.1 & 29.6 & 8.7 & 0 \\
\hline 13-Jan & -148 & -119 & 157.4 & 139.3 & 1213 & 7.9 & 7.9 & 74.6 & 22.7 & 8.7 & 0.5 \\
\hline 14-Jan & -72 & -40 & 76.2 & 56.2 & 964 & 7.9 & 8 & 72.9 & 21.4 & 8.7 & 0 \\
\hline 15-Jan & -47 & -16 & 65.6 & 50 & 953 & 6.8 & 7.3 & 82 & 24.5 & 8.3 & 0.7 \\
\hline 16-Jan & -71 & -42 & 73.1 & 50.6 & 942 & 8.4 & 8.4 & 73 & 10.3 & 8.9 & 0.5 \\
\hline 17-Jan & -121 & -90 & 124.2 & 98.3 & 1069 & 9.1 & 9.2 & 63.4 & 10.2 & 9.9 & 0 \\
\hline 18-Jan & -110 & -82 & 116.7 & 94.1 & 1036 & 8.9 & 9 & 65.2 & 11.4 & 9.8 & 0.5 \\
\hline 19-Jan & -96 & -65 & 135.9 & 119.2 & 1143 & 7.2 & 8 & 70.8 & 22.2 & 9.1 & 0.5 \\
\hline 20-Jan & -116 & -88 & 178.3 & 161.7 & 1333 & 7 & 7.4 & 74.2 & 30.1 & 8.5 & 0 \\
\hline 21-Jan & -54 & -24 & 73 & 63.1 & 985 & 6.8 & 7.2 & 75.5 & 31.7 & 8.4 & 0 \\
\hline 22-Jan & -45 & -14 & 75.5 & 64.6 & 972 & 6.4 & 7.2 & 77.9 & 31.4 & 8.4 & 0 \\
\hline 23-Jan & -99 & -68 & 104.5 & 85.2 & 1091 & 8.1 & 8.1 & 69 & 21.2 & 9 & 1.1 \\
\hline
\end{tabular}

a. The INRIX data quality evaluations on SB19 segment were from January 2 - 31

b. The missing dates were caused by the absent of Bluetooth or Raw data 
Table A-11 Final tables and percent blank out of INRIX data analysis on I-95 corridor, SB33 segment

\begin{tabular}{|c|c|c|c|c|c|c|c|c|c|c|c|}
\hline \multirow[t]{3}{*}{ Date } & \multicolumn{2}{|c|}{$\begin{array}{c}\text { Travel Time } \\
\text { Error Bias (sec) }\end{array}$} & \multicolumn{2}{|c|}{$\begin{array}{l}\text { Absolute Travel } \\
\text { Time Error (sec) }\end{array}$} & \multirow{3}{*}{$\begin{array}{l}\text { Mean } \\
\text { Travel } \\
\text { Time } \\
(\mathrm{sec}) \\
\end{array}$} & \multirow{3}{*}{$\begin{array}{c}\text { Raw } \\
\text { Speed } \\
\text { Error } \\
\text { Bias } \\
\\
\\
(\mathrm{mph}) \\
\end{array}$} & \multirow{3}{*}{$\begin{array}{c}\text { Raw } \\
\text { Speed } \\
\text { Absolute } \\
\text { Error } \\
(\mathrm{mph}) \\
\end{array}$} & \multirow{2}{*}{\multicolumn{2}{|c|}{$\begin{array}{c}\% \text { of Raw } \\
\text { Travel } \\
\text { Time within } \\
\text { Error } \\
\text { Thresholds }\end{array}$}} & \multirow{3}{*}{$\begin{array}{c}\text { Raw } \\
\text { Data } \\
\text { RMSE } \\
(\mathrm{mph}) \\
\end{array}$} & \multirow{3}{*}{$\begin{array}{r}\text { Blank } \\
\text { Out } \\
(\%) \\
\end{array}$} \\
\hline & \multirow{2}{*}{$\begin{array}{l}\text { Raw } \\
\text { Time }\end{array}$} & \multirow{2}{*}{$\begin{array}{c}\text { Reported } \\
\text { Time }\end{array}$} & \multirow{2}{*}{$\begin{array}{l}\text { Raw } \\
\text { Time }\end{array}$} & \multirow{2}{*}{$\begin{array}{c}\text { Reported } \\
\text { Time }\end{array}$} & & & & & & & \\
\hline & & & & & & & & $\begin{array}{l} \pm 10 \\
\mathrm{mph}\end{array}$ & $\begin{array}{c} \pm 5 \\
\mathrm{mph}\end{array}$ & & \\
\hline 7-Dec & -559 & -527 & 588 & 560 & 2277 & 11.3 & 11.7 & 40.9 & 12.4 & 13.2 & 0 \\
\hline 8-Dec & -337 & -307 & 381 & 358 & 2327 & 8.7 & 8.9 & 61.6 & 29.7 & 10.8 & 0 \\
\hline 9-Dec & -327 & -297 & 327.3 & 298.2 & 1891 & 9.6 & 9.6 & 57 & 12.9 & 10.4 & 0 \\
\hline 10-Dec & -248 & -219 & 256 & 230 & 1641 & 10.4 & 10.6 & 51.8 & 15.1 & 11.8 & 0 \\
\hline 11-Dec & -251 & -223 & 255 & 229 & 1655 & 10.5 & 10.6 & 48.2 & 12.2 & 11.7 & 0 \\
\hline 12-Dec & -307 & -277 & 311.7 & 283.2 & 1859 & 9.9 & 10 & 55.9 & 15.1 & 11 & 0 \\
\hline 13-Dec & -403 & -375 & 466.7 & 447.3 & 2290 & 9.4 & 9.9 & 56.5 & 26.3 & 11.8 & 0 \\
\hline 2-Jan & -289 & -258 & 290 & 261 & 1616 & 11.8 & 11.8 & 39.8 & 7.5 & 12.8 & 0 \\
\hline 3-Jan & -381 & -351 & 386 & 357 & 1806 & 11.9 & 11.9 & 41.9 & 12.9 & 13.6 & 0 \\
\hline 4-Jan & -313 & -284 & 313.7 & 286.3 & 1778 & 10.9 & 10.9 & 46.2 & 8.1 & 12 & 0 \\
\hline 5-Jan & -340 & -311 & 346.8 & 321.4 & 1815 & 11.1 & 11.3 & 44.1 & 10.8 & 12.6 & 0 \\
\hline 6-Jan & -432 & -403 & 447.2 & 420.6 & 2074 & 10.5 & 10.6 & 45.7 & 15.1 & 12 & 0 \\
\hline 7-Jan & -264 & -235 & 268 & 240 & 1634 & 11.3 & 11.3 & 40.3 & 7.2 & 12.1 & 0 \\
\hline 8-Jan & -237 & -207 & 237 & 208 & 1551 & 11.2 & 11.2 & 45 & 5 & 12.2 & 0 \\
\hline 9-Jan & -397 & -370 & 402.2 & 376.8 & 1913 & 10.7 & 10.8 & 51.1 & 10.8 & 12.2 & 0 \\
\hline 10-Jan & -390 & -359 & 397.5 & 369.1 & 1830 & 11.9 & 12 & 42.5 & 8.1 & 13.4 & 0 \\
\hline 12-Jan & -391 & -362 & 421.6 & 398.1 & 2041 & 9.8 & 10.1 & 52.2 & 15.6 & 11.4 & 0 \\
\hline 13-Jan & -387 & -357 & 390.6 & 362.2 & 1929 & 10.5 & 10.5 & 52.2 & 12.5 & 11.7 & 0 \\
\hline 14-Jan & -234 & -205 & 234.3 & 206.9 & 1570 & 10.8 & 10.8 & 48.6 & 8.6 & 11.9 & 0 \\
\hline 15-Jan & -193 & -163 & 204.8 & 178.6 & 1559 & 9.7 & 10 & 57.1 & 12.1 & 11.2 & 0 \\
\hline 16-Jan & -230 & -202 & 230.7 & 204 & 1549 & 11 & 11 & 44.1 & 4.8 & 12 & 0 \\
\hline 17-Jan & -302 & -274 & 301.8 & 275.1 & 1696 & 11.3 & 11.3 & 40.9 & 8.1 & 12.2 & 0 \\
\hline 18-Jan & -275 & -246 & 275.7 & 247.5 & 1650 & 11.1 & 11.1 & 43 & 4.3 & 12 & 0 \\
\hline 19-Jan & -290 & -258 & 314.6 & 287.8 & 1847 & 10.2 & 10.6 & 46.8 & 16.1 & 11.9 & 0 \\
\hline 20-Jan & -297 & -268 & 336.2 & 311.1 & 1949 & 9.1 & 9.5 & 61.3 & 21 & 11 & 0 \\
\hline 21-Jan & -217 & -187 & 220.1 & 193.1 & 1606 & 9.9 & 9.9 & 54 & 17.3 & 11.1 & 0 \\
\hline 22-Jan & -198 & -171 & 214.3 & 191.9 & 1613 & 9.3 & 9.6 & 55 & 17.9 & 10.8 & 0 \\
\hline 23-Jan & -274 & -245 & 275 & 247.4 & 1708 & 10.6 & 10.6 & 45.7 & 10.2 & 11.7 & 0 \\
\hline 24-Jan & -283 & -254 & 284.7 & 257.4 & 1700 & 10.9 & 10.9 & 46.2 & 8.1 & 12 & 0 \\
\hline 25-Jan & -288 & -256 & 289.5 & 259.6 & 1689 & 11 & 11.1 & 45.2 & 11.3 & 12.3 & 0 \\
\hline 26-Jan & -277 & -246 & 278.3 & 249 & 1773 & 10.6 & 10.6 & 46.2 & 12.9 & 11.8 & 0 \\
\hline
\end{tabular}




\begin{tabular}{|c|c|c|c|c|c|c|c|c|c|c|c|} 
27-Jan & -339 & -309 & 351.4 & 326.1 & 1815 & 11.6 & 11.7 & 38.7 & 12.9 & 13.2 & 0 \\
\hline 29-Jan & -278 & -247 & 278.8 & 250.3 & 1601 & 11.8 & 11.8 & 38.6 & 7.9 & 12.9 & 0 \\
\hline 30-Jan & -291 & -259 & 292.8 & 263.3 & 1662 & 11.3 & 11.4 & 47.8 & 10.8 & 12.7 & 0 \\
\hline 31-Jan & -308 & -279 & 308 & 281 & 1714 & 11.5 & 11.5 & 0 & 8.1 & 12.5 & 0 \\
\hline
\end{tabular}

a. The INRIX data quality evaluations on SB33 segment were between December 7 and January 31, excluding December 14 - January 1.

b. The missing dates were caused by the absent of Bluetooth or Raw data 


\section{APPENDIX B}

\section{DATA QUALITY ASSESSMENT IN HAMPTON ROADS AREA}

Table B-1 Final tables and percent blank out of INRIX data analysis on I-64 corridor, link 5840

\begin{tabular}{|c|c|c|c|c|c|c|}
\hline Date & $\begin{array}{c}\text { Avg. BT } \\
\text { travel time }\end{array}$ & $\begin{array}{c}\text { Mean Bias } \\
(\mathrm{mph})\end{array}$ & $\begin{array}{c}\text { Mean } \\
\text { Absolute } \\
\text { Error (mph) }\end{array}$ & $\begin{array}{c}\% \text { within } 5 \\
\text { MPH of } \\
\text { BlueToad }\end{array}$ & $\begin{array}{l}\% \text { Within } \\
10 \mathrm{mph} \text { of } \\
\text { BlueToad }\end{array}$ & $\begin{array}{c}\% \text { of Time } \\
\text { Blanked } \\
\text { Out }\end{array}$ \\
\hline 16-Jul & 477 & -2.8 & 4.5 & $70 \%$ & $92 \%$ & $0 \%$ \\
\hline 17-Jul & 477.8 & -0.5 & 3 & $79 \%$ & $98 \%$ & $0.00 \%$ \\
\hline 18-Jul & 477.5 & -0.7 & 3.3 & $79 \%$ & $97 \%$ & $1 \%$ \\
\hline 19-Jul & 476 & -2.2 & 3.9 & $72 \%$ & $93 \%$ & $0 \%$ \\
\hline 20-Jul & 476.8 & -2.7 & 4.6 & $67 \%$ & $85 \%$ & $0 \%$ \\
\hline 21-Jul & 485 & -5.9 & 8.1 & $41 \%$ & $66 \%$ & $1.39 \%$ \\
\hline 22-Jul & 460.1 & -2 & 3.1 & $85 \%$ & $98 \%$ & $8.33 \%$ \\
\hline 23-Jul & 471.1 & -1.3 & 3.4 & $76 \%$ & $97 \%$ & $0 \%$ \\
\hline 24-Jul & 484.1 & -0.9 & 2.8 & $87 \%$ & $99 \%$ & $0.52 \%$ \\
\hline 25-Jul & 476.9 & -0.9 & 3 & $85 \%$ & $95 \%$ & $1 \%$ \\
\hline 26-Jul & 477.6 & -2.6 & 4.3 & $64 \%$ & $89 \%$ & $4 \%$ \\
\hline 27-Jul & 481.5 & -3.6 & 5.2 & $61 \%$ & $85 \%$ & $0 \%$ \\
\hline 28-Jul & 471.3 & -5.8 & 7.2 & $49 \%$ & $69 \%$ & $2.78 \%$ \\
\hline 29-Jul & 458.4 & -1.2 & 3 & $81 \%$ & $98 \%$ & $4.17 \%$ \\
\hline 30-Jul & 500.3 & 0.2 & 2.6 & $85 \%$ & $99 \%$ & $1 \%$ \\
\hline 31-Jul & 477.7 & -0.3 & 2.6 & $88 \%$ & $99 \%$ & $1.04 \%$ \\
\hline 1-Aug & 476.3 & -1.2 & 3.3 & $79 \%$ & $95 \%$ & $6 \%$ \\
\hline 2-Aug & 475.8 & -0.8 & 2.9 & $85 \%$ & $99 \%$ & $1 \%$ \\
\hline 3-Aug & 473.9 & -5.3 & 6.6 & $62 \%$ & $77 \%$ & $1 \%$ \\
\hline 4-Aug & 488 & -4.4 & 7.1 & $46 \%$ & $73 \%$ & $0.00 \%$ \\
\hline 5-Aug & 463.5 & -3.4 & 4.6 & $61 \%$ & $91 \%$ & $15.28 \%$ \\
\hline 6-Aug & 481.1 & -1.9 & 3.9 & $71 \%$ & $94 \%$ & $0 \%$ \\
\hline 7-Aug & 483.9 & 0.2 & 3.1 & $83 \%$ & $97 \%$ & $0.52 \%$ \\
\hline 8-Aug & 472.6 & -2.2 & 3.9 & $77 \%$ & $94 \%$ & $0 \%$ \\
\hline 9-Aug & 475.2 & -1.3 & 3.4 & $77 \%$ & $97 \%$ & $0 \%$ \\
\hline 10-Aug & 474.1 & -4.4 & 5.5 & $56 \%$ & $83 \%$ & $0 \%$ \\
\hline 11-Aug & 520.4 & -9.4 & 10.2 & $43 \%$ & $63 \%$ & $0.69 \%$ \\
\hline 12-Aug & 454.3 & -2 & 2.8 & $86 \%$ & $100 \%$ & $4.17 \%$ \\
\hline 13-Aug & 473.4 & -0.6 & 2.8 & $85 \%$ & $99 \%$ & $1 \%$ \\
\hline 14-Aug & 475.6 & -0.2 & 2.6 & $85 \%$ & $98 \%$ & $0.00 \%$ \\
\hline 15-Aug & 481.1 & -1.3 & 3.7 & $75 \%$ & $91 \%$ & $0 \%$ \\
\hline 16-Aug & 468.6 & -1.3 & 3.2 & $77 \%$ & $96 \%$ & $1 \%$ \\
\hline 17-Aug & 472.6 & -3.3 & 4.9 & $63 \%$ & $86 \%$ & $0 \%$ \\
\hline 18-Aug & 472.1 & -3.5 & 5.2 & $64 \%$ & $84 \%$ & $0 \%$ \\
\hline 19-Aug & 467.9 & -2.3 & 5.1 & $60 \%$ & $88 \%$ & $1.39 \%$ \\
\hline
\end{tabular}


Table B-2 Final tables and percent blank out of INRIX data analysis on I-64 corridor, link 5841

\begin{tabular}{|c|c|c|c|c|c|c|}
\hline Date & $\begin{array}{l}\text { Avg. BT } \\
\text { travel time }\end{array}$ & $\begin{array}{c}\text { Mean Bias } \\
(\mathrm{mph})\end{array}$ & $\begin{array}{c}\text { Mean } \\
\text { Absolute } \\
\text { Error (mph) }\end{array}$ & $\begin{array}{c}\% \text { within } 5 \\
\text { MPH of } \\
\text { BlueToad }\end{array}$ & $\begin{array}{l}\% \text { Within } \\
10 \text { mph of } \\
\text { BlueToad }\end{array}$ & $\begin{array}{c}\% \text { of Time } \\
\text { Blanked } \\
\text { Out }\end{array}$ \\
\hline 16-Jul & 510 & 1.1 & 6 & $72 \%$ & $84 \%$ & $0.52 \%$ \\
\hline 17-Jul & 482.7 & 0.6 & 3.1 & $85 \%$ & $96 \%$ & $2.60 \%$ \\
\hline 18-Jul & 477.1 & -0.1 & 2.4 & $88 \%$ & $99 \%$ & $1.04 \%$ \\
\hline 19-Jul & 482.2 & -0.7 & 3.5 & $84 \%$ & $94 \%$ & $0.52 \%$ \\
\hline 20-Jul & 1064.9 & 11.3 & 12.9 & $44 \%$ & $60 \%$ & $1.04 \%$ \\
\hline 21-Jul & 909.2 & 8.5 & 11.4 & $39 \%$ & $65 \%$ & $0.69 \%$ \\
\hline 22-Jul & 563.2 & -1.6 & 6.9 & $51 \%$ & $75 \%$ & $0.69 \%$ \\
\hline 23-Jul & 476.7 & 0.1 & 2.7 & $90 \%$ & $99 \%$ & $0.52 \%$ \\
\hline 24-Jul & 505.7 & 0 & 3 & $83 \%$ & $97 \%$ & $1.56 \%$ \\
\hline 25-Jul & 480.5 & -0.1 & 2.6 & $88 \%$ & $98 \%$ & $0.52 \%$ \\
\hline 26-Jul & 505.7 & 1.4 & 3.9 & $72 \%$ & $90 \%$ & $5.73 \%$ \\
\hline 27-Jul & 587.1 & 5.4 & 7 & $49 \%$ & $68 \%$ & $0.52 \%$ \\
\hline 28-Jul & 1266.2 & 5.8 & 6.8 & $48 \%$ & $80 \%$ & $0.00 \%$ \\
\hline 29-Jul & 592.1 & 4.8 & 6.2 & $54 \%$ & $76 \%$ & $0.00 \%$ \\
\hline 30-Jul & 478.8 & -0.2 & 2.8 & $86 \%$ & $98 \%$ & $1.04 \%$ \\
\hline 31-Jul & 478.7 & 0.4 & 2.7 & $87 \%$ & $99 \%$ & $1.56 \%$ \\
\hline 1-Aug & 564.8 & 2 & 4.4 & $72 \%$ & $91 \%$ & $3.65 \%$ \\
\hline 2 -Aug & 639 & 2.2 & 3.7 & $76 \%$ & $91 \%$ & $0.52 \%$ \\
\hline 3-Aug & 623.6 & 4.2 & 5.7 & $58 \%$ & $80 \%$ & $0.00 \%$ \\
\hline 4-Aug & 806.6 & 3.9 & 6.9 & $46 \%$ & $75 \%$ & $0.00 \%$ \\
\hline 5-Aug & 881.2 & 7.4 & 8.5 & $42 \%$ & $62 \%$ & $15.97 \%$ \\
\hline 6-Aug & 510 & 1.1 & 2.9 & $85 \%$ & $96 \%$ & $1.56 \%$ \\
\hline 7-Aug & 482.7 & 0.6 & 2.8 & $88 \%$ & $96 \%$ & $3.13 \%$ \\
\hline 8-Aug & 477.1 & -0.2 & 2.4 & $87 \%$ & $99 \%$ & $1.04 \%$ \\
\hline 9-Aug & 482.2 & 0.3 & 2.6 & $86 \%$ & $100 \%$ & $1.04 \%$ \\
\hline 10-Aug & 1064.9 & 3.6 & 5.2 & $58 \%$ & $87 \%$ & $1.04 \%$ \\
\hline 11-Aug & 909.2 & 5.6 & 6.9 & $48 \%$ & $74 \%$ & $1.39 \%$ \\
\hline 12-Aug & 563.2 & 4.3 & 6.3 & $57 \%$ & $73 \%$ & $6.94 \%$ \\
\hline 13-Aug & 477.5 & 0.4 & 2.8 & $83 \%$ & $97 \%$ & $1.04 \%$ \\
\hline 14-Aug & 501.6 & 1.1 & 3.7 & $81 \%$ & $92 \%$ & $0.52 \%$ \\
\hline 15-Aug & 486.2 & 0.1 & 2.8 & $87 \%$ & $97 \%$ & $0.00 \%$ \\
\hline 16-Aug & 1004 & 2.8 & 4.6 & $63 \%$ & $89 \%$ & $0.52 \%$ \\
\hline 17-Aug & 738.5 & 4.7 & 6.5 & $50 \%$ & $73 \%$ & $1 \%$ \\
\hline 18-Aug & 1018.6 & 6.8 & 7.7 & $50 \%$ & $69 \%$ & $2.08 \%$ \\
\hline 19-Aug & 746.5 & 5.4 & 6.9 & $47 \%$ & $71 \%$ & $0.69 \%$ \\
\hline
\end{tabular}


Table B-3 Final tables and percent blank out of INRIX data analysis on I-64 corridor, link 5842

\begin{tabular}{|c|c|c|c|c|c|c|}
\hline Date & $\begin{array}{l}\text { Avg. BT } \\
\text { travel time }\end{array}$ & $\begin{array}{c}\text { Mean Bias } \\
(\mathrm{mph})\end{array}$ & $\begin{array}{c}\text { Mean } \\
\text { Absolute } \\
\text { Error (mph) }\end{array}$ & $\begin{array}{c}\% \text { within } 5 \\
\text { MPH of } \\
\text { BlueToad }\end{array}$ & $\begin{array}{l}\text { \% Within } \\
10 \mathrm{mph} \text { of } \\
\text { BlueToad }\end{array}$ & $\begin{array}{c}\% \text { of Time } \\
\text { Blanked } \\
\text { Out }\end{array}$ \\
\hline 16-Jul & 97.5 & -0.6 & 2.4 & $91 \%$ & $99 \%$ & $3 \%$ \\
\hline 17-Jul & 97.2 & -0.8 & 2.3 & $89 \%$ & $99 \%$ & $0 \%$ \\
\hline 18-Jul & 97.3 & -0.9 & 2.7 & $88 \%$ & $99 \%$ & $0 \%$ \\
\hline 19-Jul & 97.6 & -0.7 & 2.2 & $91 \%$ & $100 \%$ & $0 \%$ \\
\hline 20-Jul & 98.6 & 0 & 2.7 & $85 \%$ & $97 \%$ & $0 \%$ \\
\hline 21-Jul & 100.6 & -2.1 & 3.9 & $79 \%$ & $93 \%$ & $0 \%$ \\
\hline 22-Jul & 94.6 & -1.2 & 3.4 & $80 \%$ & $99 \%$ & $6 \%$ \\
\hline 23-Jul & 102.4 & -0.3 & 3.4 & $82 \%$ & $94 \%$ & $0 \%$ \\
\hline 24-Jul & 97.6 & -1.2 & 2.5 & $86 \%$ & $99 \%$ & $0 \%$ \\
\hline 25-Jul & 98.1 & 0.1 & 2.4 & $89 \%$ & $99 \%$ & $0 \%$ \\
\hline 26-Jul & 98.4 & -1 & 2.9 & $88 \%$ & $99 \%$ & $4 \%$ \\
\hline 27-Jul & 97.4 & -0.4 & 2.4 & $91 \%$ & $99 \%$ & $0 \%$ \\
\hline 28-Jul & 95.6 & -0.8 & 2.5 & $88 \%$ & $100 \%$ & $3 \%$ \\
\hline 29-Jul & 95.3 & -0.9 & 2.7 & $83 \%$ & $99 \%$ & $2 \%$ \\
\hline 30-Jul & 97.7 & -0.6 & 2.2 & $91 \%$ & $99 \%$ & $1 \%$ \\
\hline 31-Jul & 98.1 & -0.4 & 2.1 & $93 \%$ & $100 \%$ & $2 \%$ \\
\hline 1-Aug & 96.1 & -1.4 & 2.3 & $92 \%$ & $99 \%$ & $6 \%$ \\
\hline 2 -Aug & 96.6 & -1 & 2.3 & $94 \%$ & $100 \%$ & $0 \%$ \\
\hline 3-Aug & 96.5 & -1.1 & 2.6 & $85 \%$ & $100 \%$ & $0 \%$ \\
\hline 4-Aug & 96.2 & -0.2 & 2.8 & $88 \%$ & $100 \%$ & $0 \%$ \\
\hline 5-Aug & 95.8 & -0.4 & 2.4 & $88 \%$ & $100 \%$ & $15 \%$ \\
\hline 6-Aug & 98.9 & -0.1 & 2.7 & $85 \%$ & $98 \%$ & $0 \%$ \\
\hline 7-Aug & 98.5 & 0 & 2.6 & $84 \%$ & $100 \%$ & $1 \%$ \\
\hline 8-Aug & 96.6 & -1 & 2.5 & $89 \%$ & $100 \%$ & $0 \%$ \\
\hline 9-Aug & 97.6 & -0.5 & 2.2 & $93 \%$ & $100 \%$ & $0 \%$ \\
\hline 10-Aug & 97 & -0.8 & 2.5 & $86 \%$ & $100 \%$ & $0 \%$ \\
\hline 11-Aug & 104.3 & -0.6 & 3.9 & $75 \%$ & $90 \%$ & $0 \%$ \\
\hline 12-Aug & 92.8 & -2.7 & 3.7 & $73 \%$ & $98 \%$ & $3 \%$ \\
\hline 13-Aug & 98.4 & -0.2 & 2.4 & $88 \%$ & $99 \%$ & $1 \%$ \\
\hline 14-Aug & 98.3 & -1 & 2.6 & $92 \%$ & $98 \%$ & $0 \%$ \\
\hline 15-Aug & 98.3 & -0.3 & 2.5 & $89 \%$ & $98 \%$ & $0 \%$ \\
\hline 16-Aug & 95.8 & -1.7 & 2.6 & $88 \%$ & $99 \%$ & $2 \%$ \\
\hline 17-Aug & 96.3 & -1.5 & 2.4 & $89 \%$ & $100 \%$ & $0 \%$ \\
\hline 18-Aug & 99 & 0.4 & 2.1 & $91 \%$ & $99 \%$ & $0 \%$ \\
\hline 19-Aug & 96.3 & -1 & 2.5 & $88 \%$ & $100 \%$ & $0 \%$ \\
\hline
\end{tabular}


Table B-4Final tables and percent blank out of INRIX data analysis on I-64 corridor, link 5843

\begin{tabular}{|c|c|c|c|c|c|c|}
\hline Date & $\begin{array}{l}\text { Avg. BT } \\
\text { travel time }\end{array}$ & $\begin{array}{l}\text { Mean Bias } \\
(\mathrm{mph})\end{array}$ & $\begin{array}{c}\text { Mean } \\
\text { Absolute } \\
\text { Error (mph) }\end{array}$ & $\begin{array}{l}\text { \% within } 5 \\
\text { MPH of } \\
\text { BlueToad }\end{array}$ & $\begin{array}{c}\% \text { Within } 10 \\
\text { mph of } \\
\text { BlueToad }\end{array}$ & $\begin{array}{c}\% \text { of Time } \\
\text { Blanked Out }\end{array}$ \\
\hline 16-Jul & 99 & -1 & 2.7 & $87 \%$ & $99 \%$ & $1 \%$ \\
\hline 17-Jul & 98.8 & -0.7 & 2.9 & $84 \%$ & $98 \%$ & $2 \%$ \\
\hline 18-Jul & 99.6 & -0.4 & 2.7 & $83 \%$ & $99 \%$ & $1 \%$ \\
\hline 19-Jul & 98.7 & -0.9 & 2.7 & $88 \%$ & $98 \%$ & $1 \%$ \\
\hline 20-Jul & 100.7 & 0 & 3.2 & $85 \%$ & $97 \%$ & $1 \%$ \\
\hline 21-Jul & 97.9 & -2.5 & 3.7 & $75 \%$ & $96 \%$ & $1 \%$ \\
\hline 22-Jul & 95.5 & -2.8 & 3.9 & $71 \%$ & $97 \%$ & $6 \%$ \\
\hline 23-Jul & 98.9 & -0.6 & 3.1 & $80 \%$ & $97 \%$ & $2 \%$ \\
\hline 24-Jul & 102.9 & -0.4 & 3.4 & $80 \%$ & $94 \%$ & $1 \%$ \\
\hline 25-Jul & 98.1 & -1.1 & 3 & $83 \%$ & $98 \%$ & $0 \%$ \\
\hline 26-Jul & 99.1 & -1.1 & 3.1 & $81 \%$ & $97 \%$ & $4 \%$ \\
\hline 27-Jul & 100.2 & 0.1 & 2.5 & $89 \%$ & $99 \%$ & $0 \%$ \\
\hline 28-Jul & 97.2 & -2.1 & 3.8 & $72 \%$ & $95 \%$ & $1 \%$ \\
\hline 29-Jul & 95.3 & -3 & 4.1 & $66 \%$ & $93 \%$ & $1 \%$ \\
\hline 30-Jul & 97.5 & -1.4 & 3.1 & $81 \%$ & $97 \%$ & $0 \%$ \\
\hline 31-Jul & 97.7 & -1.5 & 3 & $81 \%$ & $98 \%$ & $2 \%$ \\
\hline 1-Aug & 99 & -0.7 & 2.9 & $82 \%$ & $98 \%$ & $4 \%$ \\
\hline 2-Aug & 99.4 & 0.1 & 2.8 & $86 \%$ & $98 \%$ & $1 \%$ \\
\hline 3-Aug & 98.5 & -0.3 & 2.6 & $84 \%$ & $99 \%$ & $1 \%$ \\
\hline 4-Aug & 96.5 & -3 & 4.2 & $63 \%$ & $97 \%$ & $3 \%$ \\
\hline 5-Aug & 95.5 & -2.5 & 3.5 & $77 \%$ & $97 \%$ & $15 \%$ \\
\hline 6-Aug & 100.2 & -0.6 & 3.1 & $80 \%$ & $98 \%$ & $2 \%$ \\
\hline 7-Aug & 98.8 & -0.8 & 2.9 & $83 \%$ & $98 \%$ & $3 \%$ \\
\hline 8-Aug & 98.3 & -0.8 & 2.6 & $90 \%$ & $99 \%$ & $1 \%$ \\
\hline 9-Aug & 98.6 & -0.5 & 2.7 & $84 \%$ & $99 \%$ & $1 \%$ \\
\hline 10-Aug & 99.2 & -0.1 & 2.6 & $86 \%$ & $99 \%$ & $1 \%$ \\
\hline 11-Aug & 111.2 & -0.1 & 3.9 & $73 \%$ & $93 \%$ & $1 \%$ \\
\hline 12-Aug & 95.8 & -1.3 & 2.9 & $82 \%$ & $100 \%$ & $5 \%$ \\
\hline 13-Aug & 97.5 & -1 & 2.9 & $83 \%$ & $99 \%$ & $1 \%$ \\
\hline 14-Aug & 98.2 & -1.3 & 3 & $80 \%$ & $98 \%$ & $3 \%$ \\
\hline 15-Aug & 100 & -0.8 & 2.8 & $87 \%$ & $98 \%$ & $0 \%$ \\
\hline 16-Aug & 157.1 & -0.4 & 3.5 & $83 \%$ & $97 \%$ & $2 \%$ \\
\hline 17-Aug & 99 & -0.4 & 3.1 & $84 \%$ & $97 \%$ & $1 \%$ \\
\hline 18-Aug & 97.4 & -3.1 & 4 & $65 \%$ & $98 \%$ & $5 \%$ \\
\hline 19-Aug & 99.4 & -1.1 & 2.8 & $84 \%$ & $99 \%$ & $2 \%$ \\
\hline
\end{tabular}


Table B-5 Final tables and percent blank out of INRIX data analysis on I-64 corridor, link 5846

\begin{tabular}{|c|c|c|c|c|c|c|}
\hline Date & $\begin{array}{l}\text { Avg. BT } \\
\text { travel time }\end{array}$ & $\begin{array}{l}\text { Mean Bias } \\
(\mathrm{mph})\end{array}$ & $\begin{array}{c}\text { Mean } \\
\text { Absolute } \\
\text { Error (mph) }\end{array}$ & $\begin{array}{c}\% \text { within } 5 \\
\text { MPH of } \\
\text { BlueToad }\end{array}$ & $\begin{array}{c}\% \text { Within } 10 \\
\text { mph of } \\
\text { BlueToad }\end{array}$ & $\begin{array}{c}\% \text { of Time } \\
\text { Blanked Out }\end{array}$ \\
\hline 16-Jul & 52.3 & 2.9 & 3.9 & $69 \%$ & $97 \%$ & $4 \%$ \\
\hline 17-Jul & 53.4 & 4.4 & 5 & $55 \%$ & $91 \%$ & $0 \%$ \\
\hline 18-Jul & 53.5 & 4.7 & 5.1 & $57 \%$ & $91 \%$ & $1 \%$ \\
\hline 19-Jul & 53.7 & 4.6 & 4.9 & $56 \%$ & $93 \%$ & $0 \%$ \\
\hline 20-Jul & 54.3 & 4.2 & 5.1 & $58 \%$ & $92 \%$ & $0 \%$ \\
\hline 21-Jul & 78.8 & 4.4 & 6.2 & $49 \%$ & $86 \%$ & $3 \%$ \\
\hline 22-Jul & 51.5 & 3.3 & 4.1 & $66 \%$ & $94 \%$ & $7 \%$ \\
\hline 23-Jul & 54.8 & 3.9 & 5 & $60 \%$ & $92 \%$ & $0 \%$ \\
\hline 24-Jul & 54.1 & 4.8 & 5.3 & $45 \%$ & $94 \%$ & $0 \%$ \\
\hline 25-Jul & 53.3 & 4.8 & 5.2 & $51 \%$ & $94 \%$ & $2 \%$ \\
\hline 26-Jul & 53.1 & 3 & 4.1 & $66 \%$ & $94 \%$ & $4 \%$ \\
\hline 27-Jul & 52.4 & 3.7 & 4.4 & $59 \%$ & $91 \%$ & $0 \%$ \\
\hline 28-Jul & 52.5 & 4.5 & 4.8 & $53 \%$ & $94 \%$ & $2 \%$ \\
\hline 29-Jul & 51 & 2.5 & 3.4 & $73 \%$ & $98 \%$ & $8 \%$ \\
\hline 30-Jul & 53.6 & 4.3 & 4.6 & $56 \%$ & $95 \%$ & $1 \%$ \\
\hline 31-Jul & 53.5 & 4 & 4.7 & $57 \%$ & $95 \%$ & $1 \%$ \\
\hline 1-Aug & 53.2 & 4 & 5 & $56 \%$ & $94 \%$ & $6 \%$ \\
\hline 2-Aug & 55.3 & 4.3 & 5.8 & $47 \%$ & $92 \%$ & $1 \%$ \\
\hline 3-Aug & 52.3 & 3.3 & 4.1 & $69 \%$ & $97 \%$ & $1 \%$ \\
\hline 4-Aug & 52.9 & 4.6 & 5 & $54 \%$ & $93 \%$ & $0 \%$ \\
\hline 5-Aug & 52.6 & 4.5 & 5.3 & $49 \%$ & $89 \%$ & $13 \%$ \\
\hline 6-Aug & 54.1 & 4.6 & 5.1 & $58 \%$ & $91 \%$ & $1 \%$ \\
\hline 7-Aug & 53.6 & 3.9 & 5 & $55 \%$ & $92 \%$ & $1 \%$ \\
\hline 8-Aug & 53.5 & 4.8 & 5.2 & $52 \%$ & $93 \%$ & $2 \%$ \\
\hline 9-Aug & 54 & 5.4 & 5.6 & $49 \%$ & $90 \%$ & $2 \%$ \\
\hline 10-Aug & 52.6 & 3.8 & 4.5 & $62 \%$ & $95 \%$ & $0 \%$ \\
\hline 11-Aug & 75.8 & 5.2 & 6.4 & $49 \%$ & $84 \%$ & $1 \%$ \\
\hline 12-Aug & 51.2 & 2.4 & 3.3 & $77 \%$ & $96 \%$ & $11 \%$ \\
\hline 13-Aug & 53.2 & 4.1 & 4.7 & $55 \%$ & $93 \%$ & $3 \%$ \\
\hline 14-Aug & 53.5 & 4.2 & 4.8 & $55 \%$ & $97 \%$ & $2 \%$ \\
\hline 15-Aug & 55 & 4.2 & 4.9 & $55 \%$ & $93 \%$ & $0 \%$ \\
\hline 16-Aug & 53.5 & 4.9 & 5.5 & $51 \%$ & $90 \%$ & $3 \%$ \\
\hline 17-Aug & 64.3 & 2.9 & 4.9 & $62 \%$ & $91 \%$ & $0 \%$ \\
\hline 18-Aug & 53.2 & 3.6 & 4.3 & $63 \%$ & $96 \%$ & $0 \%$ \\
\hline 19-Aug & 53.7 & 4.5 & 5 & $56 \%$ & $89 \%$ & $1 \%$ \\
\hline
\end{tabular}


Table B-6 Final tables and percent blank out of INRIX data analysis on I-64 corridor, link 5847

\begin{tabular}{|c|c|c|c|c|c|c|}
\hline Date & $\begin{array}{l}\text { Avg. BT } \\
\text { travel time }\end{array}$ & $\begin{array}{l}\text { Mean Bias } \\
(\mathrm{mph})\end{array}$ & $\begin{array}{c}\text { Mean } \\
\text { Absolute } \\
\text { Error (mph) }\end{array}$ & $\begin{array}{c}\% \text { within } 5 \\
\text { MPH of } \\
\text { BlueToad }\end{array}$ & $\begin{array}{c}\% \text { Within } 10 \\
\text { mph of } \\
\text { BlueToad }\end{array}$ & $\begin{array}{c}\% \text { of Time } \\
\text { Blanked Out }\end{array}$ \\
\hline 16-Jul & 54.7 & -5.6 & 5.8 & $48 \%$ & $89 \%$ & $1 \%$ \\
\hline 17-Jul & 54.1 & -5.6 & 5.8 & $44 \%$ & $86 \%$ & $1 \%$ \\
\hline 18-Jul & 54 & -6.1 & 6.3 & $38 \%$ & $86 \%$ & $2 \%$ \\
\hline 19-Jul & 54.1 & -5.7 & 5.9 & $46 \%$ & $88 \%$ & $1 \%$ \\
\hline 20-Jul & 55 & -5.4 & 5.8 & $49 \%$ & $84 \%$ & $2 \%$ \\
\hline 21-Jul & 53.6 & 4.1 & 4.9 & $55 \%$ & $90 \%$ & $3 \%$ \\
\hline 22-Jul & 53.3 & 5.5 & 6.3 & $42 \%$ & $82 \%$ & $5 \%$ \\
\hline 23-Jul & 54.8 & -4.9 & 5.2 & $52 \%$ & $93 \%$ & $2 \%$ \\
\hline 24-Jul & 54.2 & -6.3 & 6.4 & $36 \%$ & $86 \%$ & $1 \%$ \\
\hline 25-Jul & 54.5 & -5.2 & 5.3 & $48 \%$ & $93 \%$ & $1 \%$ \\
\hline 26-Jul & 54.9 & -5.2 & 5.4 & $45 \%$ & $90 \%$ & $4 \%$ \\
\hline 27-Jul & 55.2 & -4.7 & 5.3 & $51 \%$ & $90 \%$ & $2 \%$ \\
\hline 28-Jul & 53 & 4 & 4.6 & $56 \%$ & $92 \%$ & $1 \%$ \\
\hline 29-Jul & 54.9 & 6.7 & 7.1 & $32 \%$ & $76 \%$ & $3 \%$ \\
\hline 30-Jul & 53.1 & -6 & 6.3 & $39 \%$ & $83 \%$ & $1 \%$ \\
\hline 31-Jul & 54 & -5.7 & 5.9 & $46 \%$ & $91 \%$ & $2 \%$ \\
\hline 1-Aug & 54.3 & -5.5 & 5.8 & $47 \%$ & $88 \%$ & $5 \%$ \\
\hline 2-Aug & 54.6 & -4.9 & 5.1 & $51 \%$ & $92 \%$ & $1 \%$ \\
\hline 3-Aug & 54.2 & -5.1 & 5.4 & $50 \%$ & $93 \%$ & $1 \%$ \\
\hline 4-Aug & 53.6 & 4.3 & 4.7 & $59 \%$ & $91 \%$ & $3 \%$ \\
\hline 5-Aug & 53.8 & 5.7 & 6.2 & $42 \%$ & $81 \%$ & $15 \%$ \\
\hline 6-Aug & 55.3 & -4.6 & 5 & $52 \%$ & $92 \%$ & $4 \%$ \\
\hline 7-Aug & 54.7 & -5.2 & 5.4 & $48 \%$ & $92 \%$ & $3 \%$ \\
\hline 8-Aug & 53.8 & -5.6 & 5.8 & $43 \%$ & $89 \%$ & $0 \%$ \\
\hline 9-Aug & 53.7 & -6.1 & 6.3 & $37 \%$ & $88 \%$ & $3 \%$ \\
\hline 10-Aug & 54.5 & -5.1 & 5.4 & $48 \%$ & $92 \%$ & $2 \%$ \\
\hline 11-Aug & 58.1 & -5.5 & 6.6 & $39 \%$ & $83 \%$ & $1 \%$ \\
\hline 12-Aug & 53.4 & -6.2 & 6.3 & $38 \%$ & $84 \%$ & $5 \%$ \\
\hline 13-Aug & 54.3 & -5.4 & 5.7 & $46 \%$ & $92 \%$ & $2 \%$ \\
\hline 14-Aug & 54.8 & -4.8 & 5.2 & $52 \%$ & $92 \%$ & $4 \%$ \\
\hline 15-Aug & 54.6 & -5.5 & 5.7 & $45 \%$ & $90 \%$ & $1 \%$ \\
\hline 16-Aug & 53.8 & -6.5 & 6.6 & $34 \%$ & $87 \%$ & $0 \%$ \\
\hline 17-Aug & 54.1 & -5.7 & 5.8 & $45 \%$ & $87 \%$ & $0 \%$ \\
\hline 18-Aug & 53.5 & 4.7 & 5.2 & $47 \%$ & $95 \%$ & $4 \%$ \\
\hline 19-Aug & 53 & 3.8 & 5.4 & $48 \%$ & $91 \%$ & $1 \%$ \\
\hline
\end{tabular}


Table B-7 Final tables and percent blank out of INRIX data analysis on I-64 corridor, link 5850

\begin{tabular}{|c|c|c|c|c|c|c|}
\hline Date & $\begin{array}{l}\text { Avg. BT } \\
\text { travel time }\end{array}$ & $\begin{array}{l}\text { Mean Bias } \\
(\mathrm{mph})\end{array}$ & $\begin{array}{c}\text { Mean } \\
\text { Absolute } \\
\text { Error (mph) }\end{array}$ & $\begin{array}{l}\text { \% within } 5 \\
\text { MPH of } \\
\text { BlueToad }\end{array}$ & $\begin{array}{c}\% \text { Within } 10 \\
\text { mph of } \\
\text { BlueToad }\end{array}$ & $\begin{array}{c}\% \text { of Time } \\
\text { Blanked Out }\end{array}$ \\
\hline 16-Jul & 69.1 & -6.2 & 7.6 & $40 \%$ & $76 \%$ & $4 \%$ \\
\hline 17-Jul & 94.2 & -3.2 & 6.1 & $50 \%$ & $81 \%$ & $2 \%$ \\
\hline 18-Jul & 72.9 & -2.7 & 5.3 & $62 \%$ & $84 \%$ & $4 \%$ \\
\hline 19-Jul & 70.6 & -4.2 & 6 & $54 \%$ & $83 \%$ & $1 \%$ \\
\hline 20-Jul & 68.7 & -5.7 & 6.3 & $49 \%$ & $79 \%$ & $3 \%$ \\
\hline 21-Jul & 69.4 & -4 & 5.2 & $59 \%$ & $89 \%$ & $10 \%$ \\
\hline 22-Jul & 65.6 & -3.6 & 4.6 & $65 \%$ & $87 \%$ & $28 \%$ \\
\hline 23-Jul & 68.8 & -3.9 & 5.2 & $59 \%$ & $89 \%$ & $0 \%$ \\
\hline 24-Jul & 70.5 & -3.3 & 4.6 & $64 \%$ & $91 \%$ & $0 \%$ \\
\hline 25-Jul & 73.3 & -7.9 & 9.1 & $41 \%$ & $70 \%$ & $1 \%$ \\
\hline 26-Jul & 67.6 & -3.5 & 4.4 & $65 \%$ & $93 \%$ & $5 \%$ \\
\hline 27-Jul & 68.9 & -4.9 & 5.8 & $60 \%$ & $86 \%$ & $2 \%$ \\
\hline 28-Jul & 66 & -3.4 & 4 & $69 \%$ & $96 \%$ & $4 \%$ \\
\hline 29-Jul & 65.4 & -4.6 & 5 & $58 \%$ & $87 \%$ & $22 \%$ \\
\hline 30-Jul & 83 & -0.8 & 5.5 & $64 \%$ & $85 \%$ & $3 \%$ \\
\hline 31-Jul & 67.8 & -4.3 & 5.4 & $57 \%$ & $86 \%$ & $4 \%$ \\
\hline 1-Aug & 75.3 & -3.3 & 4.5 & $66 \%$ & $93 \%$ & $5 \%$ \\
\hline 2-Aug & 70.2 & -3.9 & 5.2 & $56 \%$ & $87 \%$ & $4 \%$ \\
\hline 3-Aug & 69.2 & -4 & 5.1 & $65 \%$ & $91 \%$ & $6 \%$ \\
\hline 4-Aug & 66.3 & -3.8 & 4.4 & $64 \%$ & $95 \%$ & $10 \%$ \\
\hline 5-Aug & 65.3 & -7.8 & 8.3 & $40 \%$ & $71 \%$ & $28 \%$ \\
\hline 6-Aug & 81.4 & -4.4 & 6 & $55 \%$ & $84 \%$ & $1 \%$ \\
\hline 7-Aug & 70.6 & -3.5 & 5 & $61 \%$ & $89 \%$ & $4 \%$ \\
\hline 8-Aug & 71 & -2.9 & 4.8 & $62 \%$ & $91 \%$ & $3 \%$ \\
\hline 9-Aug & 68.3 & -4.8 & 5.6 & $55 \%$ & $87 \%$ & $3 \%$ \\
\hline 10-Aug & 69.4 & -2.8 & 4.1 & $70 \%$ & $95 \%$ & $4 \%$ \\
\hline 11-Aug & 66.4 & -2.7 & 3.8 & $70 \%$ & $96 \%$ & $4 \%$ \\
\hline 12-Aug & 66.9 & -2.9 & 4.1 & $74 \%$ & $94 \%$ & $19 \%$ \\
\hline 13-Aug & 70.5 & -2.7 & 4.2 & $72 \%$ & $91 \%$ & $3 \%$ \\
\hline 14-Aug & 70.6 & -2.9 & 5.3 & $58 \%$ & $86 \%$ & $5 \%$ \\
\hline 15-Aug & 72.8 & -2.7 & 5.2 & $61 \%$ & $85 \%$ & $2 \%$ \\
\hline 16-Aug & 71.5 & -6.6 & 8.1 & $41 \%$ & $68 \%$ & $3 \%$ \\
\hline 17-Aug & 68.4 & -3.9 & 4.6 & $66 \%$ & $89 \%$ & $2 \%$ \\
\hline 18-Aug & 65.9 & -3.6 & 4.5 & $61 \%$ & $95 \%$ & $6 \%$ \\
\hline 19-Aug & 96.3 & -2.3 & 6.3 & $59 \%$ & $80 \%$ & $2 \%$ \\
\hline
\end{tabular}


Table B-8 Final tables and percent blank out of INRIX data analysis on I-64 corridor, link 5853

\begin{tabular}{|c|c|c|c|c|c|c|}
\hline Date & $\begin{array}{l}\text { Avg. BT } \\
\text { travel time }\end{array}$ & $\begin{array}{c}\text { Mean Bias } \\
(\mathrm{mph})\end{array}$ & $\begin{array}{c}\text { Mean } \\
\text { Absolute } \\
\text { Error (mph) }\end{array}$ & $\begin{array}{l}\% \text { within } 5 \\
\text { MPH of } \\
\text { BlueToad }\end{array}$ & $\begin{array}{c}\% \text { Within } 10 \\
\text { mph of } \\
\text { BlueToad }\end{array}$ & $\begin{array}{c}\% \text { of Time } \\
\text { Blanked Out }\end{array}$ \\
\hline 16-Jul & 217.3 & 3.0 & 3.5 & $75 \%$ & $97 \%$ & $3 \%$ \\
\hline 17-Jul & 233.7 & 3.1 & 4.3 & $69 \%$ & $93 \%$ & $1 \%$ \\
\hline 18-Jul & 219.8 & 3.4 & 3.9 & $76 \%$ & $96 \%$ & $3 \%$ \\
\hline 19-Jul & 242.3 & 3.1 & 4.4 & $70 \%$ & $91 \%$ & $5 \%$ \\
\hline 20-Jul & 218.9 & 3.1 & 3.6 & $75 \%$ & $96 \%$ & $3 \%$ \\
\hline 21-Jul & 217.0 & 3.0 & 3.4 & $77 \%$ & $99 \%$ & $2 \%$ \\
\hline 22-Jul & 206.0 & 2.2 & 3.3 & $76 \%$ & $98 \%$ & $4 \%$ \\
\hline 23-Jul & 222.7 & 2.4 & 4.4 & $74 \%$ & $91 \%$ & $3 \%$ \\
\hline 24-Jul & 219.1 & 2.9 & 3.5 & $77 \%$ & $97 \%$ & $5 \%$ \\
\hline 25-Jul & 226.9 & 2.7 & 3.9 & $74 \%$ & $96 \%$ & $1 \%$ \\
\hline 26-Jul & 215.6 & 2.6 & 3.3 & $79 \%$ & $98 \%$ & $8 \%$ \\
\hline 27-Jul & 218.7 & 2.7 & 4.1 & $78 \%$ & $94 \%$ & $3 \%$ \\
\hline 28-Jul & 207.8 & 2.6 & 3.1 & $85 \%$ & $99 \%$ & $1 \%$ \\
\hline 29-Jul & 205.5 & 2.1 & 2.9 & $78 \%$ & $99 \%$ & $14 \%$ \\
\hline 30-Jul & 217.6 & 3.5 & 3.9 & $73 \%$ & $96 \%$ & $2 \%$ \\
\hline 31-Jul & 218.2 & 3.4 & 4.0 & $72 \%$ & $94 \%$ & $3 \%$ \\
\hline 1-Aug & 217.9 & 2.9 & 4.3 & $74 \%$ & $93 \%$ & $6 \%$ \\
\hline 2-Aug & 223.3 & 3.9 & 4.4 & $69 \%$ & $94 \%$ & $2 \%$ \\
\hline 3-Aug & 212.9 & 2.1 & 3.1 & $86 \%$ & $98 \%$ & $2 \%$ \\
\hline 4-Aug & 206.8 & 2.4 & 3.1 & $83 \%$ & $99 \%$ & $2 \%$ \\
\hline 5-Aug & 206.3 & 2.5 & 3.0 & $85 \%$ & $97 \%$ & $13 \%$ \\
\hline 6-Aug & 228.6 & 3.2 & 4.7 & $68 \%$ & $90 \%$ & $2 \%$ \\
\hline 7-Aug & 238.4 & 3.0 & 5.3 & $60 \%$ & $88 \%$ & $4 \%$ \\
\hline 8-Aug & 219.6 & 3.0 & 3.5 & $81 \%$ & $97 \%$ & $1 \%$ \\
\hline 9-Aug & 219.1 & 3.3 & 4.0 & $77 \%$ & $94 \%$ & $2 \%$ \\
\hline 10-Aug & 217.3 & 2.5 & 3.1 & $84 \%$ & $98 \%$ & $1 \%$ \\
\hline 11-Aug & 206.5 & 2.6 & 3.0 & $82 \%$ & $100 \%$ & $1 \%$ \\
\hline 12-Aug & 209.1 & 3.1 & 3.5 & $75 \%$ & $97 \%$ & $8 \%$ \\
\hline 13-Aug & 218.8 & 2.6 & 3.6 & $79 \%$ & $97 \%$ & $1 \%$ \\
\hline 14-Aug & 217.3 & 3.3 & 3.6 & $77 \%$ & $97 \%$ & $1 \%$ \\
\hline 15-Aug & 218.7 & 2.9 & 3.7 & $77 \%$ & $98 \%$ & $2 \%$ \\
\hline 16-Aug & 224.0 & 1.8 & 4.7 & $70 \%$ & $91 \%$ & $3 \%$ \\
\hline 17-Aug & 239.3 & 3.0 & 3.8 & $77 \%$ & $95 \%$ & $1 \%$ \\
\hline 18-Aug & 213.1 & 2.8 & 3.2 & $82 \%$ & $99 \%$ & $2 \%$ \\
\hline 19-Aug & 209.4 & 2.9 & 3.6 & $74 \%$ & $97 \%$ & $9 \%$ \\
\hline
\end{tabular}


Table B-9 Final tables and percent blank out of INRIX data analysis on I-64 corridor, link 5856

\begin{tabular}{|c|c|c|c|c|c|c|}
\hline Date & $\begin{array}{l}\text { Avg. BT } \\
\text { travel time }\end{array}$ & $\begin{array}{l}\text { Mean Bias } \\
(\mathrm{mph})\end{array}$ & $\begin{array}{c}\text { Mean } \\
\text { Absolute } \\
\text { Error (mph) }\end{array}$ & $\begin{array}{c}\% \text { within } 5 \\
\text { MPH of } \\
\text { BlueToad }\end{array}$ & $\begin{array}{c}\text { \% Within } 10 \\
\text { mph of } \\
\text { BlueToad }\end{array}$ & $\begin{array}{c}\% \text { of Time } \\
\text { Blanked Out }\end{array}$ \\
\hline 16-Jul & 47.9 & -12.9 & 12.9 & $3 \%$ & $30 \%$ & $5 \%$ \\
\hline 17-Jul & 48.7 & -12 & 12.1 & $10 \%$ & $38 \%$ & $4 \%$ \\
\hline 18-Jul & 47.3 & -13.7 & 13.7 & $7 \%$ & $25 \%$ & $5 \%$ \\
\hline 19-Jul & 47.8 & -13.6 & 13.7 & $5 \%$ & $24 \%$ & $3 \%$ \\
\hline 20-Jul & 51.8 & -12.3 & 12.7 & $7 \%$ & $36 \%$ & $2 \%$ \\
\hline 21-Jul & 48.8 & -13.8 & 13.9 & $7 \%$ & $22 \%$ & $7 \%$ \\
\hline 22-Jul & 46.3 & -14.1 & 14.1 & $7 \%$ & $24 \%$ & $23 \%$ \\
\hline 23-Jul & 48.1 & -12.3 & 12.3 & $9 \%$ & $33 \%$ & $5 \%$ \\
\hline 24-Jul & 48.6 & -11.2 & 11.2 & $10 \%$ & $39 \%$ & $5 \%$ \\
\hline 25-Jul & 47.3 & -15.7 & 15.8 & $3 \%$ & $23 \%$ & $3 \%$ \\
\hline 26-Jul & 47.4 & -12.9 & 12.9 & $8 \%$ & $32 \%$ & $6 \%$ \\
\hline 27-Jul & 47.4 & -14.1 & 14.2 & $6 \%$ & $28 \%$ & $1 \%$ \\
\hline 28-Jul & 46.5 & -13.7 & 13.7 & $7 \%$ & $25 \%$ & $6 \%$ \\
\hline 29-Jul & 47 & -13 & 13.2 & $11 \%$ & $30 \%$ & $25 \%$ \\
\hline 30-Jul & 48.2 & -12.3 & 12.3 & $8 \%$ & $35 \%$ & $4 \%$ \\
\hline 31-Jul & 47.5 & -13.9 & 13.9 & $3 \%$ & $24 \%$ & $3 \%$ \\
\hline 1-Aug & 49 & -13.2 & 13.3 & $5 \%$ & $27 \%$ & $8 \%$ \\
\hline 2-Aug & 47.8 & -13.5 & 13.5 & $10 \%$ & $28 \%$ & $7 \%$ \\
\hline 3-Aug & 48.9 & -11.2 & 11.3 & $12 \%$ & $43 \%$ & $0 \%$ \\
\hline 4-Aug & 47.7 & -11.8 & 11.9 & $9 \%$ & $32 \%$ & $7 \%$ \\
\hline 5-Aug & 46.9 & -13.2 & 13.3 & $9 \%$ & $30 \%$ & $35 \%$ \\
\hline 6-Aug & 49.9 & -12.6 & 12.6 & $9 \%$ & $36 \%$ & $2 \%$ \\
\hline 7-Aug & 49.1 & -12.3 & 12.6 & $12 \%$ & $30 \%$ & $4 \%$ \\
\hline 8-Aug & 46.7 & -14.2 & 14.2 & $7 \%$ & $21 \%$ & $2 \%$ \\
\hline 9-Aug & 47.1 & -14 & 14 & $6 \%$ & $27 \%$ & $4 \%$ \\
\hline 10-Aug & 47.7 & -13 & 13 & $6 \%$ & $31 \%$ & $2 \%$ \\
\hline 11-Aug & 47.3 & -13 & 13 & $8 \%$ & $31 \%$ & $1 \%$ \\
\hline 12-Aug & 47.2 & -14.3 & 14.5 & $11 \%$ & $25 \%$ & $6 \%$ \\
\hline 13-Aug & 48 & -12.3 & 12.4 & $8 \%$ & $36 \%$ & $2 \%$ \\
\hline 14-Aug & 47.8 & -14.2 & 14.2 & $3 \%$ & $26 \%$ & $3 \%$ \\
\hline 15-Aug & 48 & -13 & 13 & $8 \%$ & $29 \%$ & $1 \%$ \\
\hline 16-Aug & 51.7 & -7.7 & 9.1 & $26 \%$ & $56 \%$ & $5 \%$ \\
\hline 17-Aug & 48.2 & -11.1 & 11.5 & $14 \%$ & $36 \%$ & $3 \%$ \\
\hline 18-Aug & 48 & -15 & 15.1 & $7 \%$ & $35 \%$ & $12 \%$ \\
\hline 19-Aug & 47.6 & -13.4 & 13.5 & $7 \%$ & $27 \%$ & $28 \%$ \\
\hline
\end{tabular}


Table B-10 Final tables and percent blank out of INRIX data analysis on I-64 corridor, link 5857

\begin{tabular}{|c|c|c|c|c|c|c|}
\hline Date & $\begin{array}{l}\text { Avg. BT } \\
\text { travel time }\end{array}$ & $\begin{array}{l}\text { Mean Bias } \\
(\mathrm{mph})\end{array}$ & $\begin{array}{c}\text { Mean } \\
\text { Absolute } \\
\text { Error (mph) }\end{array}$ & $\begin{array}{c}\% \text { within } 5 \\
\text { MPH of } \\
\text { BlueToad }\end{array}$ & $\begin{array}{c}\% \text { Within } 10 \\
\text { mph of } \\
\text { BlueToad }\end{array}$ & $\begin{array}{c}\% \text { of Time } \\
\text { Blanked Out }\end{array}$ \\
\hline 16-Jul & 64.3 & 7.1 & 7.1 & $27 \%$ & $81 \%$ & $2 \%$ \\
\hline 17-Jul & 76.3 & 6.8 & 7.4 & $25 \%$ & $79 \%$ & $3 \%$ \\
\hline 18-Jul & 66.2 & 8.2 & 8.4 & $16 \%$ & $69 \%$ & $1 \%$ \\
\hline 19-Jul & 65.2 & 7.7 & 7.7 & $14 \%$ & $84 \%$ & $3 \%$ \\
\hline 20-Jul & 67.7 & 8.2 & 8.4 & $14 \%$ & $75 \%$ & $3 \%$ \\
\hline 21-Jul & 69.3 & 9 & 9 & $12 \%$ & $63 \%$ & $9 \%$ \\
\hline 22-Jul & 63.6 & 8.3 & 8.3 & $18 \%$ & $71 \%$ & $22 \%$ \\
\hline 23-Jul & 64.6 & 7.4 & 7.5 & $28 \%$ & $78 \%$ & $1 \%$ \\
\hline 24-Jul & 65.4 & 7.4 & 7.5 & $22 \%$ & $79 \%$ & $1 \%$ \\
\hline 25-Jul & 65.9 & 8.5 & 8.6 & $16 \%$ & $70 \%$ & $1 \%$ \\
\hline 26-Jul & 65.3 & 7.7 & 7.7 & $17 \%$ & $80 \%$ & $7 \%$ \\
\hline 27-Jul & 66.3 & 8 & 8.4 & $15 \%$ & $70 \%$ & $0 \%$ \\
\hline 28-Jul & 64.7 & 8.3 & 8.3 & $14 \%$ & $73 \%$ & $5 \%$ \\
\hline 29-Jul & 63.8 & 8.4 & 8.4 & $19 \%$ & $66 \%$ & $18 \%$ \\
\hline 30-Jul & 64.6 & 7.4 & 7.5 & $22 \%$ & $80 \%$ & $1 \%$ \\
\hline 31-Jul & 64.6 & 7.3 & 7.4 & $23 \%$ & $77 \%$ & $3 \%$ \\
\hline 1-Aug & 66.3 & 7.9 & 8 & $17 \%$ & $71 \%$ & $4 \%$ \\
\hline 2-Aug & 66 & 9.1 & 9.1 & $12 \%$ & $63 \%$ & $1 \%$ \\
\hline 3-Aug & 81.6 & 7.6 & 8 & $16 \%$ & $73 \%$ & $0 \%$ \\
\hline 4-Aug & 63.6 & 7.3 & 7.4 & $24 \%$ & $74 \%$ & $3 \%$ \\
\hline 5-Aug & 64.6 & 8 & 8.1 & $18 \%$ & $74 \%$ & $22 \%$ \\
\hline 6-Aug & 86.5 & 8.2 & 8.4 & $20 \%$ & $69 \%$ & $2 \%$ \\
\hline 7-Aug & 68 & 7.9 & 8.1 & $19 \%$ & $76 \%$ & $2 \%$ \\
\hline 8-Aug & 66.6 & 7.5 & 8.1 & $19 \%$ & $74 \%$ & $2 \%$ \\
\hline 9-Aug & 66.3 & 7.9 & 8.2 & $21 \%$ & $73 \%$ & $0 \%$ \\
\hline 10-Aug & 64.9 & 7.4 & 7.4 & $20 \%$ & $81 \%$ & $0 \%$ \\
\hline 11-Aug & 64.4 & 8 & 8 & $14 \%$ & $76 \%$ & $0 \%$ \\
\hline 12-Aug & 65.1 & 6.8 & 7 & $37 \%$ & $80 \%$ & $9 \%$ \\
\hline 13-Aug & 95.6 & 7.8 & 8.1 & $24 \%$ & $72 \%$ & $1 \%$ \\
\hline 14-Aug & 97.6 & 7.9 & 8.4 & $23 \%$ & $76 \%$ & $3 \%$ \\
\hline 15-Aug & 68.5 & 7.8 & 7.9 & $25 \%$ & $74 \%$ & $2 \%$ \\
\hline 16-Aug & 63.1 & 5 & 7.5 & $26 \%$ & $77 \%$ & $0 \%$ \\
\hline 17-Aug & 65.2 & 8.3 & 8.3 & $15 \%$ & $73 \%$ & $1 \%$ \\
\hline 18-Aug & 62.9 & 6.7 & 6.8 & $32 \%$ & $82 \%$ & $8 \%$ \\
\hline 19-Aug & 64 & 6.2 & 6.6 & $34 \%$ & $86 \%$ & $19 \%$ \\
\hline
\end{tabular}


Table B-11 Speed categories analysis of 10 BlueTOAD links on I-64 and I-264 corridors

\begin{tabular}{|c|c|c|c|c|c|}
\hline Link & Time Period & $\begin{array}{c}\text { BlueToad } \\
\text { Speed }\end{array}$ & $\begin{array}{c}\text { Number of 5- } \\
\text { minute periods }\end{array}$ & $\begin{array}{c}\text { Bias } \\
\text { (mph) }\end{array}$ & $\begin{array}{c}\text { Absolute } \\
\text { Error (mph) }\end{array}$ \\
\hline \multirow{20}{*}{5840} & \multirow{4}{*}{ July 16-22 } & $>60 \mathrm{mph}$ & 834 & -2.06 & 3.77 \\
\hline & & $45-60 \mathrm{mph}$ & 29 & 5.83 & 7.26 \\
\hline & & $30-45 \mathrm{mph}$ & 0 & 0.00 & 0.00 \\
\hline & & $<30 \mathrm{mph}$ & 0 & 0.00 & 0.00 \\
\hline & \multirow{4}{*}{ July 23-29 } & $>50 \mathrm{mph}$ & 840 & -2.11 & 3.69 \\
\hline & & $30-50 \mathrm{mph}$ & 36 & 2.91 & 5.14 \\
\hline & & $30-45 \mathrm{mph}$ & 0 & 0.00 & 0.00 \\
\hline & & $<30 \mathrm{mph}$ & 0 & 0.00 & 0.00 \\
\hline & \multirow{4}{*}{$\begin{array}{c}\text { July } 30 \text { - Aug } \\
5\end{array}$} & $>60 \mathrm{mph}$ & 820 & -1.75 & 3.48 \\
\hline & & $45-60 \mathrm{mph}$ & 19 & 5.87 & 6.70 \\
\hline & & $30-45 \mathrm{mph}$ & 7 & 6.20 & 6.20 \\
\hline & & $<30 \mathrm{mph}$ & 2 & 8.50 & 8.50 \\
\hline & \multirow{4}{*}{ Aug 6-12 } & $>50 \mathrm{mph}$ & 829 & -2.13 & 3.82 \\
\hline & & $30-50 \mathrm{mph}$ & 44 & 1.49 & 6.90 \\
\hline & & $30-45 \mathrm{mph}$ & 0 & 0.00 & 0.00 \\
\hline & & $<30 \mathrm{mph}$ & 0 & 0.00 & 0.00 \\
\hline & \multirow{4}{*}{ Aug 13-19 } & $>50 \mathrm{mph}$ & 858 & -1.38 & 3.37 \\
\hline & & $30-50 \mathrm{mph}$ & 18 & -1.09 & 7.50 \\
\hline & & $30-45 \mathrm{mph}$ & 0 & 0.00 & 0.00 \\
\hline & & $<30 \mathrm{mph}$ & 0 & 0.00 & 0.00 \\
\hline \multirow{18}{*}{5841} & \multirow{4}{*}{ July 16-22 } & $>60 \mathrm{mph}$ & 727 & -1.34 & 3.49 \\
\hline & & $45-60 \mathrm{mph}$ & 62 & 8.59 & 9.60 \\
\hline & & $30-45 \mathrm{mph}$ & 32 & 18.27 & 20.62 \\
\hline & & $<30 \mathrm{mph}$ & 46 & 26.32 & 26.32 \\
\hline & \multirow{4}{*}{ July 23-29 } & $>50 \mathrm{mph}$ & 684 & -0.33 & 2.34 \\
\hline & & $30-50 \mathrm{mph}$ & 128 & 3.15 & 4.82 \\
\hline & & $30-45 \mathrm{mph}$ & 50 & 3.52 & 4.68 \\
\hline & & $<30 \mathrm{mph}$ & 0 & 0.00 & 0.00 \\
\hline & \multirow{4}{*}{$\begin{array}{c}\text { July } 30 \text { - Aug } \\
5\end{array}$} & $>60 \mathrm{mph}$ & 684 & -0.09 & 2.50 \\
\hline & & $45-60 \mathrm{mph}$ & 77 & 3.68 & 5.73 \\
\hline & & $30-45 \mathrm{mph}$ & 58 & 1.51 & 4.31 \\
\hline & & $<30 \mathrm{mph}$ & 39 & -0.06 & 4.29 \\
\hline & \multirow{4}{*}{ Aug 6-12 } & $>50 \mathrm{mph}$ & 725 & -0.18 & 2.23 \\
\hline & & $30-50 \mathrm{mph}$ & 62 & 4.63 & 5.02 \\
\hline & & $30-45 \mathrm{mph}$ & 32 & 1.76 & 3.91 \\
\hline & & $<30 \mathrm{mph}$ & 46 & 3.05 & 4.41 \\
\hline & \multirow{2}{*}{ Aug 13-19 } & $>50 \mathrm{mph}$ & 633 & -0.72 & 2.60 \\
\hline & & $30-50 \mathrm{mph}$ & 103 & 2.85 & 4.87 \\
\hline
\end{tabular}




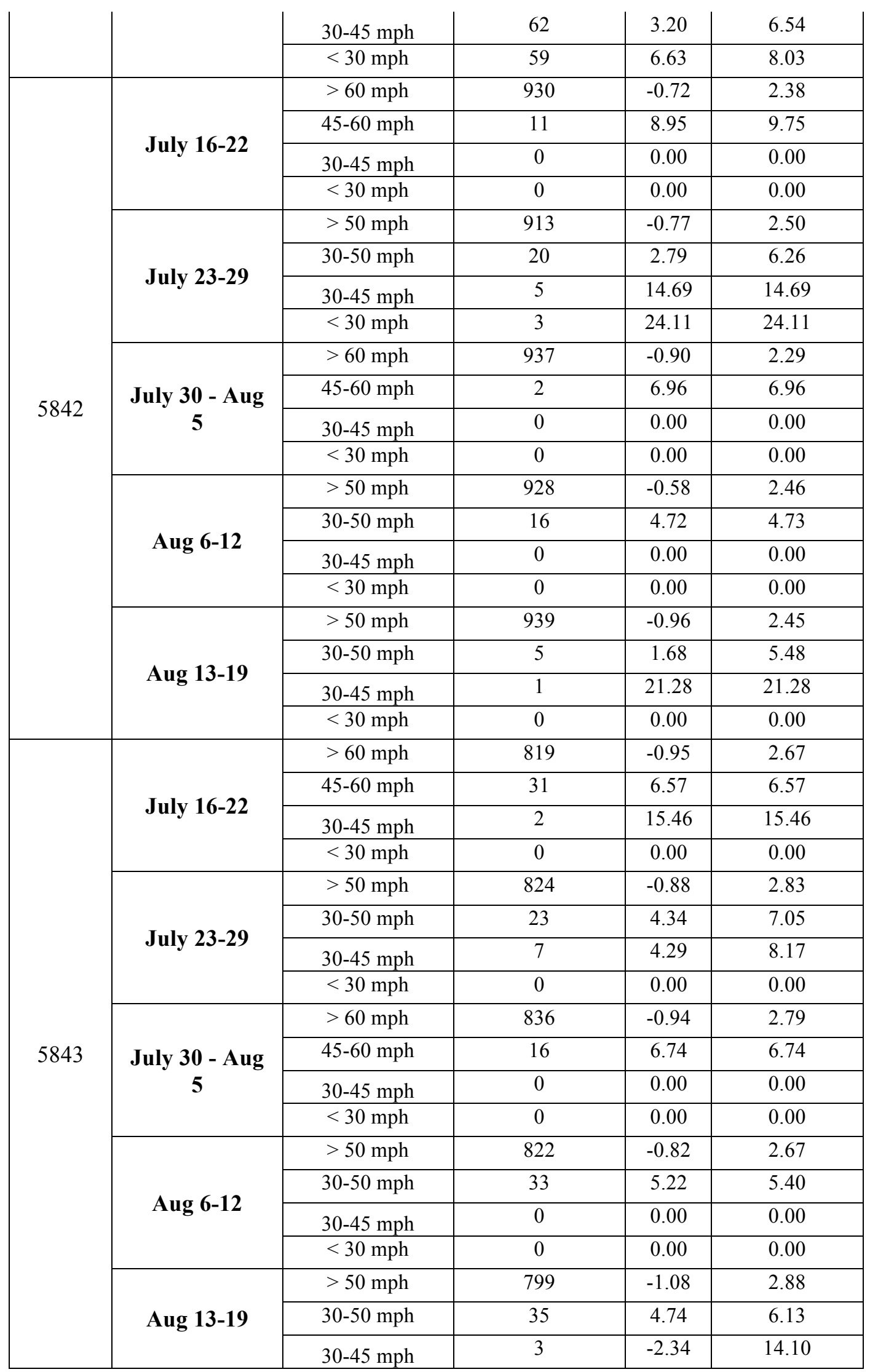




\begin{tabular}{|c|c|c|c|c|c|}
\hline & & $<30 \mathrm{mph}$ & 9 & 1.54 & 2.81 \\
\hline \multirow{20}{*}{5846} & \multirow{4}{*}{ July 16-22 } & $>60 \mathrm{mph}$ & 543 & 2.11 & 3.14 \\
\hline & & 45-60 mph & 305 & 7.52 & 7.52 \\
\hline & & $30-45 \mathrm{mph}$ & 9 & 9.64 & 10.73 \\
\hline & & $<30 \mathrm{mph}$ & 0 & 0.00 & 0.00 \\
\hline & \multirow{4}{*}{ July 23-29 } & $>50 \mathrm{mph}$ & 564 & 2.40 & 3.26 \\
\hline & & $30-50 \mathrm{mph}$ & 307 & 6.83 & 7.33 \\
\hline & & $30-45 \mathrm{mph}$ & 4 & 0.66 & 13.81 \\
\hline & & $<30 \mathrm{mph}$ & 3 & 22.65 & 22.65 \\
\hline & \multirow{4}{*}{$\begin{array}{c}\text { July } 30 \text { - Aug } \\
5\end{array}$} & $>60 \mathrm{mph}$ & 549 & 2.26 & 3.18 \\
\hline & & $45-60 \mathrm{mph}$ & 299 & 6.70 & 7.53 \\
\hline & & $30-45 \mathrm{mph}$ & 7 & 8.96 & 11.88 \\
\hline & & $<30 \mathrm{mph}$ & 1 & 17.50 & 17.50 \\
\hline & \multirow{4}{*}{ Aug 6-12 } & $>50 \mathrm{mph}$ & 515 & 2.49 & 3.22 \\
\hline & & $30-50 \mathrm{mph}$ & 342 & 7.36 & 7.68 \\
\hline & & $30-45 \mathrm{mph}$ & 2 & 7.89 & 14.16 \\
\hline & & $<30 \mathrm{mph}$ & 0 & 0.00 & 0.00 \\
\hline & \multirow{4}{*}{ Aug 13-19 } & $>50 \mathrm{mph}$ & 505 & 1.96 & 3.22 \\
\hline & & $30-50 \mathrm{mph}$ & 353 & 6.99 & 7.32 \\
\hline & & $30-45 \mathrm{mph}$ & 10 & 1.89 & 6.76 \\
\hline & & $<30 \mathrm{mph}$ & 18 & 5.17 & 6.93 \\
\hline \multirow{20}{*}{5847} & \multirow{4}{*}{ July 16-22 } & $>60 \mathrm{mph}$ & 363 & -8.90 & 8.90 \\
\hline & & 45-60 mph & 432 & -3.00 & 3.40 \\
\hline & & $30-45 \mathrm{mph}$ & 3 & 4.12 & 4.23 \\
\hline & & $<30 \mathrm{mph}$ & 0 & 0.00 & 0.00 \\
\hline & \multirow{4}{*}{ July 23-29 } & $>50 \mathrm{mph}$ & 321 & -8.49 & 8.49 \\
\hline & & $30-50 \mathrm{mph}$ & 465 & -3.03 & 3.48 \\
\hline & & $30-45 \mathrm{mph}$ & 1 & 1.92 & 1.92 \\
\hline & & $<30 \mathrm{mph}$ & 0 & 0.00 & 0.00 \\
\hline & \multirow{4}{*}{$\begin{array}{c}\text { July } 30 \text { - Aug } \\
5\end{array}$} & $>60 \mathrm{mph}$ & 385 & -8.21 & 8.21 \\
\hline & & 45-60 mph & 401 & -2.83 & 3.36 \\
\hline & & $30-45 \mathrm{mph}$ & 0 & 0.00 & 0.00 \\
\hline & & $<30 \mathrm{mph}$ & 0 & 0.00 & 0.00 \\
\hline & \multirow{4}{*}{ Aug 6-12 } & $>50 \mathrm{mph}$ & 367 & -8.17 & 8.17 \\
\hline & & $30-50 \mathrm{mph}$ & 420 & -2.83 & 3.36 \\
\hline & & $30-45 \mathrm{mph}$ & 0 & 0.00 & 0.00 \\
\hline & & $<30 \mathrm{mph}$ & 0 & 0.00 & 0.00 \\
\hline & \multirow{4}{*}{ Aug 13-19 } & $>50 \mathrm{mph}$ & 365 & -8.47 & 8.47 \\
\hline & & $30-50 \mathrm{mph}$ & 428 & -3.10 & 3.52 \\
\hline & & $30-45 \mathrm{mph}$ & 0 & 0.00 & 0.00 \\
\hline & & $<30 \mathrm{mph}$ & 0 & 0.00 & 0.00 \\
\hline
\end{tabular}




\begin{tabular}{|c|c|c|c|c|c|}
\hline \multirow{20}{*}{5850} & \multirow{4}{*}{ July 16-22 } & $>60 \mathrm{mph}$ & 660 & -6.24 & 6.38 \\
\hline & & $45-60 \mathrm{mph}$ & 160 & -0.92 & 5.01 \\
\hline & & $30-45 \mathrm{mph}$ & 30 & 8.55 & 10.11 \\
\hline & & $<30 \mathrm{mph}$ & 20 & 7.10 & 7.71 \\
\hline & \multirow{4}{*}{ July 23-29 } & $>50 \mathrm{mph}$ & 704 & -5.11 & 5.34 \\
\hline & & $30-50 \mathrm{mph}$ & 155 & -3.92 & 7.60 \\
\hline & & $30-45 \mathrm{mph}$ & 26 & -1.03 & 10.14 \\
\hline & & $<30 \mathrm{mph}$ & 0 & 0.00 & 0.00 \\
\hline & \multirow{4}{*}{$\begin{array}{c}\text { July } 30 \text { - Aug } \\
5\end{array}$} & $>60 \mathrm{mph}$ & 680 & -4.50 & 4.90 \\
\hline & & $45-60 \mathrm{mph}$ & 119 & -0.88 & 4.98 \\
\hline & & $30-45 \mathrm{mph}$ & 12 & 4.80 & 8.03 \\
\hline & & $<30 \mathrm{mph}$ & 25 & 12.87 & 12.87 \\
\hline & \multirow{4}{*}{ Aug 6-12 } & $>50 \mathrm{mph}$ & 662 & -4.82 & 5.06 \\
\hline & & $30-50 \mathrm{mph}$ & 178 & -0.50 & 4.86 \\
\hline & & $30-45 \mathrm{mph}$ & 27 & -1.22 & 6.98 \\
\hline & & $<30 \mathrm{mph}$ & 9 & 8.16 & 8.56 \\
\hline & \multirow{4}{*}{ Aug 13-19 } & $>50 \mathrm{mph}$ & 677 & -5.06 & 5.39 \\
\hline & & $30-50 \mathrm{mph}$ & 145 & -1.19 & 5.02 \\
\hline & & $30-45 \mathrm{mph}$ & 35 & 7.24 & 8.62 \\
\hline & & $<30 \mathrm{mph}$ & 7 & 11.84 & 11.84 \\
\hline \multirow{20}{*}{5853} & \multirow{4}{*}{ July 16-22 } & $>60 \mathrm{mph}$ & 260 & 0.71 & 1.84 \\
\hline & & 45-60 mph & 593 & 3.74 & 4.28 \\
\hline & & $30-45 \mathrm{mph}$ & 62 & 7.56 & 9.46 \\
\hline & & $<30 \mathrm{mph}$ & 7 & 3.16 & 5.99 \\
\hline & \multirow{4}{*}{ July 23-29 } & $>50 \mathrm{mph}$ & 256 & 0.66 & 1.83 \\
\hline & & $30-50 \mathrm{mph}$ & 617 & 3.13 & 4.25 \\
\hline & & $30-45 \mathrm{mph}$ & 36 & 8.75 & 11.12 \\
\hline & & $<30 \mathrm{mph}$ & 0 & 0.00 & 0.00 \\
\hline & \multirow{4}{*}{$\begin{array}{c}\text { July } 30 \text { - Aug } \\
5\end{array}$} & $>60 \mathrm{mph}$ & 297 & 0.97 & 2.10 \\
\hline & & $45-60 \mathrm{mph}$ & 595 & 3.89 & 4.55 \\
\hline & & $30-45 \mathrm{mph}$ & 24 & 12.54 & 12.54 \\
\hline & & $<30 \mathrm{mph}$ & 0 & 0.00 & 0.00 \\
\hline & \multirow{4}{*}{ Aug 6-12 } & $>50 \mathrm{mph}$ & 295 & 1.11 & 2.00 \\
\hline & & $30-50 \mathrm{mph}$ & 581 & 3.58 & 4.73 \\
\hline & & $30-45 \mathrm{mph}$ & 43 & 6.31 & 9.44 \\
\hline & & $<30 \mathrm{mph}$ & 13 & 7.24 & 8.15 \\
\hline & \multirow{4}{*}{ Aug 13-19 } & $>50 \mathrm{mph}$ & 263 & 0.50 & 2.09 \\
\hline & & $30-50 \mathrm{mph}$ & 627 & 3.53 & 4.38 \\
\hline & & $30-45 \mathrm{mph}$ & 32 & 5.22 & 7.16 \\
\hline & & $<30 \mathrm{mph}$ & 11 & 3.77 & 8.64 \\
\hline 5856 & July 16-22 & $>60 \mathrm{mph}$ & 854 & -13.02 & 13.06 \\
\hline
\end{tabular}




\begin{tabular}{|c|c|c|c|c|c|}
\hline & & $45-60 \mathrm{mph}$ & 5 & -19.30 & 19.30 \\
\hline & & $30-45 \mathrm{mph}$ & 3 & -2.93 & 4.53 \\
\hline & & $<30 \mathrm{mph}$ & 3 & 8.84 & 8.84 \\
\hline & \multirow{4}{*}{ July 23-29 } & $>50 \mathrm{mph}$ & 865 & -13.25 & 13.29 \\
\hline & & $30-50 \mathrm{mph}$ & 0 & 0.00 & 0.00 \\
\hline & & $30-45 \mathrm{mph}$ & 0 & 0.00 & 0.00 \\
\hline & & $<30 \mathrm{mph}$ & 0 & 0.00 & 0.00 \\
\hline & \multirow{4}{*}{$\begin{array}{c}\text { July } 30 \text { - Aug } \\
5\end{array}$} & $>60 \mathrm{mph}$ & 859 & -12.87 & 12.91 \\
\hline & & $45-60 \mathrm{mph}$ & 2 & -5.67 & 7.51 \\
\hline & & $30-45 \mathrm{mph}$ & 5 & -3.29 & 7.53 \\
\hline & & $<30 \mathrm{mph}$ & 0 & 0.00 & 0.00 \\
\hline & \multirow{4}{*}{ Aug 6-12 } & $>50 \mathrm{mph}$ & 839 & -13.41 & 13.45 \\
\hline & & $30-50 \mathrm{mph}$ & 20 & -5.68 & 8.11 \\
\hline & & $30-45 \mathrm{mph}$ & 1 & -3.21 & 3.21 \\
\hline & & $<30 \mathrm{mph}$ & 0 & 0.00 & 0.00 \\
\hline & \multirow{4}{*}{ Aug 13-19 } & $>50 \mathrm{mph}$ & 857 & -12.05 & 12.22 \\
\hline & & $30-50 \mathrm{mph}$ & 19 & 3.62 & 4.67 \\
\hline & & $30-45 \mathrm{mph}$ & 0 & 0.00 & 0.00 \\
\hline & & $<30 \mathrm{mph}$ & 0 & 0.00 & 0.00 \\
\hline \multirow{20}{*}{5857} & \multirow{4}{*}{ July 16-22 } & $>60 \mathrm{mph}$ & 20 & 1.84 & 2.39 \\
\hline & & $45-60 \mathrm{mph}$ & 898 & 7.73 & 7.86 \\
\hline & & $30-45 \mathrm{mph}$ & 15 & 11.72 & 14.29 \\
\hline & & $<30 \mathrm{mph}$ & 8 & 1.74 & 2.75 \\
\hline & & $>50 \mathrm{mph}$ & 42 & 1.58 & 2.55 \\
\hline & & $30-50 \mathrm{mph}$ & 893 & 8.17 & 8.20 \\
\hline & Jury $25-29$ & $30-45 \mathrm{mph}$ & 6 & 6.90 & 10.08 \\
\hline & & $<30 \mathrm{mph}$ & 0 & 0.00 & 0.00 \\
\hline & & $>60 \mathrm{mph}$ & 34 & 8.09 & 3.06 \\
\hline & & $45-60 \mathrm{mph}$ & 886 & 8.09 & 8.17 \\
\hline & July 50 - Aug 5 & $30-45 \mathrm{mph}$ & 11 & 11.12 & 11.53 \\
\hline & & $<30 \mathrm{mph}$ & 11 & 6.76 & 7.92 \\
\hline & & $>50 \mathrm{mph}$ & 45 & 2.31 & 2.93 \\
\hline & & $30-50 \mathrm{mph}$ & 838 & 7.87 & 8.08 \\
\hline & Aug 6-12 & $30-45 \mathrm{mph}$ & 31 & 7.96 & 10.04 \\
\hline & & $<30 \mathrm{mph}$ & 27 & 14.32 & 14.32 \\
\hline & & $>50 \mathrm{mph}$ & 79 & -1.45 & 4.36 \\
\hline & & $30-50 \mathrm{mph}$ & 796 & 7.98 & 8.18 \\
\hline & Aug 13-19 & $30-45 \mathrm{mph}$ & 15 & 14.37 & 16.41 \\
\hline & & $<30 \mathrm{mph}$ & 48 & 10.35 & 10.38 \\
\hline
\end{tabular}

